Burkhard Pahnke

Einkommensorientierte

Förderung des sozialen

Mietwohnungsbaues 


\section{Einkommensorientierte Förderung des sozialen Mietwohnungsbaues}

Der soziale Mietwohnungsbau - bis heute eine der tragenden Säulen staatlicher Wohnungspolitik - ist vor allem wegen seiner Verteilungswirkungen in die Kritik geraten. Bemängelt wird, daß auch besserverdienende Mieter trotz Fehlbelegungsabgabe massiv subventioniert werden. Anfang der 90er Jahre setzten daher Bestrebungen ein, die Mietwohnungsbauförderung noch stärker an der individuellen Einkommenssituation der Begünstigten auszurichten. Sie mündeten 1994 in der rechtlichen Verankerung der einkommensorientierten Förderung im Zweiten Wohnungsbaugesetz. Zahlreiche Bundesländer sammeln nun Erfahrungen mit dem „vierten Förderweg“. Die variantenreiche Ausgestaltung der neuen Förderform wird in der Arbeit nachgezeichnet und einer ökonomischen Analyse unterworfen. Ist die neue Fördermethode wirklich gerechter und sparsamer? Kann sie die Mängel der herkömmlichen Förderung vermeiden?

Burkhard Pahnke wurde 1966 in Olpe geboren. Nach einer zweijährigen Ausbildung im Journalismus begann er 1987 das Studium der Volkswirtschaftslehre an der Albert-Ludwigs-Universität in Freiburg (Breisgau). Im Frühjahr 1993 legte er das Diplomexamen ab und war anschließend wissenschaftlicher Mitarbeiter am Lehrstuhl Finanzwissenschaft I. Ende 1997 hat er bei Professor Dr. Alois Oberhauser promoviert. 
Einkommensorientierte Förderung des sozialen Mietwohnungsbaues 


\section{FINANZWISSENSCHAFTLICHE SCHRIFTEN}

Herausgegeben von den Professoren

Albers, Krause-Junk, Littmann, Oberhauser, Pohmer, Schmidt

Band 85

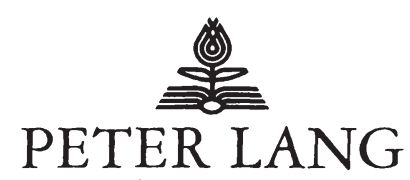

Frankfurt am Main · Berlin - Bern · New York · Paris · Wien 


\section{Burkhard Pahnke}

\section{Einkommensorientierte Förderung des sozialen Mietwohnungsbaues}

Bestandsaufnahme und Kritik

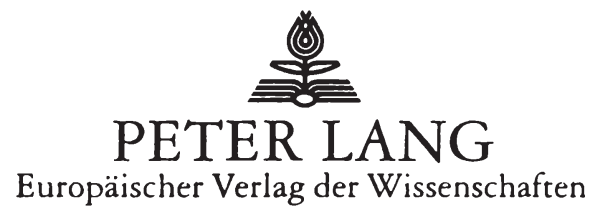


Die Deutsche Bibliothek - CIP-Einheitsaufnahme

Pahnke, Burkhard:

Einkommensorientierte Förderung des sozialen

Mietwohnungsbaues : Bestandsaufnahme und Kritik / Burkhard Pahnke. - Frankfurt am Main ; Berlin ; Bern ; New York ; Paris ; Wien : Lang, 1998

(Finanzwissenschaftliche Schriften ; Bd. 85)

Zugl.: Freiburg (Breisgau), Univ., Diss., 1997

ISBN 3-631-33153-3

Open Access: The online version of this publication is published on www.peterlang.com and www.econstor.eu under the international Creative Commons License CC-BY 4.0. Learn more on how you can use and share this work: http://creativecommons. org/licenses/by/4.0.

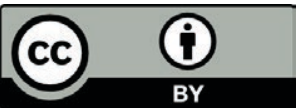

This book is available Open Access thanks to the kind support of ZBW - Leibniz-Informationszentrum Wirtschaft.

D 25

ISSN 0170-8252

ISBN 3-631-33153-3

ISBN 978-3-631-75215-9 (eBook)

(C) Peter Lang $\mathrm{GmbH}$

Europäischer Verlag der Wissenschaften

Frankfurt am Main 1998

Alle Rechte vorbehalten.

Das Werk einschließlich aller seiner Teile ist urheberrechtlich geschützt. Jede Verwertung außerhalb der engen Grenzen des

Urheberrechtsgesetzes ist ohne Zustimmung des Verlages unzulässig und strafbar. Das gilt insbesondere für

Vervielfältigungen, Übersetzungen, Mikroverfilmungen und die Einspeicherung und Verarbeitung in elektronischen Systemen.

Printed in Germany 124567 


\section{Meinen Eltern}

Burkhard Pahnke - 978-3-631-75215-9

Downloaded from PubFactory at 01/11/2019 07:00:27AM

via free access 
Burkhard Pahnke - 978-3-631-75215-9

Downloaded from PubFactory at 01/11/2019 07:00:27AM

via free access 


\section{Vorwort}

Anfang der 90er Jahre setzte im Bereich des sozialen Mietwohnungsbaues das Bemühen um eine noch gezieltere Ausrichtung der Förderung an der individuellen Einkommenssituation der Begünstigten ein. Nachdem bereits einige kommunale Modellvorhaben in diese Richtung begonnen worden waren, schuf der Gesetzgeber durch den 1994 ins Zweite Wohnungsbaugesetz eingefügten § $88 \mathrm{e}$ die rechtlichen Grundlagen für eine breite Anwendung der ,einkommensorientierten Förderung". Mit den Charakteristika dieser neuen Förderform und ihrer Umsetzung auf Länderebene befaßt sich die vorliegende Arbeit, die im November 1997 abgeschlossen und von der wirtschaftswissenschaftlichen Fakultät der Freiburger Albert-Ludwigs-Universität als Dissertation angenommen worden ist.

Mein besonderer Dank gilt Professor Dr. Alois Oberhauser, der die Arbeit als Erstreferent betreute und mich als wissenschaftlicher Mitarbeiter ins Institut Finanzwissenschaft I aufnahm. Er hat mir nicht nur wichtige Einsichten in ökonomische Zusammenhänge vermittelt, sondern durch seine besonderen menschlichen Eigenschaften auch stark dazu beigetragen, daß ich an seinem Institut den schönsten Abschnitt meiner Studienzeit verleben durfte. Danken möchte ich außerdem Professor Dr. Bernd Raffelhüschen für die Übernahme des Zweitreferats und das Wohlwollen, das er mir als Lehrstuhlnachfolger von Professor Oberhauser entgegenbrachte.

In meinen Dank einschließen will ich die vielen freundlichen, hilfsbereiten Mitarbeiter der zuständigen Ministerien von Bund und Ländern sowie der Wohnungs- und Liegenschaftsämter in den von mir besuchten baden-württembergischen Kommunen. Sehr geholfen hat mir auch die Sekretärin des Instituts, Frau Ingeborg Häfner. Last but not least möchte ich Mechtild Lendermann für ihre (unerklärbare) Zuneigung und Geduld danken, Werner Busch für seine Lebenshilfen und Kochkünste, den „Falkensteinern“ für die vielen schönen Stunden und allen, die mich mit ihrer Freundschaft auch in schwierigen Phasen begleitet haben. 
Burkhard Pahnke - 978-3-631-75215-9

Downloaded from PubFactory at 01/11/2019 07:00:27AM

via free access 


\section{Inhaltsübersicht}

Verzeichnis der Übersichten

XIII

Verzeichnis der Diagramme

XV

Abkürzungsverzeichnis

XVII

Symbolverzeichnis

XXI

Einleitung

\section{Teil: Der klassische soziale Mietwohnungsbau}

A. Begriff und Entstehungsgeschichte 5

B. Ziele der staatlichen Förderung $\quad 8$

I. Erhöhung des Wohnungsbestands 9

II. Versorgung sozial schwacher Gruppen mit preiswertem Wohnraum

C. Charakteristika des klassischen sozialen Mietwohnungsbaues

I. Art der Förderung

II. Kostenmietprinzip 13

$\begin{array}{ll}\text { III. Belegungsbindung } & 15\end{array}$

$\begin{array}{ll}\text { D. Mängel des alten Fördersystems } & 18\end{array}$

$\begin{array}{ll}\text { I. Förderung für Wenige } & 18\end{array}$

II. Ineffizienzen und hoher fiskalischer Aufwand infolge des Kostenmietprinzips

III. Fehl- und Unterbelegung im Sozialwohnungsbestand 22

E. Reformmaßnahmen der 80er Jahre 24

I. Erhebung einer Fehlbelegungsabgabe 24

II. Einführung der ,,vereinbarten Förderung“ nach § $88 \mathrm{~d}$ 


\section{Teil: Merkmale der einkommensorientierten Förderung (EOF)}

A. Grundlegendes $\quad 35$

B. Art und Aufgabe der Grundförderung 36

$\begin{array}{ll}\text { C. Charakteristika der Zusatzförderung } & 38\end{array}$

I. Funktion im Rahmen der EOF 38

II. Art und Auszahlung der Mittel 39

III. Koordination der Zusatzförderung mit dem Wohngeld 42

D. Finanzierung der EOF durch Bund, Länder und Gemeinden 43

E. Dauer der Förderung und der Zweckbestimmung der Sozialwohnungen 44

F. Konkretisierung der EOF in den Ländern $\quad 44$

I. Geförderte Maßnahmen 46

II. Art und Höhe der Grundförderung 47

III. Bezugsberechtigter Personenkreis $\quad 50$

IV. Bindungsdauer 51

V. Höhe der Basismieten $\quad 52$

VI. Art und Auszahlung der Zusatzförderung 53

VII. Höhe der Zusatzförderung 54

VIII. Kommunale Mitfinanzierung 56

$\begin{array}{ll}\text { IX. Periodizität der Einkommensüberprüfung } & 57\end{array}$

\section{Teil: Analyse der einkommensorientierten Förderung}

A. Die EOF im Vergleich zur klassischen Wohnungsbauförderung $\quad 59$

I. Fiskalische Entlastung durch die Abkehr vom Kostenmietprinzip 59

II. Kurzfristige Einsparungen durch verkürzte Förderzeiträume 64

III. Geringere Fördervorteile für Besserverdienende 69

IV. Mietpreisverzerrungen können im Ansatz vermieden werden 70 
B. Eignung der EOF zum Erwerb von Belegungsbindungen 71

$\begin{array}{ll}\text { I. Theoretische Vorüberlegungen } & 71\end{array}$

II. Risiken einer Wohnungsvergabe an „Problemmieter“ 73

$\begin{array}{ll}\text { a. Mietausfallwagnis } & 73\end{array}$

b. Erhöhte Abnutzung der Mietsache 74

c. Beeinträchtigung der Wohnverhältnisse anderer Mieter $\quad 74$

III. Belegungsvorgaben der Länder 75

a. Belegungsstruktur 75

b. Belegungsverfahren 77

$\begin{array}{lll}\text { IV. Kritik } & 77\end{array}$

a. Schwierigkeiten bei der Steuerung der Belegungsstruktur $\quad 77$

b. Ineffiziente Pauschalförderung 83

C. Eignung der EOF als Instrument der Subjektförderung 91

I. Anforderungen an ein einkommensorientiertes Fördersystem 91

II. Mietvergünstigungen durch die Grundförderung 97

a. Definition und Begründung der Basissubvention 97

b. Ausmaß der Abweichungen von Basis- und Marktmiete 98

c. Kritische Würdigung 101

III. Subventionswirkungen der Zusatzförderung 103

a. Zur Grundproblematik einer Verknüpfung von Objekt- und Subjektförderung 103

b. Abgrenzung des zu berücksichtigenden Einkommens 108

c. Periodizität der Einkommensprüfung und Berücksichtigung zwischenzeitlicher Einkommensänderungen

d. Zusammenhang von Einkommen und Transferhöhe 115

e. Einfluß der Haushaltsgröße auf die Förderung 120

f. Berücksichtigung von Wohnwertunterschieden 124

g. Übergang der Wohnungen in den Markt 126

IV. Zum Verwaltungsaufwand bei der EOF 131 


\section{Teil: Wohnungspolitische Reformansätze}

A. Notwendigkeit einer grundlegenden Neugestaltung der Wohnungspolitik

B. Alternative Maßnahmen zur Ausweitung des Mietwohnungsangebotes 136

I. Vergünstigungen im Rahmen der Einkommensteuer 136

II. Verstärkte Ausweisung von Bauland 138

III. Deregulierung des Mietrechts 139

C. Senkung der individuellen Wohnkostenbelastung durch Gewährung von Wohngeld

D. Versorgung von Haushalten mit besonderen Marktzutrittsproblemen durch den Erwerb von Belegungsrechten im Wohnungsbestand

I. Gängige Formen des Erwerbs von Belegungsrechten 145

II. Wege zur Erhöhung der Effektivität kommunaler Belegungspolitik

III. Zur Ausgestaltung von Mietsubventionen 152

a. Sollten die Belegungsrechte an eine Mietvergünstigung gekoppelt werden?

b. Vorschläge zur Ausgestaltung von Mietsubventionen 


\section{Verzeichnis der Übersichten}

\section{Im Text:}

Übersicht 1: $\quad$ Einkommensgrenzen nach § $25 \mathrm{Abs}$. 2 II. WoBauG (seit Oktober 1994)

Übersicht 2: $\quad$ Staffelung der Fehlbelegungsabgabe in den Ländern

Übersicht 3: $\quad$ Quantitative Bedeutung der Förderwege in der Bundesrepublik

Übersicht 4: $\quad$ Auszahlungsformen der Zusatzförderung

Übersicht 5: $\quad$ Barwerte der Grundförderung in ausgewählten

Ländern

Übersicht 6: Höchstzulässige Überschreitung der

Einkommensgrenze nach § 25 II. WoBauG

Übersicht 7: Höhe der Zusatzförderung in ausgewählten Ländern

Übersicht 8:

Annahmen zu den Kosten des ersten Förderwegs

(Wohnung I) im Rahmen des modellhaften Vergleichs mit der EOF

Übersicht 9: $\quad$ Ergebnis des modellhaften Vergleichs der Kosten des ersten Förderwegs mit den Kosten der EOF

Übersicht 10: Belegungsergebnisse bei den Pilotmodellen in Baden-Württemberg

Übersicht 11: $\quad$ Ermittlung der auf die Belegungsbindung entfallenden Förderbeträge am Beispiel ausgewählter Städte

Übersicht 12: $\quad$ Mietbelastung der Haushalte in Deutschland (Hochrechnung auf der Basis der 1\%-Gebäude- und Wohnungsstichprobe von 1993)

Übersicht 13: Baualtersbedingte Mietunterschiede (Ergebnisse der 1\%-Gebäude- und Wohnungsstichprobe von 1993)

Übersicht 14: $\quad$ Barwerte der Zusatzförderung in ausgewählten Bundesländern bei einer Wohnungsgröße von 70 qm 106

Übersicht 15: Bestimmungen einzelner Bundesländer zur außerplanmäßigen Neufestsetzung der Zusatzförderung 


\section{Im Anhang:}

Übersicht 16: $\quad$ Förderkonditionen in Baden-Württemberg 165

$\begin{array}{ll}\text { Übersicht 17: } & \text { Förderkonditionen in Bayern }\end{array}$

Übersicht 18: $\quad$ Förderkonditionen in Berlin 168

Übersicht 19: $\quad$ Förderkonditionen in Brandenburg 170

Übersicht 20a: Förderkonditionen in Bremen - Grundmodell 171

Übersicht 20b: Förderkonditionen in Bremen - Kombimodell 173

Übersicht 20c: $\quad$ Förderkonditionen in Bremen - „Modell 1+3“ 174

Übersicht 21: $\quad$ Förderkonditionen in Hessen 175

Übersicht 22: $\quad$ Förderkonditionen in Niedersachsen 176

Übersicht 23: $\quad$ Förderkonditionen in Nordrhein-Westfalen 178

Übersicht 24: $\quad$ Förderkonditionen in Rheinland-Pfalz 180

$\begin{array}{lll}\text { Übersicht 25: } & \text { Förderkonditionen in Sachsen } & 181\end{array}$

Übersicht 26: Förderkonditionen in Schleswig-Holstein 183

Übersicht 27: Förderkonditionen in Thüringen 185 


\section{Verzeichnis der Diagramme}

Diagramm 1: $\quad$ Einsparungen bei der EOF durch die Abkehr vom Kostenmietprinzip

Diagramm 2: $\quad$ Kostenmieten und Mitteleinsatz im ersten Förderweg und bei der EOF

Diagramm 3: Höhe der von einzelnen Investoren erwarteten

Prämien für die Überlassung des Belegungsrechts

Diagramm 4: $\quad$ Einkommensorientierte Anfangsmieten in ausgewählten Bundesländern bei einer 70-qm-Wohnung

Diagramm 5: Belastungsquote eines Drei-Personen-Haushaltes bei Erstbezug einer einkommensorientiert geförderten 70-qm-Wohnung in einer baden-württembergischen Großstadt

Diagramm 6: $\quad$ Auswirkungen einer Haushaltsvergrößerung auf die Höhe der Wohntransfers (kein Wohnungswechsel) am Beispiel eines Drei-Personen-Haushaltes in Berlin

Diagramm 7: $\quad$ Vergleich der Förderung eines Drei- und eines Vier-Personen-Haushaltes in verschieden großen Wohnungen am Beispiel Berlins

Diagramm 8: $\quad$ Dynamisierung der Mietermieten bei der EOF in Berlin

Diagramm 9: $\quad$ Konzept einer „stufenlosen“ Zusatzförderung 
Burkhard Pahnke - 978-3-631-75215-9

Downloaded from PubFactory at 01/11/2019 07:00:27AM

via free access 


\section{Abkürzungsverzeichnis}

a.F.

AfA

AFWoG

AFWoG Bln

AFWoG NW

AFWoG SH

AGAFWoG

ARGEBAU

BayAFWoG

BGB

BGBl.

$\mathrm{Br}$.

Brem.

BremAFWoG

BSHG

BV

BVerfGE

Diff.

EAF

EAWBF

alte Fassung

Absetzung für Abnutzung

Gesetz über den Abbau der Fehlsubventionierung im Wohnungswesen

Gesetz über den Abbau der Fehlsubventionierung im Berliner Wohnungswesen

Gesetz über den Abbau der Fehlsubventionierung im Wohnungswesen für das Land Nordrhein-Westfalen

Schleswig-Holsteinisches Gesetz über den Abbau der Fehlsubventionierung im Wohnungswesen

Rheinland-Pfälzisches Landesgesetz zur Ausführung des Gesetzes über den Abbau der Fehlsubventionierung im Wohnungswesen

Arbeitsgemeinschaft der für das Bau-, Wohnungs- und Siedlungswesen zuständigen Minister der Länder Gesetz über den Abbau der Fehlsubventionierung im Wohnungswesen in Bayern

Bürgerliches Gesetzbuch

Bundesgesetzblatt

Brutto

Bremisches

Bremisches Gesetz über den Abbau der Fehlsubventionierung im Wohnungswesen

Bundessozialhilfegesetz

Berechnungsverordnung Amtliche Sammlung der Entscheidungen des BVerfG Differenz

Einkommensabhängige Förderung einkommensabhängige Wohnungsbauförderung 
EAL Einkommensabhängige Leistungen

EigZulG Eigenheimzulagengesetz

EOF/EoF/eoF Einkommensorientierte Förderung

EStG Einkommensteuergesetz

GBl. Gesetzesblatt

GdW Gesamtverband der Wohnungswirtschaft e.V.

GG Grundgesetz für die Bundesrepublik Deutschland

GVBl. Gesetz(es)- und Verordnungsblatt

GVOBl. Gesetz- und Verordnungsblatt

GV. Gesetz- und Verordnungsblatt

HessAFWoG Hessisches Gesetz zum Abbau der Fehlsubventionierung im Wohnungswesen

HmbAFWoG Gesetz über den Abbau der Fehlsubventionierung im Wohnungswesen in Hamburg

i.d.F. $\quad$ in der Fassung

Ifo Institut für Wirtschaftsforschung

i.V.m. in Verbindung mit

LAFWoG Gesetz über den Abbau der Fehlsubventionierung im Wohnungswesen für Baden-Württemberg

LAKRA Landeskreditbank Baden-Württemberg

LMW/Pr. Landesmietwohnungsbauprogramm

LWBPr. Landeswohnungsbauprogramm

MHG Miethöhegesetz

MietwohnungsbauR

Mietwohnungsbau-Richtlinie

Nds. AFWoG Niedersächsisches Gesetz über den Abbau der Fehlsubventionierung im Wohnungswesen

n.F. neue Fassung

NMV

Neubaumietenverordnung

NRW

Nordrhein-Westfalen 


$\begin{array}{ll}\text { NW } & \text { Nordrhein-Westfalen } \\ \text { o.ü.V. } & \text { ortsübliche Vergleichsmiete } \\ \text { p.a. } & \text { per annum } \\ \text { RDM } & \text { Ring Deutscher Makler } \\ \text { Schl.-H. } & \text { Schleswig-Holstein } \\ \text { u.R. } & \text { unterer Rand } \\ \text { VwV } & \text { Verwaltungsvorschrift } \\ \text { WBFA } & \text { Wohnungsbauförderungsanstalt } \\ \text { WBFR } & \text { Wohnungsbauförderrichtlinie } \\ \text { WE } & \text { Wohneinheit(en) } \\ \text { WFB } & \text { Wohnungsbauförderungsbestimmungen } \\ \text { Whg. } & \text { Wohnung } \\ \text { WiStG } & \text { Wirtschaftsstrafgesetz } \\ \text { WKSchG } & \text { Wohnraumkündigungsschutzgesetz } \\ \text { WoBauÄndG } & \text { Wohnungsbauänderungsgesetz } \\ \text { WoBauFördG } & \text { Wohnungsbauförderungsgesetz } \\ \text { WoBauG } & \text { Wohnungsbaugesetz } \\ \text { WoBindG } & \text { Wohnungsbindungsgesetz } \\ \text { WoGG } & \text { Wohngeldgesetz } \\ \text { WoGV } & \text { Wohngeldverordnung } \\ \text { ZPO } & \text { Zivilprozeßordnung }\end{array}$


Burkhard Pahnke - 978-3-631-75215-9

Downloaded from PubFactory at 01/11/2019 07:00:27AM

via free access 


\section{Symbolverzeichnis}

$A_{B}$

$A_{F}$

$E_{B}$

$\mathrm{E}_{\mathrm{F}}$

G

i

$\mathrm{M}_{\text {MAX }}$

$\mathrm{M}_{\mathrm{MIN}}$

$\mathrm{N}_{\mathrm{B}}$

$\mathrm{N}_{\mathrm{F}}$

q

R

t'

Y

$\mathrm{Y}_{\mathrm{BR}}$

$\mathrm{Y}_{\mathrm{OG}}$

$\mathrm{Y}_{\mathrm{UG}}$

$\mathrm{Z}$

$\Delta$

$\lambda$ erwartete Aufwendungen im Falle einer Belegungsbindung

erwartete Aufwendungen bei freier Vermietung

erwartete Mieteinnahmen im Falle einer Belegungsbindung

erwartete Mieteinnahmen bei freier Vermietung

Grundförderung

Zinssatz

(maximal zu entrichtende) Vertragsmiete

Mindestmiete

Nutzeneinheiten des Wohnungseigentümers bei der Vermietung

seiner belegungsgebundenen Wohnung

Nutzeneinheiten des Wohnungseigentümers bei freier Vermietung seiner Wohnung

Diskontsatz (7\%)

Risikoaufschlag

Grenzabgabensatz bezogen auf Steuern vom Einkommen und Sozialabgaben

Einkommen

Bruttoeinkommen

Einkommensobergrenze

Einkommensuntergrenze

Zusatzförderung

absolute Veränderung

Abschöpfungssatz 
Burkhard Pahnke - 978-3-631-75215-9

Downloaded from PubFactory at 01/11/2019 07:00:27AM

via free access 


\section{Einleitung}

Der soziale Mietwohnungsbau erfreut sich bei den Parteien und in der Öffentlichkeit bis heute großer Beliebtheit, denn er gilt als wirksames Instrument zur Schaffung preiswerten Wohnraums zugunsten geringverdienender Haushalte. Weitgehend unbestritten ist aber auch, daß die klassische Art der Förderung wegen ihrer gravierenden Mängel auf Dauer nicht aufrechterhalten werden kann: Die Anwendung des Kostenmietprinzips (Förderung bis zur Deckung aller laufenden Aufwendungen) hat zur Folge, daß die pro Wohnung benötigten Fördervolumina baukostenbedingt ein enormes Ausmaß erreichen und die Investoren nur geringe Anreize zu kostensparendem Bauen haben. Hinzu kommt, daß die Sozialmieten - anders als die Marktmieten - nur in einem geringen MaBe Wohnwertunterschiede widerspiegeln, sondern vielmehr jahrgangsweise und regional in Abhängigkeit von den historischen Baukosten und unterschiedlichen Fördermodalitäten streuen. Besonders in die Kritik geraten ist die Mietwohnungsbauförderung wegen ihrer geringen sozialen Treffsicherheit. In über $40 \%$ der Sozialwohnungen des ersten Förderwegs leben heute Haushalte, die aufgrund gestiegener Einkommen gar nicht mehr förderberechtigt sind und trotzdem hohe Mietvergünstigungen erhalten. Durch die seit Mitte der 80er Jahre bestehende Fehlbelegungsabgabe sind diese ungerechtfertigten Fördervorteile nur unzureichend abgeschöpft worden.

In Anbetracht der genannten Mängel hat der Bund die Förderung 1989 durch eine neue Methode, die sogenannte „vereinbarten Förderung“, ergänzt. Die Reform eröffnet den Ländern die Möglichkeit, ihre Förderkonditionen nach eigenen Vorstellungen auszugestalten oder auf privatrechtlicher Basis mit dem Fördernehmer zu vereinbaren. Dadurch soll eine einzelfallbezogene, wettbewerbsorientierte Mittelvergabe erreicht werden, bei der vom Kostenmietprinzip abgewichen und Einsparpotentiale so weit wie möglich ausgeschöpft werden.

Zielte die Einführung der vereinbarten Förderung in erster Linie auf eine Erhöhung der Fördereffizienz ab, so blieb das Problem der Fehlsubventionierungen weiterhin ungelöst. Bei der neuen Fördermethode kommt erschwerend hinzu, daß die Wohnungen zur Erreichung sozial durchmischter Belegungsstrukturen von vornherein auch an besserverdienende Haushalte vergeben werden, aber im Regelfall keine Staffelung der Wohnkosten nach der Einkommenshöhe vorgenommen wird. Dieser Mißstand hat den Gesetzgeber 1994 zu einem zweiten Reformschritt veranlaßt, der in der rechtlichen Verankerung der einkommensorientierten Förderung im sozialen Mietwohnungsbau (EOF) bestand. 
Die einkommensorientierte Förderung nach $\S 88$ e II. WoBauG zeichnet sich gegenüber der vereinbarten Förderung dadurch aus, daß die Objektförderung (Grundförderung) durch eine subjektorientierte Zusatzförderung ergänzt wird, deren Zweck darin besteht, die am Markt orientierte Vertragsmiete - je nach Einkommenssituation und Mitgliederzahl des Haushalts - auf das als tragbar definierte Niveau abzusenken. Um die Tragbarkeit der Wohnkosten auch im Zeitablauf sicherzustellen und Fehlsubventionierungen zu vermeiden, soll die Zusatzförderung in regelmäßigen zeitlichen Abständen an die Einkommensentwicklung des Mieters angepaßt werden. Vertreter des Bundesbauministeriums sehen in der EOF das Modell der Zukunft für den sozialen Mietwohnungsbau, da es die Vorzüge der vereinbarten Förderung auf sich vereinige und zugleich einkommensmäßig ungerechtfertigte Mietsubventionen vermeide. Die Einbeziehung von Besserverdienenden in die Förderung sei nun unproblematisch, da die Miete für diese Haushalte entsprechend höher angesetzt werde und der Staat zu ihren Gunsten daher weniger Mittel einsetzen müsse.

Die vorliegende Arbeit beschäftigt sich mit Frage, ob die EOF tatsächlich eine effiziente und verteilungsgerechte Förderung des sozialen Mietwohnungsbaues ermöglicht. Im Zentrum der Untersuchung steht die Umsetzung der EOF durch die Bundesländer. Seit der Verankerung der EOF im Zweiten Wohnungsbaugesetz haben rund zwei Drittel der Länder Förderkonditionen erarbeitet und Pilotmodelle begonnen. Erst auf der Basis der Detailgestaltung der EOF und der bei den Pilotmodellen gewonnenen Erfahrungen läßt sich beurteilen, ob die von der Bundesregierung angestrebte Umstellung der gesamten Neubauförderung auf die EOF wirklich eine sinnvolle Alternative zu der wegen ihrer gravierenden Mängel in Mißkredit geratenen herkömmlichen Fördermethode darstellt.

Die bis zur Einführung der EOF praktizierte Förderung des sozialen Mietwohnungsbaues sind Gegenstand des ersten Teils der Arbeit. Nach einer kurzen Beschreibung der mit der staatlichen Förderung verfolgten Ziele sollen die Charakteristika und Mängel der herkömmlichen Fördermethode dargestellt werden. Die klassische Förderung des sozialen Mietwohnungsbaues erfolgt überwiegend im Rahmen des ersten Förderwegs, auf den sich die Ausführungen daher konzentrieren werden. Im Anschluß daran wird dargelegt, wie durch die Einführung der Fehlbelegungsabgabe und der vereinbarten Förderung in den 80er Jahren versucht worden ist, die Mängel des ersten Förderwegs zu verringern oder zu beseitigen. Beide Instrumente sollen zunächst in ihren Grundzügen beschrieben und dann kritisch gewürdigt werden. 
Den Merkmalen der einkommensorientierten Förderung widmet sich der zweite Teil der Arbeit. Nach einer knappen Darstellung der bundesgesetzlichen Bestimmungen zur EOF wird auf die Art der Umsetzung des neuen Förderwegs in den Ländern eingegangen. Bei der Analyse der EOF im dritten Teil der Arbeit geht es zunächst um die Frage, ob die neue Förderform gegenüber dem ersten Förderweg tatsächlich die sparsamere und verteilungsgerechtere Alternative darstellt. Die sich anschließenden Ausführungen fragen daher nach der Eignung der EOF zur Erfüllung der ihr zugedachten Funktionen: Dies ist zum einen der Erwerb von Belegungsrechten zugunsten der als förderungswürdig klassifizierten Personengruppen, zum anderen die an der individuellen Bedürftigkeit ausgerichtete Gewährung von Mietsubventionen. Werden diese Funktionen tatsächlich in einer unter Effizienzgesichtspunkten zufriedenstellenden Weise erreicht und Fehlsubventionierungen vermieden?

Der abschließende vierte Teil der Arbeit befaßt sich mit den Möglichkeiten einer grundlegenden Reform der Wohnungspolitik, in der auf eine Förderung des sozialen Mietwohnungsbaues ganz verzichtet wird. Es soll der Frage nachgegangen werden, wie die mit dem sozialen Mietwohnungsbau angestrebten Ziele durch den Einsatz anderer, unter Umständen geeigneterer Instrumente erreicht werden könnten. So steht mit dem Wohngeld bereits ein funktionsfähiges Instrument zur sozialen Absicherung des Wohnens zur Verfügung. Durch den verstärkten Erwerb von Belegungsrechten im preisgünstigen Wohnungsbestand kann der Staat außerdem die Versorgungslage solcher Personengruppen verbessern, die auf dem freien Wohnungsmarkt wegen sozialer Merkmale diskriminiert werden (z.B. kinderreiche Familien, Ausländer etc.). Ferner stehen dem Staat zahlreiche Wege offen, die Bautätigkeit anzuregen, etwa indem er steuerliche Vergünstigungen gewährt oder die von ihm selbst verursachten Angebotshemmnisse abbaut, die vor allem in der restriktiven Bodenpolitik und der anbieterfeindlichen Ausgestaltung des Bau- und des Mietrechts liegen. 
Burkhard Pahnke - 978-3-631-75215-9

Downloaded from PubFactory at 01/11/2019 07:00:27AM

via free access 


\section{Teil: Der klassische soziale Mietwohnungsbau}

\section{A. Begriff und Entstehungsgeschichte}

Der soziale Wohnungsbau stellt seit Bestehen der Bundesrepublik Deutschland ein zentrales Instrument staatlicher Wohnungspolitik dar. Seine Verankerung im Ersten Wohnungsbaugesetz von 1950 war die politische Reaktion auf die gravierende Wohnungsnot der Nachkriegszeit, die vor allem auf drei Bestimmungsgründe zurückzuführen war. Zum einen hatte im Deutschen Reich schon vor Beginn des Zweiten Weltkrieges ein Wohnungsdefizit von ca. einer Million vorgelegen; des weiteren waren durch den Krieg rund 2,25 Millionen Wohnungen zerstört worden. Schließlich brachte der nach Kriegsende einsetzende Zustrom von Flüchtlingen und Vertriebenen eine starke Zunahme der westdeutschen Wohnbevölkerung. Der dadurch insgesamt verursachte Wohnungsfehlbestand in der alten Bundesrepublik ist auf 4 bis 5,5 Millionen Wohnungen geschätzt worden. ${ }^{1}$

Aufgrund dieser extremen Marktsituation, verbunden mit einer allgemeinen Kapitalknappheit, nahm die Förderung des Wohnungsbaues den Rang einer vordringlichen Staatsaufgabe ein. Der allgemeinen Auffassung, zur Erfüllung dieser Staatsaufgabe klare, bundesgesetzliche Vorgaben schaffen zu müssen, wurde durch das 1950 erlassene Erste Wohnungsbaugesetz (I. WoBauG) ${ }^{2}$ entsprochen. An seine Stelle trat im Jahre 1956 das Zweite Wohnungsbaugesetz (Wohnungsbau- und Familienheimgesetz - II. WoBauG) ${ }^{3}$, das bis heute - wenn auch wohl nur noch für kurze Zeit - die gesetzliche Grundlage des sozialen Wohnungsbaues darstellt.

Auf das I. WoBauG geht die später vom II. WoBauG übernommene Dreiteilung des Wohnungsbaues in die folgenden Unterformen zurück:

1. Der öffentlich geförderte (soziale) Wohnungsbau. Hierzu rechnen alle selbstgenutzten Eigentumswohnungen, Familienheime und Mietwohnungen, die mit öffentlichen Mitteln im Sinne des § 6 II. WoBauG gefördert werden. Voraussetzung für die Gewährung der öffentlichen Mittel ist, daß die Einkommen der Wohnungsnutzer bestimmte Obergrenzen nicht überschreiten. Bei Vermietung

1 Vgl. Pergande, H.-G., Einführung zum Zweiten Wohnungsbaugesetz, S. 1; Kornemann, R. (1973), S. 7ff.; Külp, B. u.a. (1984), S. 98f.

2 Vom 24. April 1950 (BGBl. S. 83). Das Gesetz trat am 27. April in Kraft.

3 Vom 27. Juni 1956 (BGBl. I S. 523), i.d.F. der Bekanntmachung vom 19. August 1994 (BGBl. I S. 2166), zuletzt geändert durch Gesetz vom 18. Dezember 1995 (BGBl. I S. 1959). 
darf höchstens das zur Deckung der laufenden Aufwendungen erforderliche Entgelt verlangt werden (Kostenmietprinzip - vgl. Kapitel 1.C.II). Die öffentlich geförderten Wohnungen unterliegen den Bestimmungen des Gesetzes zur Sicherung der Zweckbestimmung von Sozialwohnungen (Wohnungsbindungsgesetz - WoBindG) ${ }^{1}$, der Verordnung über wohnungswirtschaftliche Berechnungen (Zweite Berechnungsverordnung - II. BV) ${ }^{2}$ und der Verordnung über die Ermittlung der zulässigen Miete für preisgebundene Wohnungen (Neubaumietenverordnung 1970 - NMV 1970) ${ }^{3}$. Darüber hinaus gelten die Kündigungsschutzbestimmungen des Bürgerlichen Gesetzbuches (BGB) und einige weitere für den Gesamtbereich der Vermietung von Wohnraum erlassene Normen, die die sozialen Belange des Mieters sichern sollen, nicht jedoch die Bestimmungen des Gesetzes zur Regelung der Miethöhe (MHG) ${ }^{4}$. Die Wohnungsbauförderung mit öffentlichen Mitteln wird im allgemeinen Sprachgebrauch als ,erster Förderweg" bezeichnet.

2. Der steuerbegünstigte Wohnungsbau. Wohnungen, die vor 1990 fertiggestellt worden sind, konnten nach den Vorschriften der $\S \S 82$ und 83 WoBauG als steuerbegünstigt anerkannt und durch eine für die Dauer von 10 Jahren gewährte Befreiung von der Grundsteuer gefördert werden. Voraussetzung für die Anerkennung als steuerbegünstigt war, daß die in $\S 39$ Abs. 1 Satz 1 Nr. 1 bis 4 und Satz 2 II. WoBauG bestimmten Wohnflächengrenzen für den öffentlich geförderten Wohnungsbau um nicht mehr als 20\% überschritten wurden. Die Eigentümer der auf diesem Wege gegenwärtig noch geförderten Wohnungen können ihre Mietforderung - unter Beachtung des MHG - eigenverantwortlich festsetzen. ${ }^{5}$

1 Vom 24. August 1965 (BGBl. I S. 954), i.d.F. der Bekanntmachung vom 19. August 1994 (BGBl. I S. 2166, berichtigt auf S. 2319).

2 Vom 17. Oktober 1957 (BGBl. I S. 1719), i.d.F. der Bekanntmachung vom 12. Oktober 1990 (BGBl. I S. 2178), zuletzt geändert durch Verordnung vom 23. Juli 1996 (BGBl. I S. 1167).

3 Vom 14. Dezember 1970 (BGBl. I S. 1660), i.d.F. der Bekanntmachung vom 12. Oktober 1990 (BGBl. I S. 2203), zuletzt geändert durch Verordnung vom 13. Juli 1992 (BGBl. I S. 1250).

4 Das MHG regelt die Zulässigkeit von Mieterhöhungen für nicht preisgebundene Wohnungen. Es ist ergangen als Artikel 3 des Zweiten Gesetzes über den Kündigungsschutz für Mietverhältnisse über Wohnraum (Zweites Wohnraumkündigungsschutzgesetz - II. WKSchG) vom 18. Dezember 1974 (BGBl. I S. 3603).

5 Dieser Grundsatz wurde ursprünglich durch die Absätze 2 bis 4 des inzwischen weggefallenen $\S 85$ II. WoBauG dahingehend eingeschränkt, daß der Mieter sich innerhalb einer bestimmten Frist auf die Einhaltung der Kostenmiete berufen konnte, wenn diese überschritten worden war. 
3. Der frei finanzierte Wohnungsbau. Er umfaßt alle Wohnungen, die weder mit öffentlichen Mitteln noch durch eine Grundsteuerbegünstigung gefördert werden. Die frei finanzierten Mietwohnungen gelten zwar als nicht preisgebunden, unterliegen aber den einschränkenden Bestimmungen des MHG. Der Terminus „frei finanziert" bedeutet nicht, daß Bauherrn dieser Wohnungen ganz ohne staatliche Förderung auskommen müssen. Vielmehr können sie allgemeine, im Rahmen der Einkommensbesteuerung gewährte Vergünstigungen in Anspruch nehmen, die auch steuerpflichtigen Investoren im öffentlich geförderten und steuerbegünstigten Wohnungsbau gewährt werden. Im Mietwohnungsbau ist dies vor allem die erhöhte Gebäudeabschreibung nach § 7 Abs. 5 EStG.

Neben dem oben angeführten „öffentlich geförderten sozialen Wohnungsbau“ gibt es den Oberbegriff des „sozialen Wohnungsbaues“. Nach § 1 Abs. 1 II. WoBauG handelt es sich dabei um den Bau von Wohnungen, die „,nach Größe, Ausstattung und Miete oder Belastung für die breiten Schichten des Volkes bestimmt und geeignet sind". Der Begriffsgebrauch hier wie auch an anderen Stellen im II. WoBauG ${ }^{1}$ zeigt, daß sich der Terminus „sozialer Wohnungsbau“" nicht allein auf die Förderung mit öffentlichen Mitteln, sondern auch auf Maßnahmen des steuerbegünstigten und des freifinanzierten Wohnungsbaues bezieht. Steuerbegünstigte Wohnungen zählen dann zum sozialen Wohnungsbau, wenn sie - über die Grundsteuervergünstigung hinaus - mit Annuitätshilfen nach $\S 88$ a.F. II. WoBauG gefördert worden sind. Man spricht bei dieser 1965 ins Leben gerufenen Förderform auch vom ,zweiten Förderweg“. Sie wurde, nachdem sie zunächst nur den Bau von Eigenheimen, Eigensiedlungen und selbstgenutzten Eigentumswohnungen des steuerbegünstigten Wohnungsbaues umfaßte, durch das Finanzänderungsgesetz von 1967 auf alle Wohnungsarten des steuerbegünstigten Wohnungsbaues, also einschließlich Miet- und Genossenschaftswohnungen, übertragen. Eigentumsmaßnahmen bilden aber bis heute den Schwerpunkt dieser Förderform. Die im zweiten Förderweg vergebenen Mittel gelten als nicht öffentlich, d. h. sie können abweichend von den Bestimmungen des öffentlich geförderten sozialen Wohnungsbaues gewährt werden. Als Wohnungsnutzer kommen auch Haushalte in Frage, deren Einkommen die Bezugsberechtigungsgrenze im ersten Förderweg um bis zu $40 \%$ bzw. - seit 1992 - um bis zu 60\% überschreitet oder die eine mit öffentlichen Mitteln geförderte Wohnung freimachen. Auch für die Wohnungen des zweiten Förderwegs gilt das Kostenmietprinzip. Bei der Mietpreisbildung sind die entsprechenden Bestimmungen des WoBindG ${ }^{2}$, der II. BV und der NMV zu beachten.

1 So in $\S 6$ Abs. $3, \S 20, \S 24$ und $\S 89$ Abs. 1 Satz 2 II. WoBauG; vgl. Pergande, H.-G., Kommentar zum $\S 1$ II. WoBauG, S. 3f.

2 Es handelt sich um die $\S \S 8$ bis 11 WoBindG. Im übrigen gilt das Wohnungsbindungsgesetz ausschließlich für den öffentlich geförderten sozialen Wohnungsbau. 
Des weiteren gehören zum sozialen Wohnungsbau, nachdem eine Anerkennung als steuerbegünstigt nicht mehr zugelassen ist, die nunmehr frei finanzierten Wohnungen, die nach $\S \S 87$ a oder 88 n.F. II. WoBauG ebenfalls im Rahmen des zweiten Förderwegs gefördert werden. Die Förderung erfolgt unter der Voraussetzung, daß die Wohnflächenvorgaben des steuerbegünstigten Wohnungsbaues eingehalten werden. Außerdem umfaßt der soziale Wohnungsbau auch frei finanzierte Wohnungen, für die nicht-öffentliche Mittel im Rahmen der „,vereinbarten Förderung“ nach $\S 88 \mathrm{~d}$ bereitgestellt werden. Die vereinbarte Förderung, mitunter auch als ,dritter Förderweg“ bezeichnet, existiert erst seit 1989. Sie wurde durch das am 25. Februar in Kraft getretene Wohnungsbauänderungsgesetz $1988^{1}$ im II. WoBauG verankert. Gegenüber den beiden erstgenannten Förderwegen zeichnet sie sich dadurch aus, daß die Länder die Förderkonditionen - einschließlich der Bestimmungen zu den Einkommensgrenzen und den zulässigen Mieten - weitgehend selbständig festlegen oder mit den Investoren aushandeln können.

\section{B. Ziele der staatlichen Förderung}

Die Zielsetzung des sozialen Wohnungsbaues besteht nach $\S 1$ Abs. 2 II. WoBauG darin, ,den Wohnungsmangel zu beseitigen und für weite Kreise der Bevölkerung breitgestreutes Eigentum zu schaffen. Die Förderung soll eine ausreichende Wohnungsversorgung aller Bevölkerungsschichten entsprechend den unterschiedlichen Wohnbedürfnissen ermöglichen und diese namentlich für diejenigen Wohnungsuchenden sicherstellen, die hierzu selbst nicht in der Lage sind. In ausreichendem Maße sind solche Wohnungen zu fördern, die die Entfaltung eines gesunden Familienlebens, namentlich für kinderreiche Familien, gewährleisten ..." Aus der Gesetzesformulierung lassen sich die Ziele der staatlichen Wohnungsbauförderung ableiten. Dazu zählen (a) die Ausweitung des Wohnungsbestands, insbesondere in Gebieten mit erhöhtem Wohnraumbedarf, (b) die Versorgung solcher Bevölkerungsgruppen, die aufgrund niedriger Einkommen oder anderer sozialer Merkmale zur Beschaffung einer ihren Wohnbedürfnissen entsprechenden Wohnung nicht in der Lage und daher auf staatliche Hilfe angewiesen sind und (c) die Förderung der Eigentumsbildung im Wohnungssektor. Für den sozialen Mietwohnungsbau sind nur die beiden erstgenannten Zielsetzungen relevant. Sie sollen im folgenden etwas eingehender dargestellt werden.

1 Gesetz zur Änderung des Zweiten Wohnungsbaugesetzes und des Wohnungsbaugesetzes für das Saarland (Wohnungsbauänderungsgesetz 1988 - WoBauÄndG 1988) vom 21. Februar 1989 (BGBl. I S. 242). 


\section{Erhöhung des Wohnungsbestands}

Die Verbesserung der Wohnungsversorgung der Bevölkerung durch ein quantitativ hinreichendes Angebot war in der Nachkriegszeit die dominierende Zielsetzung staatlicher Wohnungspolitik. Sie fand ihren Ausdruck in der Formulierung des $\S 1$ im Ersten Wohnungsbaugesetz, der festlegte, daß innerhalb von sechs Jahren möglichst 1,8 Millionen Wohnungen im sozialen Wohnungsbau geschaffen werden sollten. Nachdem die Zielvorgabe bis 1956 mit über zwei Millionen neuerrichteten Sozialwohnungen mehr als erreicht worden war $^{1}$, wurde im $\S 1$ des Zweiten Wohnungsbaugesetzes auf eine Quantifizierung verzichtet und nunmehr allgemein die „Beseitigung der Wohnungsnot" als Ziel angegeben. Seine heutige Form hat $\S 1$ II. WoBauG durch das 1976 erlassene Gesetz zur Förderung von Wohnungseigentum und Wohnbesitz im sozialen Wohnungsbau ${ }^{2}$ erhalten. Bis Mitte der 70er Jahre war der Wohnungsbestand auf über 23 Millionen Wohnungen angewachsen, von einer allgemeinen Wohnungsnot konnte nicht mehr gesprochen werden. Aus diesem Grunde gebraucht das Gesetz seither die abgeschwächte Zielformulierung „Beseitigung des Wohnungsmangels". Durch die Ende der 80er Jahre aufgetretenen Wohnungsmarktanspannungen hat die quantitative Zielsetzung wieder an Bedeutung gewonnen.

Hinter der staatlichen Zielsetzung, für eine Erhöhung des Wohnungsbestandes zu sorgen, steht die Vorstellung, daß der Markt allein - gemessen an den Präferenzen der Wirtschaftssubjekte - kein ausreichendes Angebot an Wohnraum garantiere. In der wissenschaftlichen Literatur wird das Auftreten vorübergehender oder dauerhafter Angebotsdefizite auf Besonderheiten des Gutes „Wohnung " zurückgeführt, die das Funktionieren des Marktprozesses beeinträchtigen können. ${ }^{3}$ Ein typisches Charakteristikum ist die Standortgebundenheit der Wohnungen, die zur Segmentierung des Wohnungsmarktes in viele regionale Teilmärkte führt. Wegen der Immobilität des Gutes „Wohnung“ können Anpassungen des Angebots auf regionale Nachfrageverschiebungen nicht aus dem Bestand anderer Teilmärkte, sondern nur im Rahmen der Neuproduktion erfolgen. Diese ist aber aufgrund der hohen Produktionskosten und der langen Lebensdauer der Wohnungen von überdurchschnittlichen wirtschaftlichen Risiken gekennzeichnet, die sich hemmend auf die Investitionsbereitschaft potentieller

Vgl. Pergande, H.-G., Einführung zum Zweiten Wohnungsbaugesetz, S. 5.

2

Vom 23. März 1976 (BGBl. I S. 737).

3 Vgl. Sullivan, A. M. (1990), S. 344ff.; Keil, K. (1996), S. 19ff.; Heuer, J. H. B. (1979), S. 65ff.; Heuer, J. H. B. (1991), S. $20 \mathrm{ff}$. 
Wohnungsanbieter auswirken. ${ }^{1}$ Außerdem führt die lange Produktionsdauer von durchschnittlich zwei Jahren zu einer Verzögerung der Angebotsreaktion. ${ }^{2}$

$\mathrm{Zu}$ den Besonderheiten des Gutes „Wohnung“ wird mitunter auch das Auftreten externer Effekte gerechnet. Vertreter dieser Auffassung argumentieren, daß die durch unzureichende Wohnverhältnisse einzelner Haushalte ausgelösten Nachteile (z.B. Gesundheitsbeeinträchtigungen, Kriminalität etc.) schädigende Auswirkungen für die gesamte Gesellschaft haben können. ${ }^{3}$ Trotz der angeführten Besonderheiten des Gutes Wohnung läßt sich der soziale Wohnungsbau durch allokative Mängel auf dem Wohnungsmarkt allein kaum rechtfertigen. ${ }^{4}$ Dennoch gibt es auf der politischen Ebene einen breiten Konsens über die Notwendigkeit einer staatlichen Angebotsförderung im Wohnungssektor. ${ }^{5}$ Durch Maßnahmen des sozialen Wohnungsbaues sollen in erster Linie regionale Wohnungsmarktengpässe, die gerade in Ballungsgebieten auftreten, sowie Angebotsdefizite im mittleren und unteren Preissegment verringert bzw. beseitigt werden.

\section{Versorgung sozial schwacher Gruppen mit preiswertem Wohnraum}

Die zweite Zielsetzung des sozialen Wohnungsbaues ist die Sicherstellung einer ausreichenden Wohnungsversorgung für Haushalte, die hierzu selbst nicht in der Lage sind. Vordringlich zu fördern sind nach § 26 Abs. 2 Satz 1 II. WoBauG kinderreiche Familien, junge Ehepaare, alleinstehende Elternteile mit Kindern, ältere Menschen, Schwerbehinderte, Vertriebene und Flüchtlinge im Sinne des Bundesvertriebenengesetzes sowie Übersiedler. In der Wissenschaft

Vgl. Expertenkommission „Wohnungspolitik“(1995), S. 1; Keil, K. (1996), S. $67 f$.

2 Vgl. Kornemann, R. (1973), S. 17f.; Heuer, J. H. B. u.a. (1979), S. 69; Keil, K. (1996), S. 22.

Vgl. Keil, K. (1996), S. 24ff.; Sullivan, A. M. (1990), S. 349.

4 Vgl. Schneider, H. K., Deichmann, W. (1984), S. 11ff.; Keil, K. (1996), S. 13ff.

5 Vgl. Kansy, D. (1991), Falthauser, K. (1991), Hitschler, W. (1991), Müntefering, F. (1991), Kommission Wirtschafts-, Landwirtschafts- und Sozialpolitik beim Parteivorstand der Partei des Dernokratischen Sozialismus (1991) und Arbeitskreis IV (Wohnungspolitik / Städtebau) der Grünen Bundestagsfraktion (1991). Mithin wird in den quantitativen Auswirkungen auf den Wohnungsbestand das zentrale Argument zur Aufrechterhaltung des sozialen Wohnungsbaues gesehen. Der ehemalige Präsident des Deutschen Mieterbundes, F. A. Jahn, hat diese Auffassung zugespitzt so formuliert: „Über Arbeitslosengeld schaffe ich keine Arbeitsplätze, und über Wohngeld schaffe ich keine Wohnungen." Zitiert nach Meyer, B. (1994), S. 38. 
und Politik herrscht breiter Konsens darüber, daß die Wohnungsversorgung auch eine sozialpolitische Aufgabe darstellt. Wohnen gehört zu den „Vitalbedürfnissen des Menschen, deren Befriedigung zur Sicherung seiner biologischen ... Existenz unerläßlich ist. "' Weder existieren Ersatzgüter für das Gut „Wohnung“, noch kann der Bedarf zeitlich ausgesetzt werden. Der Staat hat daher nach allgemeiner Auffassung dafür Sorge zu tragen, daß alle Gesellschaftsmitglieder unter Wahrung eines (kulturellen) Mindeststandards mit Wohnraum versorgt sind. ${ }^{2}$

Die Schwierigkeiten der Haushalte, sich mit angemessenem Wohnraum zu versorgen, rühren vielfach daher, daß ihnen nur ein geringes Einkommen zur Verfügung steht. „Berücksichtigt man die Unterschiede auf den regionalen Wohnungsmärkten, die sich nicht in gleicher Weise im Einkommensniveau widerspiegeln, wird deutlich, daß zumindest für bestimmte Einkommensgruppen eine reine Marktsteuerung bedeuten würde, daß der überwiegende Teil des Einkommens für das Wohnen verausgabt werden muß." ${ }^{3}$ Durch die Bereitstellung von Sozialwohnungen soll diesen Haushalten eine hinreichende Wohnraumversorgung garantiert und die Wohnkostenbelastung auf ein tragbares Maß begrenzt werden.

Daneben können die Probleme, eine angemessene Wohnung zu bekommen, auch darauf zurückzuführen sein, daß die betroffenen Haushalte bestimmte Merkmale aufweisen, die einen speziellen Wohnbedarf begründen oder zu einer anbieterseitigen Diskriminierung führen. $\mathrm{Zu}$ den Personengruppen mit einem speziellen Wohnbedarf zählen vor allem Behinderte und ältere Menschen. Die von ihnen benötigten Wohnungen stehen oft nicht in ausreichendem Maße zur Verfügung, da sie ,einerseits in ihrer Herstellung vergleichsweise teuer sind und andererseits einem erhöhten Vermietungsrisiko unterliegen." ${ }^{4}$ Besondere Versorgungsprobleme kennzeichnen auch die Situation von Ausländern, kinderreichen Familien, alleinerziehenden Elternteilen und anderen Personengruppen mit geringem Sozialprestige wie Arbeitslose, Strafentlassene etc. Sie werden auf dem Wohnungsmarkt diskriminiert, da die Wohnungseigentümer bei ihnen erhöhte Vermietungsrisiken vermuten oder ihnen aus persönlichen Gründen ablehnend gegenüberstehen. Für die betroffenen Haushalte hat dies zur Folge,

1 Heuer, J. H. B. u.a. (1979), S. 66.

2 Vgl. Heuer, J. H. B. u.a. (1979), S. 66.

3 Neumann, L. F., Romahn, H. (1994), S. 14.

4 Keil, K. (1996), S. 44f. 
daß sie sich nicht oder nur unter Aufwendung erhöhter Mietbeträge mit ausreichendem Wohnraum versorgen können. ${ }^{1} \mathrm{Da}$ es in der Praxis nicht möglich ist, die hier beschriebenen Versorgungsprobleme allein durch Gewährung von Transfers zu lösen, „muß der Staat weitergehende Maßnahmen ergreifen, um diese Versorgungslücken zu schließen und die daraus resultierenden sozialen Härten zu vermeiden“².

\section{Charakteristika des klassischen sozialen Mietwohnungsbaues}

\section{Art der Förderung}

Bis in die späten 80er Jahre hinein ist der soziale Mietwohnungsbau hauptsächlich im ersten Förderweg gefördert worden, der deshalb als die „klassische“ Form der Förderung bezeichnet wird. ${ }^{3}$ Dabei wird so vorgegangen, daß der Staat öffentliche Mittel zur Absenkung der Gesamtkosten des Bauvorhabens oder der laufenden Aufwendungen aus Kapitaldienst und Bewirtschaftung einsetzt. Als Gegenleistung verpflichtet sich der Investor zur Einhaltung der Belegungsbindung und der Kostenmiete als Mietobergrenze. Die finanzielle Beteiligung des Bundes an der Förderung erfolgt auf der Basis des Artikels 104 a GG, wonach der Bund den Ländern für besonders bedeutsame Investitionen Finanzhilfen gewähren kann, die zur Abwehr einer Störung des gesamtwirtschaftlichen Gleichgewichts oder zum Ausgleich unterschiedlicher Wirtschaftskraft im Bundesgebiet oder zur Förderung des wirtschaftlichen Wachstums erforderlich sind. Nach § 29 II. WoBauG ist es Aufgabe der Länder, Wohnungsbauprogramme aufzustellen. Der Bund stellt ihnen dafür Finanzmittel zur Verfügung, die die Länder mit eigenen Mitteln aufstocken und an die Landkreise und Kommunen weiterleiten. ${ }^{4}$ Den Gemeinden obliegt es, geeignete Grundstücke zu beschaffen, zu erschließen, planerisch auszuweisen und an die Investoren $\mathrm{zu}$

1 So hat die 1\%-Gebäude- und Wohnungsstichprobe von 1993 ergeben, daß Ausländer in Westdeutschland eine durchschnittliche Bruttokaltmiete in Höhe von 9,89 DM pro qm und Monat, Deutsche dagegen nur eine Miete von durchschnittlich 9,50 DM entrichtet haben (Angaben des Statistischen Bundesamtes). Geht man davon aus, daß Deutsche tendenziell in ,besseren“ Wohnungen leben, dann ist die effektive Preisdiskriminierung sogar noch größer.

2 Keil, K. (1996), S. 45.

3 Zur quantitativen Bedeutung des ersten Förderwegs seit $1980 \mathrm{vgl}$. Übersicht 3 in Kapitel 1.E.II.

$4 \mathrm{Zu}$ den ökonomischen Implikationen der Mischfinanzierung vgl. Musgrave, R. A. u.a. (1987), S. 23ff.; Break, G. F. (1980), S. 73ff. 
veräußern. Außerdem haben die Kommunen zuletzt vielfach ,mit hohen Beiträgen und wachsender Belastung die 'Spitzenfinanzierung' für alle jene Neubauvorhaben übernommen, für die die Bund-Länder-Förderung nicht ausreicht, um die vom Land vorgeschriebenen (niedrigen) Bewilligungsmieten zu erreichen."1

Die staatlichen Fördermittel können als Kapital- und/oder als Ertragssubventionen bewilligt werden. Während die Kapitalsubventionen unmittelbar zur Finanzierung der Gesamtkosten eines Bauvorhabens dienen, setzen die Ertragssubventionen an den durch Finanzierung und Bewirtschaftung einer Wohnung entstehenden laufenden Belastungen an. Zur erstgenannten Subventionsart zählen die zinsverbilligten öffentlichen Baudarlehen nach $\S 42$ II. WoBauG, zu der an zweiter Stelle genannten die Zinszuschüsse sowie Darlehen zur Deckung der zu entrichtenden Zinsen oder Tilgungen (Annuitätsdarlehen) und Darlehen oder Zuschüsse zur Deckung der laufenden Aufwendungen (Aufwendungsdarlehen, Aufwendungszuschüsse).

\section{Kostenmietprinzip}

Nach $\S 8$ Abs. 1 WoBindG darf der Verfügungsberechtigte die Wohnung nicht gegen ein höheres Entgelt zum Gebrauch überlassen, als zur Deckung der laufenden Aufwendungen (Kostenmiete) erforderlich ist. Durch die öffentlichen Mittel (z.B. zinsverbilligte Darlehen) wird die Kostenmiete auf das Niveau der vom Mieter zu entrichtenden Sozialmiete herabgeschleust. Für die Ermittlung der Kostenmiete sind nach $\S 28$ WoBindG die Bestimmungen der II. BV und der NMV 1970 anzuwenden. Der Investor hat für das Bauvorhaben zunächst eine Wirtschaftlichkeitsberechnung aufzustellen und der Bewilligungsstelle vorzulegen. Die Wirtschaftlichkeitsberechnung muß eine Gebäude- und Grundstücksbeschreibung, eine Vorabkalkulation der Gesamtkosten, einen Finanzierungsplan und eine Aufstellung der laufenden Aufwendungen und Erträge enthalten (§ 3 II. BV). Die Kostenmiete wird vom Bauherrn auf der Grundlage der anerkennungsfähigen laufenden Aufwendungen aus Kapitalkosten und Bewirtschaftungskosten ermittelt:

(1) Kapitalkosten sind die Kosten, die sich für die im Finanzierungsplan ausgewiesenen Finanzierungsmittel nachhaltig vor allem in Form von Zinsen und Verwaltungskostenbeiträgen ergeben. Tilgungen werden i.d.R. nicht als Kapitalkosten anerkannt. ${ }^{2}$ Handelt es sich um Eigenkapital, so darf für den $15 \%$ der

1 Julitz, L. (1993).

2 Eine Ausnahme stellt der sogenannte „Zinsersatz“ dar. Nach $§ 22$ Abs. 1 II. BV dürfen bei unverzinslichen Fremdmitteln, deren Tilgungssatz $1 \%$ überschreitet, Tilgungen als Kapi- 
Gesamtkosten nicht übersteigenden Betrag eine Verzinsung von $4 \%$, für den darüber hinausgehenden Betrag eine Verzinsung in Höhe des marktüblichen Zinssatzes für erststellige Hypotheken (bei Bewilligung der Mittel vor 1974) oder in Höhe von 6,5\% (bei Bewilligung ab 1974) angesetzt werden. Bei Fremdmitteln darf der vereinbarte Zinssatz einschließlich Verwaltungskostenbeitrag bis zu dem für erste Hypotheken im Zeitpunkt der Antragstellung oder Darlehensbewilligung marktüblichen Zinssatz, höchstens jedoch der tatsächlich zu entrichtende niedrigere Zinsbetrag zugrunde gelegt werden. Für Zinsen auf Tilgungsdarlehen entspricht der ansetzbare Betrag während der gesamten Laufzeit der erstmaligen Zinszahlung, obwohl durch Tilgung zunehmend Fremddurch Eigenkapital ersetzt wird. ${ }^{1}$

(2) Bewirtschaftungskosten sind die Kosten, die zur Bewirtschaftung des Gebäudes oder der Wirtschaftseinheit laufend erforderlich sind; dazu gehören die Abschreibung, die Verwaltungs-, Instandhaltungs- und Betriebskosten sowie das Mietausfallwagnis. Die Abschreibung ist nach der mutmaßlichen Nutzungsdauer zu errechnen; im Regelfall beträgt sie bei Gebäuden $1 \%$ der Bau- und bei Erbbaurechten $1 \%$ der Gesamtkosten. ${ }^{2}$ Als Verwaltungskosten dürfen derzeit höchstens 420 DM je Wohnung und 55 DM für eine Garage angesetzt werden. Bei den Instandhaltungskosten belaufen sich die pro Jahr und qm Wohnfläche maximal anzusetzenden Beträge je nach dem Zeitpunkt der Bezugsfertigstellung auf $20 \mathrm{DM}$ (vor 1953), 18,50 DM (ab 1953 bis 1969), $14 \mathrm{DM}$ (ab 1970 bis 1979) oder 11 DM (ab 1980). Daneben sind Zu- und Abschläge in Abhängigkeit von der Ausstattung der Wohnungen vorgesehen. Die Betriebskosten dürfen seit Mitte der 80er Jahre nicht mehr in der Wirtschaftlichkeitsrechnung angesetzt werden, sondern sind durch Umlage zu erheben. Für das Mietausfallwagnis schließlich darf der Vermieter 2\% der Erträge ansetzen.

talkosten angesetzt werden; das gleiche gilt, wenn der Zinssatz niedriger als $4 \%$ ist. Ansätze für Zinsersatz sind nur insoweit zulässig, als die Bewilligungsstelle zustimmt ( $\$ 22 \mathrm{Abs}$. 3). Sie dürfen bei den einzelnen Fremdmitteln deren Tilgung nicht überschreiten und zusammen mit dem Ansatz für Zinsen nicht höher sein als der Betrag, der sich aus einer Verzinsung des jeweiligen Fremdmittels mit 4\% ergibt. Die Summe aller Ansätze für Zinsersatz darf auch nicht die Summe der Tilgungen übersteigen, die aus der gesamten Abschreibung nicht gedeckt werden können ( $\$ 22 \mathrm{Abs} .2$ ).

1 In der Literatur wird daraus vielfach auf das Entstehen von ungerechtfertigten Entschuldungsgewinnen geschlossen. Dieser Auffassung ist entgegenzuhalten, daß eine Verzinsung des durch die Tilgung zunehmend an die Stelle von Fremdkapital tretenden Eigenkapitals wohl kaum als unangemessen bezeichnet werden kann; vgl. Eekhoff, J. (1985), S. 626ff. Eine Begünstigung des Investors ist nur insoweit gegeben, als der beim Tilgungsdarlehen zugrunde gelegte Zinssatz oberhalb des sonst üblicherweise für das Eigenkapital anzusetzenden Kostensatzes liegt.

2 Für bestimmte Anlagen und Einrichtungen kann über den allgemeinen Ansatz von 1\% hinaus eine zusätzliche Abschreibung nach der mutmaßlichen Lebensdauer berechnet werden. 
Der Gesamtbetrag der (herabsubventionierten) laufenden Aufwendungen geteilt durch die Wohnfläche des Hauses ergibt die Durchschnittsmiete, die von der Bewilligungsstelle genehmigt werden muß. Auf ihrer Grundlage hat der Bauherr gemäß $\S 8$ a Abs. 5 WoBindG die Miete für die einzelnen Wohnungen (Einzelmieten) unter angemessener Berücksichtigung ihres durchschnittlichen Wohnwertes, insbesondere von Lage, Ausstattung und Zuschnitt zu berechnen. Nach $\S 72$ Abs. 3 II. WoBauG können die obersten Landesbehörden Obergrenzen für die Durchschnittsmiete festlegen, bei deren Überschreitung die Genehmigung versagt wird. Dadurch soll eine Förderung solcher Bauvorhaben verhindert werden, bei denen bereits aus der Wirtschaftlichkeitsberechnung entnommen werden kann, daß die Miete für die bezugsberechtigten Haushalte kaum tragbar sein wird.

\section{Belegungsbindung}

Auch bei der Auswahl der Mieter unterliegt der Investor gesetzlichen Bindungen, durch die gewährleistet werden soll, daß die geförderten Wohnungen ausschließlich der als förderungswürdig eingestuften Zielgruppe zur Verfügung stehen. Nach § 4 WoBindG darf eine mit öffentlichen Mitteln geförderte Sozialwohnung nur solchen Haushalten zum Gebrauch überlassen werden, deren Einkommen die in $\S 25$ Abs. 2 II. WoBauG aufgeführten Obergrenzen nicht überschreitet und die aufgrund ihrer Mitgliederzahl zum Bezug einer Wohnung der entsprechenden Größe berechtigt sind. Die Mietinteressenten weisen dies durch Vorlage eines Wohnberechtigungsscheines nach, der von den durch Landesverordnung bestimmten zuständigen Stellen - in größeren Städten sind dies die Wohnungsämter - bei Nachweis der Fördervoraussetzungen für die Dauer von i.d.R. zwölf Monaten ausgestellt wird. Die Bescheinigung enthält Vorgaben für die nach der Quadratmeter- und/oder Raumzahl bestimmte, angemessene Wohnungsgröße und die Art der Fördermaßnahmen, die der Haushalt aufgrund seines Einkommens in Anspruch nehmen darf.

Die Entscheidung über die Bezugsberechtigung erfolgt auf der Basis des - am verfügbaren Haushaltseinkommen orientierten - Gesamteinkommens nach $\S 25$ Abs. 1, 3. Dabei handelt es sich um den Gesamtbetrag der Jahreseinkommen des Wohnungssuchenden und der nach $\S 8$ zu seiner Familie rechnenden Angehörigen ( $\$ \S 25$ a bis $c$ ), abzüglich bestimmter Frei- und Abzugsbeträge ( $\$ 25 \mathrm{~d}$ ). Die Einkommensgrenze beträgt nach $\S 25$ Abs. 2 II. WoBauG 23.000 DM für einen Ein-Personen-Haushalt und 33.400 DM für einen Zwei-PersonenHaushalt. Sie erhöht sich bei Haushalten mit drei oder mehr Personen um jeweils 8.000 DM für jeden weiteren zur Familie rechnenden Angehörigen. Nach $\S 25 \mathrm{c}$ Abs. 1 erfolgt die Einkommensermittlung auf der Basis der Einkünfte, 
die in den zwölf Monaten ab dem Monat der Antragstellung zu erwarten sind. Nur wenn eine solche Prognose nicht vorgenommen werden kann, ist gemäß $\S 25$ c Abs. 2 ,grundsätzlich das Einkommen der zurückliegenden zwölf Monate vor Antragstellung zugrunde zu legen".

Bei der Einkommensermittlung wird im einzelnen so vorgegangen, daß der Haushalt durch entsprechende Nachweise, z.B. Lohnabrechnungen, Steuerbescheide etc., die Summe der positiven Einkünfte im Sinne des $\S 2$ Abs. 1, 2 EStG offenlegt und die zuständige Stelle informiert, wenn im Bewilligungszeitraum mehr als nur geringfügige Änderungen der Einkommensverhältnisse zu erwarten sind. Die ermittelten Einkünfte werden um bestimmte, in $\S 25$ a Abs. 2 II. WoBauG aufgelistete Einnahmen (abzüglich Werbungskosten) ergänzt, die vom empfangenden Haushalt zwar nicht versteuert werden müssen, aber seine Leistungsfähigkeit erhöhen. Dazu zählen u.a. Lohnersatzleistungen und ausländische Einkünfte nach $\S 32$ b Abs. 1 EStG, Leistungen der laufenden Hilfe zum Lebensunterhalt nach dem Bundessozialhilfegesetz (BSHG), Zuschläge für Sonntags-, Feiertags- oder Nachtarbeit etc.

Vom so ermittelten Jahreseinkommen nach $\S 25 a$ werden gemäß $\S 25$ b die geleisteten Zahlungen für Einkommensteuern sowie für Pflichtbeiträge zur gesetzlichen Kranken- und zur gesetzlichen Rentenversicherung bzw. den Pflichtbeiträgen zweckgleiche, mehr als nur geringfügige, laufende Beiträge an öffentliche oder private Versicherungen oder ähnliche Einrichtungen abgezogen. Zur Vereinfachung wird für jede der drei genannten Zahlungen ein pauschaler Abzugsbetrag von jeweils $10 \%$ vom Jahreseinkommen nach $\S 25$ a angesetzt. Bei Haushalten, die keinen der genannten Pauschalabzüge in Ansatz bringen können, wird ein Betrag in Höhe von 6\% abgezogen. Man erhält das Gesamteinkommen nach $\S 25$ a bis $c$, das zuletzt noch um die in $\S 25 \mathrm{~d}$ aufgelisteten Frei- und Abzugsbeträge bereinigt wird, mit denen die besonderen Aufwendungen von Alleinerziehenden in Beruf und Ausbildung, Schwerbehinderten und jungen Ehepaaren, sowie Aufwendungen zur Erfüllung gesetzlicher Unterhaltsverpflichtungen berücksichtigt werden sollen. Ein Freibetrag nach $\S 25 \mathrm{~d}$ kann darüber hinaus für eigene Einkünfte von zum Haushalt rechnenden Kindern abgezogen werden. ${ }^{1}$

Mit dem Freibetrag soll der „Lebenserfahrung“ Rechnung getragen werden, daß „Einnahmen der Kinder aus erster Erwerbstätigkeit dem Familienhaushalt nur zu einem geringen Teil zufließen, da die Kinder einen Teil ihrer Einnahmen für Vorkehrungen zur angestrebten Gründung eines eigenen Haushalts verwenden."Deutscher Bundestag (1994a), S. 24.

Burkhard Pahnke - 978-3-631-75215-9 
Übersicht 1: Einkommensgrenzen nach § 25 Abs. 2 II. WoBauG (seit Oktober 1994)

\begin{tabular}{|c|c|c|c|}
\hline $\begin{array}{l}\text { Zahl der } \\
\text { Haushalts- } \\
\text { mitglieder }\end{array}$ & $\begin{array}{l}\text { Einkommens- } \\
\text { grenze nach } \\
\S 25 \text { II. WoBauG }\end{array}$ & Erwerbsbeteiligung & $\begin{array}{l}\text { entsprechende } \\
\text { Bruttojahreseinkomen } \\
\text { für typische Fälle }\end{array}$ \\
\hline 1 & 23.000 & $\begin{array}{l}\text { Beamte } \\
\text { Arbeiter / Angestellte } \\
\text { Erwerbslose } \\
\text { Nichterwerbsperson }\end{array}$ & $\begin{array}{l}30.750 \\
34.857 \\
24.468 \\
25.756\end{array}$ \\
\hline 2 & 33.400 & $\begin{array}{l}\text { Beamte } \\
\text { Arbeiter / Angestellte } \\
\text { Erwerbslose } \\
\text { Nichterwerbsperson } \\
\text { (zwei Sozialrentner) } \\
\text { Alleinerziehende mit } \\
\text { Kind unter zwölf Jahren } \\
\text { - Beamte } \\
\text { - Arbeiter / Angestellte } \\
\text { - Erwerbslose } \\
\text { - Nichterwerbsperson } \\
\text { (Alleinerz. in Ausbildung) } \\
\text { junges Ehepaar } \\
\text { - Beamte } \\
\text { - Arbeiter / Angestellte }\end{array}$ & $\begin{array}{l}43.750 \\
49.714 \\
35.532 \\
37.511 \\
\\
\\
\\
\\
46.000 \\
52.286 \\
35.532 \\
37.447 \\
\\
\\
\\
\\
53.750 \\
61.143\end{array}$ \\
\hline 3 & 41.400 & $\begin{array}{l}\text { Beamte } \\
\text { Arbeiter / Angestellte } \\
\text { Alleinerziehende mit zwei } \\
\text { Kindern unter zwölf Jahren } \\
\text { - Beamte } \\
\text { - Arbeiter / Angestellte } \\
\text { junges Ehepaar } \\
\text { - Beamte } \\
\text { - Arbeiter / Angestellte }\end{array}$ & $\begin{array}{l}53.750 \\
61.143 \\
\\
\\
58.250 \\
66.286 \\
\\
\\
63.750 \\
72.571\end{array}$ \\
\hline 4 & 49.400 & $\begin{array}{l}\text { Beamte } \\
\text { Arbeiter / Angestellte }\end{array}$ & $\begin{array}{l}63.750 \\
72.571\end{array}$ \\
\hline 5 & 57.400 & $\begin{array}{l}\text { Beamte } \\
\text { Arbeiter / Angestellte }\end{array}$ & $\begin{array}{l}73.750 \\
84.000\end{array}$ \\
\hline
\end{tabular}


Abschließend vergleicht die zuständige Stelle das nach Vornahme dieser Abzüge ermittelte Gesamteinkommen nach § 25 Abs. 1, 3 mit dem in $\S 25$ Abs. 2 angeführten, höchstzulässigen Betrag. Wird die Einkommensgrenze eingehalten (oder nur geringfügig überschritten), stellt sie dem Wohnungssuchenden einen Berechtigungsschein für eine Sozialwohnung des ersten Förderwegs aus. Übersicht 1 gibt einen Überblick über die mit der Einkommensgrenze korrespondierenden Bruttoeinkommen, die - je nach Haushaltstyp - sehr unterschiedlich ausfallen. Nach Schätzungen des Bundesbauministeriums aus dem Jahr $1994^{1}$ bezogen $40 \%$ aller Haushalte in der Bundesrepublik ein unterhalb dieser Beträge liegendes Einkommen. Von den Erwerbstätigen-Haushalten waren $28 \%$ und von den Nichterwerbstätigen-Haushalten 58\% zum Bezug einer mit öffentlichen Mitteln geförderten Sozialwohnung berechtigt.

\section{Mängel des alten Fördersystems}

\section{Förderung für Wenige}

Die herkömmliche Förderung des sozialen Mietwohnungsbaues steht wegen ihrer Mängel und der sich daraus ergebenden Fehlentwicklungen schon seit den 60er Jahren in der Kritik. ${ }^{2}$ Ein zentrales Problem besteht in der Diskrepanz zwischen der großen Anzahl der förderberechtigten Haushalte und der weit niedrigeren - überdies jährlich sinkenden - Zahl der Sozialwohnungen. Der Anteil der im ersten Förderweg bezugsberechtigten Haushalte dürfte in Westdeutschland gegenwärtig (1997) zwischen 35\% und 40\% liegen, während die Zahl der belegungsgebundenen Sozialwohnungen des ersten Förderwegs dort bei etwa 2,1 Millionen anzusetzen ist. ${ }^{3}$ Angesichts dieser Diskrepanz muß die Zuteilung einer Sozialwohnung aus der Sicht der Antragsteller als „Glücksfall“ angesehen werden. Es ergibt sich die sozialpolitisch bedenkliche Situation, daß wenige Mieter eine massive Förderung erhalten - die durchschnittliche Mietsubvention wird auf 1.000 DM pro Jahr geschätzt -, während die meisten berechtigten Haushalte leer ausgehen. Eekhoff sieht darin einen Verstoß gegen das „Gleich-

1 Deutscher Bundestag (1994d), S. 44ff. Die Schätzungen wurden auf der Basis der Einkommensangaben des Mikrozensus von 1992 vorgenommen.

2 Die Mängel des ersten Förderwegs werden ausführlich dargestellt in Keil, K. (1996), S. 86ff. Vgl. auch Külp, B. u.a. (1984), S. 101ff. und Eekhoff, J. (1993), S. 69ff.

3 Nach einer Schätzung von U. Pfeiffer u.a. sind - ohne die Zugänge nach 1995 - gegenwärtig in Westdeutschland ca. 2,03 Millionen Sozialwohnungen des ersten Förderwegs in der Bindung. Bezieht man die Zugänge mit ein, dürfte die Zahl in der Nähe von 2,1 Millionen liegen. Vgl. Pfeiffer, U. u.a. (1996), S. 138ff. 
behandlungsprinzip“, wonach „Haushalte mit gleichen sozialen Merkmalen gleiche Leistungen erhalten" sollen. ${ }^{1}$

Hinzu kommt, daß sich unter den Haushalten, die um die knappen Sozialwohnungen konkurrieren, vielfach nicht diejenigen durchsetzen können, die der staatlichen Förderung am meisten bedürfen. Die Ursache dafür ist vor allem im Vergabeverfahren zu suchen, das den Eigentümern bei der Auswahl der Mieter unter den förderberechtigten Personen das alleinige Entscheidungsrecht oder bei Anwendung des $\S 5$ a WoBindG - ein Mitspracherecht einräumt. ${ }^{2}$ Der Vermieter wird in der Absicht, das Mietausfallwagnis möglichst gering zu halten, solchen Mietinteressenten den Vorrang einräumen, die über sichere Einkünfte knapp unter der Einkommensgrenze verfügen. Auch wird er eher an solche Personen vermieten, von denen er ein ,reibungsloses“ Mietverhältnis und einen schonenden Umgang mit seiner Wohnung erwartet. Bei der Belegung der Sozialwohnungen wiederholt sich somit teilweise die für den freien Wohnungsmarkt charakteristische Selektion zum Nachteil der sozial Schwächsten. ${ }^{3}$ Erhärtet werden diese Schlußfolgerungen durch statistische Erhebungen für die Jahre 1978 und 1982, bei denen eine Unterrepräsentation von Haushalten mit sehr niedrigen Einkommen (unteres Einkommensquintil) und jungen Familien im Sozialwohnungsbestand festgestellt worden ist. ${ }^{4}$

Auch allokativ wirkt sich das Mißverhältnis zwischen den geförderten Wohnungen und dem Kreis der Förderberechtigten nachteilig aus, denn es verstärkt die räumliche Immobilität der Sozialmieter. Diese werden, wenn sie das Glück hatten, eine Sozialwohnung zu bekommen, zu einem späteren Zeitpunkt nur noch eingeschränkt bereit sein, den Wohnort zu wechseln, weil ihnen eine neue Sozialwohnung dann unter Umständen erst nach langer Wartezeit oder gar nicht zur Verfügung gestellt werden kann. Die aus dem Verlust der Sozialwohnung

1 Eekhoff, J. (1993), S. 70.

2 Üblicherweise wählt der Vermieter selbst aus, wem er aus dem Kreis der Bezugsberechtigten seine Wohnung zur Nutzung überläßt. Nach $\S 5$ a WoBindG kann diese Entscheidungsfreiheit allerdings beschränkt werden. Durch die Gesetzesregelung werden die Landesregierungen ermächtigt, für Gebiete mit erhöhtem Wohnraumbedarf Rechtsverordnungen zu erlassen, die befristet oder unbefristet bestimmen, daß der Verfügungsberechtigte eine frei oder bezugsfertig werdende Wohnung nur einem von der zuständigen Stelle benannten Wohnungssuchenden zum Gebrauch überlassen darf. Die zuständige Stelle hat dem Vermieter mindestens drei wohnberechtigte Mietinteressenten zur Auswahl zu benennen. Darüber hinaus üben die Gemeinden nach Vereinbarung mit dem Fördernehmer Benennungsrechte aus, wenn sie sich an der Förderung finanziell beteiligt haben.

3 Vgl. Oberhauser, A. (1993), S. 5.

4 Vgl. Ulbrich, R. (1992), S. 32ff. 
resultierenden finanziellen Nachteile können die betroffenen Haushalte davon abhalten, einen ansonsten lohnenden Ortswechsel vorzunehmen. Die räumliche Allokation des Produktionsfaktors Arbeit wird verzerrt - mit der Folge gesamtwirtschaftlicher Wohlfahrtseinbußen.

Durch die Objektgebundenheit der Förderung erhöhen sich ferner die finanziellen Einbußen infolge einer Familienvergrößerung, sofern diese einen Wohnungswechsel erforderlich macht. Wegen der allgemeinen Prognoseunsicherheit können die zuständigen Stellen bei der Wohnungsvergabe die Möglichkeit des Hinzukommens weiterer Familienmitglieder nur bis zu einem gewissen Grade berücksichtigen. Im Regelfall wird nur bei jungen Ehepaaren im Sinne des $§ 26$ Abs. 2 Satz 2 II. WoBauG, die zum Bezugszeitpunkt kinderlos sind, ein Zusatzbedarf anerkannt, der zudem auf einen Raum beschränkt bleibt. ${ }^{1}$ Bei Ehepaaren, die bereits Kinder haben, wird meist nur dann eine erhöhte Wohnungsgröße im Wohnberechtigungsschein ausgewiesen, wenn über die anstehende Familienvergrößerung kein Zweifel besteht (etwa bei Nachweis einer Schwangerschaft). ${ }^{2}$ Die unzureichende Berücksichtigung künftiger Familienvergrößerungen hat zur Folge, daß die Entscheidung für ein (weiteres) Kind bei Sozialmietern zu enormen Härten führen kann: Nicht nur, daß das pro Kopf verfügbare Einkommen zurückgeht, es ergibt sich unter Umständen auch die Notwendigkeit eines Wohnungswechsels, verbunden mit dem Verlust einer hochsubventionierten Wohnung. Es ist zu vermuten, daß die Sozialmieter daher vielfach von einer Familienvergrößerung absehen.

$1 \S 5$ Abs. 2 WoBindG nennt als Maßstab für die Abschätzung zukünftigen Raumbedarfs die „statistisch erhärtete Lebenserfahrung“. Nach einer Untersuchung des Landesamtes für Datenverarbeitung und Statistik NW kamen in Nordrhein-Westfalen 1987 rund 85\% der ehelichen erstgeborenen Kinder in den ersten fün Jahren nach der Eheschließung zur Welt, also in einer Phase, in der die Ehepaare nach dem Kriterium des $\S 26$ II. WoBauG noch als ,jungverheiratet“ gelten. Vgl. Bellinger, Kommentar zu § 5 WoBindG, S. 51 (mit Quellenangabe).

2 Diese Praxis läßt sich dagegen nicht mit der statistisch erhärteten Lebenserfahrung begründen. Bei einer Erhebung des statistischen Bundesamtes vom April 1996 wurde die Zahl der Ehepaare mit Kindern unter 18 Jahren auf 7,67 Millionen geschätzt. Von diesen Familien hatten $54 \%$ zwei oder mehr Kinder. 


\section{Ineffizienzen und hoher fiskalischer Aufwand infolge des Kostenmietprinzips}

In Mißkredit geraten ist der soziale Mietwohnungsbau insbesondere wegen der Anwendung des Kostenmietprinzips, das zu kostenaufwendigem Bauen verleitet und Mietpreisverzerrungen im Sozialwohnungsbestand verursacht. Kostentreibend wirkt das Prinzip deshalb, weil bis auf die Eigenkapitalverzinsung sowie die Verwaltungs- und Instandhaltungspauschalen alle Kosten in voller Höhe in die Wirtschaftlichkeitsberechnung eingehen. Der auf den Unternehmen üblicherweise lastende Druck zu vorsichtiger Kalkulation und sparsamem Wirtschaften wird insbesondere durch die Praxis der Nachsubventionierung gemindert. So entscheidet die Bewilligungsstelle über die Genehmigung der Durchschnittsmiete auf der Basis der Verhältnisse, wie sie sich zum Zeitpunkt der Antragstellung darstellen. Die im Laufe der Bauzeit üblicherweise eingetretenen Kostensteigerungen werden entweder vom Staat selbst übernommen, indem er die Förderung anpaßt, oder an den Mieter in Form einer höheren Durchschnittsmiete weitergegeben. Auch verringert das Kostenmietprinzip den Anreiz der Unternehmen zu einer i.d.R. nachfragegerechteren minderen Ausstattung der Wohnungen. Die Ineffizienzen schlagen sich in - relativ zum freifinanzierten Wohnungsbau - erhöhten Baukosten und einem unangemessen hohen Qualitätsstandard nieder. ${ }^{1}$

Wegen des überdurchschnittlichen Anstiegs der Bau- und Grundstückskosten haben auch die Kostenmieten im Zeitablauf ein immer höheres Niveau erreicht. Die Mehraufwendungen sind großenteils vom Staat selbst übernommen und der Rest auf die Sozialmiete aufgeschlagen worden. Die Finanzierbarkeit des sozialen Wohnungsbaues wurde dadurch zunehmend in Frage gestellt. Außerdem ergaben sich die im Sozialwohnungsbestand zu beobachtenden "Jahresringe“ bei den Mietpreisen: Je länger das Baudatum eines Objektes zurückliegt, desto niedriger sind die vom Mieter aufzubringenden Wohnkosten. Objekte mit gleichem Wohnwert weisen daher aufgrund unterschiedlicher Baujahrgänge mitunter starke Abweichungen in der Miethöhe auf. ${ }^{2}$ Die Mietpreisverzerrungen werden auch in starkem Maße von zeitlichen und regionalen Unterschieden in den von den Ländern eingesetzten Fördervolumina bestimmt.

Gerade in Ballungsräumen werden besonders hohe Mietvorteile gewährt: Dort liegt die Sozialmiete ,häufig nur um 0,50 bis $1 \mathrm{DM}$ je qm über der Sozialmiete in strukturschwachen ländlichen Räumen, obwohl die Marktmiete im Ballungs-

1 Vgl. Expertenkommission Wohnungspolitik (1995), S. 202f.; Meyer, D. (1986), S. 208; Eekhoff, J. (1993), S. 73f.; Schröder, Ch. (1990), S. 49f.

2 Vgl. Meyer, D. (1986), S. 208f.; Kornemann, R. (1973), S. 103ff., Leonhardt, K. (1996), S. $122 \mathrm{ff}$. 
kern die doppelte oder dreifache Höhe hat." "' Ein systematischer Zusammenhang zwischen dem Wohnwert und der Miethöhe besteht nicht: Die Sozialmieter müssen daher „bei gleichen Einkommen für Wohnungen vergleichbarer Qualität häufig unterschiedliche Mieten bzw. für Wohnungen unterschiedlicher Qualität gleiche Mieten entrichten““2. Hinzu kommt, daß „der größere Teil der in den begünstigten Personenkreis hineinwachsenden Wohnungsuchenden nur wenn überhaupt - in neuen und damit teureren, mit öffentlichen Mitteln geförderten Wohnungen unterkommen kann“, während „die inzwischen finanziell gut situierten Sozialmieter häufig in den älteren und damit billigeren Wohnungen (leben) ${ }^{، 3}$.

\section{Fehl- und Unterbelegung im Sozialwohnungsbestand}

$\mathrm{Zu}$ Verstößen gegen die Fördergerechtigkeit kommt es auch dadurch, daß bei der Entscheidung über die Zuteilung der Sozialwohnungen allein auf die soziale Situation der Mietinteressenten zum Zeitpunkt der Wohnungsvergabe abgestellt wird. Wie sich das Einkommen und der Familienstand des Mieters verändern, kann - da kaum prognostizierbar - bei der Wohnungszuteilung nicht berücksichtigt werden. Eine Fehlsubventionierung kann im Laufe der Zeit eintreten, wenn sich die Haushaltsgröße durch den Familienzyklus verringert und/oder das Einkommen über die Grenzen des Zweiten Wohnungsbaugesetzes hinaus ansteigt. ${ }^{4}$ Da die Sozialwohnungen nicht geräumt werden müssen, kommen Personengruppen in den Genuß einer aufgrund ihrer Einkommensverhältnisse bzw. ihres Wohnflächenbedarfs unangemessen hohen Förderung.

Von Fehlbelegung wird gesprochen, wenn das Gesamteinkommen des Haushalts oberhalb der Grenze des $\S 25$ II. WoBauG liegt. Eine Sonderauswertung der 1\%-Gebäude- und Wohnungsstichprobe von 1993 hat ergeben, daß im Erhebungszeitraum $42 \%$ aller öffentlich geförderten Sozialwohnungen fehlbelegt waren. ${ }^{5}$ Aus distributiver Sicht ist die hohe Fehlbelegungsquote in hohem Maße unbefriedigend, weil ein Großteil der ohnehin knappen Sozialwohnungen nicht

1 Eekhoff, J. (1993), S. 72.

2 Deutscher Bundestag (1995), S. 23.

3 Kornemann, R. (1973), S. 105.

4 Vgl. Oberhauser, A. (1993), S. 5f.

5 Dabei wird von der seit dem 1. Oktober 1994 gültigen Fassung des § 25 ausgegangen. Gemessen am $\S 25$ a.F. beläuft sich die Fehlbelegungsquote auf $45 \%$; vgl. Pfeiffer, U. u. a. (1996), S. 56. 
für die Belegung durch förderbedürftige Haushalte zur Verfügung steht. Die staatlichen Mittel werden ineffizient eingesetzt und kommen in viel zu großem Umfang solchen Mietern zugute, die ihrer im Grunde nicht bedürfen. Aus allokativer Perspektive ist die Fehlbelegung u.a. deshalb von Nachteil, weil durch sie die räumliche Immobilität der Sozialmieter noch verstärkt wird. Fehlbeleger haben bei einem Umzug grundsätzlich keinen Anspruch mehr auf eine neue öffentlich geförderte Wohnung und müssen deshalb den definitiven Verlust der Fördervorteile einkalkulieren. Die Schwelle zu einem Wohnungswechsel ist bei ihnen noch höher. ${ }^{1}$

Eine Unterbelegung liegt vor, wenn sich die Personenzahl eines Mieterhaushaltes verringert und die Sozialwohnung deshalb die nach der Familiengröße bestimmten landesrechtlichen Wohnflächengrenzen überschreitet. Durch die Objektgebundenheit der Mietsubventionen erweist sich das Instrument des sozialen Mietwohnungsbaues als ungeeignet, die im Familienzyklus eintretenden Veränderungen im Wohnraumbedarf zu berücksichtigen. Die Bemühungen der zuständigen Stelle, bei der Bescheinigung über die angemessene Wohnungsgröße auch die Entwicklung des zukünftigen Raumbedarfs in gewissem Umfang $\mathrm{zu}$ berücksichtigen, dienen zur Vermeidung einer Überbelegung (siehe Kapitel 1.D.I). Insbesondere soll gewährleistet werden, daß für junge Familien ausreichend Wohnraum zur Verfügung steht. Nicht verhindert werden kann die in späteren Lebensphasen häufig auftretende Unterbelegung der Wohnungen, etwa wegen einer Trennung der Eheleute, dem Auszug der erwachsenen Kinder oder durch Tod eines Familienmitgliedes. Kommt es zur Unterbelegung einer Sozialwohnung, wird die Bereitschaft des Haushaltes zu einem Wohnungswechsel aus mehreren Gründen gering sein: Zum einen steigt die Wohnqualität mit der pro Kopf zur Verfügung stehenden Wohnfläche. Wird durch das Ausscheiden eines Haushaltsmitgliedes das verfügbare Familieneinkommen nicht nachhaltig verringert, so besteht für den Haushalt i.d.R. auch kein finanzieller Zwang zu einem Umzug in eine kleinere Wohnung. ${ }^{2}$ Außerdem führt der Wohnungswechsel nicht zwangsläufig zu einer Kostenersparnis, denn es muß damit gerechnet werden, daß für die neue Wohnung eine höhere Quadratmetermiete zu entrichten ist. Dies wird insbesondere dann der Fall sein, wenn es sich bei der neuen um eine freifinanzierte Wohnung handelt oder der Mieter aus einer preisgünstigen älteren in eine teurere Sozialwohnung neueren Baudatums ziehen muß. ${ }^{3}$ Schließlich müssen auch die Umzugskosten und die - bei älteren Menschen er-

1 Vgl. Keil, K. (1996), S. 91 ff.

2 Eine Unterbelegung wird manchmal vom Mieter sogar bewußt angestrebt. So wurde in einer baden-württembergischen Kommune beobachtet, daß ein Ehepaar die erwachsene Tochter kurzfristig wieder in den Haushalt aufnahm, um eine größere Sozialwohnung zu bekommen.

3 Vgl. Keil, K. (1996), S. $125 f$. 
fahrungsgemäß hohen - Nutzeneinbußen durch den Wechsel des Wohnumfeldes berücksichtigt werden.

Im allgemeinen wird man also auch bei Unterbelegung von einer geringen Mobilität der Mieter ausgehen können. Die resultierende Überversorgung besonders der alteingesessenen Mieter ist vor allem aus fiskalischer und distributiver Sicht kaum akzeptabel. Im Extremfall ergibt sich die absurde Situation, daß junge Familien mit dringendem Förderbedarf keine Sozialwohnung erhalten können, weil diese durch Einzelpersonen blockiert werden.

\section{E. Reformmaßnahmen der 80er Jahre}

\section{Erhebung einer Fehlbelegungsabgabe}

Bereits in den 60er Jahren setzten auf politischer Ebene Beratungen ein, wie die aus der Fehlbelegung resultierenden ungerechtfertigten Subventionen abgebaut werden könnten. Unter anderem wollte ein Referentenentwurf aus dem Jahre 1965 die Vermieter dazu verpflichten, Sozialmietern in Fällen einer über 25prozentigen Überschreitung der Einkommensgrenze die Kündigung auszusprechen. Das Vorhaben stieß in der Öffentlichkeit auf Ablehnung („Rausschmeißergesetz") und wurde nicht weiter verfolgt. Ebensowenig konnten sich Vorschläge durchsetzen, die das Fehlbelegungsproblem durch Einführung einer Steuer (1971), eines negativen Wohngeldes (1973) oder eines Tabellenmietsystems im Sozialwohnungsbestand (1980) lösen wollten. Der Gesetzgeber entschied sich schließlich für die Einführung einer Fehlbelegungsabgabe, deren rechtliche Grundlage er im Dezember 1981 durch das Gesetz über den Abbau der Fehlsubventionierung im Wohnungswesen (AFWoG) ${ }^{1}$ schuf.

Die - bisher zweimal novellierte - Gesetzesregelung sieht vor, daß die Mieter öffentlich geförderter Wohnungen eine Ausgleichszahlung zu leisten haben, sofern ihr Einkommen die Einkommensgrenze um mehr als 20\% überschreitet ( 1 Abs. 1). Die Abgabe ist so gestaffelt, daß bei einer Überschreitung von nicht mehr als $35 \%$ ein Betrag von 0,50 DM pro Monat und qm zu zahlen ist, im Falle einer Überschreitung von über $35 \%$ bis einschließlich $50 \%$ ein Betrag von 1,25 DM und bei noch höheren Einkommen ein Betrag von 2 DM ( $\$ 2$ Abs. 3). Die Ausgleichszahlung kann auf Antrag des Mieters beschränkt werden, wenn die Wohnkosten infolge der Zahlungen bestimmte, an den ortsübli-

1 Vom 22. Dezember 1981 (BGBl. I S. 1523, 1542), i.d.F. der Bekanntmachung vom 19. August 1994 (BGBl. I S. 2180), zuletzt geändert durch Gesetz vom 24. März 1997 (BGBl. I, S. 594); vgl. Dyong, H., Einführung zum Gesetz über den Abbau der Fehlsubventionierung im Wohnungswesen, S. $11 \mathrm{ff}$. 
chen Vergleichsmieten orientierte Höchstbeträge überschreiten würden ( $\S 6$ Abs. 1 bis 4). Der Mieter wird verpflichtet, der vom Land zu bestimmenden zuständigen Stelle ( $\$ 11$ Satz 1$)$ das Gesamteinkommen seines Haushaltes im Rahmen einer Einkommensprüfung nachzuweisen. Die monatlichen Zahlungen sollen jeweils für die Dauer von drei Jahren festgesetzt und danach unter Berücksichtigung der Einkommensentwicklung des Mieters neu ermittelt werden. Nach $\S 9$ AFWoG ist die Fehlbelegungsabgabe auch von Inhabern steuerbegünstigter Wohnungen zu erheben sowie von Inhabern freifinanzierter Wohnungen, die mit Wohnungsfürsorgemitteln im Sinne der $\S \S 87$ a und 111 II. WoBauG gefördert worden sind.

Das Aufkommen aus der Abgabe steht den Ländern zu und ist für Maßnahmen des sozialen Wohnungsbaues zweckgebunden ( $\$ 10$ Abs. 1). Räumlich ist das Gesetz auf die von den Ländern ausgewählten Gemeinden begrenzt. Nach § 1 Abs. 4 können nur solche Gemeinden bestimmt werden, in denen die Kostenmieten öffentlich geförderter Mietwohnungen die ortsüblichen Mieten nicht preisgebundener vergleichbarer Mietwohnungen erheblich unterschreiten. Liegt bei einer Gemeinde diese Voraussetzung vor, können die Länder dennoch von einer Bestimmung absehen, wenn der Verwaltungsaufwand für die Erhebung der Ausgleichszahlung in einem unangemessenen Verhältnis zu den erwarteten Einnahmen stehen würde ( $\$ 1$ Abs. 4 AFWoG).

Die bundesgesetzlichen Regelungen zur Fehlbelegungsabgabe müssen von den Ländern jedoch nicht angewendet werden, sofern sie eigene Bestimmungen an deren Stelle erlassen. Ausgenommen hiervon sind die Regelung zur Auswahl der von der Abgabe betroffenen Gemeinden ( $\$ 4$ Abs. 1) und einige Vorschriften zur Zweckbestimmung des Aufkommens bei den mit Treuhand- oder Wohnungsfürsorgemitteln geförderten Wohnungen ( $\S 10$ Abs. 2 bis 4). Von der Möglichkeit, eigene landesrechtliche Bestimmungen $\mathrm{zu}$ erlassen, haben mit Ausnahme des Saarlandes alle Länder des alten Bundesgebietes - nur dort wird die Abgabe erhoben - Gebrauch gemacht. Übereinstimmend mit dem AFWoG ist die Höhe der Ausgleichszahlung auch in den Landesbestimmungen nach der Prozentüberschreitung der Einkommensgrenze des § 25 II. WoBauG zu ermitteln. Vom AFWoG abweichende Regelungen wurden zur Höhe der Ausgleichszahlungen und ihrer Staffelung nach dem Einkommen getroffen. 
Übersicht 2: Staffelung der Fehlbelegungsabgabe in den Ländern

\begin{tabular}{|c|c|c|c|}
\hline Bundesland - Gesetzesgrundlage & \multicolumn{2}{|c|}{$\begin{array}{l}\text { Abgabe pro qm bei } \\
\text { Einkommen bis zur } \\
\text { Grenze des } \S 25 \ldots\end{array}$} & Höchstbeträge \\
\hline $\begin{array}{l}\text { Baden-Württemberg } \\
\text { Gesetz über den Abbau der Fehlsubventionierung } \\
\text { im Wohnungswesen für Baden-Württemberg } \\
\text { (LAFWoG) i. d. F. der Bekanntmachung vom } \\
\text { 23. März 1993, GBl. S. 229, zuletzt geändert durch } \\
\text { Gesetz vom 16. Dezember 1996, GBl. S. } 781 \text {. }\end{array}$ & $\begin{array}{r}+30 \% \\
+50 \% \\
+70 \% \\
+90 \% \\
+110 \% \\
\text { mehr }\end{array}$ & $\begin{array}{l}0,50 \mathrm{DM} \\
1,50 \mathrm{DM} \\
3,00 \mathrm{DM} \\
4,50 \mathrm{DM} \\
6,00 \mathrm{DM}\end{array}$ & $\begin{array}{l}\text { Obergrenze der } \\
\text { im Mietspiegel } \\
\text { enthaltenen } \\
\text { Mietzinsspanne } \\
\text { für vergleichbaren } \\
\text { Wohnraum }\end{array}$ \\
\hline $\begin{array}{l}\text { Bayern } \\
\text { Gesetz über den Abbau der Fehlsubventionierung } \\
\text { im Wohnungswesen in Bayern (BayAFWoG) } \\
\text { i.d.F. der Bekanntmachung vom 31. Oktober 1995, } \\
\text { GVB1. S. 806, zuletzt geändert durch Gesetz vom } \\
\text { 26. Juli 1997, GVB1. S. } 355 \text {. }\end{array}$ & $\begin{array}{r}+55 \% \\
+65 \% \\
+80 \% \\
+95 \% \\
+110 \% \\
+125 \% \\
+140 \% \\
\text { mehr }\end{array}$ & $\begin{array}{c}- \\
1,00 \mathrm{DM} \\
2,00 \mathrm{DM} \\
3,00 \mathrm{DM} \\
4,00 \mathrm{DM} \\
5,00 \mathrm{DM} \\
6,00 \mathrm{DM} \\
7,00 \mathrm{DM}\end{array}$ & $\begin{array}{l}\text { Zugrundelegung } \\
\text { der bei Neuver- } \\
\text { mietung erzielbaren } \\
\text { Entgelte für nicht } \\
\text { preisgebundenen } \\
\text { vergleichbaren } \\
\text { Wohnraum }\end{array}$ \\
\hline $\begin{array}{l}\text { Berlin } \\
\text { Gesetz über den Abbau der Fehlsubventionierung } \\
\text { im Berliner Wohnungswesen (AFWoG Bln) vom } \\
\text { 26. März 1992, GVBl. S. 82, zuletzt geändert durch } \\
\text { Gesetz vom 22. November 1996, GVBI. S. } 505 \text {. }\end{array}$ & $\begin{array}{l}+25 \% \\
+35 \% \\
+50 \% \\
+65 \% \\
+80 \% \\
+95 \% \\
\text { mehr }\end{array}$ & $\begin{array}{l}- \\
0,50 \mathrm{DM} \\
1,00 \mathrm{DM} \\
1,75 \mathrm{DM} \\
2,75 \mathrm{DM} \\
4,00 \mathrm{DM} \\
5,00 \mathrm{DM}\end{array}$ & $\begin{array}{l}\text { Mittelwert des } \\
\text { Mietspiegels für } \\
\text { vergleichbare } \\
\text { Wohnungen }\end{array}$ \\
\hline $\begin{array}{l}\text { Bremen (§ } 25 \text { i.V.m. § } 3 \text { BremAFWoG) } \\
\text { Bremisches Gesetz über den Abbau der } \\
\text { Fehlsubventionierung im Wohnungswesen } \\
\text { (BremAFWoG) i.d.F. der Bekanntmachung vom } \\
\text { 16. Mai. 1995, Brem.GBI. S. } 299 \text { (berichtigt } \\
\text { auf S. 340). }\end{array}$ & $\begin{array}{r}\text { Bewillig } \\
-10 \% \\
+0 \% \\
+10 \% \\
+25 \% \\
+40 \% \\
\text { mehr } \\
\text { Bewillig } \\
+25 \% \\
+40 \% \\
\text { mehr }\end{array}$ & $\begin{array}{c}\text { vor } 1966: \\
- \\
1,80 \mathrm{DM} \\
2,60 \mathrm{DM} \\
3,40 \mathrm{DM} \\
4,20 \mathrm{DM} \\
5,00 \mathrm{DM} \\
\text { ab } 1966: \\
3,40 \mathrm{DM} \\
4,20 \mathrm{DM} \\
5,00 \mathrm{DM}\end{array}$ & $\begin{array}{l}\text { Staffelung der } \\
\text { Höchstbeträge } \\
\text { nach dem Grad der } \\
\text { Überschreitung } \\
\text { der Einkommens- } \\
\text { grenze }\end{array}$ \\
\hline $\begin{array}{l}\text { Hamburg } \\
\text { Gesetz über den Abbau der Fehlsubventionierung } \\
\text { im Wohnungswesen in Hamburg (HmbAFWoG) } \\
\text { i.d.F. der Bekanntmachung vom 15. Januar 1993, } \\
\text { Hamburgisches Gesetz- u. Verordnungsbl. S. 1, } \\
\text { zuletzt geändert durch Gesetz vom 17. März 1997, } \\
\text { Hamburgisches Gesetz- u. Verordnungsblatt S. 75. }\end{array}$ & $\begin{array}{r}+25 \% \\
+40 \% \\
+55 \% \\
+70 \% \\
+85 \% \\
+100 \% \\
\text { mehr }\end{array}$ & $\begin{array}{l}1,00 \mathrm{DM} \\
2,00 \mathrm{DM} \\
3,00 \mathrm{DM} \\
4,00 \mathrm{DM} \\
5,00 \mathrm{DM} \\
6,00 \mathrm{DM}\end{array}$ & $\begin{array}{l}\text { Zugrundelegung } \\
\text { der im Mietspiegel } \\
\text { enthaltenen } \\
\text { Mietzinsspannen }\end{array}$ \\
\hline
\end{tabular}




\section{Übersicht 2 (Fortsetzung)}

\begin{tabular}{|c|c|c|c|}
\hline Bundesland - Gesetzesgrundlage & \multicolumn{2}{|c|}{$\begin{array}{l}\text { Abgabe pro qm bei } \\
\text { Einkommen bis zur } \\
\text { Grenze des } \S 25 \ldots\end{array}$} & Höchstbeträge \\
\hline $\begin{array}{l}\text { Hessen } \\
\text { Hessisches Gesetz zum Abbau der Fehlsub- } \\
\text { ventionierung im Wohnungswesen (HessAFWoG) } \\
\text { i.d.F. der Bekanntmachung vom 5. Juni 1996, } \\
\text { GVB1. S. } 262 .\end{array}$ & $\begin{array}{r}+20 \% \\
+40 \% \\
+60 \% \\
+80 \% \\
+100 \% \\
+120 \% \\
+150 \% \\
\text { mehr }\end{array}$ & $\begin{array}{c}- \\
1,00 \mathrm{DM} \\
2,00 \mathrm{DM} \\
3,00 \mathrm{DM} \\
4,50 \mathrm{DM} \\
6,00 \mathrm{DM} \\
7,50 \mathrm{DM} \\
9,00 \mathrm{DM}\end{array}$ & $\begin{array}{l}\text { nach Maßgabe } \\
\text { des üblichen } \\
\text { Entgelts für nicht } \\
\text { preisgebundenen } \\
\text { Wohnraum } \\
\text { vergleichbarer Art, } \\
\text { Ausgestaltung } \\
\text { und Größe }\end{array}$ \\
\hline $\begin{array}{l}\text { Niedersachsen } \\
\text { Niedersächsisches Gesetz über den Abbau der } \\
\text { Fehlsubventionierung im Wohnungswesen } \\
\text { (Nds. AFWoG) i.d.F. der Bekanntmachung } \\
\text { vom 30. Januar 1997, Nds.GVBl. S. } 43 .\end{array}$ & $\begin{array}{r}+10 \% \\
+20 \% \\
+30 \% \\
+40 \% \\
+50 \% \\
+55 \% \\
+60 \% \\
+65 \% \\
+70 \% \\
+75 \% \\
\text { mehr }\end{array}$ & $\begin{array}{c}- \\
1,00 \mathrm{DM} \\
1,50 \mathrm{DM} \\
2,00 \mathrm{DM} \\
2,50 \mathrm{DM} \\
3,50 \mathrm{DM} \\
4,50 \mathrm{DM} \\
5,50 \mathrm{DM} \\
6,50 \mathrm{DM} \\
7,50 \mathrm{DM} \\
8,50 \mathrm{DM}\end{array}$ & $\begin{array}{l}\text { nach Maßgabe der } \\
\text { bei Neuvermietung } \\
\text { erzielbaren Entgelte } \\
\text { für nicht preis- } \\
\text { gebundenen } \\
\text { vergleichbaren } \\
\text { Wohnraum }\end{array}$ \\
\hline $\begin{array}{l}\text { Nordrhein-Westfalen } \\
\text { Gesetz über den Abbau der Fehlsubventionierung } \\
\text { im Wohnungswesen für das Land Nordrhein- } \\
\text { Westfalen (AFWoG NW) vom 31. Oktober 1989, } \\
\text { GV. NW. S. 530, zuletzt geändert durch Gesetz vom } \\
\text { 17. Dezember 1996, GV. NW. S. } 568 \text {. }\end{array}$ & $\begin{array}{l}+10 \% \\
+20 \% \\
+35 \% \\
+50 \% \\
+65 \% \\
\text { mehr }\end{array}$ & $\begin{array}{l}1,00 \mathrm{DM} \\
2,00 \mathrm{DM} \\
4,00 \mathrm{DM} \\
5,50 \mathrm{DM} \\
7,00 \mathrm{DM}\end{array}$ & $\begin{array}{l}\text { Obergrenze der } \\
\text { im Mietspiegel } \\
\text { enthaltenen } \\
\text { Mietzinsspanne } \\
\text { für vergleichbaren } \\
\text { Wohnraum }\end{array}$ \\
\hline $\begin{array}{l}\text { Rheinland-Pfalz } \\
\text { Landesgesetz zur Ausführung des Gesetzes über } \\
\text { den Abbau der Fehlsubventionierung im } \\
\text { Wohnungswesen (AGAFWoG) vom 7. Dezember } \\
\text { 1990, GVBI. S. 325; zuletzt geändert durch Gesetz } \\
\text { vom 19. März 1997, GVBI. S. } 99 \text {. }\end{array}$ & $\begin{array}{r}+20 \% \\
+35 \% \\
+50 \% \\
+80 \% \\
+110 \% \\
+140 \% \\
+170 \% \\
+200 \% \\
+230 \% \\
\text { mehr }\end{array}$ & $\begin{array}{c}- \\
0,50 \mathrm{DM} \\
1,25 \mathrm{DM} \\
2,00 \mathrm{DM} \\
3,00 \mathrm{DM} \\
4,00 \mathrm{DM} \\
5,00 \mathrm{DM} \\
6,00 \mathrm{DM} \\
7,00 \mathrm{DM} \\
8,00 \mathrm{DM}\end{array}$ & je nach Gemeinde \\
\hline $\begin{array}{l}\text { Schleswig-Holstein } \\
\text { Schleswig-Holsteinisches Gesetz über den Abbau } \\
\text { der Fehlsubventionierung im Wohnungswesen } \\
\text { (AFWoG SH) i.d.F. der Bekanntmachung vom } \\
\text { 10. November 1995, GVOBl. Schl.-H. S. } 385 \text {. }\end{array}$ & $\begin{aligned} & D \\
+ & 20 \% \\
+ & 40 \% \\
+ & 60 \% \\
+ & 80 \% \\
& \text { mehr }\end{aligned}$ & $\begin{array}{c}\text { zur o.ü.V. } \\
- \\
30 \% \\
50 \% \\
70 \% \\
90 \%\end{array}$ & - \\
\hline
\end{tabular}


Übersicht 2 verdeutlicht, in welch unterschiedlichem Maße die einzelnen Bundesländer die Mietvorteile der fehlbelegten Wohnungen abschöpfen. Ländereigene Regelungen betreffen ferner die Dauer der Leistungszeiträume, die sich auch in Abhängigkeit vom Förderjahrgang der Wohnungen - zwischen einem und vier Jahren bewegen, die Zweckbestimmung des Aufkommens ${ }^{1}$, die Höhe der Einkommensgrenze ${ }^{2}$ etc.

Mit einem geschätzten Gesamtaufkommen von ca. 725 Millionen Mark im Jahre $1994^{3}$ hat die Fehlbelegungsabgabe inzwischen eine hohe quantitative Bedeutung erlangt. Die Mehrzahl der Wissenschaftler und Politiker sieht in ihr ein notwendiges Korrekturinstrument für die verteilungspolitischen Unzulänglichkeiten der klassischen Objektförderung. Gleichwohl ist sie in ihrer gegenwärtigen Ausgestaltung nur bedingt zum Abbau der Mietenverzerrung und Fehlsubventionierung geeignet, da sie insbesondere die folgenden Mängel aufweist:

- Unzureichende Abschöpfung der Mietvorteile. Wegen § 4 AFWoG und entsprechender Bestimmungen der Länder wird die Fehlbelegungsabgabe in vielen Gemeinden gar nicht erhoben. Weil die Ausgleichszahlungen außerdem vielfach erst bei einer deutlichen Überschreitung der Einkommensgrenze - in Bayern um mehr als 55\% - zu leisten sind, werden vermutlich nicht einmal zwei Drittel der Fehlbeleger überhaupt zur Abgabe herangezogen. ${ }^{4}$ Hinzu kommt, daß die leistungspflichtigen Fehlbeleger in einigen Ländern trotz deutlicher Überschreitung der Einkommensgrenze oft nur sehr geringe Leistungen zu entrichten haben. Die Ausgleichszahlungen betragen z.B. für Haushalte, die bereits um $80 \%$ über der Grenze des $§ 25$ liegen, nach der Bundesregelung (Saarland) sowie den Bestimmungen für Bayern und Rheinland-Pfalz gerade einmal 2 DM.

1 In Baden-Württemberg, Hessen, Niedersachsen, Rheinland-Pfalz und dem Saarland steht das Aufkommen aus der Abgabe den sie erhebenden Gemeinden zu. Für SchleswigHolstein gilt, daß Städte, Gemeinden, Kreise und Ämter bei einer Beteiligung an der Förderung ab dem Bewilligungsjahr 1989 einen ihren Darlehen entsprechenden Anteil der Ausgleichszahlungen erhalten ( $\$ 12$ Abs. 2 AFWoG SH).

2 Die für die Fehlbelegungsabgabe maßgebliche Einkommensgrenze beträgt in Bremen bei einer Person 24.000 Mark und bei zwei Personen 34.000 Mark ( 3 Abs. 1 BremAFWoG). Daneben haben einige Länder (z.B. Hamburg) Sonderregelungen bei den Freibeträgen nach $\S 25 \mathrm{~d}$ II. WoBauG getroffen.

3 Pfeiffer, U. u.a. (1996), S. 10 der Kurzfassung.

4 Nach Schätzungen wurden im Jahr 1993 nur 20 bis 35\% aller Haushalte in Sozialwohnungen zur Zahlung einer Fehlbelegungsabgabe veranlagt (Fehlbelegungsquote: 45\%). Unter Berücksichtigung der seit 1994 geltenden Einkommensgrenzen und der veränderten Tarife einzelner Länder kommen Pfeiffer u.a. auf einen Anteil von 20 bis 30\% (Fehlbelegungsquote: 42\%); Pfeiffer U. u.a. (1996), S. 56 und 103. 
Da einige Landesregierungen die Mietvorteile der Fehlbeleger konsequenter abschöpfen, kommt es bei der Höhe der Zahlungen auch zu deutlichen Diskrepanzen unter den Ländern. So haben Haushalte in Niedersachsen bei gleicher Einkommenssituation wie im vorangegangenen Beispiel bis zu 8,50 DM pro qm zu entrichten - ein um 6,50 höherer Betrag. Aus dem Blickwinkel des Föderalismus mag die Gestaltungsfreiheit der Länder positiv erscheinen, doch steht die ungleiche Abschöpfung der Fehlsubventionierungen im Widerspruch zur verfassungsrechtlich angestrebten Einheitlichkeit der Lebensverhältnisse in der Bundesrepublik (Art. 104 a GG).

- Unzulängliche Korrektur der Mietverzerrungen: Die Fehlbelegungsabgabe in ihrer jetzigen Ausgestaltung trägt nur in geringem Maße zum Abbau der wohnwertunabhängigen Mietunterschiede im Sozialwohnungsbestand bei, da sie ,i.d.R. nicht marktorientiert, sondern als Zuschlag zur historischen Sozialmiete

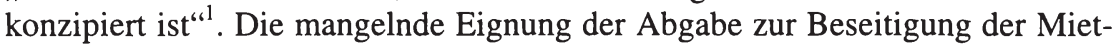
preisverzerrungen sei am Beispiel zweier Haushalte, A und B, verdeutlicht, wobei A eine Kostenmiete von 6,50 DM pro qm und B eine Kostenmiete von 9,50 DM pro qm zu zahlen hat. Die ortsübliche Vergleichsmiete, die den Wohnwert widerspiegelt, betrage in beiden Fällen 13 DM, so daß Haushalt A eine Vergünstigung von 6,50 DM und Haushalt $\mathrm{B}$ von 3,50 DM erhält. Bei identischer Einkommenssituation beider Haushalte führt die Fehlbelegungsabgabe zunächst nur zu einer Absenkung der Mietvorteile um gleiche Beträge. Beträgt die Ausgleichszahlung beispielsweise $2 \mathrm{DM}$, so werden die Quadratmetersubventionen lediglich auf nunmehr 4,50 DM (A) und 1,50 DM (B) gekürzt, ihr Abstand aber nicht verringert. Die Mietverzerrung zwischen A und B bleibt - absolut gesehen - unverändert. Erst wenn Haushalt B die Vergleichsmiete erreicht hat, setzt der Abbau der Mietunterschiede ein. Bei weiteren Einkommenssteigerungen wird die von $\mathrm{B}$ zu leistende Abgabe dann nämlich nicht mehr erhöht, während sie für A, der die Vergleichsmiete noch nicht erreicht hat, weiter angehoben werden kann. Lediglich in Schleswig-Holstein werden die Mietverzerrungen bereits von Anfang an abgebaut, weil die Ausgleichszahlungen dort als Prozentsätze der Mietvorteile bestimmt sind.

- Geringe Anreize zu einem Wohnungswechsel: Trotz der Fehlbelegungsabgabe werden sich die Mieter meist nicht zu einem Wohnungswechsel entschließen, da die Mietvorteile durch die Abgabe i.d.R. nur unvollständig abgebaut werden. Dies gilt insbesondere für die Bundesländer, in denen die Fehlbelegungsabgabe erst bei hohen Einkommen einsetzt und in denen nur geringe Beträge zu entrichten sind. Auch bei einer vollständigen Abschöpfung der Mietvorteile würden viele Fehlbeleger wegen der mit dem Wechsel des Wohnumfeldes verbundenen Wohlfahrtsverluste von einem Umzug absehen. Um die Fehlbeleger dennoch zum Verlassen der geförderten Wohnungen zu bewegen, wäre daher die Fest-

1 Deutscher Bundestag (1996), S. 23f. 
setzung von Höchstbeträgen oberhalb der ortsüblichen Vergleichsmieten geboten, was politisch jedoch kaum durchsetzbar erscheint. Das eigentliche Problem, die Fehlbelegung, bleibt trotz Erhebung der Abgabe daher ungelöst, und es ist damit zu rechnen, daß auch künftig über $40 \%$ des Sozialwohnungsbestandes für eine Nutzung durch die förderberechtigten Haushalte, für die sie gebaut worden sind, nicht zur Verfügung stehen werden.

\section{Einführung der, ,vereinbarten Förderung“ nach § 88 d}

In der Absicht, einen effizienteren Einsatz der Fördermittel zu gewährleisten, hat der Gesetzgeber Anfang 1989 sein Förderinstrumentarium durch die „vereinbarte Förderung" ergänzt. Ihre rechtliche Grundlage ist der ins Zweite Wohnungsbaugesetz aufgenommene $\S 88 \mathrm{~d}$, der den Ländern eine von den Bestimmungen zum ersten und zweiten Förderweg weitgehend unabhängige Förderung ermöglicht. Wie der Name aussagt, sollen die Einzelheiten der Förderung (z.B. Höhe und Einsatzart der Mittel, Zweckbestimmung der Wohnungen, Art der Belegungsrechte, Einkommensgrenzen etc.) mit dem Investor vereinbart werden. ${ }^{1}$

Um den Ländern größtmögliche Flexibilität zu erhalten, hat der Gesetzgeber die zulässigen Vereinbarungen nur durch wenige, von ihm für nötig erachtete Bestimmungen eingeengt. So sieht $\S 88$ d Abs. 2 Nr. 1 vor, daß die ,örtlichen und regionalen wohnungswirtschaftlichen Gegebenheiten und Zielsetzungen“, also insbesondere die unterschiedlichen Bau- und Grundstïckspreise, die regionale Wohnungsmarktlage etc., sowie die ,erkennbaren und unterschiedlichen Investitionsbedingungen des Bauherrn", also beispielsweise steuerliche Aspekte ${ }^{2}$, bei der Förderung zu berücksichtigen sind. Seit Inkrafttreten des Wohnungsbauförderungsgesetzes 1994 ist in $\S 88 \mathrm{~d}$ Abs. 2 Nr. 2 festgelegt, daß die Dauer der Zweckbestimmung der Belegungsrechte und der vereinbarten Mietzinsregelung 15 Jahre nicht überschreiten soll, wenn nicht auf Grund der Zielsetzung und der Art der Förderung, insbesondere der Bereitstellung von Bauland oder wegen der Förderung zugunsten bestimmter Personengruppen, ein längerer

1 Die häufig verwendete Bezeichnung ,dritter Förderweg“ ist deshalb im Grunde nicht treffend, denn durch $\S 88 \mathrm{~d}$ werden für die Länder sehr viele unterschiedliche Wege einer Förderung eröffnet.

2 Beispielsweise hat ein privates Versicherungsunternehmen andere Investitionsbedingungen als eine gemeinnützige Vereinigung. Nicht zu berücksichtigen sind dagegen die subjektiven Investitionsbedingungen, z.B. die Gewinnsituation; vgl. Dyong, H., Kommentar zur $\S$ 88 d II. WoBauG, S. 10. 
Zeitraum geboten ist. ${ }^{1}$ Des weiteren sollen nach $\S 88$ Abs. 2 Nr. 3 die auch für den ersten Förderweg geltenden $\S \S 38$ und 39 über kosten- und flächensparendes Bauen und die einzuhaltenden Wohnungsgrößen Anwendung finden. Kosten- und flächensparender Wohnungsbau soll außerdem dadurch gefördert werden, daß die Förderung auf einen bestimmten Betrag begrenzt wird (Förderpauschale).

Die Anwendung von Förderpauschalen zeichnet sich dadurch aus, daß die vergebenen Mittel unabhängig von den tatsächlich eingetretenen Baukosten festgesetzt (Ausschluß von Nachsubventionierungen) und die Bauherren so zu kostenbewußterem Bauen animiert werden. Der Adressatenkreis der Förderung wird durch keine bundesgesetzliche Vorschrift eingeschränkt, d.h. es steht im Ermessen der Länder, ob und in welcher Höhe sie Einkommensgrenzen für Maßnahmen des dritten Förderwegs ansetzen. Wird eine Einkommensermittlung vorgenommen, so hat sie aus Gründen der Verwaltungsvereinfachung nach den Bestimmungen des $\S 25 \mathrm{zu}$ erfolgen ( $\S 88 \mathrm{~d}$ Abs. 2 Nr. 4). Ein besonderes Merkmal der vereinbarten Förderung liegt darin, daß die Bestimmungen über die Anwendung des Kostenmietprinzips nicht zulässig sind ( $\$ 88 \mathrm{~d}$ Abs. 3 Satz 2). Für die Mietpreisbildung bei den geförderten Wohnungen gilt daher grundsätzlich das $\mathrm{MHG}^{2}$ Zusätzlich zu diesen bundesgesetzlichen Regelungen können die Länder die Konditionen der vereinbarten Förderung durch Erlaß entsprechender Richtlinien weiter einengen bzw. konkretisieren.

Die vereinbarte Förderung ist bei der Mehrzahl der Länder auf großes Interesse gestoßen. Wie aus Übersicht 3 hervorgeht, sind bereits 1990 auf der Grundlage des $\S 88 \mathrm{~d}$ bundesweit mehr Mietwohnungen bewilligt worden als im traditionellen ersten Förderweg. Auch in den Folgejahren - mit Ausnahme von 1992 ist die vereinbarte Förderung die zahlenmäßig bedeutendste Förderform geblieben. Sie ist heute in allen Ländern außer Brandenburg, Hamburg, NordrheinWestfalen und Schleswig-Holstein die dominierende Methode der Mietwohnungsbauförderung. Ein besonders großes Gewicht nimmt sie in Baden-

1 Hat beispielsweise eine Kommune kostengünstiges Bauland bereitgestellt, wird sie zumeist daran interessiert sein, daß ihr die geförderten Objekte längerfristig zur Erfüllung ihrer wohnungspolitischen Aufgaben zur Verfügung stehen. Eine Vereinbarung von langen Förder- bzw. Bindungszeiträumen ist insbesondere auch dann angezeigt, wenn die Wohnungen aufgrund spezieller Ausstattungsmerkmale auf bestimmte Personengruppen, z.B. alte oder behinderte Menschen, zugeschnitten sind.

2 Vereinbarungen, die zum Nachteil des Mieters von den Vorschriften des MHG abweichen, sind gemäß § 10 MHG (außer im Falle der Zustimmung durch den Mieter) unwirksam. Dagegen steht es der öffentlichen Hand und dem Investor frei, Mietvereinbarungen zugunsten des Mieters zu treffen. 
Württemberg (13.844 Bewilligungen im Jahr 1995) und Sachsen (20.167) ein, das ausschließlich nach der neuen Konzeption fördert. ${ }^{1}$

Übersicht 3: Quantitative Bedeutung der Förderwege in der Bundesrepublik ${ }^{2}$

\begin{tabular}{|c|c|c|c|c|}
\hline \multirow[t]{2}{*}{ Jahr } & \multicolumn{4}{|c|}{ Anzahl der im sozialen Wohnungsbau bewilligten Mietwohnungen } \\
\hline & Gesamt & 1. Förderweg & 2. Förderweg & Vereinbarte Förderung \\
\hline \multicolumn{5}{|c|}{ ehemaliges Bundesgebiet } \\
\hline 1980 & 40.257 & 33.180 & 7.077 & \\
\hline 1981 & 46.237 & 37.722 & 8.515 & \\
\hline 1982 & 59.469 & 45.679 & 13.790 & \\
\hline 1983 & 59.130 & 38.909 & 20.221 & \\
\hline 1984 & 40.056 & 27.355 & 12.701 & \\
\hline 1985 & 30.340 & 25.438 & 4.902 & \\
\hline 1986 & 16.645 & 15.767 & 878 & \\
\hline 1987 & 12.699 & 12.212 & 487 & \\
\hline 1988 & 12.685 & 12.417 & 268 & \\
\hline 1989 & 39.154 & 23.135 & 156 & 15.863 \\
\hline 1990 & 61.545 & 28.818 & 614 & 32.113 \\
\hline 1991 & 62.106 & 28.605 & 1.758 & 31.743 \\
\hline 1992 & 57.016 & 27.641 & 5.959 & 23.416 \\
\hline 1993 & 76.321 & 26.987 & 12.196 & 37.138 \\
\hline 1994 & 69.696 & 23.224 & 11.727 & 34.745 \\
\hline 1995 & 59.823 & 24.425 & 6.885 & 28.513 \\
\hline 1996 & 54.014 & 23.511 & 4.467 & 26.036 \\
\hline \multicolumn{5}{|c|}{ neue Bundesländer und Berlin-Ost } \\
\hline 1991 & 2.291 & 393 & 7 & 1.891 \\
\hline 1992 & 10.178 & 3.382 & 609 & 6.187 \\
\hline 1993 & 19.896 & 4.694 & 1.500 & 13.702 \\
\hline 1994 & 35.059 & 7.635 & 9.313 & 18.111 \\
\hline 1995 & 30.555 & 7.718 & 6.010 & 16.827 \\
\hline 1996 & 19.180 & 4.624 & - & 14.556 \\
\hline
\end{tabular}

1 Völker, A. (1996), S. 743ff.

2 Zahlen entnommen bei Völker, A. (1996, 1997). 
Durch die Flexibilisierung der Förderung hat der Gesetzgeber den Ländern die Chance einer effizienteren Ausgestaltung ihrer Förderangebote eingeräumt. Kosteneinsparungen sind dadurch möglich, daß die Bewilligungsstellen die speziellen Gegebenheiten der einzelnen Projekte, z.B. die steuerliche Belastung des Investors, besser berücksichtigen können. Von besonderer Bedeutung ist das Verbot des Kostenmietprinzips, denn der Wohnungsanbieter erhält nun nicht mehr die volle Differenz zwischen der Bewilligungs- und der Kostenmiete, sondern einen mitunter deutlich niedrigeren Betrag als Förderung. Indem die Mittel unabhängig von den tatsächlichen Baukosten in Form von Pauschalbeträgen vergeben werden, haben die Investoren außerdem Anreize zu kostensparendem Bauen. Ein weiterer, zumindest kurzfristiger Einsparungseffekt wird in der Festlegung kürzerer Belegungsbindungen gesehen, da die Förderung um so niedriger ausfallen kann, je früher der Vermieter nach Auslaufen der Bindung die Marktmiete erheben kann. Dadurch, daß die Wohnungen wegen der kurzen Bindungsfristen schon frühzeitig zur freien Vermietung zur Verfügung stehen, ist außerdem davon auszugehen, daß sich die Investoren im Hinblick auf den Mittelaufwand und die Ausgestaltung der Wohnungen verstärkt an den Erfordernissen des Marktes orientieren. Des weiteren verringert sich mit abnehmender Förder- und Bindungsdauer die Gefahr einer Fehlbelegung des geförderten Wohnraums.

Bei der Beurteilung der vereinbarten Förderung muß allerdings berücksichtigt werden, daß $\S 88 \mathrm{~d}$ zunächst nur die Möglichkeit einer Effizienzverbesserung bietet und es von den einzelnen Bundesländern abhängt, ob und in welchem Maße die Gestaltungsspielräume genutzt werden. Die bisherige Praxis der Umsetzung in den Ländern hat noch nicht im erhofften Maße zu einer flexiblen Förderung geführt. Wie bei den herkömmlichen Verfahren sind die Bedingungen meist sehr detailliert in den Förderrichtlinien geregelt, so daß für ein „Aushandeln“ der Konditionen zwischen der Bewilligungsstelle und dem Investor kaum noch Spielraum besteht. Viele Länder sahen die Festlegung landeseinheitlicher Bestimmungen in Anbetracht der hohen Förderzahlen oder aus Furcht vor Rechtsstreitigkeiten bei unterschiedlicher Behandlung von Investoren als notwendig an. Zudem konnte beobachtet werden, daß die Mitarbeiter in den Bewilligungsstellen z.T. Schwierigkeiten hatten, den gestiegenen Anforderungen an ihre Qualifikation und Verhandlungsbereitschaft beim neuen Fördermodell gerecht zu werden. ${ }^{1}$ Auch ist durch die Abkehr vom Kostenmietprinzip nicht sichergestellt, daß die Förderung wirklich effizienter erfolgt. Die bisherigen Erfahrungen zeigen, daß die Mittel mitunter immer noch sehr großzügig bemessen sind. Die Tendenz zur Vereinbarung vergleichsweise kurzer Belegungsbindungen kann nicht ohne weiteres als Beitrag zur Erhöhung der

1 Vgl. Hamm, H. (1990), S. 70; Keil, K. (1996), S. 163 (einschließlich Fußnote 2 mit der dort angegebenen Literatur). 
Fördereffizienz gesehen werden, denn die öffentliche Hand muß nun zu einem früheren Zeitpunkt neue Objekte fördern, wenn sie den Sozialwohnungsbestand aufrecht erhalten will. Die Einsparungen treten unter Umständen nur kurzfristig auf (vgl. Kapitel 3.A.II).

Aus verteilungspolitischer Sicht bedenklich ist die fehlende Eingrenzung des Adressatenkreises der Förderung durch eine bundesgesetzliche Vorgabe. Die Länder haben den Gestaltungsspielraum genutzt und höhere als die in $\S 25 \mathrm{c}$ II. WoBauG genannten Einkommensgrenzen festgelegt. Dadurch haben sie den sozialen Mietwohnungsbau für die Bezieher mittlerer Einkommen geöffnet, die nunmehr mit den sozial schwachen Haushalten um die knappen Sozialwohnungen konkurrieren. Die Ausweitung des sozialen Wohnungsbaues auf die breiten Schichten der Bevölkerung wird u.a. mit der Absicht begründet, eine ghettoartige Konzentration von sozial schwachen Haushalten im Sozialwohnungsbestand $\mathrm{zu}$ vermeiden. Bei einer konsequenten Verfolgung dieser Zielsetzung müßte allerdings in Kauf genommen werden, daß sich die bereits im klassischen sozialen Mietwohnungsbau unzureichende Versorgung sozial Schwacher mit zunehmender Bedeutung der vereinbarten Förderung weiter verschlechtert. „Durch ein verstärktes Einbeziehen von Haushalten mit mittleren Einkommen würde sich der soziale Wohnungsbau ... noch weiter von einem sozialpolitischen Instrument entfernen, und die Willkür der Verteilung knapper Mittel würde noch größer.“l Hinzu kommt, daß die gutsituierten Mieter, deren Einkommen schon beim Wohnungsbezug über der Grenze des $\S 25$ II. WoBauG liegen und unter Umständen im Zeitablauf noch kräftig ansteigen, die gleiche Miete wie geringverdienende Haushalte zahlen müssen. Dies wiegt um so schwerer, als die Länder im dritten Förderweg gegenwärtig keine Fehlbelegungsabgabe erheben. ${ }^{2}$ Auf Bundesebene setzten daher Bestrebungen ein, die soziale Treffsicherheit der vereinbarten Förderung zu erhöhen. Sie mündeten 1994 in der Einführung der einkommensorientierten Förderung im sozialen Mietwohnungsbau.

1 Eekhoff, J. (1993), S. 75.

2 In seiner Fassung vom 25. Februar 1992 sah das Hessische Gesetz zur Abbau der Fehlsubventionierung im Wohnungswesen eine Ausgleichszahlung auch für nach $\S 88 \mathrm{~d}$ geförderte Wohnungen vor ( $§ 2$ Abs. 2). Nach der aktuellen Fassung von 1996 muß für diese Wohnungen keine Fehlbelegungsabgabe mehr entrichtet werden. 


\section{Teil: Merkmale der einkommensorientierten Förderung (EOF)}

\section{A. Grundlegendes}

Mit dem am 1. Oktober 1994 in Kraft getretenen Wohnungsbauförderungsgesetz $1994^{1}$ sind die rechtlichen Grundlagen für die Anwendung der einkommensorientierten Förderung im sozialen Mietwohnungsbau geschaffen worden. Durch das Gesetz wurde das Zweite Wohnungsbaugesetz um die $\S \S 88$ e und $\mathrm{f}$ ergänzt, in denen die wesentlichen Merkmale der neuen Förderform enthalten sind. Fördersystematisch stellt die EOF - oft auch als „,vierter Förderweg“ bezeichnet - eine spezifische Ausprägung der vereinbarten Förderung dar $(\S 88 \mathrm{e}$ Abs. 1 Satz 1), die sich gegenüber den herkömmlichen Formen der vereinbarten Förderung dadurch auszeichnet, daß neben der Objektförderung (Grundförderung) eine an den individuellen Einkommensverhältnissen des Mieters orientierte Zusatzförderung geleistet wird. Durch die Zusatzförderung - sie ist anders als die nachträglich erhobene Fehlbelegungsabgabe integrierter Bestandteil der Förderung - sollen die Wohnkosten auf das als „tragbar“ definierte Niveau abgesenkt und zugleich Fehlsubventionierungen vermieden werden. Für die Grundförderung gelten die gleichen Grundsätze wie bei der vereinbarten Förderung im allgemeinen. Sie soll ausreichende Investitionsanreize bieten und zugleich einen sparsamen Mitteleinsatz gewährleisten.

Der Gesetzgeber verbindet mit der EOF die Absicht einer ,grundlegenden Neuorientierung des sozialen Wohnungsbaues“"2. In der Begründung zum Gesetzesentwurf heißt es, daß „die herkömmliche Förderung des sozialen Wohnungsbaues angesichts des hohen Förderaufwands je Wohnung an die Grenzen ihrer Finanzierbarkeit gestoßen “' ${ }^{\text {3 }}$ sei. Die künftige Förderung müsse sich zudem stärker als bisher ,an der individuellen Bedürftigkeit des einzelnen orientieren, um Fehlbelegungen und damit Fehlsubventionierungen von vornherein zu vermeiden und um die soziale Akzeptanz des sozialen Wohnungsbaues zu erhalten. “4 In der Absicht, den Wohnungsbau in Richtung einer höheren Effizienz und sozialen Treffsicherheit zu reformieren, hatte die Bundesregierung bereits im Jahre 1992 ein Konzept zur einkommensorientierten Förderung vorgelegt, in dem

1 Gesetz zur Förderung des Wohnungsbaues (Wohnungsbauförderungsgesetz 1994 WoBauFördG 1994) vom 6. Juni 1994 (BGBl. S.1184).

2 Deutscher Bundestag (1994a), S. 1.

3 Deutscher Bundestag (1994a), S. 1.

4 Deutscher Bundestag (1994a), S. 2. 
die wesentlichen Grundsätze der neuen Förderform festgelegt waren. Auf Wunsch der ARGEBAU-Ministerkonferenz ${ }^{1}$ sind die Investitionsbedingungen bei der EOF, sowie rechtliche und verwaltungspraktische Fragen, die das neue Konzept aufwarf, im Rahmen eines am 16. und 17. September 1993 in Würzburg veranstalteten Planspiels untersucht worden, an dem Vertreter von Bund, Ländern, Gemeinden und Wohnungswirtschaft teilnahmen. Dabei wurde das Grundanliegen der Reform zwar begrüßt, doch stieß das Modell vor allem wegen der Detailregelungen im Planspiel auch auf Skepsis. ${ }^{2}$ Auf der Basis der im Planspiel gewonnenen Erfahrungen haben die Koalitionsfraktionen von CDU / CSU und FDP einen Entwurf zum Wohnungsbauförderungsgesetz $1994^{3}$ ausgearbeitet und am 19. Januar 1994 als Initiativantrag in den Bundestag eingebracht. Der Gesetzesvorschlag ist nach Beratungen mit den anderen Parteien sowie den Ländern am 28. April 1994 vom Bundestag in dritter Lesung verabschiedet und am 20. Mai vom Bundesrat bestätigt worden.

\section{B. Art und Aufgabe der Grundförderung}

Die Grundförderung stellt die rein objektorientierte Komponente der Förderung dar. Sie wird nach $\S 88$ e Abs. 1 Satz 2 ,zum Zwecke des Erwerbs von Belegungsrechten und der Festlegung von höchstzulässigen Mieten“ gewährt. In ihrer Funktion als Gegenleistung für die Belegungsbindung soll sie den Investor vor allem für die ökonomischen Nachteile einer Wohnungsvergabe an den zu fördernden Personenkreis entschädigen. Solche Nachteile können u.a. in einem erhöhten Mietausfallwagnis, einer stärkeren Abnutzung der Wohnungseinrichtung und in Beeinträchtigungen der Vermietbarkeit von benachbarten Wohnungen bestehen (vgl. Kapitel 3.B.II.a bis 3.B.II.c). Dabei ist zu berücksichtigen, daß die belegungsgebundenen Wohnungen aufgrund des gesetzlichen Kündigungsschutzes ${ }^{4}$ nach Ablauf der Bindung zumeist nicht neubelegt werden kön-

1 Der Begriff bezeichnet die Arbeitsgemeinschaft der für das Bau-, Wohnungs- und Siedlungswesen zuständigen Minister der Länder.

2 Vgl. Bundesministerium für Raumordnung, Bauwesen und Städtebau (1993), S. 5ff. Zur Kritik an den Annahmen und Ergebnissen des Planspiels: Helzer, U., Mündemann, T. (1993), Brintzinger, O. L. (1993); Krabbes, R. (1994), S. $106 f$.

Deutscher Bundestag (1994a).

4 Wichtigste Bestimmung im Kündigungsschutz ist $\S 564$ b BGB, wonach eine Kündigung des Mietverhältnisses durch den Vermieter nur bei Vorliegen eines ,berechtigten Interesses“ zulässig ist. Der Gesetzgeber erkennt als Gründe für ein berechtigtes Interesse u.a. eine nicht unerhebliche schuldhafte Verletzung der Vertragspflichten durch den Mieter, Eigenbedarf des Vermieters und die Verhinderung einer angemessenen wirtschaftlichen Ver- 
nen, die ökonomischen Folgen der Wohnungsbelegung also weit über die Bindungsdauer hinausreichen können.

In ihrer zweiten Funktion soll die Grundförderung die finanziellen Einbußen ausgleichen, die dem Investor entstehen, wenn er aufgrund der Bindung an die höchstzulässige Miete, auch „Basismiete“ genannt, nicht die auf dem Markt durchsetzbare Mietforderung erheben kann. Die Differenz von Basismiete und Marktmiete kann im Einzelfall sehr unterschiedlich ausfallen. Sie hängt von der Ausgestaltung der Grundförderung durch die einzelnen Bundesländer und dem Stand und der Entwicklung des Mietniveaus auf den Wohnungsmärkten ab. In der Förderpraxis wird die Basismiete durch Vorgaben der Länder über die höchstzulässige Anfangsmiete und ihre Dynamisierung zumeist im gesamten Bindungszeitraum unter das marktübliche Niveau abgesenkt. Wirtschaftliche Einbußen können außerdem nach Ablauf der Wohnungsbindung auftreten, wenn die Miete wegen der Kappungsgrenze des $\S 2 \mathrm{MHG}^{1}$ nicht sogleich auf das Niveau der ortsüblichen Vergleichsmiete angehoben werden kann.

In bezug auf Art und Höhe der Grundförderung hat der Gesetzgeber den Ländern weitgehende Gestaltungsfreiheit eingeräumt. Aus der Einstufung der EOF als Anwendungsfall der vereinbarten Förderung nach $\S 88 \mathrm{~d}$ ergibt sich lediglich, daß die Anwendung des Kostenmietprinzips verboten ist. Die Höhe der Grundförderung ist nicht einzelfallbezogen nach einer Kostenmietkalkulation aufgrund der Zweiten Berechnungsverordnung, sondern im Rahmen einer allgemeinen Investitionsrechnung zu bestimmen. Bei der Festlegung der Mittel haben die Länder ,insbesondere auch die Mietentwicklung, steuerliche Effekte und Verwertungsmöglichkeiten nach Auslaufen der Mietpreis- und Belegungsbindung sowie die mit der jeweiligen Wohnungsbelegung verbundenen Kosten und Risiken zu berücksichtigen“2. Die Grundförderung soll eine fixierte Höhe aufweisen und von der Kostenentwicklung der einzelnen Vorhaben unabhängig sein. Ebenso wie bei der vereinbarten Förderung sind die $\S \S 38$ und 39 über kosten- und flächensparendes Bauen anzuwenden. Als Förderart kommen alle

wertung des Grundstücks an. Ferner bestimmt $§ 1$ MHG die Unzulässigkeit einer Kündigung zum Zwecke der Mieterhöhung. Eine Sozialklausel nach § 556 a BGB sieht zudem vor, daß der Mieter einer im Sinne des $\S 564$ b BGB zulässigen Kündigung widersprechen kann, „wenn die vertragsgemäße Beendigung des Mietverhältnisses für den Mieter oder seine Familie eine Härte bedeuten würde, die auch unter Würdigung der berechtigten Interessen des Vermieters nicht zu rechtfertigen ist. Eine Härte liegt auch vor, wenn angemessener Ersatzwohnraum zu zumutbaren Bedingungen nicht beschafft werden kann.“

1 Vgl. Kapitel 3.C.II.b.

2 Berkefeld, D., Kommentar zum $\S 88$ e II. WoBauG, S. 5. 
im $\S 42$ II. WoBauG genannten Möglichkeiten, also Baudarlehen, Aufwendungsdarlehen, Aufwendungszuschüsse, Zinszuschüsse etc. in Frage. ${ }^{1}$

\section{Charakteristika der Zusatzförderung}

\section{Funktion im Rahmen der EOF}

Das zweite Förderelement, die einkommensorientierte Zusatzförderung, wird nach $\S 88$ e Abs. 1 Satz 1 ,,zum Zwecke einer einkommensorientierten Wohnkostenbelastung des jeweiligen Mieters und einer dementsprechenden Sicherstellung der durch die Förderzusage festgelegten Mietzahlung gewährt". Durch sie soll die Basismiete - je nach der Einkommenssituation des Mieters, der Anzahl der zu seinem Haushalt rechnenden Familienmitglieder und sonstigen förderrelevanten Tatbeständen - auf ein sozialverträgliches Niveau abgesenkt werden. Formalrechtlich wird die Zusatzförderung - wie auch die Grundförderung an den Vermieter geleistet ${ }^{2}$, doch kommt sie materiell dem Sozialmieter zugute, dessen Wohnkostenbelastung verringert wird. Die Zusatzförderung entspricht dem Differenzbetrag von Basismiete und Mietermiete (Endmiete). Bei maximaler Förderung zugunsten von einkommensschwachen Haushalten wird die Mietermiete auf die sog. Mindestmiete herabsubventioniert. Kennzeichnend für die Zusatzförderung ist, daß sie - ähnlich wie das Wohngeld oder die Fehlbelegungsabgabe - in gewissen Zeitabständen an die Einkommensentwicklung der Mieterhaushalte angepaßt wird (vgl. Kapitel 2.F.IX). Auf diese Weise soll die Ausrichtung der Leistungen an der Förderungswürdigkeit der Mieterhaushalte auch im Zeitablauf sichergestellt werden. Ähnlich wie das Wohngeld zählt die Zusatzförderung nicht zu den steuerpflichtigen Einkünften im Sinne des EStG.

Die Zusatzförderung soll es den Ländern ermöglichen, Besserverdienende in die Förderung einzubeziehen und dennoch Fehlsubventionierungen zu vermeiden. ${ }^{3}$ Während sich einkommensmäßig gemischte Belegungsstrukturen bei öffentlich geförderten Sozialwohnungen erst im Zeitablauf durch Fehlbelegung einstellen, können die Wohnungen bei der EOF von vornherein auch an Mieter vergeben werden, deren Einkommen über der Grenze des $\S 25 \mathrm{c}$ II. WoBauG liegen und die eine entsprechend niedrigere Zusatzförderung erhalten. Hinter der Einbezie-

1 Vgl. Berkefeld, D., Kommentar zum $\S 88$ e II. WoBauG, S. 6.

2 Die Bestimmung des Vermieters als Empfänger der Zusatzförderung ergibt sich aus deren investivem Wesensgehalt, ohne den eine Beteiligung des Bundes mit Finanzhilfen gemäß Art. 104 a Abs. 4 GG nicht möglich wäre; vgl. Berkefeld, D., Kommentar zu $§ 88$ e II. WoBauG, S. 11; vgl. auch Kapitel 2.D.

3 Vgl. Deutscher Bundestag (1994d), S. 34. 
hung besserverdienender Mieter in die Förderung steht die Absicht des Staates, das Entstehen ghettoähnlicher Siedlungen und die daraus vermeintlich resultierenden sozialen Spannungen zu vermeiden. Auch wird davon ausgegangen, daß die Fördervorhaben bei ,sozial ausgewogenen“ Belegungsstrukturen an Attraktivität gewinnen und somit die Investitionsbereitschaft potentieller Bauherren positiv beeinflußt wird. Außerdem soll durch die Abkehr von der Einkommensgrenze des $\S 25$ als Zugangsbeschränkung für die Sozialwohnungen der im ersten Förderweg auftretende „Eiger-Nordwand-Effekt" verhindert werden. Mit dem Begriff wird die Situation von Wohnungssuchenden charakterisiert, deren Einkommen nur knapp über der Grenze des $§ 25$ liegt, und die sich daher im Regelfall auf dem freien Wohnungsmarkt zu wesentlich höheren Mieten versorgen müssen. ${ }^{1}$ Das Problematische daran ist, daß nur minimale Einkommensunterschiede den Ausschlag dafür geben, ob in voller Höhe oder überhaupt nicht gefördert wird. Bei der EOF kann die Problematik durch eine einkommensorientierte Abstufung der Förderung entschärft werden.

\section{Art und Auszahlung der Mittel}

Zur Art der Zusatzförderung enthält das Wohnungsbaugesetz keine Bestimmungen. Daraus wird gefolgert, daß die Länder wie bei der Grundförderung die unterschiedlichsten Gestaltungsformen wählen können. Nicht erforderlich ist, daß die Zusatzförderung in der gleichen Art wie die Grundförderung geleistet wird. $^{2}$ In der Förderpraxis werden die Mittel zumeist als laufende Zuschüsse gewährt. Die Ermittlung und Auszahlung der Zusatzförderung erfolgt nach § 103 II. WoBauG durch die landesrechtlich zuständigen oder von der Landesregierung in sonstiger Weise zu bestimmenden zuständigen Stellen. Gemäß $\S 88 \mathrm{e}$ Abs. 3 sind die zuständigen Stellen während der Dauer der Zweckbestimmung zur Zahlung der jeweiligen Zusatzförderung verpflichtet.

Auch beim Auszahlungsmodus hat der Gesetzgeber den Ländern weitgehende Gestaltungsfreiheit eingeräumt (vgl. Kapitel 2.F.VI). Nach § 88 e Abs. 3 Satz 3 ist zwar der Vermieter stets als Empfänger der Zusatzförderung anzusehen, doch kann die Zahlung unabhängig davon auch über den Mieter erfolgen. In der Praxis haben die folgenden drei Auszahlungsformen Anwendung gefunden (vgl. Übersicht 4):

\footnotetext{
1 Vgl. Gesamtverband der Wohnungswirtschaft e.V. (1994b), S. 154 (25).

2 Vgl. Berkefeld, D., Kommentar zum $\S 88$ e II. WoBauG, S. 6.
} 
Übersicht 4: Auszahlungsformen der Zusatzförderung

Variante I: Auszahlung an den Mieter

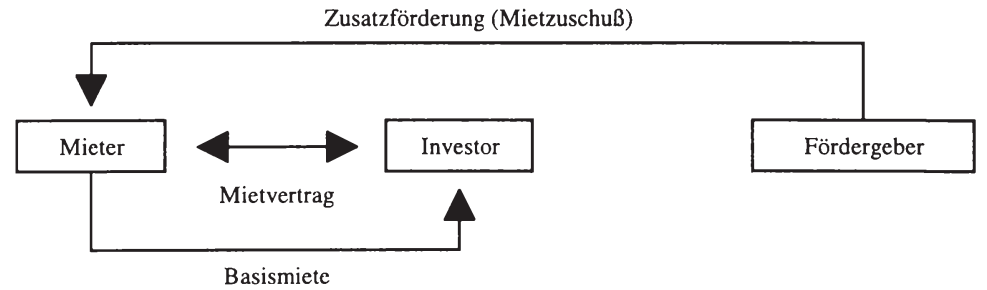

Variante II: Auszahlung an den Vermieter

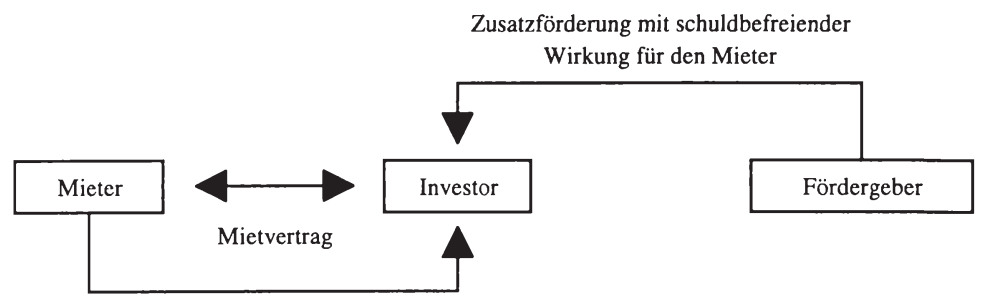

Einkommensabhängige Endmiete

Variante III: Zwischenanmietung durch den Fördergeber

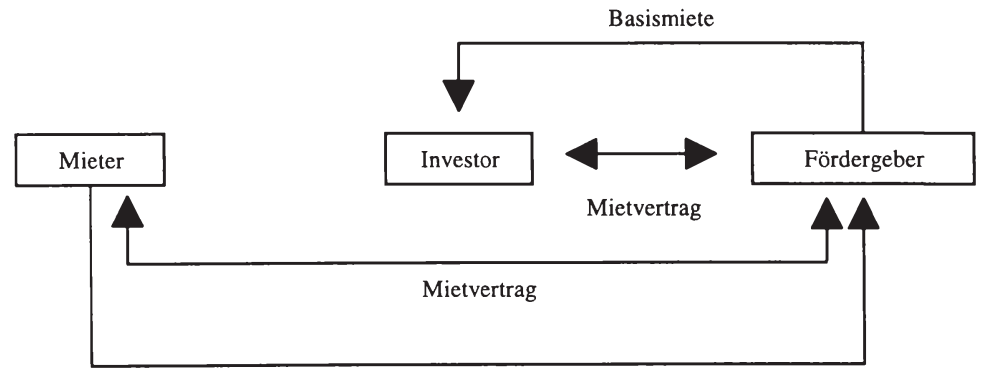

Einkommensabhängige Endmiete 
Bei Variante I, der gebräuchlichsten Methode, zahlt der Fördergeber die Zusatzförderung als Zuschuß an den Mieter aus, der sie an den Investor weiterleitet, indem er die vertraglich vereinbarte Basismiete entrichtet.

Variante II ist die direkte Gewährung der Förderung an den Vermieter. Dabei kann so verfahren werden, daß Investor und Mieter einen Vertrag über die Basismiete abschließen und die zuständige Stelle die Zusatzförderung an den Investor mit schuldbefreiender Wirkung für den Mieter leistet. Dieser braucht dann nur eine entsprechend verringerte Miete zu zahlen. Die dargestellte Vorgehensweise ist als Ausnahme von Variante I immer dann angezeigt, wenn der Mieter die von der zuständigen Stelle erhaltenen Zuschüsse nicht an den Vermieter weiterleitet.

Ein Spezialfall der zweiten Variante liegt vor, wenn der Mietvertrag von vornherein über die einkommensorientierte Mietermiete abgeschlossen wird, eine einheitliche Basismiete also gar nicht existiert. ${ }^{1}$ Unter der Zusatzförderung ist dann sinngemäß der Abstand zwischen der höchstmöglichen und der vom jeweiligen Mieter tatsächlich zu zahlenden Mietermiete zu verstehen. Sie ist als der Teil der Förderung zu betrachten, der zur Kompensation einkommensabhängiger Mietverbilligungen an den Investor geleistet wird.

Bei Variante III, die bislang nur in Baden-Württemberg praktiziert wird, tritt die zuständige Stelle als Zwischenmieter der geförderten Wohnung auf. Das Mietverhältnis zwischen zuständiger Stelle und dem Wohnungseigentümer wird über die Basismiete abgeschlossen, während die zuständige Stelle vom Mieterhaushalt nur die einkommensabhängige Endmiete einfordert.

Die Wahl der Auszahlungsform ist keineswegs nur von formaler Bedeutung. So weisen die Varianten I und III gegenüber der Alternative II den Vorteil auf, daß der Investor lediglich über den Tatbestand der Gewährung einer Zusatzförderung unterrichtet werden muß. Die Höhe der Zahlungen, aus denen Rückschlüsse auf das Mietereinkommen gezogen werden könnten, braucht er jedoch nicht zu erfahren. Dagegen kann der Eigentümer bei Variante II aus den Zahlungseingängen der Zusatzförderung auf die Einkommenssituation des Mieters schließen, was unter dem Gesichtspunkt des Grundrechts auf informationelle Selbstbestimmung (BVerfGE 65, 1ff.) nicht unbedenklich ist. ${ }^{2}$ Zur rechtlichen Absicherung hat der Gesetzgeber in $\S 88 \mathrm{f}$ Abs. 2 II. WoBauG bestimmt, daß die Zusatzförderung auch dann an den Vermieter ausgezahlt werden kann, wenn dieser aus den geleisteten Zahlungen Rückschlüsse auf das Einkommen des

1 Ein solches Verfahren wird in Schleswig-Holstein praktiziert (vgl. Übersicht 26 im Anhang).

2 Vgl. Berkefeld, D., Kommentar zu $§ 88$ e II. WoBauG, S. 11. 
Mieterhaushaltes ziehen kann. Trotz dieser Klausel bevorzugen viele Länder gerade aus datenschutzrechtlichen Gründen - die Auszahlung der Zusatzförderung an die Mieter.

Für die Varianten II und III spricht, daß die Fördermittel auf direktem Wege zum Adressaten gelangen und so das Risiko einer mißbräuchlichen Verwendung der Zuschüsse durch den Mieter entfällt. Die Wahl der Auszahlungsform ist ferner im Hinblick auf die Bestimmungen des Miethöhegesetzes von Bedeutung. Wird die Zusatzförderung in Form eines Zuschusses zur Vertragsmiete gewährt, so sind bei ihrer Rückführung keine Verstöße gegen die Kappungsgrenze nach § $2 M H G$ möglich, da sich diese auf die vertraglich vereinbarte Miete bezieht. Die Kappungsgrenze muß dagegen eingehalten werden, wenn die Mietermiete zugleich Vertragsmiete ist (Spezialfall von Variante II). Aufgrund dieser Beschränkung kann es zu unerwünschten Fehlsubventionierungen kommen, wenn das Einkommen des Mieterhaushaltes in kurzer Zeit stark ansteigt, der Abbau der Zusatzförderung aber wegen der Kappungsgrenze hinausgezögert wird.

Schließlich unterscheiden sich die dargestellten Auszahlungsformen im Verwaltungsaufwand für den Zuschußgeber. Nach den bisherigen Erfahrungen sind die Kommunen, die als Zwischenmieter auftreten, in besonderer Weise beansprucht, denn sie müssen in ihrer Doppelfunktion als Mieter und Vermieter viele, über die Einkommensprüfung und Gewährung der Zusatzförderung hinausgehende Aufgaben übernehmen, die bei den Alternativen I und II durch den Investor oder in dessen Auftrag von einem Generalvermieter wahrgenommen werden (Einzug der Miete, Überwachung des ordnungsgemäßen Zustandes der Wohnungen etc.). Dagegen dürfte die EOF bei Zwischenmietung durch die zuständige Stelle für die von Aufgaben und Risiken entlasteten Investoren an Attraktivität gewinnen.

\section{Koordination der Zusatzförderung mit dem Wohngeld}

Durch die Zusatzförderung sollen die Wohnkosten nach dem Willen des Gesetzgebers auch unter die Höchstbeträge der beim Wohngeld berücksichtigungsfähigen Miete ${ }^{1}$ abgesenkt werden können. Wie zu verfahren ist, wenn sich die beiden Leistungsbereiche überschneiden, ist in $\S 88$ e Abs. 5 II. WoBauG geregelt. Danach „kann die Zusatzförderung unabhängig davon bestimmt werden, ob für Mietanteile zugleich Leistungen nach dem Wohngeldgesetz zustehen würden." Bei der Berechnung von Wohngeld wird die Zusatzförderung zu den Beiträgen Dritter zur Bezahlung der Miete gezählt, die nach $\S 7$ Abs. 2 Nr. 3

1 Siehe § 8 Abs. 1 des Wohngeldgesetzes. 
des Wohngeldgesetzes (WoGG) von den berücksichtigungsfähigen Wohnkosten abgezogen werden müssen. In der Praxis ist demzufolge so zu verfahren, daß zunächst die Zusatzförderung bewilligt und dann die Höhe des Wohngeldanspruches auf der Grundlage der um die Zusatzförderung gekürzten Miete ermittelt wird. Dies gilt auch, wenn es sich um pauschaliertes Wohngeld für die Bezieher von Leistungen nach dem BSHG handelt: Von der berücksichtigungsfähigen Miete des Sozialhilfeempfängers wird die Zusatzförderung abgezogen und auf den verbleibenden Betrag der jeweils einschlägige Prozentsatz zur Bemessung des Wohngeldes angewendet. Diese Regelungen gelten unabhängig davon, ob die Auszahlung unmittelbar an den Vermieter oder über den Mieter erfolgt.

\section{Finanzierung der EOF durch Bund, Länder und Gemeinden}

Die Finanzierung der EOF erfolgt aus Mitteln des Bundes und der Länder sowie in einigen Bundesländern auch durch kommunale Beteiligungen. Den Hauptteil der Lasten haben in aller Regel die Länder zu tragen, während der Bund nach § 88 e Abs. 6 II. WoBauG vom Haushaltsjahr 1995 an jährlich 300 Millionen DM als Verpflichtungsrahmen für Grund- und Zusatzförderung bereitzustellen hat. Wegen der Beschränkung des Bundesanteils auf einen Fixbetrag liegt das finanzielle Risiko aus der von der Einkommensentwicklung abhängigen Zusatzförderung bei den Ländern oder Gemeinden.' Soweit die Finanzhilfen nicht für die einkommensorientierte Förderung eingesetzt werden, ist ihre Verwendung auch für andere Maßnahmen des sozialen Wohnungsbaues möglich. Die Beteiligung des Bundes an der Grund- und Zusatzförderung erfolgt auf der Grundlage des Art. 104 a Abs. 4 GG. Bei der Zusatzförderung wird die Anwendung des Art. 104 a durch Verweis auf ihre Investitionsbezogenheit begründet. Diese leitet sich nach Auffassung des Bundes daraus ab, daß Grund- und Zusatzförderung in bezug auf die Realisierbarkeit der Wohnungsmaßnahme eine Einheit darstellen. „Für Investoren im Förderkonzept der einkommensabhängigen Förderung ist entscheidend, daß Grund- und Zusatzförderung vor Baubeginn zugesagt werden. Die einkommensabhängige Entlastung des Mieters ist akzessorisch und verändert nicht den investiven Wesensgehalt der objektgebundenen Zusatzförderung, auch wenn diese auf die Miete angerechnet wird.“2

1 Bei den Planungen zur Ausgestaltung der EOF ist an diesem Punkt häufig Kritik geübt worden. Eine Beteiligung in Form einer Quote hatte der Bund mit dem Argument abgelehnt, sich nicht auf diese Weise an eine Förderung binden zu wollen, deren Ausgestaltung ganz bei den Ländern liege. Vgl. Deutscher Bundestag (1994d), S. 34; Gierke, H.-G. (1994), S. 5; Krabbes, R. (1994), S. 106f.; Bundesvereinigung der kommunalen Spitzenverbände (1994), S. 240 (3).

2 Bundesministerium für Raumordnung, Bauwesen und Städtebau (1993), S. 10. 


\section{E. Dauer der Förderung und der Zweckbestimmung der Sozialwohnungen}

Während der Dauer der Zweckbestimmung ist die zuständige Stelle nach § $88 \mathrm{e}$ Abs. 3 Satz 1 zur Zahlung der jeweiligen Zusatzförderung und ist der Investor nach Abs. 2 zur Einhaltung der höchstzulässigen Miete und der Belegungsbindung verpflichtet. Über die Länge des Zeitraumes der Zweckbestimmung werden in $\S 88$ e keine Regelungen getroffen. Ihre Konkretisierung steht im Ermessen der Länder, die diesbezüglich - trotz der Festlegung des $\S 88 \mathrm{~d}$ Abs. $2 \mathrm{Nr}$. 2, nach dem die Zweckbestimmung bei der vereinbarten Förderung grundsätzlich nicht länger als 15 Jahre betragen soll - de facto keiner Beschränkung unterworfen sind. Denn zum einem wird die gesetzliche Regelung dadurch abgeschwächt, daß auch längere Zeiträume bestimmt werden können, wenn dies aufgrund von Art und Zielsetzung der Förderung geboten erscheint. Zum anderen ist zweifelhaft, ob diese für die vereinbarte Förderung geltende Regelung überhaupt auf die einkommensorientierte Förderung übertragen werden kann. ${ }^{1}$ In der Förderpraxis werden - ähnlich wie bei der vereinbarten Förderung - zumeist kürzere Bindungszeiträume als im ersten Förderweg festgelegt (vgl. Kapitel 2.F.IV).

\section{F. Konkretisierung der EOF in den Ländern}

Die Konkretisierung der einkommensorientierten Förderung hat - wie bei der vereinbarten Förderung im allgemeinen - durch die Länder zu erfolgen. Nach $\S 88$ e Abs. 4 II. WoBauG bestimmen sie u.a. über die Höhe der Grundförderung, die höchstzulässigen Mieten und deren Erhöhung, die Art und Dauer der Belegungsrechte der geförderten Wohnungen, die begünstigten Personengruppen, die Höhe der Zusatzförderung und den gesamten Leistungszeitraum für die Zusatzförderung. Auch steht es in ihrem Ermessen, ob sie die Förderung nach $\S 88$ e überhaupt anwenden wollen. Nachdem anfänglich noch die Skepsis gegenüber der neuen Fördervariante überwog, entschlossen sich dann aber immer mehr Länder zur modellhaften Erprobung der einkommensorientierten Förderung. Ende 1996 waren mit Baden-Württemberg, Bayern, Berlin, Brandenburg, Bremen, Hessen, Niedersachsen, Rheinland-Pfalz, Sachsen, Schleswig-Holstein und Thüringen bereits elf Bundesländer in die Förderung nach $\S 88$ e eingestiegen. Des weiteren hat Nordrhein-Westfalen eine einkommensorientierte Förderung auf der Grundlage des $\S 88 \mathrm{~d}$ in sein Förderprogramm aufgenommen. ${ }^{2}$ Die

Vgl. Berkefeld, D., Kommentar zu § 88 e II. WoBauG, S. 10.

2 Darüber hinaus sind in Bremen der erste Förderweg und in Hamburg seit 1995 der zweite Förderweg einkommensorientiert ausgestaltet. 
Förderzahlen fallen im Vergleich mit den übrigen Förderwegen allerdings noch bescheiden aus. So sollten 1996 insgesamt 8.000 Wohnungen im Rahmen der EOF saniert und über 1.000 Wohnungen neugebaut werden. Das Bundesbauministerium führt die relativ niedrigen Förderzahlen darauf zurück, daß es sich um eine anspruchsvolle Fördermethode handelt, bei der ,umfangreiche konzeptionelle Vorarbeiten sowie Abstimmungen mit Verbänden, Investoren und Verwaltungspraktikern unabdingbar (sind), um zu praktikablen, auf die spezifischen Verhältnisse des Landes zugeschnittenen Ausgestaltungen zu gelangen. “"

Der Stand der Umsetzung ist von Land zu Land verschieden. Während einige Länder wie Baden-Württemberg (300 Wohneinheiten im Förderjahr 1995), Bayern (je $200 \mathrm{WE}$ in 1995 und 1996), Berlin (219 WE in 1995 und $200 \mathrm{WE}$ in 1996), Bremen (300 WE in 1995 und 186 WE in 1996) bereits seit 1995 in groBem Umfang einkommensorientiert fördern ${ }^{2}$, gab es in Hessen (Frankfurt), Niedersachsen (Wolfsburg) und Brandenburg (Cottbus) bis Ende 1996 nur jeweils ein Pilotobjekt.

Am weitesten fortgeschritten ist die Umsetzung der EOF in Baden-Württemberg, das schon 1993 mit der einkommensorientierten Mietwohnungsbauförderung - damals noch auf der Grundlage des $\S 88 \mathrm{~d}$ - begonnen hat und den Mietwohnungsbau seit 1997 fast ausschließlich nach dem neuen Modell fördert. Die Förderkonditionen der frühen Modellversuche entsprechen bereits den erst später ergangenen Bestimmungen des $\S 88$ e II. WoBauG. Modellversuche zur EOF wurden unternommen in Fellbach (Objekt mit 12 WE im Förderjahr 1993), Freiburg (zwei Objekte mit 18 bzw. 20 WE in 1993), Heilbronn (vier Objekte mit 7, 12, 15 bzw. 16 WE sowie zwei einzelne WE in 1993), Möglingen (Objekt mit 10 WE in 1993), Rutesheim (Objekt mit 15 WE in 1993), Mannheim (Objekt mit 26 WE in 1994) und Stuttgart (Objekt mit 45 WE in 1994). Sämtliche Wohnungen aus diesen Projekten sind mittlerweile fertiggestellt und von den Mietern bezogen worden. Daneben praktiziert die Gemeinde Fellbach bereits seit Anfang der 90er Jahre eine rein kommunale Wohnungsbauförderung mit einkommensorientierten Mieten. ${ }^{3}$ Die aus den frühen Modellversuchen gewonnen Erfahrungen lassen Schlußfolgerungen zur praktischen Umsetzung der EOF zu, auf die an späterer Stelle noch eingegangen wird.

Auch in Bayern ist mit der EOF bereits vor der Verankerung des $\S 88$ e ins Zweite Wohnungsbaugesetz modellhaft begonnen worden. Das Besondere an

1 Bundesministerium für Raumordnung, Bauwesen und Städtebau (1996), S. 1.

2 Vgl. Deutsches Volksheimstättenwerk e.V. (1996), S. 5 ff.

3 Vgl. Kiel, F.-W. (1991); Becker, J. (1993). 
dem 70 Wohnungen umfassenden Objekt in München-Neuperlach, das Ende 1993 fertiggestellt worden ist, liegt darin, daß Grund- und Zusatzförderung ausschließlich aus Mitteln der Erzdiözese München bestritten werden. ${ }^{1}$

Die Pilotmodelle der Bundesländer zeichnen sich - vor allem wegen der Gestaltungsfreiheit, die ihnen vom Gesetzgeber eingeräumt worden ist - durch einen großen Variantenreichtum aus. Dies ist nach Auffassung von Vertretern des Bundesbauministeriums, ,in der Startphase zu begrüßen, um im Wettbewerb der Ideen und Lösungsmöglichkeiten die besten und in der Förderpraxis tragfähigsten Alternativen zu entwickeln.“2 Die länderspezifischen Regelungen sind im Anhang nach Bundesländern geordnet zusammengefaßt. Im folgenden sollen sie - aufgegliedert nach den Regelungsgegenständen - in dem für die spätere Analyse gebotenen Umfang dargestellt werden.

\section{Geförderte Maßnahmen}

Gegenstand der Förderung ist in allen Bundesländern - mit Ausnahme von Sachsen - die Neuschaffung von Miet- und Genossenschaftswohnungen. In Sachsen erstreckt sich die EOF ausschließlich auf Sanierungsmaßnahmen. Durch die Förderung soll der Anstieg der Wohnkostenbelastung, der sich aus der Beteiligung der Mieter an den Modernisierungskosten gemäß § 13 MHG (Modernisierungsumlage) ergibt, sozialverträglich abgefedert werden.

Neben dem Neubau fördern zahlreiche Bundesländer auch am Wohnungsbestand ansetzende Maßnahmen, zu denen der Ausbau, Aufbau, Umbau und die Erweiterung von Gebäuden zählen. Die einzelnen Maßnahmen werden je nach Bundesland sämtlich oder nur zum Teil und unter verschiedenen Bedingungen in die Förderung einbezogen. Nur in Bayern und Nordrhein-Westfalen ist die EOF auf Neubaumaßnahmen beschränkt. Dagegen ist sie in Bremen durch eine besondere Vielfältigkeit gekennzeichnet: Neben der Neubauförderung im Rahmen des Grundmodells der EOF bietet das Land zwei weitere Fördervarianten an, durch die Belegungsbindungen im Wohnungsbestand erworben werden. Im Kombimodell werden neugeschaffene Wohnungen zugunsten von Mietern mit etwas höheren Einkommen unter der Bedingung gefördert, daß der Investor eine gleiche Anzahl von Mietwohnungen aus seinem nicht gebundenen Bestand für die Belegung durch Mieter mit besonders niedrigen Einkommen zur Verfügung stellt. Im Rahmen der zweiten Alternative mit der Bezeichnung „Modell 1+3“

1 Vgl. Arbeitsgemeinschaft des Evangelischen Siedlungswerks e.V. und des Katholischen Siedlungsdienstes e.V. (1994), Anlage auf S. 237.

2 Bundesministerium für Raumordnung, Bauwesen und Städtebau (1996), S. 1. 
kann der Ausbau, die Erweiterung oder Modernisierung ( $\$ 17 \mathrm{WoBauG}$ ) in besonderen Fällen wie der Neubau gefördert werden, wenn der Bauherr aus seinem Wohnungsbestand i.d.R. drei weitere mietpreis- und belegungsfreie Mietwohnungen umfassend modernisiert und der Förderungsstelle für diese Wohnungen ein Belegungsrecht einräumt. Der Erwerb mittelbarer Belegungsbindungen wird seit 1997 auch in Baden-Württemberg angestrebt. Nach den Landesvorschriften zur EOF kann der Investor unter bestimmten Bedingungen für den Neubau einer Mietwohnung auch dann eine Grundförderung erhalten, wenn er der zuständigen Stelle eine vergleichbare Wohnung aus seinem Bestand zur Ausübung des Belegungsrechts überläßt. Voraussetzung für die mittelbare Belegung ist, daß keine Zusatzförderung in Anspruch genommen wird.

\section{Art und Höhe der Grundförderung}

Die Grundförderung erfolgt überwiegend in Form von Baudarlehen, die für die Dauer der Zweckbestimmung der Wohnungen zinsverbilligt oder sogar zinslos sind. In Berlin, Bremen und Thüringen werden ergänzend Aufwendungszuschüsse gewährt, die im Förderzeitraum mit steigenden Basismieten zurückgeführt werden. Baden-Württemberg und Rheinland-Pfalz bieten die Förderung durch Aufwendungszuschüsse als Alternative zur Darlehensgewährung an. In Nordrhein-Westfalen können die Investoren wählen, ob sie ein unverzinsliches Baudarlehen oder ein niedrig zu verzinsendes Baudarlehen in Verbindung mit einer Liquiditätshilfe in Anspruch nehmen wollen. Überdies gewähren einige Länder Sonderförderungen bei Niedrigenergiehäusern (Baden-Württemberg, Schleswig-Holstein) und bei Wohnungen für bestimmte Zielgruppen, z.B. Schwerbehinderte (Rheinland-Pfalz, Schleswig-Holstein), kinderreiche Familien (Baden-Württemberg, Schleswig-Holstein) oder betreute Senioren (Schleswig-Holstein). Einen Aufschlag auf die Förderung erhalten in BadenWürttemberg, Bayern und Sachsen auch diejenigen Investoren, die keine erhöhten Abschreibungen nach $\S 7$ Abs. 5 EStG bzw. nach dem Fördergebietsgesetz in Anspruch nehmen. Damit soll die Attraktivität der EOF für steuerbefreite Bauherren erhöht werden, die ohne die Sonderförderung nur einen geringen Anreiz zu Investitionen im Rahmen der vereinbarten Förderung hätten.

Die Höhe der Grundförderung variiert nicht nur im Vergleich der Bundesländer untereinander, sondern auch in den Ländern selbst. Übersicht 5 gibt den unterschiedlichen Mitteleinsatz der Länder wieder. In die Berechnungen einbezogen wurden nur solche Förderangebote, bei denen die Werte anhand der Förderbestimmungen mit hinreichender Genauigkeit ermittelt werden konnten. Es wurde 
von einer Wohnung durchschnittlicher Größe (70 qm) ausgegangen. Die zur Berechnung der Barwerte verwendete Diskontrate q beträgt $7 \%{ }^{1}$

\section{Übersicht 5: Barwerte der Grundförderung in ausgewählten Ländern}

\begin{tabular}{|c|c|c|}
\hline & Art der Förderung & Barwert (70 qm) \\
\hline $\begin{array}{l}\text { Baden- } \\
\text { Württemberg }\end{array}$ & $\begin{array}{l}\text { OS-10-Darlehen } \\
\text { - Gemeindekategorie I: } 2.100 \mathrm{DM} \text { pro qm } \\
\text { - Gemeindekategorie II: } 1.800 \mathrm{DM} \text { pro qm } \\
\text { - Gemeindekategorie III: } 1.600 \mathrm{DM} \text { pro qm } \\
\text { OS-20-Darlehen } \\
\text { - Stuttgart: } 1.000 \mathrm{DM} \text { pro qm } \\
\text { - Städte mit über } 100.000 \text { Einwohnern: } 900 \mathrm{DM} \text { pro qm } \\
\text { - sonstige Gemeinden der Kategorie I: } 750 \mathrm{DM} \text { pro qm } \\
\text { - Gemeindekategorie II: } 675 \mathrm{DM} \text { pro qm } \\
\text { - Gemeindekategorie III: } 600 \mathrm{DM} \text { pro qm } \\
\text { Aufwendungszuschüsse (10 Jahre) } \\
\text { - Gemeindekategorie I } \\
\text { - Gemeindekategorie II } \\
\text { - Gemeindekategorie III }\end{array}$ & $\begin{array}{l}36.349 \mathrm{DM} \\
31.157 \mathrm{DM} \\
27.695 \mathrm{DM} \\
\\
42.361 \mathrm{DM} \\
38.125 \mathrm{DM} \\
31.771 \mathrm{DM} \\
28.594 \mathrm{DM} \\
25.417 \mathrm{DM} \\
\\
32.640 \mathrm{DM} \\
27.330 \mathrm{DM} \\
24.970 \mathrm{DM}\end{array}$ \\
\hline Bayern & $\begin{array}{l}\text { zinsloses Baudarlehen der Bayerischen Landesboden- } \\
\text { kreditanstalt (drei Zimmer) } \\
\text { - Gebietskategorie I: } 59.400 \mathrm{DM} \\
\text { - Gebietskategorie II: } 45.400 \mathrm{DM} \\
\text { - Gebietskategorie III: } 37.200 \mathrm{DM}\end{array}$ & $\begin{array}{l}35.690 \mathrm{DM} \\
27.278 \mathrm{DM} \\
22.351 \mathrm{DM}\end{array}$ \\
\hline Berlin & $\begin{array}{l}\text { Förderdarlehen der Investitionsbank Berlin } \\
\text { plus Aufwendungszuschuß } \\
\text { - normale Bauausführung (Darlehenszins: } 4,15 \%) \\
\text { - aufwendige Bauausführung (Darlehenszins: } 3,65 \% \text { ) } \\
\text { - sehr aufwendige Bauausführung (Darlehenszins: } 3,15 \% \text { ) }\end{array}$ & $\begin{array}{l}51.292 \mathrm{DM} \\
60.029 \mathrm{DM} \\
68.766 \mathrm{DM}\end{array}$ \\
\hline Brandenburg & $\begin{array}{l}\text { Baudarlehen der Investitionsbank des Landes Brandenburg } \\
\text { (angenommener Förderzeitraum: } 20 \text { Jahre) } \\
\text { - bei } 5 \% \text { Eigenkapital ( } 2.050 \mathrm{DM} \text { pro qm) } \\
\text { - bei } 25 \% \text { Eigenkapital ( } 1.750 \mathrm{DM} \text { pro qm) }\end{array}$ & $\begin{array}{l}85.788 \mathrm{DM} \\
71.376 \mathrm{DM}\end{array}$ \\
\hline
\end{tabular}

1 Der Wert orientiert sich an der durchschnittlichen Umlaufsrendite börsennotierter Bundeswertpapiere in den letzten 10 Jahren. 
Übersicht 5 (Fortsetzung)

\begin{tabular}{|c|c|c|}
\hline & Art der Förderung & Barwert (70 qm) \\
\hline Bremen & $\begin{array}{l}\text { zinsloses Baudarlehen aus Bundesmitteln: } 30.000 \text { DM } \\
\text { plus zinsloses Zusatzdarlehen der Stadt Bremen: } 30.000 \text { DM } \\
\text { sowie Aufwendungszuschüsse I und II }\end{array}$ & $71.867 \mathrm{DM}$ \\
\hline Hessen & $\begin{array}{l}\text { zinsloses Baudarlehen des Landes (ab } 31 . \mathrm{Jahr}: \mathrm{i}=6 \% \text { ) } \\
\text { - Mietenstufe } 1 \text { und } 2 \text { der Anlage zur WoGV: } 1.150 \mathrm{DM} \text { pro qm } \\
\text { - Mietenstufe } 3 \text { und } 4 \text { der Anlage zur WoGV: } 1.350 \mathrm{DM} \text { pro qm } \\
\text { - Mietenstufe } 5 \text { und } 6 \text { der Anlage zur WoGV: } 1.600 \mathrm{DM} \text { pro qm }\end{array}$ & $\begin{array}{l}\text { 86.758 DM } \\
73.202 \mathrm{DM} \\
62.357 \mathrm{DM}\end{array}$ \\
\hline $\begin{array}{l}\text { Nordrhein- } \\
\text { Westfalen }\end{array}$ & $\begin{array}{l}\text { zinsloses Baudarlehen (ab 21. Jahr: Kapitalmarktzins) } \\
\text { - Mietenstufe } 1 \text { der Anlage zur WoGV: 101.500 DM } \\
\text { - Mietenstufe } 2 \text { der Anlage zur WoGV: } 101.500 \text { DM } \\
\text { - Mietenstufe } 3 \text { der Anlage zur WoGV: 108.500 DM } \\
\text { - Mietenstufe } 4 \text { der Anlage zur WoGV: } 115.500 \text { DM } \\
\text { - Mietenstufe } 5 \text { der Anlage zur WoGV: } 115.500 \text { DM }\end{array}$ & $\begin{array}{l}\text { abzügl. EAL: } \\
\text { 39.062 DM } \\
32.833 \mathrm{DM} \\
33.195 \mathrm{DM} \\
24.657 \mathrm{DM} \\
11.309 \mathrm{DM}\end{array}$ \\
\hline $\begin{array}{l}\text { Rheinland- } \\
\text { Pfalz }\end{array}$ & $\begin{array}{l}\text { zinsvergünstigtes Baudarlehen ( } 600 \mathrm{DM} \text { pro qm) der } \\
\text { Landesbank Rheinland-Pfalz; Zins- und Tilgungsbedingungen } \\
\text { je nach Einzelfall: } \\
\text { - Beispiel I: Verzinsung mit } \mathrm{i}=0,5 \% \text {; ab } 16 . \mathrm{Jahr} \text { : } \mathrm{i}=6 \% \\
\text { Tilgung: } 3 \% \text { p.a. plus ersparte Zinsen } \\
\text { - Beispiel II: Verzinsung mit } \mathrm{i}=0,5 \% \text {; ab } 16 . \mathrm{Jahr}: \mathrm{i}=3 \% \\
\text { Tilgung: } 1 \% \text { p.a.; ab 16. Jahr: } 3 \% \text { plus ersparte Zinsen }\end{array}$ & $\begin{array}{l}20.738 \mathrm{DM} \\
26.931 \mathrm{DM}\end{array}$ \\
\hline Sachsen & $\begin{array}{l}\text { MB-10-Darlehen der Sächsischen Aufbaubank } \\
\text { - Baukosten ab } 1.100 \text { bis } 1.200 \mathrm{DM} \text { pro qm: } 150 \mathrm{DM} \text { pro qm } \\
\text { - Baukosten ab } 1.900 \mathrm{DM} \text { pro qm: } 550 \mathrm{DM} \text { pro qm }\end{array}$ & $\begin{array}{l}1.762 \mathrm{DM} \\
6.461 \mathrm{DM}\end{array}$ \\
\hline Thüringen & $\begin{array}{l}\text { Baudarlehen der Thüringer Aufbaubank: } 950 \text { DM pro qm (max.) } \\
\text { - Förderdauer: } 12 \text { Jahre } \\
\text { - Förderdauer: } 24 \text { Jahre } \\
\text { oder: Baudarlehen: } 650 \text { DM pro qm (max.) } \\
\text { plus Aufwendungszuschuß } \\
\text { - Förderdauer: } 12 \text { Jahre } \\
\text { - Förderdauer: } 24 \text { Jahre }\end{array}$ & $\begin{array}{l}33.496 \mathrm{DM} \\
44.428 \mathrm{DM}\end{array}$ \\
\hline
\end{tabular}

Wie aus der Übersicht hervorgeht, nehmen zahreiche Länder eine regionale Staffelung der Darlehen vor. In Baden-Württemberg wird unterschieden nach drei Gemeindekategorien: Kategorie I umfaßt die Landeshauptstadt Stuttgart, Großstädte über 100.000 Einwohner und sonstige Gemeinden im Verdichtungsraum, zur Kategorie II zählen die großen Kreisstädte außerhalb der Verdichtungsräume einschließlich des Stadtkreises Baden-Baden und zur Kategorie III 
die übrigen Gemeinden. Nordrhein-Westfalen und Hessen differenzieren die Darlehensbeträge nach der Zugehörigkeit der Gemeinden zu den Mietenstufen gemäß Anlage 1 zu $\S 1$ Abs. 3 der Wohngeldverordnung (WoGV). Auch Bayern variiert die Fördersätze nach regionalen Mietkategorien. In Brandenburg hängt die Darlehenshöhe davon ab, welchen Eigenkapitalanteil der Investor einbringt, und in Berlin von der Aufwendigkeit der Bauausführung. Wie schon erwähnt, stellen einige Länder den Investoren mehrere unterschiedliche Förderangebote zur Auswahl (z.B. Gewährung von Aufwendungszuschüssen als Alternative zum Darlehen), die sich auch in der Dotierung unterscheiden (vgl. Kapitel 3.B.IV.b).

\section{Bezugsberechtigter Personenkreis}

Die maximal zulässigen Einkommen für den Bezug der neugeschaffenen Wohnungen fallen im Ländervergleich ebenfalls sehr unterschiedlich aus (vgl. Übersicht 6). Am meisten auf die Bezieher niedriger Einkommen konzentriert ist die EOF in Bremen: Die im Grundmodell geförderten Wohnungen dürfen nur an solche Haushalte vergeben werden, deren Einkommen die Grenze des $\S 25$ (in Verbindung mit $\S 3$ Abs. 1 BremAFWoG) zum Zeitpunkt der Wohnungsvergabe um nicht mehr als $10 \%$ überschreitet. Sehr großzügig wird dagegen in Berlin verfahren, wo die Grenze des $\S 25$ um bis zu $80 \%$ überschritten werden darf. Ansonsten haben die Länder als Einkommensobergrenze überwiegend die um 40\% (Baden-Württemberg, Schleswig-Holstein, Thüringen, Bremer Kombimodell) oder 60\% (Brandenburg, Nordrhein-Westfalen, RheinlandPfalz, Modellversuch in Wolfsburg) erhöhten Werte des $§ 25$ angesetzt.

Bei den modernisierten Bestandswohnungen in Sachsen gelten keine Einkommensgrenzen, da die Wohnungen nicht neuzubelegen sind und die Bewilligung der Grundförderung unabhängig vom Einkommen der aktuellen Mieter erfolgt. Dagegen sollen in Bremen die nach dem „Modell 1+3“ modernisierten Bestandswohnungen zugunsten von Haushalten neubelegt werden, deren Einkommen die Grenze des $\S 25$ (i.V.m. § 3 Abs. 1 BremAFWoG) um nicht mehr als $10 \%$ überschreitet. Beim Kombimodell gilt für die mittelbar gebundenen Bestandswohnungen eine besonders niedrige Einkommensgrenze (die Werte des $\S 25$ i.V.m. § 3 Abs. 1 BremAFWoG werden um 10\% abgesenkt), damit die Preisvorteile dieser Wohnungen ausschließlich den sozial Schwachen zugute kommen. 
Übersicht 6: Höchstzulässige Überschreitung der Einkommensgrenze nach § 25 II. WoBauG

\begin{tabular}{|c|c|c|c|c|c|}
\hline & Bremen & Bayern & $\begin{array}{l}\text { B.-Württemberg, } \\
\text { Schl.-Holstein, } \\
\text { Thüringen }\end{array}$ & $\begin{array}{c}\text { Rheinland-Pfalz, } \\
\text { Brandenburg } \\
\text { Nordrhein-W. }\end{array}$ & Berlin \\
\hline & \multicolumn{5}{|c|}{ Einkommensgrenze nach $\S 25$ II. WoBauG ... } \\
\hline & $+10 \%$ & $+30 \%$ & $+40 \%$ & $+60 \%$ & $+80 \%$ \\
\hline & \multicolumn{5}{|c|}{$\begin{array}{l}\text { Entsprechendes Brutto-Jahreseinkommen eines Arbeiter- bzw. } \\
\text { Angestelltenhaushaltes (eine Erwerbsperson) }\end{array}$} \\
\hline eine Person & $38.143 \mathrm{DM}$ & 44.714 DM & $48.000 \mathrm{DM}$ & $54.571 \mathrm{DM}$ & $61.143 \mathrm{DM}$ \\
\hline 2 Personen & $54.486 \mathrm{DM}$ & $64.029 \mathrm{DM}$ & $68.800 \mathrm{DM}$ & $78.343 \mathrm{DM}$ & $87.886 \mathrm{DM}$ \\
\hline 3 Personen & $67.057 \mathrm{DM}$ & $78.886 \mathrm{DM}$ & $84.800 \mathrm{DM}$ & $96.629 \mathrm{DM}$ & $108.457 \mathrm{DM}$ \\
\hline 4 Personen & $79.629 \mathrm{DM}$ & $93.743 \mathrm{DM}$ & $100.800 \mathrm{DM}$ & $114.914 \mathrm{DM}$ & $129.029 \mathrm{DM}$ \\
\hline junges Ehepaar & $65.914 \mathrm{DM}$ & $75.457 \mathrm{DM}$ & $80.229 \mathrm{DM}$ & $89.771 \mathrm{DM}$ & $99.314 \mathrm{DM}$ \\
\hline
\end{tabular}

\section{Bindungsdauer}

Mit einem Durchschnitt von 15 bis 20 Jahren fällt die Bindungsdauer der einkommensorientiert geförderten Wohnungen aufs Ganze gesehen deutlich niedriger als im ersten Förderweg aus. Besonders kurze Bindungszeiträume von nur zehn Jahren kennzeichnen die Förderung mit OS-10-Darlehen in BadenWürttemberg und die Modernisierungsförderung des Landes Sachsen. Langfristig gebunden sind die Wohnungen in Bremen (25 Jahre), Hessen (mindestens 30 Jahre) und beim Modellversuch in Wolfsburg (35 Jahre). Eine Besonderheit der Berliner EOF besteht darin, daß die Dauer der Mietpreisbindung davon abhängig ist, welcher Einkommenskategorie die Mieter am Ende des 15jährigen Regelbindungszeitraumes angehören. Die vertraglich vereinbarten Mietbegrenzungen enden für Mieter, die die Grenze des $\S 25$ einhalten, erst nach 27 Jahren ab Bezugsfertigkeit, für Mieter, deren Einkommen die Grenze um bis zu $20 \%$ überschreitet, nach 22 Jahren, für Mieter mit noch höheren Einkommen, die um bis zu 60\% über der Grenze liegen, nach 17 Jahren und für die übrigen Mieter unmittelbar nach 15 Jahren. Auch in Thüringen muß der Inve- 
stor mit einer nachträglichen Verlängerung der Bindungsdauer rechnen. Der gesamte Bindungszeitraum kann dort - je nach Ermessen der zuständigen Stelle - zwischen zwölf und 24 Jahren liegen.

\section{Höhe der Basismieten}

Die durch die Grundförderung subventionierten Basismieten sollen sich überwiegend am unteren Rand der ortsüblichen Vergleichsmieten orientieren. Einige Länder haben sehr detaillierte Regelungen über die höchstzulässige Anfangsmiete (pro qm) und ihre Dynamisierung getroffen. Dies gilt unter anderem für Baden-Württemberg: In den Verwaltungsvorschriften des Landes zum Landeswohnungsbauprogramm werden die im 1. Jahr höchstzulässigen Nettokaltmieten - so wie die Darlehensbeträge bei der Grundförderung - nach Gemeindeklassen gestaffelt. Für nach 1994 geförderte Objekte betragen sie in Stuttgart 14 DM, in anderen Großstädten 13,50 DM, in den sonstigen Gemeinden der Kategorie I (Verdichtungsraum) 13 DM, in Gemeinden der Kategorie II 12 DM und in solchen der Kategorie III 11 DM. Das Land Nordrhein-Westfalen nimmt - ebenfalls wie bei der Grundförderung - eine Differenzierung nach Mietenstufen gemäß WoGV ${ }^{1}$ vor. Für den ersten Förderjahrgang 1996 mit Bezugsfertigkeit im Zeitraum 1997/98 betragen die im Bewilligungsbescheid höchstens festzulegenden Anfangsmieten $11 \mathrm{DM}$ in Mietenstufe 1, $12 \mathrm{DM}$ in Mietenstufe 2, $13 \mathrm{DM}$ in Mietenstufe 3, $15 \mathrm{DM}$ in Mietenstufe 4 und $17 \mathrm{DM}$ in Mietenstufe 5 (unter Einschluß von Köln). In Bremen lagen die Basismieten im Förderjahr 1995 je nach Wohnungsgröße bei 11,40 DM (unter 60 qm), 10,90 DM (ab $60 \mathrm{qm}$ bis unter $80 \mathrm{qm}$ ) und 10,60 DM (ab 80 qm). Für 1996 und 1997 sind die Anfangsmieten jeweils um 0,30 DM angehoben worden. Beim Einzelvorhaben in Wolfsburg beträgt die Vertragsmiete bei Erstvermietung 11,50 DM, in Brandenburg allgemein sowie beim Modellversuch in Cottbus werden 11,35 DM angesetzt. Das Land Berlin hat als Eckwert für die höchstzulässige Anfangsmiete den Betrag von 15 DM festgelegt, an den die Bewilligungsstelle jedoch nicht gebunden ist. In Bayern sind die Bewilligungsstellen gehalten, sich am unteren Rand der ortsüblichen Erstvermietungsmiete zu orientieren, in Rheinland-Pfalz soll die Basismiete der ortsüblichen Vergleichsmiete entsprechen. Auch Thüringen gibt den zuständigen Stellen als Richtwert die ortsübliche Vergleichsmiete vor, daneben ist eine Obergrenze von 13 DM bzw. - in Städten mit mehr

\footnotetext{
Bei Objekten, die nach den 1996 ergangenen Bestimmungen gefördert werden, richtet sich die Zuordnung der Gemeinden zu den einzelnen Mietenstufen nach der Anlage § 1 Abs. 3 WoGV i.d.F. der Bekanntmachung vom 30. September 1992 (BGBl. I S. 1686). Die WoGV nimmt eine Differenzierung nach sechs Mietstufen vor. Die Förderbestimmungen für Nordrhein-Westfalen kommen mit fünf Stufen aus, da keine Gemeinden des Landes der sechsten Stufe zugeordnet ist.
} 
als 50.000 Einwohnern - von 14 DM festgesetzt worden. In Hessen wird die Basismiete von der Kommune in Abstimmung mit dem Land festgelegt. Die Mietsätze orientieren sich an den Höchstmieten im hessischen Mietwohnungsprogramm. Nach den Förderbestimmungen für Sachsen ist die Basismiete aus den mietrechtlichen Bestimmungen zur Modernisierungsumlage nach $\S 13$ MHG zu ermitteln. Zusätzlich hat das Land baukostenabhängige Obergrenzen von 9 bis $13 \mathrm{DM}$ festgelegt. In Schleswig-Holstein (9,20 DM bis $13 \mathrm{DM})$, beim Bremer Kombimodell (7,29 DM bis 13,60 DM) und bei den zusätzlich modernisierten Bestandswohnungen im „Modell 1+3“ (8,70 DM bis $12 \mathrm{DM})$ werden die Mietverträge über die einkommensabhängigen Mietermieten abgeschlossen.

Neben den höchstzulässigen Anfangsmieten haben die meisten Länder auch Kappungsgrenzen für spätere Mietanhebungen festgelegt. Betragsmäßig konkretisiert ist die Kappungsgrenze in Baden-Württemberg (alle zwei Jahre plus 0,60 DM), Berlin (im Regelbindungszeitraum plus 0,40 DM im Abstand von 15 Monaten), Bremen (jährlich plus 0,30 DM), Sachsen (alle drei Jahre plus 0,50 DM) sowie in Brandenburg (alle drei Jahre plus 0,75 DM). Prozentuale Obergrenzen für die Mietanhebungen sehen die Förderbestimmungen für NordrheinWestfalen (Erstbelegungsmiete plus maximal 2\% jährlich), Rheinland-Pfalz (jährlich bis 3\%). In Bayern dürfen die Mietanhebungen nicht über den unteren Rand der ortsüblichen Vergleichsmiete hinausgehen. Nach den Bestimmungen für Schleswig-Holstein ist der Anstieg der einkommensabhängigen Vertragsmieten auf 7,5\% innerhalb von drei Jahren begrenzt.

\section{Art und Auszahlung der Zusatzförderung}

Als Auszahlungsmodus für die Zusatzförderung bevorzugen die meisten Bundesländer die Zuschußgewährung an den Mieter. Davon abweichend wird die Zusatzförderung im Bremer Grundmodell und beim Pilotobjekt in Wolfsburg als Zuschuß an den Vermieter mit schuldbefreiender Wirkung für den Mieter gezahlt, wobei die Wolfsburger Variante die Besonderheit aufweist, daß die Mittel zum Teil durch Einbußen bei der Eigenkapitalrendite des Investors ${ }^{1}$ aufgebracht werden. In Schleswig-Holstein werden die Investoren durch eine Anpassung der Darlehenszinssätze dafür entschädigt, daß sie mit den geförderten Haushalten einkommensabhängige Vertragsmieten abschließen. NordrheinWestfalen gewährt die Zusatzförderung als Forderungsverzicht gegenüber dem Vermieter: Dieser erhält zunächst eine Förderung bis zur Mindestmiete und wird verpflichtet, regional unterschiedliche ,einkommensabhängige Leistungen" an die Wohnungsbauförderungsanstalt NRW (WBFA) zu entrichten. Je nach Einkommen, Haushaltsgröße und Region verzichtet die WBFA ganz oder

1 Bauherr ist eine Wohnungsgesellschaft, die sich mehrheitlich in städtischer Hand befindet. 
teilweise auf Abführung dieser Leistungen. Die Vermieter sind verpflichtet, den Mietern in Höhe dieses Verzichts einen Mietnachlaß zu gewähren. Eine ähnliche Vorgehensweise plant die Stadt Frankfurt für ihr Pilotmodell. In BadenWürttemberg schließlich bleibt es den zuständigen Stellen überlassen, ob sie die Zusatzförderung als Zuschuß an den Mieter oder Vermieter gewähren. Auch können sie als Zwischenmieter der geförderten Wohnungen auftreten. In der Förderpraxis des Landes dominiert die Auszahlung an den Mieter; für das Modell mit Zwischenmietung haben sich die Kommunen Fellbach und Rutesheim entschieden.

\section{Höhe der Zusatzförderung}

Die Höhe der Mietvergünstigungen hängt i.d.R. vom Gesamteinkommen nach § 25 II. WoBauG und mitunter auch vom regionalen (Basis-)Mietniveau ab. Zahlreiche Länder nehmen - wie bei der Fehlbelegungsabgabe üblich - eine Staffelung nach der prozentualen Über- bzw. Unterschreitung der Einkommensgrenze des § 25 II. WoBauG vor. Wie in Übersicht $7 \mathrm{zu}$ sehen, werden die Vergünstigungen pro $\mathrm{qm}$ in den betreffenden Ländern mit steigendem Einkommen schrittweise zurückgeführt (vgl. auch Kapitel 3.C.III.d). Die Höhe der Zuschüsse ist von der Dynamisierung der Basismiete unabhängig.

Eine feinere Differenzierung der Fördersätze als die in der Übersicht vertretenen Länder nimmt Sachsen vor. Die Zahlungen werden aus einem nach der Haushaltsgröße aufgegliederten Tabellensystem ermittelt, in dem landesweit einheitliche „tragbare“ Endmieten aufgeführt sind. In Rheinland-Pfalz, wo die Zusatzförderung ebenfalls anhand von Tabellen bestimmt wird, sollen die $\mathrm{Zu}-$ schüsse zu einer für alle Mieterhaushalte annähernd gleichen Prozentualbelastung des Gesamteinkommens (Mietbegriff nach Wohngeldrecht) von ca. 23\% führen. Allerdings sind die Mietzuschüsse nach oben begrenzt, so daß im Bereich niedriger Einkommen auch höhere Belastungsquoten auftreten können.

Auf eine Pauschalquote von Miete und Einkommen herabsubventioniert werden die Wohnkosten auch beim Möglinger Modell ${ }^{1}$, das in Baden-Württemberg einen Sonderfall darstellt, da die Zusatzförderung ausschließlich von der Gemeinde aufgebracht wird und daher unabhängig von den Landesvorgaben ausgestaltet werden konnte. Die Zielsetzung des Modells besteht darin, die Wohnkostenbelastung des Mieters auf 20\% des Brutto-Gesamteinkommens abzusenken. Dabei wird so vorgegangen, daß der Mieter einen Wohngeldantrag stellt

1 Zur Ausgestaltung des Modells vgl. Neise, H. (o.J., 1994). 
Übersicht 7: Höhe der Zusatzförderung in ausgewählten Ländern

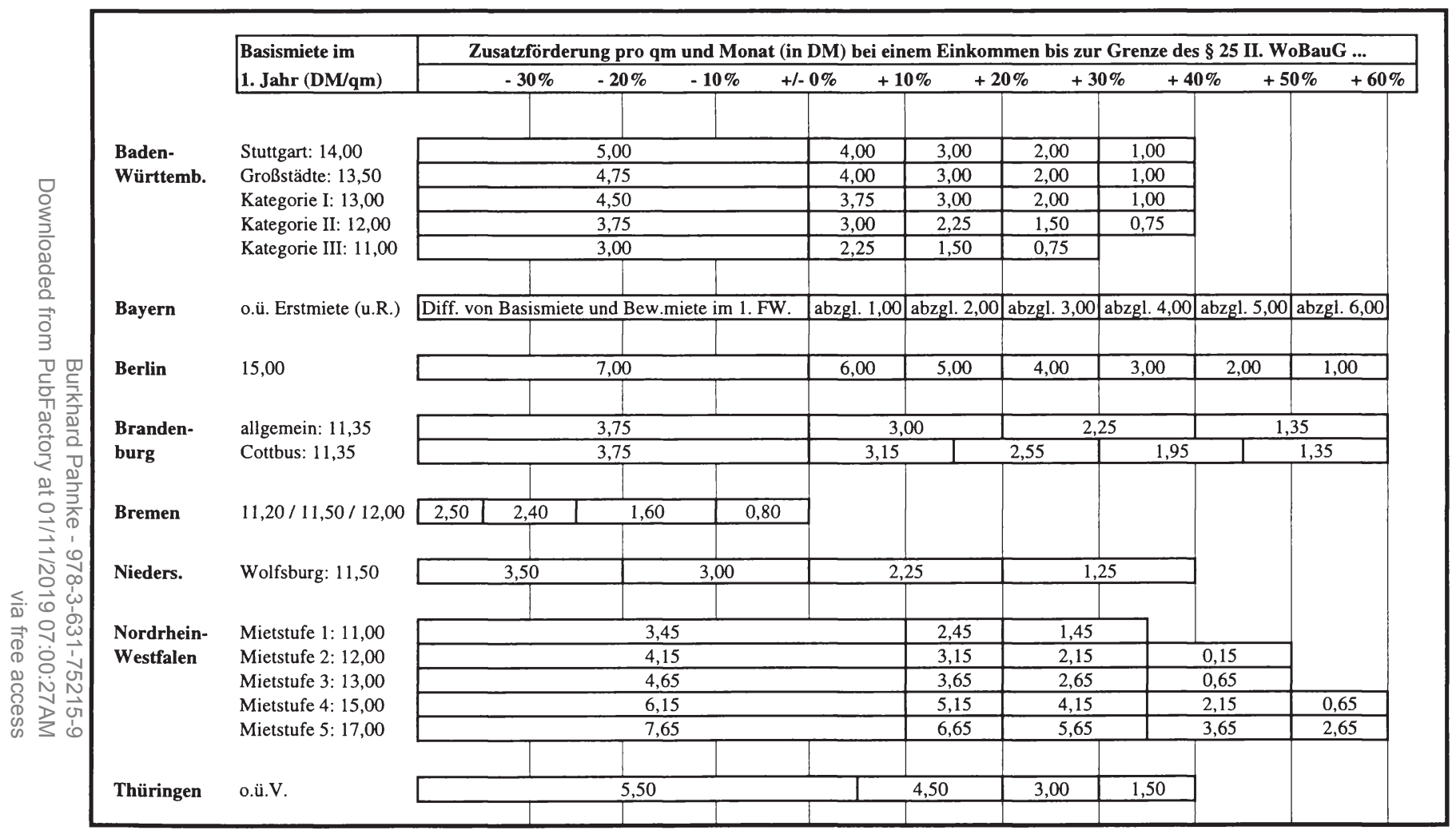


und die Gemeinde den zur Erreichung der 20-\%-Quote noch fehlenden Betrag (vorweg im Hinblick auf $\S 7$ Abs. 2 WoGG) als Zusatzförderung zuschießt. ${ }^{1}$

Nicht näher bestimmt ist die Höhe der Zusatzförderung in Hessen. Dort haben die Kommunen in Anlehnung an die Einstiegsmiete im ersten Förderweg eine Mindestmiete festzulegen, die mit dem Land abzustimmen ist. Die Basismiete und die Mindestmiete bilden die Eckwerte für eine Tabelle zur individuellen einkommensorientierten Mietabstufung, die ebenfalls mit dem Land abgestimmt werden muß und Bestandteil der Fördervereinbarung ist.

Bei den Fördervarianten, die eine einkommensabhängige Gestaltung der Vertragsmieten vorsehen (Schleswig-Holstein, Bremer Kombimodell) besteht die Schwierigkeit einer Differenzierung nach Grund- und Zusatzförderung. Der Einkommensbereich mit maximaler Zusatzförderung bis zur Mindestmiete endet in den meisten Bundesländern erst bei Erreichen der Einkommensgrenze des $\S 25$ oder sogar leicht oberhalb davon. Nur in Bremen (Einkommensgrenze minus 35\%) und Sachsen (minus 20 bis 30\%), sowie bei den Objekten in Wolfsburg (minus 20\%) und Möglingen (wohngeldabhängig) setzt der Abbau der Zusatzförderung schon bei geringeren Einkommen ein. Eingestellt werden die Zahlungen überwiegend bei Überschreiten der um $40 \%$ oder $60 \%$ erhöhten Einkommensgrenze. Deutlich nach unten weichen davon wiederum die Länder Bremen (plus 10\%) und Sachsen ab. In Sachsen richtet sich die Einkommensobergrenze für die Zuschüsse nach der Höhe der Basismiete. Beim Möglinger Modell ist diese Grenze ebenfalls einzelfallabhängig und kann mitunter sogar unterhalb der Werte des $§ 25$ liegen.

\section{Kommunale Mitfinanzierung}

Werden die Kommunen in die Förderung eingebunden, so erfolgt dies i.d.R. in Form einer Beteiligung an der Zusatzförderung. In Baden-Württemberg haben die Gemeinden die Hälfte der Mietvergünstigungen beizusteuern, bei den Pilotobjekten von 1993 und 1994 betrug der kommunale Anteil sogar zwei Drittel. Für die Finanzierung der Zusatzförderung alleinzuständig sind die Kommunen in Brandenburg und Hessen, ferner beim Möglinger Modell und beim Pilotob-

1 Aufgrund von $\S 7$ Abs. 2 WoGG ist es nicht möglich, die Zusatzförderung nachrangig in bezug auf das Wohngeld zu gewähren (vgl. Kapitel 2.C.III). Trotzdem wird zunächst der Wohngeldanspruch des geförderten Haushaltes und dann erst die zur Erreichung der 20\%Quote noch fehlende Zusatzförderung ermittelt. Um Verstöße gegen $§ 7$ Abs. 2 WoGG zu vermeiden, achtet die Gemeinde darauf, daß die Endmiete nicht unter die Höchstbeträge der nach Wohngeldrecht berücksichtigungsfähigen Miete herabsubventioniert wird, so daß die Höhe des Wohngeldanspruchs unberührt bleibt. Die Kommune will damit zugleich vermeiden, daß Bund und Länder infolge der kommunalen Zuschüsse Wohngeld einsparen. 
jekt in Wolfsburg (plus Beteiligung der mehrheitlich städtischen Wohnungsbaugesellschaft). In Schleswig-Holstein haben sich die Kommunen mit einem einkommensabhängig verzinslichen Darlehen in Höhe von mindestens $10 \%$ der Gesamtkosten an der Förderung zu beteiligen. Das Land Thüringen bestreitet die Zusatzförderung zwar aus seinen Haushaltsmitteln, erwartet aber eine spätere Beteiligung der Gemeinden. In Bayern ist eine kommunale Mitfinanzierung der Zusatzförderung in den Fördergrundsätzen des Landes zwar nicht vorgesehen, wird aber von den Kommunen praktiziert. Nur selten sind die Gemeinden über Zusatzdarlehen auch an der Grundförderung beteiligt (Bremen, SchleswigHolstein, Pilotobjekt in Wolfsburg). Ganz ohne kommunale Mittel wird die EOF in Nordrhein-Westfalen, Rheinland-Pfalz und Sachsen erbracht.

\section{Periodizität der Einkommensprüfung}

Die Einkommensprüfungen und entsprechenden Neufestsetzungen der Zusatzförderung werden in Bayern, Rheinland-Pfalz, Sachsen und im Möglinger Modell wie beim Wohngeld in einem zeitlichen Rhythmus von zwölf Monaten vorgenommen. In Baden-Württemberg, Brandenburg, und beim Wolfsburger Modellversuch betragen die Regelbewilligungszeiträume zwei, in Hessen mindestens zwei Jahre. Noch großzügiger fallen die Bestimmungen für Berlin und Thüringen mit einem dreijährigen und Bremen mit einem vierjährigen Anpassungsrhythmus aus. In Nordrhein-Westfalen erfolgen Einkommensprüfungen erstmals zum 1. Juli des fünften Jahres nach dem Kalenderjahr, in dem der Bewilligungsbescheid an den Investor erteilt worden ist, und danach im Abstand von drei Jahren. Oft steht es den zuständigen Stellen der Länder frei, die Zusatzförderung bei mehr als nur geringfügigen Änderungen der Einkommensverhältnisse bereits vor Ablauf des Regelbewilligungszeitraumes neu festzusetzen (vgl. Kapitel 3.C.III.c). 
Burkhard Pahnke - 978-3-631-75215-9

Downloaded from PubFactory at 01/11/2019 07:00:27AM

via free access 


\section{Teil: Analyse der einkommensorientierten Förderung}

\section{A. Die EOF im Vergleich zur klassischen Wohnungsbauförderung}

\section{Fiskalische Entlastung durch die Abkehr vom Kostenmietprinzip}

Als Unterfall der vereinbarten Förderung ist die EOF durch die Abkehr vom Kostenmietprinzip gekennzeichnet. Wie im folgenden gezeigt werden soll, lassen sich dadurch Mittel einsparen, ohne daß die Förderung für die Investoren unattraktiv wird. Bei Anwendung des Kostenmietprinzips deckt die Subvention idealtypisch den gesamten Unterschiedsbetrag zwischen der Sozialmiete und den sich ohne die Förderung ergebenden laufenden Aufwendungen aus Kapitalund Bewirtschaftungskosten ab. Diese liegen in den ersten Jahren i.d.R. deutlich über dem Niveau der Marktmiete, der Investor müßte daher ohne die öffentlichen Mittel zunächst Verluste hinnehmen. Solche Verluste sind im freifinanzierten Wohnungsbau aber der Regelfall. ${ }^{1}$ Ihnen stehen Steuerersparnisse, Wertsteigerungen der Immobilie und Ertragszuwächse durch den allgemeinen Mietenanstieg gegenüber, so daß trotz der anfänglichen Kostenunterdeckung hinlängliche Renditen erzielbar sind.

Steuerersparnisse resultieren daraus, daß die in den Anfangsjahren üblichen negativen Einkünfte aus Vermietung und Verpachtung gegen andere positive Einkünfte des steuerpflichtigen Investors aufgerechnet werden können, wobei die Höhe der Entlastungen positiv vom individuellen Grenzsteuersatz abhängt. Von besonderer Bedeutung sind in dieser Phase die erhöhten Abschreibungen. „Bereits die steuerliche Normalabschreibung von $2 \%$ nach § 7 Abs. 4 EStG geht über den wirtschaftlichen Werteverschleiß im allgemeinen hinaus, da die meisten Wohnobjekte eine längere Lebensdauer als 50 Jahre haben." ${ }^{2}$ Dies gilt noch mehr für die erhöhte Abschreibung nach $\S 7$ Abs. 5 EStG: Die Sätze betragen bei Gebäuden, für die ein Bauantrag nach dem 28. Februar 1989 und vor dem 1. Januar 1996 gestellt worden ist, 7\% im Jahr der Fertigstellung und den folgenden drei Jahren, 5\% im 5. bis 10. Jahr, 2\% im 11. bis 16. Jahr und 1,25\% im 17. bis 40. Jahr. Ist der Bauantrag erst am 1. Januar 1996 oder später gestellt worden, dürfen im Jahr der Fertigstellung und den folgenden sieben Jahren 5\%, im 9. bis 14. Jahr 2,5\% und im 15. bis 50. Jahr 1,25\% abgeschrieben werden. Der Vorteil der erhöhten Abschreibung besteht für die Investoren darin, daß sie durch die zeitliche Vorverlagerung der Verluste einen zinslosen Steuerkredit erhalten. Private Bauherrn, die ihr steuerpflichtiges Einkommen nicht anhand einer Bilanz ermitteln, können durch rechtzeitige Veräußerung der Immobilie

\footnotetext{
1 Vgl. Oberhauser, A. (1993), S. 3f. und Schaubild 1; Laux, H. (1993). 
sogar erreichen, daß die Steuerstundung zu einer endgültigen Steuerersparnis wird. Handeln sie rational, werden sie das Objekt verkaufen, bevor die Nachholwirkung der erhöhten Abschreibung eintritt. ${ }^{1}$ Bilanzierungspflichtige Unternehmen können beim Verkauf der Immobilie die Nachholwirkung hinauszögern, indem sie von der Regelung des $\S 6$ b EStG Gebrauch machen, wonach Gewinne aus Veräußerungen von Grund und Boden sowie Gebäuden i.d.R. nicht sofort zu versteuern sind, sondern bei der Bilanzierung in voller Höhe auf gleichartige neu erworbene Wirtschaftsgüter durch Abzug von den Anschaffungs- oder Herstellungskosten übertragen werden können. Der wirtschaftliche Vorteil dieser Bestimmung liegt wiederum in der Gewährung eines zinslosen Steuerkredits.

Neben steuerlichen Begünstigungen haben die Investoren auch Einnahmensteigerungen wegen des allgemeinen Mietenanstiegs. In den vergangenen Jahrzehnten sind die Mieten in Westdeutschland im Durchschnitt nicht nur nominal, sondern auch real gestiegen. So lag der mittlere Anstieg der Wohnungsmieten in Westdeutschland zwischen 1970 und 1995 bei 4,3\%, während die Preise für die Lebenshaltung im gleichen Zeitraum um durchschnittlich 3,6\% gestiegen sind. $^{2}$ Die langfristige Mietentwicklung ist auf der Nachfrageseite vor allem durch die mit dem allgemeinen Realeinkommensanstieg gewachsenen Ansprüche an die Quantität und Qualität der Wohnraumversorgung gekennzeichnet. Zugenommen hat die Wohnungsnachfrage außerdem aufgrund der immer stärkeren Individualisierung, die sich in einer steigenden Zahl von Haushalten äuBert. Zugleich hat sich der überdurchschnittliche Anstieg der Bau- und Grundstückskosten hemmend auf das Wohnungsangebot ausgewirkt. Von der Kostenentwicklung sind vor allem die zum betrachteten Zeitpunkt neu errichteten Objekte, mittelbar aber auch die Wohnungen aus dem Bestand betroffen, deren Mieten wegen der Wohnungsknappheit ebenfalls steigen. Sofern Preisunterschiede zwischen Wohnungen unterschiedlicher Baujahrgänge bestehen bleiben, dürften diese in erster Linie auf Unterschiede in Qualität und Lage der Wohnung zurückzuführen sein. ${ }^{3}$

1 Ein günstiger Zeitpunkt für den Verkauf ist gegeben, wenn die Differenz zwischen der Abschreibungssumme bei degressiver und normaler Abschreibung ihren Höchstwert annimmt. Dies ist bei den vor 1996 genehmigten Wohngebäuden im 11. bis 16. Jahr (Differenz in Höhe von 38\% der abschreibungsfähigen Bausumme) und bei den nach 1995 genehmigten Wohngebäuden im 15. Jahr nach der Fertigstellung der Fall (Differenz in Höhe von 27\%).

2 Die Prozentwerte wurden vom Verfasser auf der Basis von Daten des Statistischen Bundesamtes berechnet. Sie beziehen sich auf die Bruttokaltmieten.

3 Hinzu kommt, daß kontinuierlich qualitativ hochwertige Neubauwohnungen mit überdurchschnittlichem Mietpreisniveau dem Angebot zugeführt werden, während preisgünstige ältere Wohnungen mit unterdurchschnittlichem Qualitätsstandard wegen Abriß oder Modernisierung aus dem Angebot ausscheiden. Der allgemeine Mietenanstieg wird durch 
Die Investoren im Wohnungsbau beziehen ferner die Entwicklung des Vermögenswertes der Immobilie in ihre Kalkulation ein. Sie können damit rechnen, bei Veräußerung des Objekts einen über die nominalen Anschaffungskosten meist weit hinausgehenden Preis zu erzielen. Im Regelfall treten wegen der ständig wachsenden Nachfrage nach Bauland sogar reale Wertsteigerungen ein. So lag der durchschnittliche Anstieg der Kaufpreise für baureifes Land im alten Bundesgebiet zwischen 1975 und 1990 bei 7,15\%. Preistreibend wirkt auch der reale Baukostenanstieg. Dieser wird durch den Preisindex für Wohngebäude (Bauleistungen am Bauwerk) dokumentiert, der im gleichen Zeitraum einen durchschnittlichen Zuwachs von 4,18\% ausweist. ${ }^{1}$

Die Steuervergünstigungen, Wertzuwächse und Mietpreissteigerungen kommen den Bauherren teilweise auch bei einer Investition im ersten Förderweg zugute. So können steuerpflichtige Investoren trotz Anwendung des Kostenmietprinzips negative Einkünfte aus Vermietung und Verpachtung vor allem wegen der erhöhten, über den Ansatz in der Wirtschaftlichkeitsberechnung hinausgehenden steuerlichen Abschreibung nach $\S 7$ Abs. 5 EStG geltend machen und profitieren außerdem von den steuerlichen Regelungen im Zusammenhang mit den Veräußerungsgewinnen. Auch ist bei den Sozialwohnungen - selbst wenn man eine überdurchschnittliche Abnutzung unterstellt - von (zumindest) nominalen Wertsteigerungen auszugehen. Behalten die Investoren das Objekt in ihrem Vermögensbestand, so können sie ihre Mietforderungen nach dem Auslaufen der Bindungen an das ortsübliche Niveau anpassen und so - wenn auch erst spät - von dem allgemeinen Mietenanstieg profitieren.

Die Überlegungen zeigen, daß die Vollförderung bis zur Kostenmiete gerade bei Investoren mit hohen Grenzsteuersätzen zu großzügig ausfällt. Bei der EOF sind die Förderbeträge dagegen niedriger angesetzt. Wie in Diagramm 1 verdeutlicht werden soll, fördert der Staat nur bis zu einem unterhalb der Kostenmiete liegenden Betrag (Fördergrenze). Der Investor erhält im Förderzeitraum mit einer angenommenen Dauer von 15 Jahren die vom Mieter aufzubringende Sozialmiete und darüber hinaus die Grund- und Zusatzförderung. Diese Einnahmen reichen nicht aus, um - wie im ersten Förderweg - den gesamten Unterschiedsbetrag zwischen der Kostenmiete und der Sozialmiete abzudecken. Bei der graphischen Darstellung wird davon ausgegangen, daß die Dynamisierung der Basismieten durch eine entsprechende Degression der Grundförderung ausgeglichen wird, so daß die Summe aus Mieteinnahmen und Förderung konstant bleibt. Die im Förderzeitraum realisierte Einsparung gegenüber dem ersten För-

diese Umwälzung in der Angebotsstruktur zugunsten besser ausgestatteter Wohnungen noch verstärkt.

I Berechnungen auf der Basis von Daten des Statistischen Bundesamtes. 
derweg entspricht - wenn man steuerliche Aspekte ausklammert und von gleich hohen Sozialmieten ausgeht - dem dunkel markierten Bereich.

Diagramm 1: Einsparungen bei der EOF durch die Abkehr vom Kostenmietprinzip

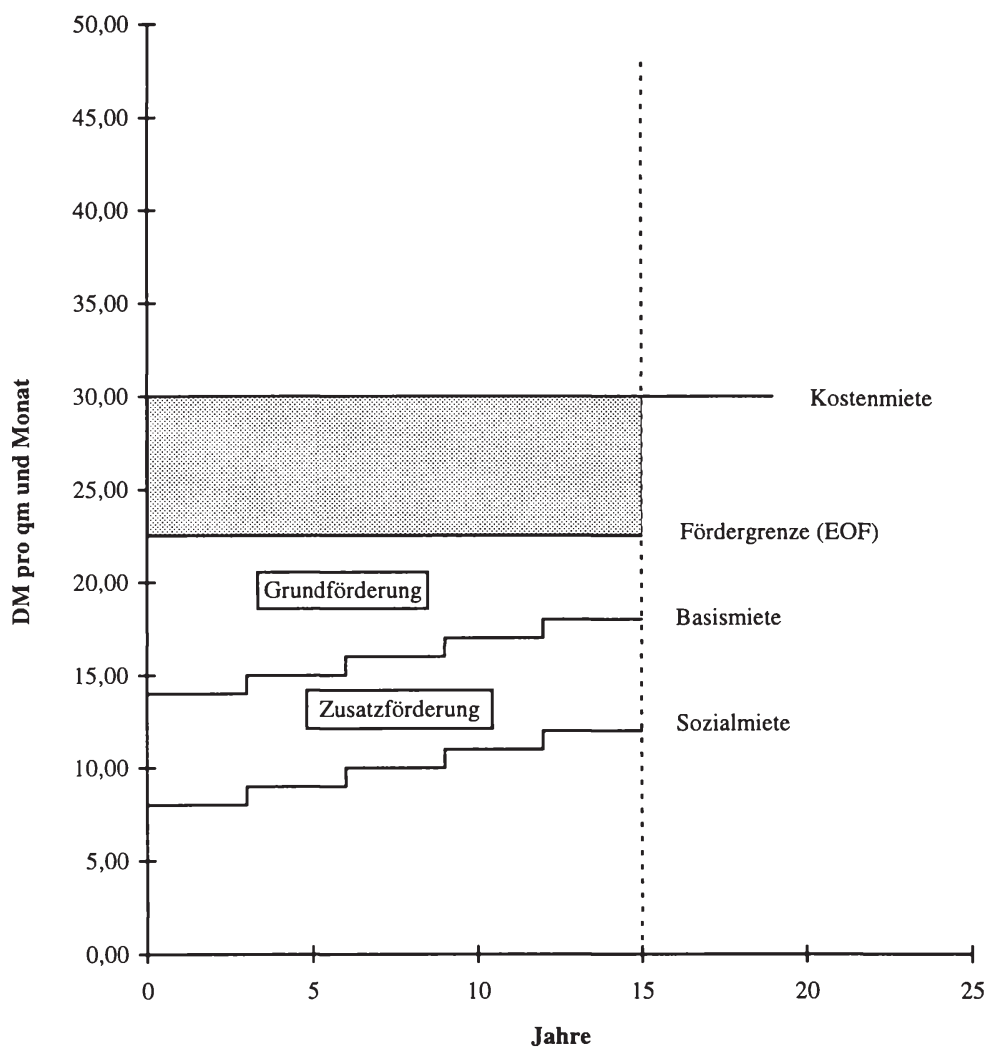


Berücksichtigt man auch steuerliche Unterschiede, ist die EOF zwar immer noch die kostengünstigere Alternative, doch fallen die fiskalischen Vorteile gegenüber der herkömmlichen Förderung nun geringer aus. Während nämlich der Investor im ersten Förderweg - von der erhöhten Abschreibung nach $\S 7$ Abs. 5 EStG sei hier abgesehen - wegen der Vollförderung bis zur Kostenmiete keine Verluste aus Vermietung und Verpachtung geltend machen kann, ist diese Möglichkeit wegen der niedrigeren Fördersätze bei der EOF gegeben. Die Mindereinnahmen des Staates entsprechen dem Unterschiedsbetrag zwischen Kostenmiete und Fördergrenze, multipliziert mit dem individuellen Grenzsteuersatz des Investors. Dabei wird vorausgesetzt, daß der Bauherr die Verluste in voller Höhe mit steuerpflichtigen Einkünften verrechnen kann. Zu beachten ist aber, daß seine Verluste aus Vermietung und Verpachtung und damit auch die Steuerausfälle für den Staat ohne die Förderung im Rahmen des sozialen Wohnungsbaues i.d.R. noch höher wären. Bei der Berechnung der Nettokosten des sozialen Wohnungsbaues müssen daher die steuerlichen Mindereinnahmen subtrahiert werden, die ohne die Förderung eingetreten wären.

Durch die Abkehr vom Kostenmietprinzip wird auch die Anwendung von Förderpauschalen erleichtert, denn die Bewilligungsstellen müssen nun nicht mehr baukostenabhängig fördern. „Durch Förderpauschalen wird der Subventionswert je Förderungsfall begrenzt, d.h. die Förderung bezieht sich nur auf einen bestimmten Kostenbetrag des Förderobjekts. Die Förderpauschalen wirken mittelbar auf die Kosten des sozialen Wohnungsbaues. Die von der Förderpauschale nicht erfaßten Kosten muß der Bauherr selbst tragen. "' Zwar sind die hohen Kosten im sozialen Wohnungsbau nach Auffassung des Gesetzgebers teilweise auf Ursachen zurückzuführen, die vom Bauherrn nicht beeinflußt werden können. Zu nennen sind die gesetzlich vorgegebenen Anforderungen des Bauordnungsrechts, des städtebaulichen Planungsrechts, des Energie-, Immissionsschutz-, Abfall-, Wasser-, Naturschutz- und Denkmalschutzrechts, sowie die unter sozialen Gesichtspunkten vorzunehmenden Standardverbesserungen (z.B. barrierefreies oder familiengerechtes Bauen). „Dennoch bestehen in der Förderpraxis Spielräume zur Kostensenkung, u.a. durch sparsame Grundrißplanung und durch Rationalisierung des Bauverfahrens und der Organisation des Bauablaufs. Die Investoren nutzen die bestehenden Möglichkeiten zum kostengünstigen Bauen jedoch vielfach nicht aus. “2 Bei der EOF sollen die Anreize zur Ausnutzung der Einsparungspotentiale erhalten bleiben, indem die Objektförderung überwiegend in Form von Festbeträgen gewährt und auf Nachsubventionierungen verzichtet wird.

1 Deutscher Bundestag (1994a), S. 21.

2 Deutscher Bundestag (1994a), S. 20. 


\section{Kurzfristige Einsparungen durch eine geringere Förderdauer}

Wegen der im Vergleich zum ersten Förderweg überwiegend kürzeren Bindungen einkommensorientiert geförderter Wohnungen können die Investoren die Mieten bereits zu einem früheren Zeitpunkt an das Niveau der Marktmiete heranführen und gegebenenfalls eine Neubelegung mit Mietern ihrer Wahl vornehmen. Sie werden sich daher auch mit einer geringeren Subvention zufriedengeben, so daß die Förderung - bezogen auf die einzelne Wohnung - geringer ausfallen kann. Ob durch die Verkürzung der Förder- und Bindungszeiträume auch die Fördereffizienz gesteigert wird, ist dagegen fraglich. Denn je früher die Bindungen auslaufen, desto eher muß der Staat eine Anschlußförderung vornehmen, wenn er den Sozialwohnungsbestand aufrechterhalten will. ${ }^{1}$

$\mathrm{Da}$ es infolge der verkürzten Bindungen zu Mehraufwendungen kommen kann, läßt sich anhand einer Modellrechnung am Beispiel der Stadt Karlsruhe zeigen. Dabei wird der Mitteleinsatz, der für eine 70-qm-Wohnung (Wohnung I) bei 30jähriger Förderung bis zur Kostenmiete geleistet werden muß, mit dem Förderaufwand verglichen, der während des gleichen Zeitraumes im Rahmen der EOF (Alternative B) bei sukzessiver, jeweils 10jähriger Förderung von Wohnung I und zwei weiteren gleich großen Wohneinheiten (Wohnungen II und III) erbracht wird. Zunächst sei das im ersten Förderweg aufgewendete Fördervolumen bestimmt. Die dafür benötigten Annahmen über die Bau- und Grundstückskosten von Wohnung I sind in Übersicht 8 aufgeführt. Der Kapitalmarktzins und die Abschreibung orientieren sich an einem im Rahmen des Planspiels von 1993 - ebenfalls für Karlsruhe - aufgestellten Rechenexempel des Bundesbauministeriums, mit dem die Vorteilhaftigkeit der EOF gegenüber dem ersten Förderweg belegt werden sollte. Bei den Verwaltungs- und Instandhaltungskosten sowie dem Mietausfallwagnis wurden leicht abweichende, mit der II. BV in Einklang stehende Ansätze gewählt. Die Sozialmiete wurde so gewählt, daß sie im gesamten Förderzeitraum mit der jeweils geltenden Mindestmiete im vierten Förderweg (siehe unten) übereinstimmt, damit die Vergleichbarkeit der beiden Förderalternativen gewährleistet ist. Unter diesen Annahmen beträgt der bei Vollförderung bis zur Kostenmiete benötigte Mitteleinsatz 152.298 DM (Barwert mit q =7\%).

Es sei nun der Mitteleinsatz bestimmt, der für die gleiche Wohnung bei nur 10jähriger Förderung im Rahmen der EOF erbracht wird. Als Grundförderung erhält der Investor ein zinsverbilligtes OS-10-Darlehen in Höhe von 2.100 DM pro qm (vgl. Übersicht 16 im Anhang). Nach der baden-württembergischen Verwaltungsvorschrift für 1997 beträgt die höchstzulässige Basismiete 13,50 DM im ersten Jahr. Sie wird im Abstand von zwei Jahren um 0,60 DM angeho-

1 Zur Vorgehensweise beim Vergleich von Förderprogrammen mit unterschiedlicher Bindungsdauer vgl. Institut Wohnen und Umwelt (1994), S. 328ff. (11ff.). 
ben. Bei einer Förderung bis zur Mindestmiete (8,75 DM plus 0,60 DM alle zwei Jahre) muß eine Zusatzförderung in Höhe von 4,75 DM pro qm und Monat erbracht werden. Das für die Grund- und Zusatzförderung insgesamt aufgewendete Fördervolumen beläuft sich dann auf 64.373 DM. Es ist erheblich niedriger als bei Alternative A, doch fällt die Förder- und Bindungsdauer mit nur zehn Jahren auch deutlich kürzer aus. Die öffentliche Hand muß daher nach zehn Jahren eine zweite Neubauwohnung (Wohnung II) und nach 20 Jahren eine dritte Neubauwohnung (Wohnung III) fördern, wenn sie wie beim ersten Förderweg insgesamt 30 Jahre lang über eine mietpreis- und belegungsgebundene Wohnung verfügen will.

Übersicht 8: Annahmen zu den Kosten des ersten Förderwegs (Wohnung I) im Rahmen des modellhaften Vergleichs mit der EOF

\begin{tabular}{|l|r|}
\hline Bau- und Grundstückskosten & \\
Baukosten pro qm & $3.000 \mathrm{DM}$ \\
Grunderwerbs- und Erschließungskosten pro qm & $500 \mathrm{DM}$ \\
Wohnungsgröße & $70 \mathrm{qm}$ \\
Bau- und Grundstückskosten insgesamt & $245.000 \mathrm{DM}$ \\
\hline Kapital- und Bewirtschaftungskosten im Jahr: & $17.150 \mathrm{DM}$ \\
Kapitalkosten bei einem Kapitalmarktzins von 7\% & $2.652 \mathrm{DM}$ \\
Abschreibungen=1,3\% der Baukosten & \\
Verwaltungskosten & $420 \mathrm{DM}$ \\
- im 1. Jahr & plus 3\% pro Jahr \\
- danach & \\
Instandhaltungskosten im 1. Förderjahr & $770 \mathrm{DM}$ \\
- im 1. Förderjahr & plus 3\% pro Jahr \\
- danach & $2 \%$ der Miete \\
Mietausfallwagnis & \\
\hline Sozialmiete pro qm und Monat & 8,75 DM \\
- im 1. Förderjahr & - bis 10. Jahr: plus 0,60 DM alle zwei Jahre \\
- Dynamisierung & - bis 30. Jahr: plus 1,00 DM alle zwei Jahre \\
\hline
\end{tabular}


Um das dafür eingesetzte Mittelvolumen abschätzen zu können, müssen Annahmen über die zukünftige Gestaltung der baden-württembergische Förderbestimmungen getroffen werden. Für die Grundförderung kommen vor allem zwei Varianten in Betracht: (1) Das Land erhöht den Mitteleinsatz nach Maßgabe der Inflationsrate, die bei 3\% angesetzt wird, oder (2) es orientiert sich an der Entwicklung der Bau- und Grundstückskosten ${ }^{1}$, die im Beispiel um 5\% pro Jahr steigen. Des weiteren sind Annahmen über die Höhe der Basismieten und der Zusatzförderung bei den später geförderten Wohnungen zu treffen. Im Beispiel wird davon ausgegangen, daß die höchstzulässigen Anfangsmieten um den gleichen Prozentsatz steigen wie die marktüblichen Erstvermietungsmieten (3,5\%). Sie betragen dann $19 \mathrm{DM}$ bei Erstvermietung im 11. Jahr (Wohnung II) und 27 DM bei Erstvermietung im 21. Jahr (Wohnung III). Die Basismieten werden im Förderzeitraum alle zwei Jahre um 0,80 DM (Wohnung II) bzw. 1,00 DM (Wohnung III) angehoben. Damit die Mietermiete mit der Sozialmiete im ersten Förderweg übereinstimmt, wird für Wohnung II eine Zusatzförderung in Höhe von 7,25 DM pro qm und für Wohnung III in Höhe von 12,25 DM pro qm und Monat gewährt. Die Förderung von Wohnung II kostet dann 45.977 DM (Variante 1) bzw. 51.243 DM (Variante 2) und die von Wohnung III 33.508 DM bzw. 41.466 DM. Der im 30jährigen Förderzeitraum insgesamt geleistete Aufwand liegt bei Variante 1 mit $143.858 \mathrm{DM}$ nur leicht unterhalb und bei Variante 2 mit 157.082 DM sogar etwas oberhalb des im ersten Förderwegs eingesetzten Subventionsvolumens (vgl. Übersicht 9).

Das Ergebnis der Modellrechnung zeigt, daß sich die Festlegung verkürzter Förder- und Bindungszeiträume - ein Charakteristikum, durch das sich die EOF von der traditionellen Wohnungsbauförderung unterscheidet - keineswegs vorteilhaft auswirken muß. Beschränkt man den Vergleich auf Wohnung I, erweist sich die EOF stets als die günstigere Alternative - und zwar auch dann, wenn man im ersten Förderweg nur den bis zum 10. Jahr erbrachten Förderaufwand zugrunde legt. Das Bild ändert sich, wenn im Rahmen der EOF nach Ablauf der 10jährigen Bindungsdauer wiederum eine Neubauförderung vorgenommen werden muß, während die Förderung im ersten Förderweg weiterhin bezogen auf Wohnung I erfolgt. Der für Wohnung II geleistete Mitteleinsatz liegt - obwohl nicht bis zur Kostenmiete gefördert wird - über dem Subventionsvolumen, das während der gleichen Zeit im ersten Förderweg erbracht wird. Noch extremer fällt diese Diskrepanz bei Wohnung III aus.

1 Ein solches Vorgehen läßt sich zwar durch den Zweck der Grundförderung (Gegenleistung für die wirtschaftlichen Einbußen aus der Mietpreis- und Belegungsbindung) nicht rechtfertigen, ist aber angesichts der noch immer vorherrschenden Orientierung der Förderung an den Kosten des Objekts sehr realitätsnah (vgl. Kapitel 3.B.IV.b). 
Übersicht 9: Ergebnis des modellhaften Vergleichs der Kosten des ersten Förderwegs mit den Kosten der EOF

\begin{tabular}{|c|c|c|c|}
\hline & \multicolumn{3}{|c|}{ Höhe der eingesetzten Fördermittel } \\
\hline & 1. Förderweg & & \\
\hline \multirow{4}{*}{ 1. bis 10. Jahr } & Wohnung I & \multicolumn{2}{|c|}{ Wohnung I } \\
\hline & $96.841 \mathrm{DM}$ & \multicolumn{2}{|c|}{$64.373 \mathrm{DM}$} \\
\hline & & Variante 1 & Variante 2 \\
\hline & & & \\
\hline \multirow[t]{2}{*}{ 11. bis 20. Jahr } & $40.502 \mathrm{DM}$ & $45.977 \mathrm{DM}$ & $51.243 \mathrm{DM}$ \\
\hline & & \multicolumn{2}{|c|}{ Wohnung III } \\
\hline 21. bis 30 . Jahr & $14.955 \mathrm{DM}$ & $33.508 \mathrm{DM}$ & $41.466 \mathrm{DM}$ \\
\hline Gesamt & $152.298 \mathrm{DM}$ & $143.858 \mathrm{DM}$ & $157.082 \mathrm{DM}$ \\
\hline
\end{tabular}

Die Ursachen dafür lassen sich anhand von Diagramm 2 verdeutlichen. Da die Kostenmiete von Wohnung I im Zeitablauf nominal nur geringfügig ansteigt, muß im ersten Förderweg wegen der Dynamisierung der Sozialmiete pro Jahr ein immer geringerer Förderaufwand erbracht werden. Bei der EOF tritt eine ähnliche Förderdegression ein, die aber nach 10 Jahren abgebrochen wird, wenn die Bindung ausläuft. Die Bewilligungsstelle nimmt dann wieder eine Neubauförderung vor, für die - verglichen mit Wohnung I - ein nominal höherer Mitteleinsatz geleistet wird. Auch wenn die Grundförderung real unverändert bleibt - dieser Fall ist im Diagramm dargestellt -, liegt die Fördergrenze bei Wohnung II bereits oberhalb der Kostenmiete von Wohnung I. Bei der noch später geförderten Wohnung III wird das nominale Fördervolumen weiter gesteigert, und der Abstand der Fördergrenze zur Kostenmiete von Wohnung I fällt entsprechend höher aus. Gemessen am jährlichen Mitteleinsatz ist die EOF bereits ab dem 11. Jahr die aufwendigere Förderform. Wird die Grundförderung im Zeitablauf auch real angehoben, kann der Fall eintreten, daß die durch die Abkehr vom Kostenmietprinzip realisierten Einsparungen von den Aufwendungen für die Anschlußförderung überkompensiert werden. Die Möglichkeit besteht vor allem dann, wenn die Kostenmiete von Wohnung I nicht allzu hoch ist und sich die im ersten Förderweg benötigten Mittel deshalb in Grenzen halten. 
Diagramm 2: Kostenmieten und Mitteleinsatz im ersten Förderweg und bei der EOF

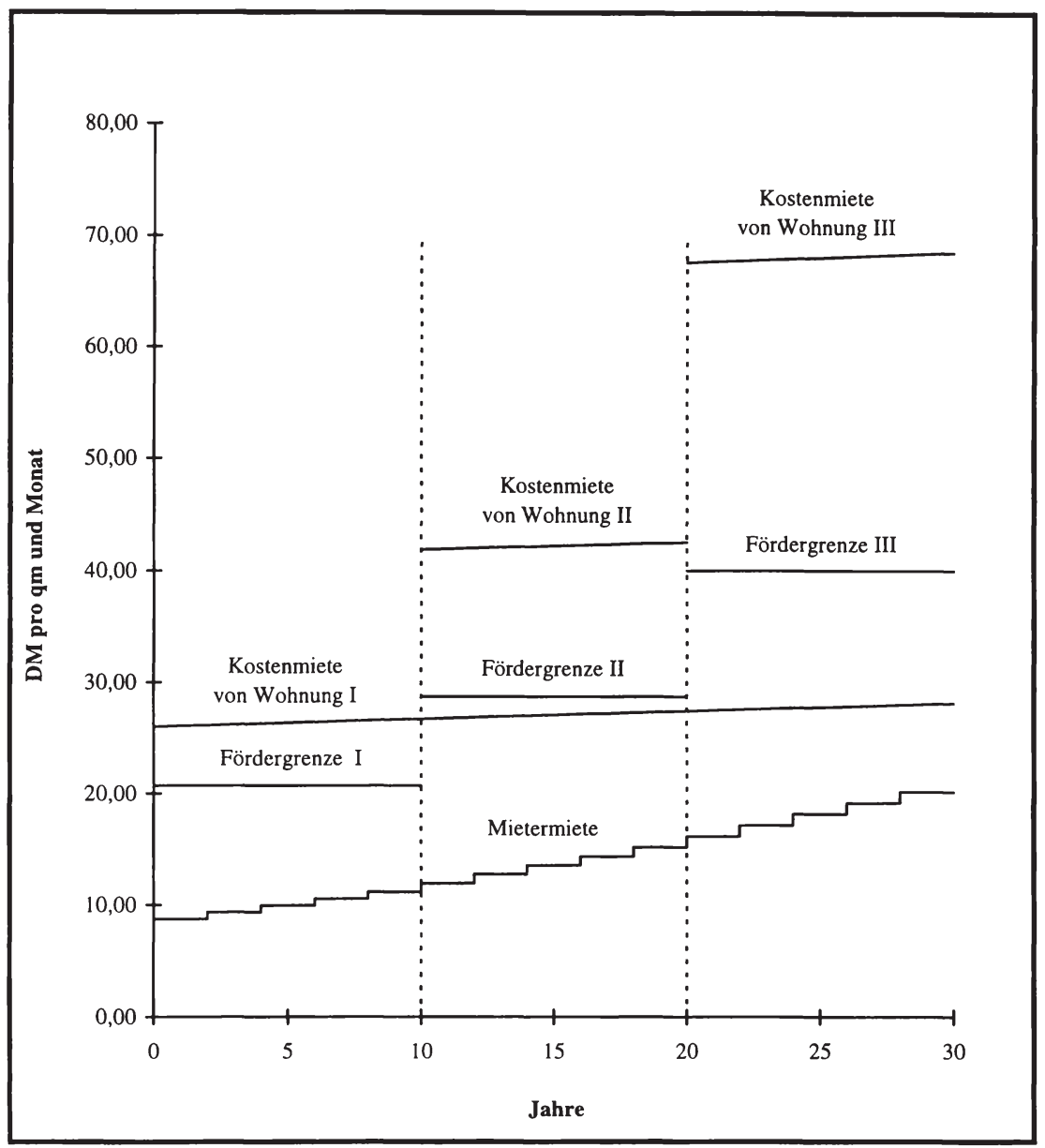

Aus den Ergebnissen der Modellrechnung kann allerdings nicht geschlossen werden, daß die Vereinbarung kurzer Förderzeiträume an sich von Nachteil ist. So verringert sich mit abnehmender Förderdauer nicht nur die Wahrscheinlichkeit des Auftretens einer Fehlbelegung, sondern auch das durchschnittliche Ausmaß, um das die Einkommen der Fehlbeleger die Bezugsberechtigungsgrenze überschreiten. Ein weiterer positiver Effekt resultiert aus den Angebots- 
und Preiseffekten des sozialen Wohnungsbaues. Bei kurzen Bindungszeiträumen kann mit den im sozialen Wohnungsbau insgesamt eingesetzten Mitteln eine größere Zahl von Wohnungen gefördert werden. Unterstellt man, daß der soziale Wohnungsbau einen positiven Nettoeffekt auf das gesamte Wohnungsangebot hat, dürfte es bei einer Erhöhung der Programmzahlen zu einer weiteren Entspannung auf dem Wohnungsmarkt kommen. Wegen der Rückwirkungen auf die Mieten würden von der Förderung dann auch Haushalte ohne Sozialwohnung profitieren. Allerdings spricht einiges dafür, daß der Nettoeffekt des sozialen Wohnungsbaues auf das gesamte Wohnungsangebot nicht allzu hoch ist und daher eine Verbesserung der Bewilligungsergebnisse sich nicht in dem politisch erhofften Maße auf das Gesamtangebot auswirkt. Es kann nämlich davon ausgegangen werden, daß ein Großteil der Investoren, die Mittel im Rahmen der EOF bekommen, auch ohne die Förderung in den Bau von Wohnungen investiert hätten. Dies dürfte um so mehr der Fall sein, wenn die Förderung lediglich zur Abgeltung der mit der Belegungs- und Mietpreisbindung verbundenen wirtschaftlichen Nachteile dienen soll, die Rendite der Investoren also nicht wesentlich beeinflußt wird. Aber selbst wenn sich die Erhöhung der Programmzahlen kurzfristig in einer Angebotserhöhung niederschlägt, könnte dieser Effekt dadurch konterkariert werden, daß die Investoren wegen der Entspannung auf dem Wohnungsmarkt und der damit verbundenen Renditeeinbußen ihre Neubautätigkeit einschränken oder zumindest weniger stark ausweiten. ${ }^{1}$

\section{Geringere Fördervorteile für Besserverdienende}

Ein wesentlicher Vorzug der EOF gegenüber dem ersten Förderweg besteht darin, daß die Fördervorteile der Mieter mit steigendem Einkommen konsequenter abgebaut werden. Ein krasses Beispiel ist Bayern: Dort kann der Fall auftreten, daß Haushalte, die die Einkommensgrenze um den gleichen Prozentsatz überschreiten, als Mieter einer mit öffentlichen Mitteln geförderten Sozialwohnung wegen zu geringer Einkünfte noch keine Fehlbelegungsabgabe entrichten müssen, in einer Wohnung des vierten Förderwegs aber bereits die volle

U. Kück beobachtet in einer statistischen Analyse für die Bundesrepublik von 1972 bis 1989 bei fast allen untersuchten Bauherrengruppen eine ,erstaunlich ähnliche - lediglich zeitverschobene - Entwicklung" der Bewilligungen im ersten Förderweg und der fertiggestellten Wohnungen; Kück, U. (1992), S. 78. Diese Beobachtungen lassen aber keine Rückschlüsse auf den langfristigen Angebotswirkungen des ersten Förderwegs und noch weniger der vereinbarten Förderung zu. Der Nettoeffekt der Fördermaßnahmen wird maßgeblich durch ihre Rückwirkung auf den freien Wohnungsmarkt bestimmt: „They decrease the demand for low-quality private dwellings, lowering the equilibrium price of private housing. The decrease in price lowers the quantity of private dwellings supplied." Sullivan, A. M. (1990), S. 387. Vgl. auch Keil, K. (1996), S. 87ff. 
Basismiete zu zahlen haben. Ähnliche Diskrepanzen treten in Rheinland-Pfalz auf: Nach dem Landesgesetz zur Fehlbelegungsabgabe haben Mieter im ersten Förderweg erst ab einer mehr als 230prozentigen (!) Überschreitung der Einkommensgrenze den Höchstbetrag von $8 \mathrm{DM}$ pro qm zu entrichten, während die Zusatzförderung bereits viel früher - i.d.R. schon weit unterhalb der um $60 \%$ erhöhten Einkommensgrenze - ausläuft. Auch Baden-Württemberg, Berlin und Schleswig-Holstein bauen die Fördervorteile bei der EOF viel konsequenter als im ersten Förderweg ab. In Bremen und Nordrhein-Westfalen fallen die Unterschiede zwischen beiden Förderwegen dagegen nur vergleichsweise gering aus (vgl. Übersicht 2 in Kapitel 1.E.I und Übersicht 7 in Kapitel 2.F.VII).

In einigen Bundesländern wird die Zusatzförderung zudem in geringeren Zeitabständen an die Einkommensentwicklung der Mieter angepaßt, als dies bei der Fehlbelegungsabgabe der Fall ist. So haben Bayern und Rheinland-Pfalz für die Zusatzförderung zwölfmonatige Regelbewilligungszeiträume, für die Fehlbelegungsabgabe dagegen dreijährige Leistungszeiträume festgesetzt. In BadenWürttemberg wird die Zusatzförderung alle zwei Jahre an die Einkommensentwicklung angepaßt, während die Fehlbelegungsabgabe im Abstand von bis zu vier Jahren neu ermittelt wird. Die EOF zeichnet sich ferner dadurch aus, daß die einkommensabhängige Zusatzförderung ein konstituierendes Merkmal dieser Förderform darstellt, während dies bei der Fehlbelegungsabgabe im ersten Förderweg nicht der Fall ist. Wie bereits erwähnt wird die Fehlbelegungsabgabe nicht flächendeckend erhoben. Auch von daher kann die Zusatzförderung als das wirksamere Instrument zur Vermeidung von Fehlsubventionierungen angesehen werden.

\section{Mietpreisverzerrungen können im Ansatz vermieden werden}

Wie bereits in Kapitel 1.E.I erläutert, wird das Problem der Mietpreisverzerrungen im öffentlich geförderten sozialen Mietwohnungsbau durch die Fehlbelegungsabgabe nicht wirklich gelöst. Denn trotz Erhebung der Abgabe können die Wohnkostenbelastungen der Haushalte auch bei gleicher Einkommenshöhe und gleichem Wohnwert der Wohnung erheblich von einander abweichen. Der EOF liegt eine andere Konzeption zugrunde: Die Zusatzförderung wird als Abschlag von der - am Vergleichsmietenniveau orientierten - Basismiete gewährt. Da die Vergleichsmieten den Wohnwert widerspiegeln, können die im ersten Förderweg beobachteten Ungerechtigkeiten vermieden werden. Mietpreisverzerrungen treten allerdings dann auf, wenn die Basismieten von den Vergleichsmieten abweichen oder wenn die Unterschiede in den Basismieten durch eine gegenläufige Differenzierung der Zusatzförderung neutralisiert werden (vgl. Kapitel 3.C.II und 3.C.III.f). 


\section{B. Eignung der EOF zum Erwerb von Belegungsbindungen}

\section{Theoretische Vorüberlegungen}

Um zu gewährleisten, daß der soziale Wohnungsbau den als versorgungsbedürftig eingestuften Personen zugute kommt, muß sich der Staat von den Investoren das Recht einräumen lassen, über die Belegung der Wohnungen mitzubestimmen. Die Einflußnahme der öffentlichen Hand auf die Belegung der Wohnungen hat zum Ziel, die bei der Wohnungssuche auf staatliche Hilfe angewiesenen Haushalte mit preiswertem Wohnraum zu versorgen. Gleichzeitig sollen durchmischte Belegungsstrukturen in den geförderten Gebäuden und Wohnsiedlungen erreicht werden, um das Entstehen sozialer Brennpunkte zu verhindern. Zu diesem Zweck werden die geförderten Wohnungen teilweise auch an solche Mietinteressenten vergeben, die aufgrund ihrer Einkommenssituation und anderer sozioökonomischer Merkmale nicht den vordringlich zu fördernden Personengruppen angehören. Es ist leicht einzusehen, daß die beiden Zielsetzungen - Versorgung sozial Schwacher und soziale Durchmischung angesichts der Knappheit der zur Verfügung stehenden Wohnungen in einem Spannungsverhältnis zueinander stehen. Bei der Belegung muß daher ein Kompromiß zwischen den beiden Zielsetzungen angestrebt werden. Wie ein solcher Kompromiß im Optimalfall auszusehen hat, kann aber nicht bestimmt werden. Es ist daher auch nicht möglich, die unterschiedlichen Vorstellungen der Länder und Gemeinden über die angestrebte Durchmischung in den geförderten Objekten zu beurteilen. Schon gar nicht soll hier der noch grundlegenderen Frage nachgegangen werden, ob die gemeinsame Unterbringung von Haushalten unterschiedlicher sozialer Schichten in einem Haus überhaupt die ihr nachgesagten Vorteile aufweist. ${ }^{1}$ Im folgenden geht es vielmehr darum zu überprüfen, wie geeignet die im Rahmen der EOF angewandten Methoden zur Realisierung der von den Ländern jeweils angestrebten Belegungsstrukturen und zur Versorgung sozial schwacher Haushalte sind.

Für die öffentliche Hand kommt es gerade angesichts der prekären Haushaltslage von Bund, Ländern und Gemeinden darauf an, die benötigten Belegungsbin-

$\mathrm{Zu}$ den theoretischen Ansätzen, die Nachbarschafts-Effekte bei der Erklärung urbaner Siedlungsstrukturen berücksichtigen, vgl. Goodman, A. C. (1989), S. 54ff. Die Thematik ist in den USA besonders im Hinblick auf ,racial externalities“ und die durch sie verursachte Segregation untersucht worden; vgl. z.B. Kain, J. F., Quigley, J. M. (1975); Fujita, M. (1989), S. 243ff.; Krugman, P. (1996), S. 15ff. Fujita weist darauf hin, ,that traditional economic theory ... is weak in normative analyses of racial externalities. For example, although one of the fundamental issues in the study of racial externalities is whether we approve of the preferences of individuals who are racially prejudiced, traditional economic theory provides little help in answering such a basic question. ... Therefore we must be cautious about the results of such purely economic analyses. For example, even if complete segregation were economically efficient, it could foster racial tensions in the long run." 
dungen zu möglichst günstigen Konditionen und unter geringstmöglichem Mitteleinsatz zu erwerben. Die Förderung sollte gerade ausreichen, um bei den Investoren, die sonst außerhalb des sozialen Wohnungsbaues investiert hätten, eine Entscheidung zugunsten des vierten Förderwegs auszulösen. Sie sollte daher dem Betrag entsprechen (oder diesen leicht übersteigen), mit dem der Investor die wirtschaftlichen Nachteile aus der Belegungsbindung veranschlagt. Die Höhe der benötigten Grundförderung $(\mathrm{G})$, durch die zugleich die wirtschaftlichen Einbußen infolge der Mietpreisbindung abgegolten werden sollen, ergibt sich als:

(1) $G=\left(E_{F}-A_{F}\right)-\left(E_{B}-A_{B}\right)-\left(N_{F}-N_{B}\right)+R$

Der Ausdruck $\left(E_{F}-A_{F}\right)$ bezeichnet den Unterschiedsbetrag zwischen den Einnahmen und Aufwendungen, die der Investor bei freier Vermietung einer Wohneinheit erwartet; $\left(E_{B}-A_{B}\right)$ ist die Differenz dieser Größen im Falle einer Investition im vierten Förderweg. Durch den Ausdruck $\left(\mathrm{N}_{F}-\mathrm{N}_{B}\right)$ wird berücksichtigt, daß der Investor auch mit außerökonomisch bedingten Nutzeneinbußen rechnet, die auf rein subjektiven, sozioemotional geprägten Einstellungen gegenüber den förderberechtigten Personengruppen basieren. Solche Nutzeneinbußen treten insbesondere im Umgang mit (vermeintlich) unsympathischen Mietern auf. Die Differenz wird im Regelfall positiv sein, denn der Vermieter muß davon ausgehen, im Falle einer Belegungsbindung einen ihm unliebsameren Mieter zu bekommen, als er bei freier Vermietung ausgesucht hätte. Schließlich gibt $\mathrm{R}$ den Risikoaufschlag wieder, mit dem die Möglichkeit von Abweichungen der tatsächlichen von den erwarteten Werten berücksichtigt wird.

Um den auf die Belegungsbindung entfallenden Teil der Grundförderung zu ermitteln, muß der Investor zunächst die Einbußen aus der Bindung an die höchstzulässige Miete abschätzen und diesen Betrag vom Gesamtvolumen der Grundförderung abziehen. Die Kosten der Mietpreisbindung entsprechen dem Barwert der im Förderzeitraum (und gegebenenfalls auch noch danach) eintretenden Abweichungen zwischen der höchstzulässigen Miete und der bei freier Vermietung erzielbaren Marktmiete. Potentielle Investoren werden diese Kosten einkalkulieren und die Restbeträge der Grundförderung mit den von ihnen erwarten Kosten der Belegungsbindung vergleichen, bevor sie sich für oder gegen eine Investition im vierten Förderweg entscheiden. Die folgenden Überlegungen sollen zeigen, welcher Art die wirtschaftlichen Nachteile aus der Belegungsbindung sein können. Gegenstand der Ausführungen sollen ausschließlich objektive Tatbestände sein, da nur sie einem rationalen Kalkül zugänglich sind. Im Anschluß wird das Vorgehen der Länder bei der Belegung der Wohnungen 
dargestellt und zuletzt eine Analyse der EOF im Hinblick auf die Belegungsergebnisse und die Effizienz des Mitteleinsatzes vorgenommen.

\section{Risiken einer Wohnungsvergabe an „Problemmieter““}

\section{a. Mietausfallwagnis}

Auch Wohnungseigentümer, die keine persönlichen Ressentiments gegen Ausländer, Arbeitslose, kinderreiche Familien usw. haben, werden die wirtschaftlichen Folgen einer Wohnungsvergabe an diese Haushalte in ihr Kalkül einbeziehen. Von besonderem Gewicht ist die Bereitschaft und Fähigkeit des Mieters, seinen Zahlungsverpflichtungen nachzukommen. Ein erhöhtes Mietausfallwagnis wird vor allem bei geringverdienenden Haushalten vermutet, zu denen die Mitglieder der Problemgruppen überdurchschnittlich häufig zählen. Die Zurückhaltung gegenüber diesen Gruppen wird dadurch verstärkt, daß die Möglichkeiten der Investoren, den durch den Mietausfall resultierenden ökonomischen Schaden für sich gering zu halten, durch miet- und prozeßrechtliche Bestimmungen erheblich eingeengt worden sind. Nach geltender Rechtslage darf der Vermieter das Mietverhältnis zwar ohne Einhaltung einer Frist kündigen, wenn der Mieter für zwei aufeinanderfolgende Termine mit der Entrichtung des Mietzinses oder eines nicht unerheblichen Teils davon in Verzug ist. Der sich anschließende Räumungsprozeß kann aber wegen der Überlastung der Gerichte sechs bis acht Monate andauern, ohne daß der Vermieter weitere Mietzahlungen erhält. Hinzu kommt, daß der Vermieter die von ihm vorzuschießenden Kosten der Räumungsklage und seine Anwaltskosten auch im Falle des Prozeßgewinns bei Zahlungsunfähigkeit des Mieters selbst tragen muß. Hat er ein Räumungsurteil erwirkt, so stehen dem Mieter die rechtlichen Mittel des Räumungsschutzes zur Verfügung; u.a. kann er sich auf eine Schutzklausel nach $\S 765$ a ZPO berufen, über die eine Zwangsvollstreckung ganz oder zeitweise aufgehoben werden kann, wenn sie etwa wegen einer Krankheit oder dem vergeblichen Bemühen um eine Ersatzwohnung zu besonderen Härten führen würde. Die Dauer des Mietausfalls bis zur Räumung der Wohnung kann dadurch nochmals verlängert werden.

Wegen der Größenordnung der beim Mietausfall möglichen finanziellen Einbußen tendieren die Vermieter dazu, die Bonität des Mieters bei Abschluß des Mietvertrages kritisch zu überprüfen. „Deshalb haben sozial schwache Mietinteressenten im allgemeinen kaum eine Chance, von Vermietern akzeptiert zu werden. Dies trifft vor allem Arbeitslose, Familien mit mehreren Kindern, alleinstehende Frauen mit Kindern und Ausländer.“"

Sonnenschein, J. (1995), S. 40. 


\section{b. Erhöhte Abnutzung der Mietsache}

Im allgemeinen werden die Wohnungseigentümer solche Personen als Mieter bevorzugen, von denen sie einen schonenden Umgang mit der Mietsache erwarten. Denn sie müssen die durch die Wohnungsabnutzung und das Auftreten von Schäden entstehenden Kosten meist zu einem Teil mittragen. Nach § 536 BGB hat der Vermieter die Wohnung während der gesamten Mietzeit im vertragsgemäßen Zustand zu erhalten. In der Praxis ist es allerdings üblich geworden, diese Verpflichtung teilweise auf den Mieter abzuwälzen, indem man ihn vertraglich zur Übernahme der Schönheitsreparaturen ${ }^{1}$ sowie zur Beteiligung an den Kosten durch Bagatellschäden verpflichtet. Mängel und Schäden, die aus einem vertragswidrigen Gebrauch der Mietsache entstehen (z.B. Unterlassen ausreichender Lüftung zur Vermeidung von Schimmelbildung) sind vom Mieter stets in voller Höhe zu übernehmen. Auch wenn es dem Vermieter gelingt, die aus der Vermietung resultierenden Instandhaltungskosten weitgehend auf den Mieter abzuwälzen, wird ihm dennoch an einem schonenden Umgang mit der Wohnung gelegen sein. Dies u.a. auch deshalb, weil er bei geringverdienenden Haushalten damit rechnen muß, daß sie die von ihnen verursachten Instandhaltungs- und Reparaturkosten nicht tragen können. Hinzu kommt, daß die Vermieter jeden zusätzlichen Verwaltungsaufwand vermeiden wollen, der beim Auftreten von Schäden an der Wohnung anfällt (z.B. im Zusammenhang mit der Schadensfeststellung, der Nachweiserbringung für das Verschulden des Mieters, der Prozeßführung etc.). $\mathrm{Zu}$ den Mietergruppen, bei denen ein weniger schonender Umgang mit der Wohnung vermutet wird, dürften erneut vor allem die Familien mit Kindern, Haushalte aus den unteren sozialen Schichten und Ausländer zählen.

\section{c. Beeinträchtigungen der Wohnverhältnisse anderer Mieter}

In Häusern mit mehreren Mietparteien hat die Entscheidung über die Belegung einer Wohnung im Regelfall Auswirkungen auf das Zusammenleben aller Mieter im Haus. Der Investor wird dies bei der Mieterauswahl insbesondere dann berücksichtigen, wenn er Eigentümer mehrerer Wohnungen im gleichen Gebäude ist. Seine Entscheidung zugunsten eines Problemhaushalts könnte die Mieterfluktuation in den benachbarten Wohnungen erhöhen bzw. deren Vermietungschancen schmälern, selbst wenn sich der Haushalt unauffällig verhält. Das Problem dürfte sich verstärken, wenn infolge der Belegungsentscheidung Span-

Soweit im Mietvertrag nicht näher präzisiert, umfassen die Schönheitsreparaturen das Tapezieren, Anstreichen oder Kalken der Wände und Decken sowie das Streichen der Innenseiten von Türen und Fenstern (jeweils Wohnungsinnenseite), der Heizkörper und Installationsrohre. 
nungen in der Hausgemeinschaft auftreten. Anlaß dazu könnte bereits ein von der allgemeinen Norm abweichendes, wenn auch nicht rechtswidriges Verhalten einzelner Mieter oder das Auftreten von Kinderlärm sein, der normalerweise von den Mitmietern hingenommen werden muß. ${ }^{1}$ Noch schwieriger wird es, wenn es zu Hausfriedensstörungen oder Verstößen gegen die Hausordnung kommt. Werden dadurch andere Mieter geschädigt, können sie vom Vermieter die Beseitigung der Störungen verlangen und gegebenenfalls auch die Miete mindern. Der Vermieter muß dann gegen den Verursacher vorgehen, indem er das Fehlverhalten abmahnt, Unterlassung verlangt und dem Mieter gegebenenfalls kündigt. ${ }^{2}$

Selbst wenn sich die Spannungen in der Hausgemeinschaft nicht auf die Höhe der Mieteinnahmen auswirken, verursachen sie doch meist einen erhöhten Verwaltungsaufwand. Wie auch beim Eintreten von Mietrückständen oder Wohnungsschäden muß der Investor - oder der von ihm bestellte Verwalter - zusätzliche Zeit aufwenden oder Ärger in Kauf nehmen. Gerade diese Unannehmlichkeiten aber wollen die Investoren vermeiden. So werden sie bei der Auswahl der Mieter darauf achten, daß sie das harmonische Zusammenleben in der Hausgemeinschaft möglichst wenig beeinträchtigen. Aus dieser Absicht resultiert wiederum eine Zurückhaltung gegenüber Mitgliedern unterer sozialer Schichten, kinderreichen Familien und Ausländern.

\section{Belegungsvorgaben der Länder}

\section{a. Belegungsstruktur}

Bei der Belegung der einkommensorientiert geförderten Sozialwohnungen wird im allgemeinen eine Doppelstrategie verfolgt: Zum einen sollen die auf dem freien Wohnungsmarkt benachteiligten Personengruppen mit preiswertem Wohnraum versorgt werden, zum anderen wird die Absicht verfolgt, die geförderten Wohnungen auch an „normale“ Haushalte mit mittleren Einkommen zu vergeben, damit keine einseitigen Belegungsstrukturen auftreten. Um eine soziale Durchmischung zu ermöglichen, haben die Länder festgelegt, daß auch solche Mieter zum Bezug der Wohnungen berechtigt sein sollen, deren Einkommen die Grenze des § 25 II. WoBauG überschreiten (vgl. Kapitel 2.F.III). Daneben nehmen einige Bundesländer Quotierungen vor, die die angestrebten sozialen Strukturen in den Mietobjekten garantieren sollen.

1 Vgl. Köhler, W., Kossmann, R. (1996), S. 191.

2 Vgl. Köhler, W., Kossmann, R. (1996), S. 186ff. 
Nach den Förderrichtlinien für Nordrhein-Westfalen müssen zwei Drittel der geförderten Wohnungen an Haushalte vergeben werden, deren Einkommen die Grenze des $\S 25$ um nicht mehr als 5\% überschreiten, während das übrige Drittel für Mieter mit Einkommen bis zu der um $60 \%$ erhöhten Grenze bestimmt ist. Die für die jeweiligen Einkommensgruppen bestimmten Wohnungen sind im Bewilligungs- und Darlehensvertrag nach ihrer Lage im Gebäude und mit einer laufenden Nummer zu bezeichnen. Eingehalten werden muß die Belegungsquote allerdings nur in den ersten 15 Jahren des 20jährigen Bindungszeitraumes; danach können die für unterhalb der Einkommensgrenze liegende Haushalte bestimmten Wohnungen auch Beziehern von Einkommen überlassen werden, die die Grenze um bis zu 60\% überschreiten.

In Schleswig-Holstein sind die einkommensbezogenen Vorgaben besonders detailliert geregelt. Die geförderten Mietbauvorhaben sollen dort bei Erst- und Wiederbelegung bezogen auf die geschaffene Gesamtwohnfläche zur Hälfte mit Haushalten unterhalb der Einkommensgrenze und im übrigen möglichst gleichmäßig mit Haushalten der anderen drei Einkommensstufen belegt werden, nach denen bei der Zusatzförderung unterschieden wird. Die Staffelung erfolgt nach Einkommen bis zur Grenze des $\S 25$ plus 20\%, 30\% und 40\%. In Bayern und Baden-Württemberg müssen mindestens $50 \%$ der Wohnungen an Haushalte vergeben werden, die die Grenze des $\S 25$ einhalten. Während sich diese Vorgabe nach den baden-württembergischen Förderbestimmungen nur auf die Erstbelegung bezieht, ist sie in Bayern auch bei der Wiedervermietung der Wohnungen einzuhalten.

Unterrepräsentiert sind die Mieter mit Einkommen unterhalb der Grenze des $\S$ 25 in Berlin und Brandenburg. Nach den Fördereckwerten für Berlin sollen diesen Haushalten 30 bis 50\% der Wohnungen eines Bauvorhabens zur Verfügung gestellt werden. In Brandenburg beträgt ihr Anteil an den geförderten Wohnungen sogar nur $25 \%$. Zu je einem Viertel sollen auch die Mieter der übrigen drei Einkommensstufen in den geförderten Objekten vertreten sein. Nach den allgemeinen Fördereckwerten sind dies die Bezieher von Einkommen bis zur Grenze des $\S 25$ plus $20 \%, 40 \%$ und $60 \%$ und beim Pilotmodell in Cottbus die Bezieher von Einkommen bis zur Grenze des $\S 25$ plus $15 \%, 30 \%$ und $45 \%$. In den übrigen Bundesländern sind keine Einkommensquoten für die Belegung der geförderten Objekte festgelegt worden. 


\section{b. Belegungsverfahren}

Die Vorgehensweise bei der Belegung der einzelnen Wohnungen fällt im Vergleich der Länder ebenfalls unterschiedlich aus. Ein sehr hohes Maß an staatlicher Einflußnahme auf die Belegungsentscheidung kennzeichnet die EOF in Baden-Württemberg, Bayern und Schleswig-Holstein, wo die Investoren dem Fördergeber während des gesamten Bindungszeitraumes ein Belegungsrecht einräumen müssen. Die zuständigen Stellen - in Baden-Württemberg und Schleswig-Holstein sind dies die Kommunen - nehmen das Belegungsrecht wahr, indem sie den Eigentümern drei, in Baden-Württemberg sogar bis zu fünf Mietinteressenten zur Auswahl vorschlagen. Das Land Nordrhein-Westfalen stellt es dem Investor frei, ob er der zuständigen Stelle in den ersten 15 Jahren ein Belegungsrecht einräumen oder ob er die Mieter aus dem Kreis der Bezugsberechtigten selbst auswählen will. Gewährt er kein Belegungsrecht, muß er sich mit einem um mindestens $20 \%$ verringerten Förderdarlehen zufrieden geben. In Bremen ist der Investor bei der Wohnungsvergabe durch eine vertragliche Zweckbindung eines Teils der geförderten Wohnungen zugunsten von Haushalten mit Wohnungsnotstandsbescheinigungen eingeschränkt. Allerdings kann er diese Verpflichtung auch durch andere Wohnungen in seinem Bestand erfüllen. Die Ausübung eines Belegungsrechts ist in den Förderrichtlinien für Bremen aber nicht vorgesehen. Ebensowenig ist dies in den übrigen Bundesländern der Fall, wo die Investoren unter den bezugsberechtigten Mietinteressenten frei auswählen können. Die Bewerber weisen dort ihre Bezugsberechtigung durch Vorlage entsprechender Bescheinigungen der Wohnungs- oder Liegenschaftsämter nach. Dabei handelt es sich i.d.R. um die im ersten Förderweg verwendeten Wohnberechtigungsscheine, die durch Angaben zur Berechtigung für Maßnahmen der übrigen Förderwege ergänzt sind.

\section{Kritik}

\section{a. Schwierigkeiten bei der Steuerung der Belegungsstruktur}

Auf der Basis der vorangegangenen Ausführungen lassen sich allgemein drei Methoden der Wohnungsbelegung unterscheiden: (1) Die freie Auswahl des Wohnungseigentümers unter den Bezugsberechtigten, (2) die Belegungsentscheidung durch den Investor unter Beachtung bestimmter Einkommensquoten und (3) die Beschränkung der Auswahl auf Wohnungssuchende, die dem Eigentümer von der zuständigen Stelle benannt werden.

Bei der freien Auswahl aus dem Kreis der Berechtigten bleibt es den Investoren überlassen, ob und in welchem Umfang sie Problemhaushalte in die geförderten 
Wohnungen aufnehmen. Es ist kaum zu erwarten, daß sie dazu in dem sozialpolitisch erwünschten Maße bereit sind. Wie im Fall einer freien Vermietung werden sie vielmehr solchen Mietern den Vorrang einräumen, bei denen sie die oben beschriebenen Vermietungsrisiken am geringsten veranschlagen. Finanzielle Anreize für eine Einbeziehung von vermeintlichen Problemhaushalten bestehen nicht, da die Belegungsentscheidung keine Auswirkung auf die Höhe der Grundförderung hat. Wegen der - gegenüber dem ersten Förderweg - erhöhten Einkommensgrenzen dürften die Wohnungseigentümer überdies keine Schwierigkeiten haben, genug ,gute“ Mieter zu finden. $\mathrm{Zu}$ einer Konzentration der Förderung auf die Mittelschicht könnte es u.a. in Rheinland-Pfalz kommen: Nach der Verwaltungsvorschrift des Landes zur EOF müssen die Investoren dem Fördergeber keine Belegungsrechte einräumen, zugleich ist die zulässige Überschreitung der Einkommensgrenze nach $\S 25$ mit 60\% vergleichsweise hoch angesetzt worden. Sofern keine weitergehenden Bestimmungen in den jeweiligen Fördervereinbarungen getroffen werden, dürften sozial Schwache kaum eine Chance haben, in den Genuß der Förderung zu kommen. Eine Einbeziehung dieser Haushalte in die Wohnungsvergabe ist allenfalls dann zu erwarten, wenn es sich bei den Fördernehmern um städtische Wohnungsbaugesellschaften oder sonstige Investoren mit besonderer sozialer Verantwortung handelt.

Auch die zweite Vorgehensweise, bei der das Land die Einhaltung einkommensbezogener Belegungsquoten vorschreibt, ist zur Gewährleistung durchmischter Belegungsstrukturen kaum geeignet, denn wiederum nimmt die Förderstelle keinen direkten Einfluß auf die Auswahl der Mieter. Die Investoren haben bei der Belegung lediglich darauf zu achten, daß die Anteile der verschiedenen Einkommensgruppen eingehalten werden. Das Kriterium der Einkommenshöhe erlaubt aber keine hinreichenden Rückschlüsse darauf, ob der betrachtete Haushalt zu den vordringlich zu fördernden Problemgruppen gehört oder nicht. Zwar beziehen Ausländer, Alleinerziehende, Arbeitslose und kinderreiche Familien zumeist unterdurchschnittliche Pro-Kopf-Einkommen, doch läßt sich daraus nicht umgekehrt folgern, daß Haushalte mit Einkommen unterhalb der Grenze des $\S 25$ im Regelfall diesen Personengruppen angehören. So zählen Bezieher von Alterseinkünften, selbst wenn diese niedrig ausfallen, wegen ihrer gesicherten finanziellen Lage nicht zu den Problemgruppen des Wohnungsmarktes. Auch die erwerbstätigen Ein-Personen-Haushalte, von denen nach Schätzungen des Bundesbauministeriums immerhin jeder vierte mit seinem Einkommen unter der Schwelle des $\S 25$ liegt $^{1}$, gehören meist nicht zu den diskriminierten Wohnungsnachfragern. Gerade in Zeiten einer angespannten Wohnungsmarktlage mit hohen Bewerberzahlen könnte es den Investoren daher gelingen, auch bei der Vergabe der für Geringverdiener reservierten Wohnun-

1 Es handelt sich um die bereits zitierte Schätzung auf der Basis des Mikrozensus 1992; vgl. Deutscher Bundestag (1994d), S. 45. 
gen die Problemgruppen mit den größten Versorgungsschwierigkeiten auszuklammern.

Eine unzulängliche Berücksichtigung der vordringlich zu fördernden Haushalte ist in einigen Ländern auch deshalb zu erwarten, weil die Quoten zugunsten einkommensschwacher Mietinteressenten vergleichsweise niedrig angesetzt sind. Dies gilt zum einen für Berlin: Die dortige Bandbreite von 30 bis $50 \%$ erlaubt es den Investoren, nur jede dritte Wohnung für die „klassischen“ Sozialmieter zu reservieren und sich bei der restlichen Belegung auf ,gute" Mieter mit vergleichsweise hohen Einkommen (bis zur Grenze des $\S 25$ plus $80 \%$ ) zu konzentrieren. In Brandenburg steht nur jede vierte geförderte Wohnung den Beziehern von Einkommen bis zur Grenze des $\S 25$ zur Verfügung, so daß die Problemgruppen des Wohnungsmarktes hier noch geringere Chancen haben dürften, bei der Wohnungsvergabe zum Zuge zu kommen.

Am wirksamsten kann der Staat die Versorgung der Problemhaushalte durch die Ausübung von Belegungsrechten sicherstellen. Denn selbst wenn die zuständige Stelle den Eigentümern bei der Auswahl der Mieter ein gewisses Mitspracherecht einräumt, kann sie bei entsprechender Vorauswahl der von ihr benannten Mietinteressenten eine ausreichende Belegung der Wohnungen mit Problemhaushalten sicherstellen. Allerdings führt auch die staatliche Wohnungszuteilung nicht zwangsläufig zu befriedigenden Belegungsergebnissen. Insbesondere besteht die Gefahr einer zu starken Konzentration der Problemhaushalte in den geförderten Objekten, wenn für sämtliche Wohnungen eines Gebäudes oder Wohnblocks Belegungsrechte vereinbart werden und sich die zuständigen Stellen bei der Wohnungszuteilung in starkem Maße von sozialpolitischen Zielsetzungen leiten lassen.

Die Belegungsstrukturen der baden-württembergischen Pilotobjekte von 1993 und 1994 bestätigen dies. Bei der Erstbelegung, die zwischen 1995 und 1997 vorgenommen wurde, ging es den Kommunen in erster Linie darum, die in ihrem Gebiet aufgetretene Wohnungsnot zu lindern. Insbesondere sollten auch Haushalte mit Einkommen oberhalb der Grenze des $\S 25$ berücksichtigt werden, um ghettoartige Belegungsstrukturen zu vermeiden. Die Wohnungsvergabe erfolgte meist anhand von Notfallkarteien unter Beachtung sozialer Dringlichkeitskriterien. Bevorzugt berücksichtigt wurden Haushalte in akuter Wohnungsnot (wegen Kündigung oder bevorstehender Räumung), wohnungsuchende Schwangere, Alleinerziehende, Schwerbehinderte sowie Haushalte in ,unzumutbaren" Wohnverhältnissen. Außerdem haben sich die zuständigen Stellen einiger Kommunen auch über Zeitungsanzeigen, Flugblätter oder „Mund-zuMund-Propaganda“" um Mieter bemüht. In Mannheim und Heilbronn hat man die Wohnungseigentümer in die Suche nach Mietinteressenten einbezogen. 
Wie die Belegungsergebnisse gezeigt haben, konnten die Kommunen ihre Absicht, die akute Wohnungsnot zu lindern und die Problemgruppen des Wohnungsmarktes zu versorgen, zumeist nicht mit der Durchmischungszielsetzung vereinbaren. Der Anteil der sozial Schwachen an den Mietern der Pilotobjekte ist oft größer ausgefallen als von den zuständigen Stellen ursprünglich beabsichtigt. Dokumentiert wird dies nicht zuletzt durch eine hohe Repräsentanz geringverdienender Mieter in den geförderten Objekten. Bei der Erstvermietung lagen mehr als zwei Drittel der Haushalte unter der Einkommensgrenze (vgl. Übersicht 10). Besonders einseitig waren die anfänglichen Belegungsstrukturen in Fellbach, Freiburg, Möglingen und Rutesheim. Neben dem hohen Anteil der Geringverdiener war mitunter auch eine Konzentration bestimmter Personengruppen in den Objekten zu beobachten. So wurden zwei Drittel der Wohnungen des Rutesheimer Pilotobjektes mit ausländischen Familien belegt, und in einem der Freiburger Objekte ergab sich wegen der großen Zahl kleiner Wohnungen eine Konzentration von Alleinerziehenden. Eine nennenswerte einkommensmäßige Durchmischung konnte nur in Stuttgart und Mannheim erreicht werden. Beim Stuttgarter Pilotobjekt ist dies darauf zurückzuführen, daß die Wohnungen vorrangig an städtische Bedienstete vergeben wurden. In Mannheim hat man sich vor dem Hintergrund der geringen Durchmischung in den anderen Kommunen in besonderer Weise um besserverdienende Mieter bemüht.

Die Schwierigkeiten bei der Erreichung durchmischter Belegungsstrukturen lagen nach Auskunft von Mitarbeitern der zuständigen Stellen u.a. darin begründet, daß es sich bei den dringenden Wohnungsnotfällen fast ausschließlich um geringverdienende Haushalte aus den Problemgruppen des Wohnungsmarktes handelt. Nach den Erfahrungen in den betrachteten Kommunen wenden sich Haushalte, die nicht zu jenen Gruppen zählen und deren Einkommen oberhalb der Grenze des § 25 liegen, bei der Wohnungssuche nur verhältnismäßig selten an die Gemeinde, da sie meist auch ohne staatliche Hilfe eine Wohnung finden und eine akute Notlage bei ihnen daher gar nicht erst eintritt. Sie haben wegen ihrer besseren finanziellen Ausstattung und des höheren Sozialprestiges eine größere Auswahl auf dem Mietwohnungsmarkt oder bevorzugen Wohneigentum. 
Übersicht 10: Belegungsergebnisse bei den Pilotmodellen in Baden-Württemberg

\begin{tabular}{|l|c|c|c|c|c|c|c|c|}
\hline & \multicolumn{7}{|c|}{ - Haushalte - } \\
\cline { 2 - 10 } & \multirow{2}{*}{ Gesamt } & \multicolumn{7}{|c|}{ Einkommen bis zur Grenze des § 25 II. WoBauG ... } \\
\cline { 2 - 10 } & & $+/-0 \%$ & $+10 \%$ & $+20 \%$ & $+30 \%$ & $+40 \%$ & $+50 \%$ & mehr \\
\hline Fellbach & $\mathbf{1 2}$ & 11 & - & - & - & - & 1 & - \\
\hline Freiburg & $\mathbf{3 8}$ & 32 & 1 & 3 & - & 1 & - & 1 \\
\hline Heilbronn & $\mathbf{4 5}$ & 30 & 1 & 6 & 2 & 2 & 1 & 3 \\
\hline Mannheim & $\mathbf{2 4}$ & 11 & 1 & 2 & 4 & 2 & 3 & 1 \\
\hline Möglingen & $\mathbf{1 0}$ & 10 & - & - & - & - & - & - \\
\hline Rutesheim & $\mathbf{1 5}$ & 13 & - & 2 & - & - & - & - \\
\hline Stuttgart & $\mathbf{4 5}$ & 24 & 1 & 5 & 3 & 1 & 3 & 8 \\
\hline Gesamt & $\mathbf{1 8 9}$ & $\mathbf{1 3 1}$ & $\mathbf{4}$ & $\mathbf{1 8}$ & $\mathbf{9}$ & $\mathbf{6}$ & $\mathbf{8}$ & $\mathbf{1 3}$ \\
\hline - in \% - & $\mathbf{1 0 0 , 0}$ & $\mathbf{6 9 , 3}$ & $\mathbf{2 , 1}$ & $\mathbf{9 , 5}$ & $\mathbf{4 , 8}$ & $\mathbf{3 , 2}$ & $\mathbf{4 , 2}$ & $\mathbf{6 , 9}$ \\
\hline
\end{tabular}

Die Mitarbeiter der zuständigen Stellen haben darüber hinaus beobachtet, daß die besserverdienenden Haushalte mitunter nur ein geringes Interesse an den einkommensorientiert geförderten Wohnungen zeigten. Sie führen dies unter anderem auf die im Vergabezeitraum deutlich entspannte Lage auf dem Wohnungsmarkt zurück. Mögen die Wohnungsmarktengpässe Ende der 80er bzw. Anfang der 90er Jahre bis zu einem gewissen Grade auch die Bezieher mittlerer und höherer Einkommen getroffen haben, so hat diese Gruppe gegenwärtig keine Schwierigkeiten, sich mit angemessenem Wohnraum zu versorgen. Der durch die Übernachfrage ausgelöste Bauboom hat gerade in den alten Bundesländern zu einer Verringerung des Angebotsdefizits geführt. Die allgemeine Marktentspannung wirkte sich zudem dämpfend auf die Mietpreisentwicklung aus. So weist der im Wohngeld- und Mietenbericht $1995^{1}$ aufgeführte Mietenindex ${ }^{2}$, der die Entwicklung der Bruttokaltmieten abbildet, zuletzt rückläufige Steigerungsraten auf. Hatten die Bruttokaltmieten im Jahr 1993 noch um 5,9\%

1 Deutscher Bundestag (1996).

2 Quelle: Volkswirtschaftliche Gesamtrechnung. 
zugenommen, betrug der Zuwachs 1994 nur 4,6\% und 1995 gerade noch 3,9\%. ${ }^{1}$ Daneben ergab eine Auswertung des vom Ring Deutscher Makler (RDM) erstellten Immobilien-Preisspiegels, daß die bei Erst- und Wiedervermietung erzielten Nettokaltmieten freifinanzierter Wohnungen im ersten Quartal 1996 gegenüber dem Vorjahresniveau um etwa $5 \%$ zurückgegangen waren. ${ }^{2}$

Das Interesse der besserverdienenden Haushalte an den geförderten Wohnungen wurde auch dadurch geschmälert, daß sich die Basismieten im Jahr der Erstvermietung wegen der Entspannung auf den Wohnungsmärkten mancherorts nicht oder nur unwesentlich vom marktüblichen Niveau unterschieden. In den betroffenen Gemeinden konnten Haushalte, denen aufgrund ihres Einkommens keine oder nur eine geringe Zusatzförderung zugestanden hätte, keine nennenswerten finanziellen Vorteile im Vergleich zum Bezug einer frei finanzierten Wohnung erkennen. Mit dem Preisvorteil ist für sie das entscheidende Argument für eine Sozialwohnung weggefallen. Beobachtet wurde des öfteren auch eine Abneigung dieser Haushalte, mit Angehörigen ,unterer" sozialer Schichten unter einem Dach zu leben. Durch solche Vorbehalte vergrößerte sich der Anteil der Problemgruppen in den geförderten Objekten - mit der Folge eines weiteren Attraktivitätsverlustes. Der hohe Ausländeranteil in dem Rutesheimer Pilotobjekt wird u.a. auf diesen Effekt zurückgeführt.

Bei der Wahrnehmung von Belegungsrechten durch die öffentliche Hand ist trotz der gegenteiligen Erfahrungen in Baden-Württemberg - aber auch der Fall denkbar, daß die sozial schwachen Haushalte nicht in dem erwünschten Maß in die Förderung einbezogen werden. Dazu kann es kommen, wenn der Träger der Belegungsentscheidung an den Kosten seiner Entscheidung beteiligt ist, da die Wohnungsvergabe dann unter Umständen von fiskalischen Aspekten mitbestimmt wird. Gerade bei rein kommunaler Finanzierung der Zusatzförderung (wie z.B. in Hessen) könnten sich die Gemeinden von Sparmotiven leiten lassen. In Baden-Württemberg, wo die Kommunen knapp 50\% der Zusatzförderung selbst aufbringen müssen, beträgt das Einsparpotential der Gemeinden bei einer 70-qm-Wohnung in zehn Jahren über 10.000 DM (Barwert). Allerdings ist die Belegungsentscheidung der dortigen Kommunen durch die Vorgabe des

1 Der immer noch starke Anstieg der Bruttokaltmieten läßt sich ,,in nicht unerheblichem Umfang auf die Nebenkosten zurückführen. Insbesondere die kommunalen Gebühren sind in den letzten Jahren sehr viel schneller gestiegen als die Nettokaltmieten“; Deutscher Bundestag (1996), S. 7.

2 An die Genauigkeit der RDM-Daten sollten allerdings keine allzu hohen Ansprüche gestellt werden, da sie nicht über statistisch repräsentative Erhebungen gewonnen werden, sondern auf der Markteinschätzung der befragten Makler basieren. Es ist davon auszugehen, daß die ermittelten Werte „die tatsächlichen Mieten etwas überzeichnen, da bei Einschaltung von Maklern häufiger als bei 'freihändiger' Vermietung vorhandene Preisspielräume weitestgehend ausgenutzt werden dürften"; Deutscher Bundestag (1992a), S. 20. 
Landes eingeschränkt, nach der mindestens 50\% der Wohnungen eines Objekts an Mieter mit Einkommen unterhalb der Grenze des $\S 25$ vergeben werden müssen. Befragungen zu den baden-württembergischen Modellprojekten ergaben, daß die Mitarbeiter der Gemeinden auch den finanziellen Konsequenzen der Belegungsentscheidung eine gewisse Bedeutung beigemessen haben.

Der letztlich geringe Einfluß fiskalischer Motive auf die Belegungsergebnisse ist vor allem auf die schon erwähnten Schwierigkeiten zurückzuführen, überhaupt besserverdienende Mietinteressenten für die Wohnungen zu finden. Sollten diese Schwierigkeiten - etwa in Zeiten großer Nachfrageüberhänge auf dem Wohnungsmarkt - nicht mehr bestehen, könnten sich die finanziellen Interessen der Kommunen auch in der Belegungsstruktur der geförderten Objekte niederschlagen. Vermeiden ließe sich dies nur dann, wenn die Kommunen einen von der Höhe der Zusatzförderung unabhängigen Finanzierungsbeitrag zu leisten hätten. Denkbar wäre eine Vorgehensweise wie in Schleswig-Holstein, wo sich die Gemeinden mit einem zinsverbilligten Baudarlehen an den Gesamtkosten des Bauvorhabens beteiligen müssen.

\section{b. Ineffiziente Pauschalförderung}

Noch weniger überzeugen kann die EOF im Hinblick auf die angestrebte Fördereffizienz, da die zur Kompensation für die Belegungsbindung vergebenen Fördermittel nur in losem oder überhaupt keinem Zusammenhang mit den wirtschaftlichen Einbußen stehen, für die sie den Investor entschädigen sollen. Dies wird bereits deutlich, wenn man die von den Ländern eingesetzten Subventionsvolumina vergleicht (vgl. Übersicht 5 in Kapitel 2.F.II). So weisen die im Rahmen der Neubauförderung aufgewendeten Förderbarwerte eine Spanne von über 70.000 DM auf. Diskrepanzen in dieser Größenordnung, die - wie der Vergleich von Brandenburg und Nordrhein-Westfalen zeigt - sogar bei Vorliegen identischer Bindungszeiträume auftreten können, lassen sich nicht allein durch Unterschiede in den aus der Wohnungsbindung resultierenden Kosten erklären, sondern spiegeln vielmehr die verschiedenen „Fördermentalitäten“ der Länder wider.

Wie wenig sich die Landesregierungen um eine zweckorientierte Gestaltung der Grundförderung bemüht haben, wird unter anderem an der eigenkapitalabhängigen Staffelung der Förderdarlehen in Brandenburg deutlich. Die Eigenkapitalquote hat mit den wirtschaftlichen Nachteilen des Investors aus der Mietpreis- und der Belegungsbindung nicht das Geringste zu tun. Ebenso unangebracht ist die in Berlin vorgenommene Differenzierung der Zinssätze nach der Aufwendigkeit des Bauvorhabens, da auch diese in keinem Zusammenhang mit 
dem Zweck der Grundförderung steht. Beide Länder geben ein Beispiel dafür, daß das Denken der für die Wohnungsbauförderung Verantwortlichen immer noch vom Kostenmietprinzip geprägt ist.

Ähnliches gilt für die Länder, in denen die Darlehensbeträge nach dem regionalen Mietniveau gestaffelt sind. Ein solches Vorgehen ist durch den Zweck der Grundförderung nur zu rechtfertigen, wenn die Einbußen des Investors aus der Mietpreisbindung in entsprechender Weise variieren, was aber nicht der Fall ist. Wegen des Zusammenhangs zwischen den ortsüblichen Mieten und den Baulandpreisen läuft die Staffelung der Darlehenssätze vielmehr auf eine Ausrichtung der Förderung an den Gesamtkosten des Objekts hinaus.

Auch in Nordrhein-Westfalen werden die Fördersätze nach dem regionalen Mietenniveau differenziert, doch kurioserweise ist die nach Abzug der einkommensabhängigen Leistungen (oder nach Mietverzicht in entsprechender Höhe) verbleibende Grundförderung in Gebieten mit einem hohem Mietniveau deutlich geringer als in Gebieten mit niedrigen Mieten. Bei konsequenter Anwendung der 1996 ergangenen Förderbestimmungen würden Investoren, die dem Land kein Besetzungsrecht an den belegungsgebundenen Wohnungen einräumen, in Gemeinden der Mietenstufe V eine negative (!) Nettoförderung erhalten. ${ }^{1}$ Das Land hat sich mit den Subventionswirkungen seiner einkommensabhängigen Förderung vor Erlaß der Bestimmungen offensichtlich gar nicht näher befaßt.

Wie unterschiedlich auch die Beträge ausfallen, die von den Ländern für den Erwerb der Belegungsbindungen aufgewendet werden, zeigt eine Berechnung am Beispiel der Städte Stuttgart, Köln und Berlin. Dabei wurde das Fördervolumen ermittelt, das den Investoren nach Abzug der Mindereinnahmen aus der Preisbindung verbleibt. Übersicht 11 zeigt die Annahmen und Ergebnisse des Vergleichs. Die dort als marktüblich angenommenen Erstvermietungsmieten sind dem RDM-Immobilien-Preisspiegel 1996 entnommen. Zu den Basismieten und ihrer Dynamisierung sowie der Ausgestaltung der Grundförderung sei auf die im Anhang aufgeführten Förderkonditionen der jeweiligen Bundesländer verwiesen. Ein Vergleich der in Übersicht 11 ganz unten aufgeführten Barwerte zeigt, daß die Grundförderung in Köln noch nicht einmal die Einbußen aus der Mietpreisbindung abdeckt, während Berlin für die Belegungsbindung - es handelt sich noch nicht einmal um ein Belegungsrecht - einen Mitteleinsatz erbringt, der die tatsächlichen Einbußen des Investors um ein Mehrfaches übersteigen dürfte. Es ist daher wenig verwunderlich, daß sich die EOF in Berlin bei

1 Die Förderbestimmungen des Landes sehen vor, daß die Darlehen der WBFA auf höchstens $80 \%$ abgesenkt werden, wenn kein Besetzungsrecht eingeräumt wird. Die in einer Gemeinde der Mietenstufe V geleistete Grundförderung fällt dann niedriger aus als die vom Vermieter geschuldeten einkommensabhängigen Leistungen. 
den Investoren auf reges Interesse gestoßen ist. In Nordrhein-Westfalen - vor allem in den Gemeinden der höheren Mietenstufen - wird vermutlich eher das Gegenteil der Fall sein.

Übersicht 11: Ermittlung der auf die Belegungsbindung entfallenden Förderbeträge am Beispiel ausgewählter Städte

\begin{tabular}{|c|c|c|c|}
\hline & $\begin{array}{l}\text { Beispiel I: } \\
\text { Stuttgart }\end{array}$ & $\begin{array}{l}\text { Beispiel II: } \\
\text { Köln }\end{array}$ & $\begin{array}{l}\text { Beispiel III: } \\
\text { Berlin }\end{array}$ \\
\hline $\begin{array}{l}\text { marktübliche Miete pro qm und Monat } \\
\text { - im Jahr der Erstvermietung } \\
\text { - danach }\end{array}$ & $\begin{array}{l}17,50 \mathrm{DM} / \mathrm{qm} \\
\text { plus } 3,5 \% \text { p.a. }\end{array}$ & $\begin{array}{r}18 \mathrm{DM} / \mathrm{qm} \\
\text { plus } 3,5 \% \text { p.a. }\end{array}$ & $\begin{array}{r}14 \mathrm{DM} / \mathrm{qm} \\
\text { plus } 3,5 \% \text { p.a. }\end{array}$ \\
\hline $\begin{array}{l}\text { Basismiete pro qm und Monat } \\
\text { - im Jahr der Erstvermietung } \\
\text { - danach }\end{array}$ & $\begin{array}{r}14 \mathrm{DM} / \mathrm{qm} \\
\text { plus } 0,60 \mathrm{DM} \\
\text { alle zwei Jahre }\end{array}$ & $\begin{array}{r}17 \text { DM/qm } \\
\text { plus } 2 \% \\
\text { jährlich }\end{array}$ & $\begin{array}{r}15 \mathrm{DM} / \mathrm{qm} \\
\text { plus } 0,40 \mathrm{DM} \\
\text { alle } 15 \text { Monate }\end{array}$ \\
\hline Art der Grundförderung & OS-10-Darlehen & Baudarlehen & $\begin{array}{l}\text { Baudarlehen } \\
\text { plus Zuschuß }\end{array}$ \\
\hline Dauer der Förderung & 10 Jahre & 20 Jahre & 15 Jahre \\
\hline $\begin{array}{l}\text { Barwert der Grundförderung } \\
\text { Teilbetrag zum Ausgleich der } \\
\text { Mietpreisbindung }\end{array}$ & $36.349 \mathrm{DM}$ & $11.309 \mathrm{DM}$ & $51.292 \mathrm{DM}$ \\
\hline Differenzbetrag (für Belegungsbindung) & $5.118 \mathrm{DM}$ & $-23.900 \mathrm{DM}$ & $47.779 \mathrm{DM}$ \\
\hline
\end{tabular}

Die hier nur beispielhaft aufgezeigten Unzulänglichkeiten bei der Festsetzung der Förderbeträge bringen es mit sich, daß die Förderangebote aus der Sicht der Bauherren unterschiedlich attraktiv ausfallen. Potentielle Investoren werden aber nur diejenigen Förderangebote auswählen, die für sie günstig sind, während die zu gering dotierten meist unausgenutzt bleiben. Daher führt die willkürliche Festsetzung der Förderbeträge aufs Ganze gesehen zur Verschwendung knapper Haushaltsmittel.

Auch von der Rücksprache mit Vertretern der Bauwirtschaft kann eine genauere Abstimmung der Fördervolumina an das von den Investoren für nötig erachtete 
Niveau nicht erwartet werden. Denn die Adressaten der Förderung haben keinen Anreiz, ihre wahren Vorstellungen darüber offenzulegen, welche Förderhöhe sie als hinreichend ansehen. Statt dessen werden sie die öffentliche Hand darin bestärken, bei der Mittelvergabe großzügig zu verfahren. Dieses Bestreben trat u.a. bei der modellhaften Erprobung der EOF im Würzburger Planspiel zutage. Einer der zentralen Kritikpunkte von seiten der bei dem Planspiel vertretenen Investoren bestand darin, daß die Grundförderung zu niedrig sei, wobei den Investoren noch die volle Abdeckung der Kostenmiete als Ziel vorschwebte. ${ }^{1}$

Nachdem die EOF inzwischen in die Testphase eingetreten ist, könnten die zuständigen Stellen aus der Resonanz, die ihre Förderangebote bei den Investoren finden, Rückschlüsse auf eine vermeintliche Unter- oder Überdotierung der Förderangebote ziehen. In der Förderpraxis ist dies jedoch kaum zu erwarten, da die politischen Entscheidungsträger dazu tendieren, stark nachgefragte Angebote als „Erfolge“ einzustufen; die hohe Akzeptanz werten sie eher als Zeichen für die Richtigkeit der bestehenden Förderkonditionen denn als Indiz für eine zu großzügige Mittelvergabe. Dagegen wird ein Förderangebot, das bei Investoren wegen einer sparsamen Mittelvergabe nur auf geringes Interesse stößt, nicht selten als „Mißerfolg“ klassifiziert. Hinzu kommt, daß trotz der geringen Nachfrage von seiten der Investoren nicht ausgeschlossen werden kann, daß die Förderung sogar zu großzügig bemessen ist. Dies gilt vor allem dann, wenn mehrere unterschiedliche Fördermaßnahmen gleichzeitig angeboten werden. Die geringe Akzeptanz einer einzelnen Maßnahme kann unter diesen Umständen darauf beruhen, daß die anderen Angebote von den Investoren als noch vorteilhafter eingestuft werden. ${ }^{2}$ Auch kann die geringe Nachfrage darauf zurückzuführen sein, daß potentielle Investoren nur unzulänglich über das betrachtete Förderangebot informiert worden sind.

Die Fördereffizienz wird mitunter auch dadurch verringert, daß die Förderangebote besondere Risiken enthalten, die von den potentiellen Investoren nur eingegangen werden, wenn in der Förderung ein Risikoaufschlag enthalten ist. Beispielsweise haben Investoren in Thüringen keine Sicherheit über die Dauer der Wohnungsbindung, weil der Bewilligungsstelle das Recht vorbehalten ist, den Regelbindungszeitraum nachträglich zu verlängern. Zwar gewährt das Land dem Investor eine Verlängerung der Zinsverbilligung, doch hat die Entscheidung über die Bindungsdauer trotzdem auch Auswirkungen auf die Rentabilität

Vgl. Bundesministerium für Raumordnung, Bauwesen und Städtebau (1993), S. 5.

2 Das Bundesbauministerium verweist darauf, daß solange die Konkurrenz durch den ersten Förderweg ,mit einer hohen und für den Investor risikoarmen Grundförderung besteht, ... die Akzeptanz bei Wohnungsunternehmen für neue und effizientere Förderwege erschwert" wird; Bundesministerium für Raumordnung, Bauwesen und Städtebau (1993), S. 5. 
des Förderangebotes. Besonders große Investoren-Risiken kennzeichnen die EOF in Berlin: Dort hängt die Dauer der Preisbindung davon ab, welcher Einkommenskategorie die Mieter am Ende des 15jährigen Regelbindungszeitraumes angehören. Im Extremfall muß der Investor weitere zwölf Jahre warten, bis er die Vertragsmiete unter Beachtung des MHG an das marktübliche Niveau heranführen kann. Eine entsprechende Differenzierung der Grundförderung ist aber nicht vorgesehen. Zum Zeitpunkt der Fördervereinbarung bestehen daher gerade bei Eigentümern nur einer oder weniger Wohnungen - große Unsicherheiten darüber, wie rentabel die Investition letztlich ist.

Selbst bei klaren Vorgaben über die Höhe der Förderung und die Dauer der Zweckbestimmung des Wohnraums ist die EOF für die Investoren nicht risikolos. Denn zum Zeitpunkt der Fördervereinbarung wissen die Bauherren noch gar nicht, welche wirtschaftlichen Nachteile sich aus der jeweiligen Belegungsbindung tatsächlich ergeben. Wegen der angestrebten sozialen Durchmischung in den geförderten Objekten können die Einbußen bei den einzelnen Wohnungen sehr unterschiedlich ausfallen. So ist das Mietausfallwagnis bei der Wohnungsvergabe an einen Bezieher niedriger Einkünfte i.d.R. größer als bei der Vermietung an einen finanziell gut situierten Haushalt. Neben der Höhe bestimmt außerdem die Sicherheit und Regelmäßigkeit der Einkünfte über die Mietzahlungsfähigkeit. Paradoxerweise ist ein Haushalt, der laufende Leistungen zum Lebensunterhalt nach dem Bundessozialhilfegesetz erhält, unter diesem Gesichtspunkt als „guter" Mieter einzustufen, da die Mietzahlung vom Sozialamt garantiert wird. Auch ist die Vermietung an einen niedrig besoldeten Beamten im allgemeinen risikoloser als ein Mietverhältnis mit einem Besserverdienenden in unsicherer Beschäftigungslage.

Es zeigt sich, daß eine differenzierte Abschätzung der wegen der Belegungsbindung eintretenden wirtschaftlichen Verluste nur unter genauen Kenntnissen des Einzelfalls möglich ist. Da die Investoren zum Zeitpunkt der Fördervereinbarung über solche Kenntnisse i.d.R. noch nicht verfügen (die Belegung der Wohnungen erfolgt oft erst zwei Jahre später), tragen sie ein hohes Risiko, für das sie eine Zusatzprämie einfordern werden. ${ }^{1}$ Die Bewilligungsstelle könnte die Unsicherheit der Investoren dadurch etwas verringern, daß sie vorab festlegt, welcher Einkommenskategorie die Mieter der einzelnen Wohnungen angehören werden. Außerdem könnte sie die Grundförderung bei Wohnungen, die für Haushalte mit Einkommen oberhalb der Grenze des $\S 25$ bestimmt sind, etwas niedriger ansetzen als bei einer Vermietung an Personen, die die Grenze

1 Die Risiken fallen gerade dann ins Gewicht, wenn es sich um Kleinanleger mit nur einer oder wenigen Wohnungen handelt. Dagegen können Wohnungsunternehmen mit einem großen Bestand an belegungsgebundenen Wohnungen die durchschnittlichen Kosten wegen des „Gesetzes der großen Zahlen“ mit einer größeren Sicherheit abschätzen. 
einhalten. Eine solche Differenzierung der Förderung findet gegenwärtig aber nicht statt. So gewährt etwa das Land Berlin seine Grundförderung in Höhe von rund 51.292 DM (Übersicht 11) auch dann, wenn der Bauherr an einen Haushalt vermietet, der aufgrund seines Einkommens (das für einen Drei-PersonenHaushalt im Extremfall bis zu 120.000 DM betragen kann) und seiner sozialen Merkmale auch ohne staatliche Hilfe eine Wohnung bekommen würde. Daraus ergibt sich ein unnötig hoher Mitteleinsatz, denn eine Grundförderung, die für die Vermietung an einen einkommensschwachen Mieter entschädigen soll, fällt bei einer weitgehend risikolosen Vermietung an finanziell bessergestellte Haushalte zu hoch aus. ${ }^{1}$

Am besten wäre es, wenn die Länder (oder Gemeinden) von der Festbetragsförderung abrücken und statt dessen selbst für die Kosten der Belegungsbindung aufkommen würden. Eine Investition im Rahmen der EOF wäre dann aus der Sicht der Kapitalanleger risikolos, und der Staat bräuchte nur noch die tatsächlich eingetretenen Kosten zu begleichen. Auf eine weitgehende Übernahme der Kosten und Risiken läuft die von einzelnen baden-württembergischen Gemeinden praktizierte Zwischenmietung der geförderten Wohnungen hinaus. Die Investoren werden dadurch mitunter sogar bessergestellt als bei einer freien Vermietung ihrer Wohnungen, so daß eine Prämie für die Belegungsbindung eigentlich gar nicht mehr gewährt werden müßte. ${ }^{2}$ Die Grundförderung durch den Staat könnte sich auf Beträge zum Ausgleich der Mietpreisbindung beschränken. Vor allem aber bräuchten keine Risikozuschläge mehr ausgezahlt werden.

I Bei der Modernisierungsförderung können noch gravierendere Ineffizienzen eintreten: Aus technischen Gründen, wegen der günstigeren Baukostensituation und vor allem wegen der zwangsläufigen Unannehmlichkeiten für die Bewohner ist es sinnvoll und allgemein üblich, ganze Häuser in die entsprechenden Baumaßnahmen einzubeziehen. Von den bisherigen Bewohnern der geförderten Objekte werden viele aber langfristig in ihren Wohnungen verbleiben oder erst zu einem späteren Zeitpunkt ausziehen. Der Staat hat dann mitunter „umsonst“ gefördert oder kann das Belegungsrecht zugunsten der bezugsberechtigten Personen erst zu einem späteren Zeitpunkt wahrnehmen. Vgl. Bundesverband Freier Wohnungsunternehmen e.V. (1994), S. 211 (39).

2 Bei der Grundförderung durch das Land wird nicht danach differenziert, ob die Gemeinden die Zusatzförderung in Zuschußform leisten oder ob sie als Zwischenmieter der geförderten Wohnungen auftreten. Die Investoren bekommen daher auch bei kommunaler Zwischenmietung die volle Grundförderung, obwohl die Gemeinden annähernd sämtliche Kosten der Belegungsbindung übernehmen. 
Diagramm 3: Höhe der von einzelnen Investoren erwarteten Prämien für die Überlassung des Belegungsrechts

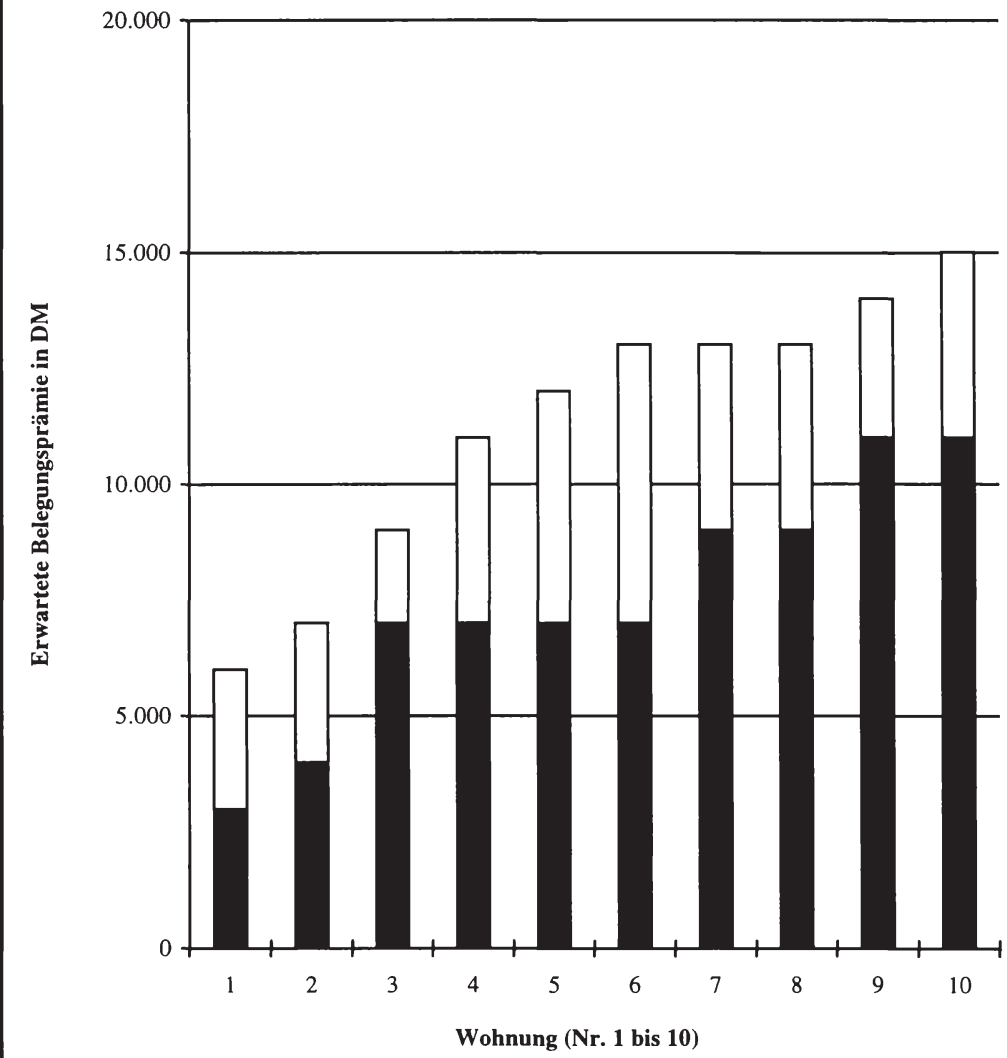

Die möglichen Einsparungen bei einer solchen Vorgehensweise gegenüber der vorherrschenden Förderung mit einheitlichen Festbeträgen seien am Beispiel eines Objekts mit zehn gleich großen Wohnungen verdeutlicht. Für jede Wohnung stehe ein potentieller Investor zur Verfügung. Die schwarzen Sockel der in Diagramm 3 dargestellten Säulen geben die von den Kaufinteressenten subjek- 
tiv erwarteten wirtschaftlichen Einbußen aus der Belegungsbindung wieder, während die weißen Bereiche den Risikoaufschlag darstellen.

Wie im Diagramm zu erkennen ist, werden bei einer im Rahmen der Grundförderung gewährten Belegungsprämie in Höhe von 10.000 DM nur drei Kapitalanleger bereit sein, im vierten Förderweg zu investieren. Die Interessenten Nr. 4 bis 8 rechnen zwar damit, daß die finanziellen Einbußen geringer ausfallen werden als der Prämienbetrag, scheuen jedoch unter Berücksichtigung des Risikos vor einer Investition im vierten Förderweg zurück. Bei den übrigen Kapitalanlegern scheitert die Einbeziehung in die Förderung daran, daß die erwarteten Verluste über die Förderpauschale hinausgehen.

Will der Staat dennoch sämtliche Wohnungen im Rahmen der EOF fördern, muß er die Prämie auf 15.000 DM anheben. Das für den Erwerb der Belegungsbindung eingesetzte Fördervolumen beläuft sich dann auf 150.000 DM. Kommt er dagegen selbst für die Kosten der Belegungsbindung auf, kann er aus zwei Gründen Mittel einsparen: Zum einen deshalb, weil nun nicht mehr jeder Investor die gleiche Prämie erhält, sondern die Mittel einzelfallorientiert vergeben werden. Zum anderen braucht der Staat keine Risikoprämien mehr zu leisten. Wird davon ausgegangen, daß die Investoren die tatsächlichen Kosten der Belegungsbindung richtig einschätzen, muß die öffentliche Hand nur noch Ausgaben in Höhe der schwarzen Säulenabschnitte tätigen. Die Werte im Diagramm wurden so gewählt, daß der Staat durch die Abkehr von der Pauschalförderung 50\% des Fördervolumens einsparen kann. 


\section{Eignung der EOF als Instrument der Subjektförderung}

\section{Anforderungen an ein einkommensorientiertes Fördersystem}

Kerngedanke der EOF ist die Ausrichtung der Wohnkosten an der individuellen Belastbarkeit der Mieter. Die einkommensabhängige Mietpreisgestaltung durch die Länder und Gemeinden ist Gegenstand der folgenden Ausführungen. Analysiert werden soll, ob und in welchem Maße die einzelnen Varianten der EOF den distributiven, allkokativen und fiskalischen Anforderungen an ein rationales Fördersystem gerecht werden. Besonderes Augenmerk wird dabei auf die folgenden Grundsätze gelegt:

- Prinzip der Tragbarkeit. Die Transfers müssen ausreichen, um die Tragbarkeit der Wohnkostenbelastung sicherzustellen. Auf der anderen Seite sollte die Belastbarkeit von Haushalten, die in den verbilligten Wohnungen leben, voll ausgeschöpft werden, damit der Förderaufwand nicht unnötig hoch ausfällt. ${ }^{1}$ Daraus folgt, daß die Mietverbilligungen mit steigendem Einkommen zurückgeführt werden müssen. Oberhalb einer normativ festzulegenden Einkommensgrenze dürfen keine Vergünstigungen mehr gewährt werden.

- Prinzip der Fühlbarkeit unterschiedlicher Wohnqualität. „Die Mietpreisrelationen sollten die Wohnwertrelationen und damit die relativen Preise am Markt widerspiegeln, auch dann wenn sie durch Subventionen insgesamt im Niveau deutlich unter den Vergleichsmieten liegen." ${ }^{\prime 2}$ Aus dem Prinzip läßt sich die Forderung ableiten, daß Mietunterschiede der belegungsgebundenen Wohnungen durch die Vergünstigungen nicht vollständig nivelliert werden dürfen. Die Unterschiede im Wohnwert sollen fühlbar bleiben.

- Grundsatz der Vermeidung zu hoher Grenzbelastungen. Einkommensabhängige Subventionen sollten so ausgestaltet sein, daß jeder Zuwachs des Bruttoeinkommens zu einer Erhöhung des verfügbaren Einkommens führt, d.h. die Transferfunktion darf keine Sprungstellen aufweisen. Um die Arbeitsanreize der Wirtschaftssubjekte nicht zu beeinträchtigen, sollte die Grenzbelastung im Funktionsbereich, in dem der Abbau der Zusatzförderung vorgenommen wird, deutlich unter $100 \%$ liegen, wobei Veränderungen sämtlicher einkommensabhängiger Abgaben und Transfers zu berücksichtigen sind.

- Prinzip der Verhältnismäßigkeit des Verwaltungsaufwandes. Bei der Ausgestaltung der Transfersysteme sollte darauf geachtet werden, daß die zuständigen Stellen nur in geringem Umfang zusätzlich beansprucht werden. Jeder unnötige

1 Vgl. Pfeiffer, U. u.a. (1996), S. 4.

2 Pfeiffer, U. u.a. (1996), S. 4. 
Verwaltungsaufwand ist zu vermeiden und der unvermeidbare Aufwand auf seine Verhältnismäßigkeit zu prüfen.

Die Ausgestaltung der Transfers hängt maßgeblich davon ab, welches Gewicht den einzelnen Grundsätzen beigemessen wird. Dies gilt insbesondere für die beiden erstgenannten Prinzipien. Je stärker die einkommensbezogene Komponente berücksichtigt wird, desto geringer ist das Gewicht der Wohnwertkomponente und umgekehrt. Dominiert das Tragbarkeitsprinzip, dann haben Haushalte mit gleichem Einkommen trotz gravierender Wohnwertunterschiede gleich hohe oder nur geringfügig abweichende Mieten zu zahlen. Bei hoher Gewichtung des Fühlbarkeitsgrundsatzes werden die Wohnwertunterschiede durch die Transfers auch bei niedrigen Einkommen der Mieter nicht oder nur in geringem Maße abgefedert. ${ }^{1}$

Ein Zielkonflikt besteht auch zwischen dem Tragbarkeitsgrundsatz und der Vermeidung allzu hoher Grenzbelastungen. Die volle Ausschöpfung der $\mathrm{Be}-$ lastbarkeit eines Haushaltes würde strenggenommen verlangen, daß jeder Anstieg des verfügbaren Einkommens zu 100\% auf die Transferhöhe angerechnet wird. Ein solches Vorgehen wird im allgemeinen abgelehnt, da Anreize zur Steigerung des Einkommens erhalten bleiben sollen. Eine Transfergestaltung, bei der die Wohnkosten ein bestimmtes Prozentverhältnis zum Einkommen von z.B. $30 \%$ nicht überschreiten, läßt sich als Kompromiß zwischen den Grundsätzen der Tragbarkeit und der Vermeidung hoher Grenzbelastungen interpretieren. Abstriche beim Tragbarkeitsprinzip können auch aus dem Bemühen resultieren, den Verwaltungsaufwand gering zu halten. Denn je exakter die Transfers an der individuellen Bedürftigkeit der begünstigten Haushalte ausgerichtet werden sollen, desto öfter müssen Einkommensprüfungen vorgenommen werden und desto höher fällt der mit der Einkommensermittlung verbundene Erfassungs- und Kontrollaufwand aus.

\section{Exkurs: Zum Verhältnis von Miete und Einkommen}

In der Vergangenheit ist es üblich gewesen, die Wohntransfers so auszugestalten, daß die Wohnkosten der begünstigten Haushalte bestimmte Prozentsätze vom Einkommen nicht überschritten. So hat der Gesetzgeber bereits $1956 \mathrm{im}$ mittlerweile weggefallenen $\S 73$ II. WoBauG die zuständigen obersten Landesbehörden dazu angehalten, die Wohnkostenbelastung für geringverdienende Mieter in den öffentlich geförderten Sozialwohnungen durch die Gewährung von Miet- und Lastenbeihilfen auf nach der Haushaltsgröße und dem Einkommen gestaffelte Sätze zwischen 10 und $18 \%$ zu begrenzen. Die als Tragbar-

Vgl. Hecht, M. (1978), S. 151. 
keitsgrenzen definierten Prozentsätze der Miete (ohne Nebenkosten) zum Jahreseinkommen im Sinne des $\S 25$ Abs. 2 II. WoBauG a.F. ${ }^{1}$ fielen um so niedriger aus, je mehr Mitglieder der Haushalt zählte und je geringer das Einkommen war. Auch im Gesetz über die Gewährung von Miet- und Lastenbeihilfen ${ }^{2}$ (Sätze zwischen 7 und 20\%), im Gesetz über Wohnbeihilfen ${ }^{3}$ (7 bis 24\%) und in der ersten Fassung des Wohngeldgesetzes ${ }^{4}$ ( 5 bis $22 \%$ ) wurden nach dem Einkommen und der Haushaltsgröße gestaffelte Mietquoten als Obergrenzen für die Wohnkostenbelastung festgelegt. Zur Höhe der Mietquoten stellt W. Knauer fest, daß sie nicht auf ökonomischen Forschungsergebnissen basieren, sondern „sich der Gesetzgeber im wesentlichen von Erfahrungswerten leiten ließ, im übrigen jedoch politisch-pragmatische Überlegungen den Ausschlag für die Höhe der Prozentsätze tragbarer Mietbelastungen gaben “5.

1 Danach war als Jahreseinkommen der durchschnittliche Gesamtbetrag der Einkünfte nach $\S 2$ des Einkommensteuergesetzes für die vorangegangenen drei Jahre zugrunde zu legen. Dem Kindergeld ähnliche Bezüge blieben bei der Feststellung des Jahreseinkommens unberücksichtigt.

2 Vom 23. Juni 1960 (BGBl. I S. 399). Das Gesetz ist ergangen als Artikel VII des Gesetzes über den Abbau der Wohnungszwangswirtschaft und über ein soziales Miet- und Wohnrecht (BGBl. I S. 389). Bei der zu entrichtenden Miete blieben Umlagen und Zulagen außer Betracht. Als Jahreseinkommen waren nach $\S 4$ ff. der Verordnung über die Gewährung von Miet- und Lastenbeihilfen vom 21. Dezember 1960 (BGBl. I S. 1056) alle Einnahmen in Geld oder Geldeswert anzusetzen, abzüglich bestimmter Leistungen wie Grundrenten, Schwerstbeschädigtenzulagen, Kindergeld, Kinderzulagen, laufende Unterstützungen aus Mitteln der öffentlichen Fürsorge etc. und eines Pauschalbetrages von 10\%, mit dem Aufwendungen für Versicherungen und Steuern berücksichtigt werden.

3 Vom 29. Juli 1963 (BGBI. I S. 508). Nach § 11 des Gesetzes war bei der Bemessung der Zuschüsse von der Bruttokaltmiete auszugehen. Diese Regelung ist ins Wohngeldgesetz übernommen worden. Die Definition des Jahreseinkommens ( $\S \S 16 \mathrm{ff}$.) lehnte sich eng an die Bestimmungen der Verordnung über die Gewährung von Miet- und Lastenbeihilfen an. Der Katalog der außer Betracht bleibenden Einnahmen wurde etwas erweitert und der Pauschalabzug für Steuern und Versicherungen auf $15 \%$ angehoben.

4 I.d.F. der Bekanntmachung vom 1. April 1965 (BGBl. I S. 177). Die erste Fassung des Wohngeldgesetzes beruht auf Artikel V des Gesetzes zur Änderung des Gesetzes über Wohnbeihilfen vom 23. März 1965 (BGBl. I S. 140). Das Wohngeldgesetz in seiner aktuellen Fassung nennt keine Prozentsätze mehr. Allerdings geht die Mietquote - als Verhältnis der um das Wohngeld gekürzten anrechenbaren Miete zum Familieneinkommen - in die Wohngeldformel ein und ist somit Steuerungsgröße bei der Bemessung der Transfers. Vgl. Hubert, F. (1995), S. 5.

5 Knauer, W. (1968), S. 29. 
Übersicht 12: Mietbelastung der Haushalte in Deutschland (Hochrechnung auf der Basis der 1\%-Gebäude- und Wohnungsstichprobe von 1993) ${ }^{I}$

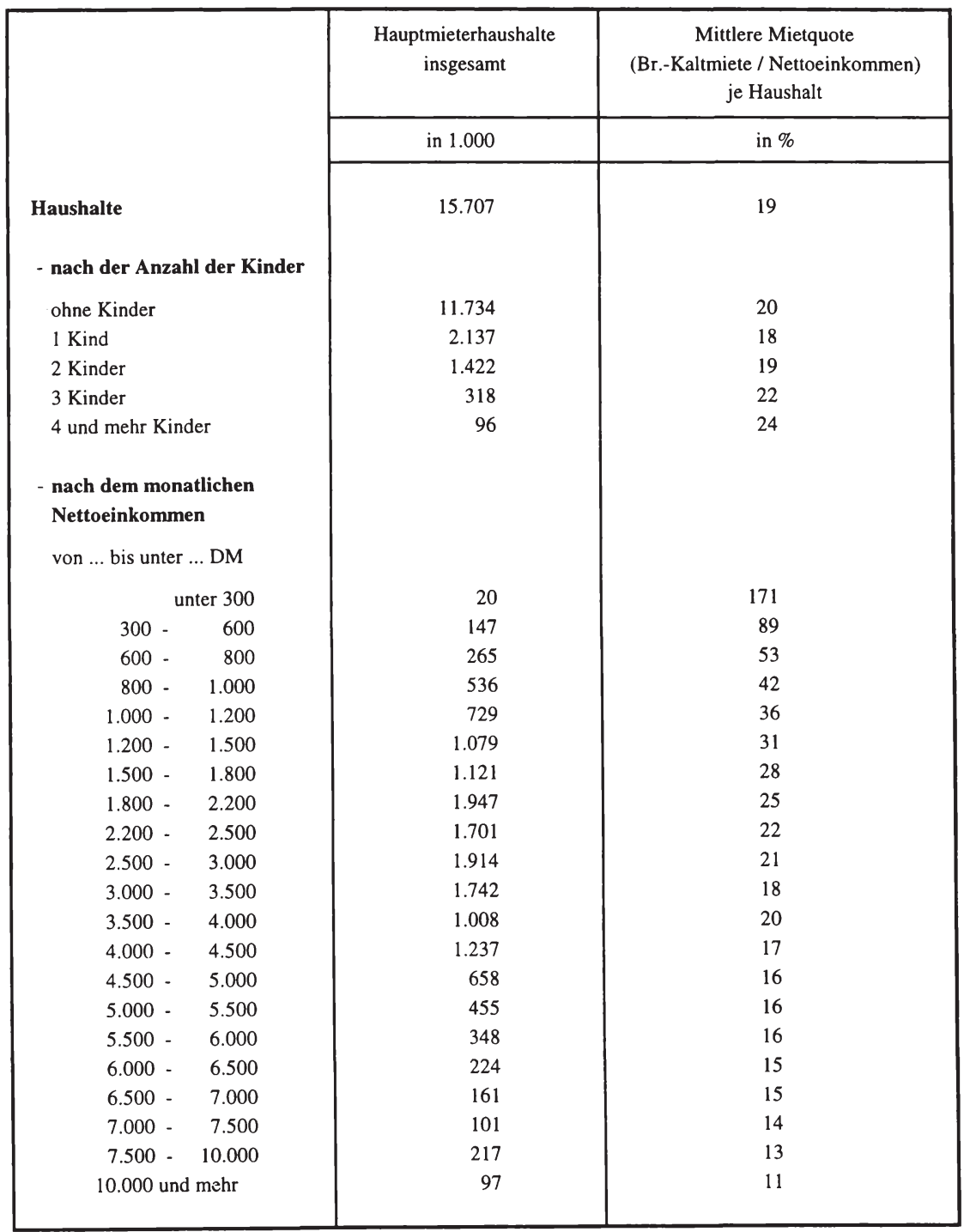

1 Ohne Haushalte in öffentlich geförderten Wohnungen, Wohnheimen, Ferien- oder Freizeitwohnungen (Angaben des Statistischen Bundesamtes). 
Auch in der wohnungspolitischen Diskussion werden oft Mietquoten herangezogen. ,Am häufigsten wird als tragbare Mietbelastung eine Quote von $20 \%$ des Einkommens genannt, wobei allerdings die Abgrenzung des Einkommens nicht immer einheitlich erfolgt. Dieser Wert ist sowohl in den Verhältnissen vor dem ersten Weltkrieg, zwischen den Weltkriegen wie in den fünfziger Jahren der Bundesrepublik vertreten worden." "Bis heute hat die 20\%-Marke kaum an Bedeutung eingebüßt. Nimmt man das Nettoeinkommen zum Maßstab, dann läßt sich die Aktualität dieser Quote sogar statistisch belegen: Nach der 1\%Gebäude- und Wohnungsstichprobe von 1993 lag der durchschnittliche Anteil der Bruttokaltmiete am Nettoeinkommen bei freifinanzierten Wohnungen im Erhebungszeitraum mit 19\% ganz dicht an besagter Marke. Wie in Übersicht 12 zu sehen ist, betrug die Mietquote bei geringverdienenden bzw. kinderreichen Haushalten im Durchschnitt sogar mehr als 20\%. Die Statistik weist diese Haushaltstypen als die Zielgruppen von Wohntransfers aus, wenn man die 20\%Marke als Tragbarkeitsgrenze ansieht.

Indes stellt sich die Frage nach der Eignung einer Pauschalquote als Maßstab für die „,zumutbare“ Belastung. Die Miet- und Lastenbeihilfen, die Wohnbeihilfen und das Wohngeld operieren mit nach dem Einkommen und der Haushaltsgröße differenzierten Quoten. Auch in der Literatur wird eine solche Staffelung als sinnvoll angesehen. W. Glatzer argumentiert am Beispiel der 20\%-Quote, daß bei Haushalten mit höheren Einkommen, die diesen Satz überschreiten, trotz der absolut gesehen hohen Mietaufwendungen nicht zwangsläufig von einer untragbaren Belastung gesprochen werden kann. „Für die ärmeren Haushalte andererseits kann ein Wert von $20 \%$ bereits viel zu hoch angesetzt sein, wenn für andere Ausgaben eine angemessene Höhe erhalten bleiben soll." ${ }^{2}$ Im Hinblick auf die Familiengröße meint Glatzer, „daß bei gleichem Einkommensniveau eine 20prozentige Einkommensbelastung durch Miete für einen großen Haushalt eine stärkere Belastung darstellt als bei einem kleineren Haushalt, weil vom restlichen Einkommen die Lebensansprüche einer größeren Personenzahl befriedigt werden müssen. Bei größeren Haushalten ist die Annahme nicht ungerechtfertigt, daß die 'Tragbarkeit' der Mietbelastung bereits bei geringeren Belastungsquoten überschritten wird. “3 ${ }^{33}$ Bi solchen Überlegungen darf allerdings nicht vergessen werden, daß sich die Zusatzförderung im Hinblick auf ihre verteilungspolitische Ausgefeiltheit nicht demselben Anspruch stellen muß wie etwa das Wohngeld. Denn die Transfers treten nicht an die Stelle des Wohngeldes, sondern werden ergänzend gewährt. Aus diesem Grunde erscheint eine Differenzierung der bei der Zusatzförderung zugrunde gelegten Bela-

\footnotetext{
1 Glatzer, W. (1980), S. 64. Vgl. auch Hecht, M. (1978), S. 31; Knauer, W. (1968), S. 30ff.

2 Glatzer, W. (1980), S. 65.

3 Glatzer, W. (1980), S. 106f.
} 
stungsquoten nach dem Einkommen nicht dringend erforderlich. Im Falle einer solchen Staffelung würde zudem das Problem auftreten, daß Haushalte, die aufgrund einer geringen Einkommenssteigerung in eine höhere Belastungsstufe kommen, u.U. sehr hohe Grenzbelastungen hätten; bei einer sehr feinen Staffelung wäre dagegen zu fragen, ob überhaupt noch mit Mietquoten operiert werden sollte, wenn sich die Anteilssätze am Einkommen mit diesem laufend verändern. Eindeutig sinnvoll erscheint aber eine Differenzierung der Quote nach der Haushaltsgröße. Denn gerade aus familienpolitischer Sicht ist es unbefriedigend, wenn zwei Haushalte mit gleichem Einkommen aber unterschiedlicher Mitgliederzahl auch nach der Gewährung der Transfers einkommensmäßig gleichgestellt sind. Die größere Familie muß dann stets eine höhere Pro-KopfBelastung tragen.

Gegen eine Pauschalquote ist außerdem einzuwenden, daß die Mietbelastung nicht nach dem Wohnwert differenziert wird. Bei gleichem Einkommen haben Haushalte, die in einer gutausgestatteten Wohnung in attraktiver Wohnlage leben, die gleiche Mietbelastung wie Haushalte in Wohnungen minderer Qualität. Der Fühlbarkeitsgrundsatz wird ignoriert. ${ }^{1}$ Es stellt sich die Frage, ob es nicht der Entscheidung der Haushalte überlassen bleiben soll, inwieweit sie für ihren Wohnkomfort eine höhere Miete im Verhältnis zu ihrem Einkommen bezahlen wollen. Dieses Argument gilt allerdings nur, wenn die Mieter bei der Wohnungssuche eine Auswahlmöglichkeit haben, was in Zeiten großer Angebotsdefizite oder bei Wohnungszuteilung durch die öffentliche Hand oft nicht der Fall ist.

${ }^{1}$ Vgl. Krabbes, R. (1993), S. 596. 


\section{Mietvergünstigungen durch die Grundförderung}

\section{a. Definition und Begründung der Basissubvention}

Die im Rahmen der EOF gewährten Mietvergünstigungen lassen sich in zwei Komponenten aufspalten: die Verbilligung der höchstzulässigen Basismiete gegenüber der Marktmiete und die Zusatzförderung. Die erstgenannte Komponente - sie sei im weiteren als „Basissubvention“ bezeichnet - wird durch die Grundförderung finanziert ( $\S 88$ e Abs. 1 II. WoBauG) und kommt jedem Haushalt zugute, der eine nach dem neuen Modell geförderte Wohnung beziehen kann. Eine Einkommensabhängigkeit besteht nur insoweit, als der Haushalt zum Zeitpunkt der Wohnungsvergabe die (erhöhten) Einkommensgrenzen einhalten muß. Von einer Subjektförderung im eigentlichen Wortsinne kann nicht gesprochen werden.

Es stellt sich die Frage, warum überhaupt Mietvergünstigungen außerhalb der Zusatzförderung gewährt werden. Dies mag zum einen daran liegen, daß der gesamten Zielgruppe der EOF eine gewisse Förderungswürdigkeit unterstellt wird. Ein zweites Argument zugunsten verbilligter Basismieten besteht darin, $\mathrm{da} ß$ die Wohnungen für besserverdienende Haushalte attraktiver werden, die keine oder nur eine geringe Zusatzförderung erhalten. Die Basissubvention verringert die Mehraufwendungen, die diese Haushalten wegen der Preisnachteile von Neubauwohnungen gegenüber Wohnungen aus dem älteren Bestand erbringen müssen. Zugleich mag sie einen Anreiz darstellen, trotz gegebenenfalls bestehender Vorbehalte mit sozial schwachen Haushalten unter einem Dach zu leben. Ohne die Basissubventionen dürfte es daher schwieriger sein, die angestrebte soziale Durchmischung in den Wohnungsbeständen zu erreichen.

Die Abstände zwischen höchstzulässiger und marktüblicher Miete können sich schließlich aus der Konstruktion der Grundförderung ergeben. Diese ist in einigen Ländern so ausgestaltet, daß den Investoren ein bestimmter Ertrag pro qm aus Mieteinnahmen und Grundförderung garantiert wird. Die Vorgehensweise ähnelt der beim Kostenmietprinzip: Die Grundförderung ist degressiv gestaltet, ihr Abbau erfolgt nach Maßgabe der zulässigen Anhebungen der Basismiete. Durch die Vorabfestlegung von Förderdegression und Mietanhebung über den gesamten Förderzeitraum soll den Investoren eine sichere Kalkulationsbasis gegeben werden. Damit die kalkulierte Basismiete auch bei einem wider Erwarten geringen Anstieg der Marktmiete nicht über deren Niveau hinausgeht, müssen die Länder bei der Dynamisierung vorsichtige Wertansätze wählen. Andernfalls wäre die Miete gegenüber Haushalten ohne Zusatzförderung kaum durchsetzbar und die Durchmischungszielsetzung würde verfehlt. ${ }^{1}$

Die Prognoseschwierigkeiten bei der Festsetzung der Basismiete werden am Beispiel des Landes Baden-Württemberg deutlich. Dort wurden für die nach 1994 geförderten Objekte 


\section{b. Ausmaß der Abweichungen von Basis- und Marktmiete}

In den meisten Bundesländern, die einkommensorientiert fördern, sollen die Basismieten unterhalb der Marktmiete festgesetzt werden. Bei der Marktmiete handelt es sich um den Mietzins, den der Investor durchsetzen könnte, wenn seine Wohnung keiner Mietpreis- und Belegungsbindung unterliegen würde. $\mathrm{Zu}$ Anfang ist dies die marktübliche Erstvermietungsmiete von in Ausstattung und Lage vergleichbaren freifinanzierten Neubauwohnungen. Bei freier Vermietung können die Investoren Anfangsmieten verlangen, die das Niveau der ortsüblichen Vergleichsmieten um bis zu 20\% überschreiten (Obergrenze des $\S 5$ WiStG). Unter der ortsüblichen Vergleichsmiete sind nach $\S 2$ Abs. 1 Satz $1 \mathrm{Nr}$. 2 MHG die üblichen Entgelte zu verstehen, die in der Gemeinde oder in vergleichbaren Gemeinden für nicht preisgebundenen Wohnraum vergleichbarer Art, Größe, Ausstattung und Lage in den letzten vier Jahren vereinbart oder, von Erhöhungen wegen gestiegener Betriebskosten nach § 4 MHG abgesehen, geändert worden sind. Ausschlaggebend für das Niveau der Anfangsmieten ist die Lage auf dem Wohnungsmarkt, wobei gerade die Erstvermietungsmieten durch starke Schwankungen gekennzeichnet sind. Beim Auftreten von Wohnungsmarktengpässen können sie deutlich über den Vergleichsmieten liegen, in Phasen der Entspannung dürften die Abweichungen dagegen eher gering ausfallen. In bestehenden Mietverhältnissen wird die auf dem Markt erzielbare Miete zunehmend durch das Niveau der ortsüblichen Vergleichsmiete bestimmt. Nach $\S 2$ Abs. 1 Satz 1 Nr. 2 MHG kann der Vermieter die Zustimmung des Mieters zu einer Mieterhöhung nur dann verlangen, wenn die geforderte Miete die Vergleichsmiete nicht übersteigt. Die anfänglichen Abstände zwischen der Erstvermietungsmiete und der (niedrigeren) Vergleichsmiete werden daher im Laufe des Mietverhältnisses verschwinden, denn Mieterhöhungen sind erst dann wieder zulässig, wenn die Vergleichsmiete über die Anfangsmiete hinaus angestiegen ist.

Aus den Überlegungen folgt, daß die vom Bund empfohlene Festsetzung der höchstzulässigen Anfangsmiete auf dem Niveau der ortsüblichen Vergleichsmiete (evtl. an deren unterem Rand) ${ }^{1}$ vielfach schon eine Basissubvention beinhaltet. Die Vergünstigung entspricht dem Betrag, um den die marktüblichen Erstvermietungsmieten die Vergleichsmieten in der Anfangsphase des Mietverhältnisses übersteigen. Die Mietvorteile dürften allerdings - außer bei gravie-

geringere Mietbeträge angesetzt als in den beiden Jahren zuvor, da eine unvorhergesehene Entspannung auf dem Wohnungsmärkten eingetreten und das Niveau der Neuvermietungsmieten vielerorts sogar gesunken war. Die anfänglichen Basismieten der Pilotmodelle von 1993 und 1994 erwiesen sich im nachhinein als etwas zu hoch. Dieser Tatbestand hat sicherlich dazu beigetragen, daß das Interesse der besserverdienenden Haushalte an den einkommensorientiert geförderten Wohnungen nur gering war (vgl. Kapitel 3.B.IV.a).

1 Vgl. Deutscher Bundestag (1994a), S. 19. 
renden Wohnungsmarktengpässen - nur von untergeordneter quantitativer $\mathrm{Be}$ deutung sein.

In den meisten Ländern dürften die Basismieten aber noch unterhalb der Vergleichsmieten liegen. Da die höchstzulässigen Anfangsmieten und ihre Dynamisierung oftmals schon in den Verwaltungsvorschriften der Länder festgelegt werden und daher eine Orientierung an den Gegebenheiten des Einzelfalls nur bedingt möglich ist, können die Abstände zwischen Basismiete und Marktmiete bei den geförderten Objekten sehr unterschiedlich ausfallen. Die für den ersten Förderweg charakteristischen Mietpreisverzerrungen, die bei der EOF ja eigentlich vermieden werden sollen, treten mitunter erneut auf.

Die Verzerrungen lassen sich u.a. auf die meist unzulängliche Ausrichtung der Basismieten an der regionalen Mietstruktur zurückführen. In erster Linie betroffen sind davon die Flächenländer Nordrhein-Westfalen und BadenWürttemberg, die die höchstzulässigen Basismieten bereits in den allgemeinen Förderbestimmungen betragsmäßig fixiert und damit eine flexible Anpassung an das ortsübliche Niveau verhindert oder zumindest erschwert haben. In Nordrhein-Westfalen werden die höchstzulässigen Mieten nach fünf Mietstufen gestaffelt, die Zuordnung der Gemeinden zu den Mietenstufen richtet sich nach der Anlage zu $\S 1$ Abs. 3 der Wohngeldverordnung in der jeweils geltenden Fassung. Neben der etwas groben Strukturierung hat dieses Vorgehen auch den Nachteil, daß die statistische Erhebung der Mietniveaus in den Gemeinden nur in großen zeitlichen Abständen erfolgt und die Zuordnung der Gemeinden zu den Mietstufen daher im Durchschnitt nur einen geringen Aktualitätsgrad aufweist. So basiert die beim ersten Förderjahrgang 1996 zugrunde gelegte Einstufung auf Daten, die bereits 1988, also etwa zehn Jahre vor der erwarteten Bezugsfertigstellung der Wohnungen, ermittelt wurden. ${ }^{1}$ Die daraus resultierenden Ungenauigkeiten lassen sich am Beispiel Kölns verdeutlichen. Köln zählte nach dem RDM-Immobilien-Preisspiegel von 1996 zu den fünf Großstädten mit den höchsten Erstvermietungsmieten, in der Wohngeldverordnung wurde die Stadt aber nur der dritthöchsten (IV) von insgesamt sechs Mietenstufen zugeordnet. Das Land hat Köln daher - abweichend von den Bestimmungen der WoGV - bei den Gemeinden der Mietenstufe V eingeordnet.

Auch Baden-Württemberg nimmt eine fünfstufige regionale Differenzierung der Basismieten vor. Die Zuordnung der Gemeinden zu den Kategorien erfolgt aber nicht auf der Basis von statistischen Erhebungen über das regionale Mietenniveau, sondern nach der Einwohnerzahl bzw. der Lage in oder außerhalb von Verdichtungsräumen (vgl. Kapitel 2.F.V). Die Vorgehensweise hat den Nachteil, daß Wohnwertunterschiede nur unzulänglich erfaßt werden. Beispielsweise werden alle Großstädte außer Stuttgart derselben Kategorie mit einer Basismiete

1 Vgl. Kapitel 2.F.V (Fußnote). 
von 13,50 DM zugeordnet, obwohl ihre ortsüblichen Mieten mitunter stark voneinander abweichen. Nach den Erhebungen des RDM lagen die durchschnittlichen Erstvermietungsmieten pro qm in den betroffenen Städten zwischen 11 DM (Heilbronn) und 16 DM (Heidelberg). Im allgemeinen gilt, daß die Mietvorteile an attraktiven Orten wie beispielsweise Baden-Baden, Heidelberg, Stuttgart, Freiburg und Konstanz am höchsten sind. Die Überlegungen zeigen, daß über die höchstzulässigen Basismieten gerade in den Flächenländern direkt ,vor Ort“ und frühestens bei der Bewilligung der Fördermittel entschieden werden sollte, da dann den spezifischen Bedingungen auf den regionalen Wohnungsmärkten am besten Rechnung getragen werden kann.

Die unzulängliche Ausrichtung der Basismieten am marktüblichen Niveau wird auch daran deutlich, daß die von den Ländern in ihren Verwaltungsvorschriften genannten Beträge überwiegend nicht nach der Wohnungsgröße gestaffelt sind. Nur Bremen hat in seinem Förderrichtlinien eine entsprechende Differenzierung der Mieten vorgenommen. Auf dem freien Wohnungsmarkt hängen die durchschnittlichen Quadratmetermieten aber nicht unwesentlich von der Gesamtfläche der Wohnung ab, wie die 1\%-Gebäude- und Wohnungsstichprobe von 1993 belegt. Danach kosteten freifinanzierte Wohnungen unter $40 \mathrm{qm}$ nettokalt durchschnittlich 11,30 DM, größere Wohnungen dagegen zwischen 8,12 DM (100 bis $120 \mathrm{qm}$ ) und 8,57 DM (40 bis $60 \mathrm{qm}) .{ }^{1}$ Durch die Nichtberücksichtigung dieser Mietunterschiede erhalten kleine Haushalte gegenüber den großen Familien eine in der Tendenz höhere Subvention.

Schließlich führen auch die Kappungsgrenzen bei der Dynamisierung der Basismieten zu hohen und stark variierenden Basissubventionen. Die Förderrichtlinien begrenzen das Wachstum der Basismieten auf Werte, die auf das Jahr umgerechnet je nach Bundesland zwischen 2 und 3\% liegen und damit deutlich geringer ausfallen als der statistisch ermittelte marktübliche Mietenanstieg (vgl. Kapitel 3.A.I). Die Kappungsgrenzen beziehen sich nicht nur auf Mieterhöhungen in bestehenden Mietverhältnissen, sondern gelten bei der Wiedervermietung fort. Es ist daher damit zu rechnen, daß die Obergrenzen zu einem scherenartigen Auseinanderlaufen der Basismieten und der Vergleichsmieten führen. Die sich daraus ergebenden Basissubventionen können im Zeitablauf eine beträchtliche Größenordnung erreichen - und zwar auch dann, wenn die Basismieten anfänglich noch mit dem marktüblichen Mietniveau übereinstimmen. Das Beispiel Nordrhein-Westfalens verdeutlicht dies: Selbst wenn der Anstieg der marktüblichen Mieten dort nur um $1 \%$ über der vom Land fixierten Kappungsgrenze (2\%) liegt, kumulieren sich die Basissubventionen im 20jährigen Förderzeitraum auf Barwerte $(\mathrm{q}=7 \%)$ zwischen 9.700 DM (Mietenstufe 1) und 15.000 DM (Mietenstufe 5). Noch stärker wirkt sich die Kappungsgrenze aus,

1 Angaben des Statistischen Bundesamtes. 
wenn die Basismieten bereits im Zeitpunkt der Erstvermietung unterhalb der Marktmiete liegen. ${ }^{1}$

Zusammenfassend läßt sich festhalten, daß die höchsten Basissubventionen pro qm solchen Haushalten zufließen, die in kleinen Wohnungen sowie in Städten mit einem hohen Wohnwert leben und die während des gesamten Förderzeitraums in ihren Sozialwohnungen verbleiben. Die Mietvorteile können in Einzelfällen ein enormes Ausmaß annehmen, wie sich an der EOF in BadenWürttemberg belegen läßt. Am Beispiel der Stadt Stuttgart sollen die kumulierten Mieteinsparungen geschätzt werden, die sich bei 20jähriger Förderung (OS20-Darlehen) für eine Wohnung mit $45 \mathrm{qm}$ und eine mit $70 \mathrm{qm}$ Wohnfläche ergeben. Geht man von einer ortsüblichen Erstvermietungsmiete in Höhe von 18 DM bei der kleineren und 17 DM bei der größeren Wohnung aus und unterstellt ferner, daß bei freier Vermietung eine Mietanhebung von 3\% pro Jahr erfolgen würde, dann summiert sich die Basissubvention pro qm im Förderzeitraum auf einen Gegenwartswert von $871 \mathrm{DM}$ bei der 45-qm-Wohnung und $705 \mathrm{DM}$ bei der 70-qm-Wohnung. Bei Multiplikation mit der qm-Zahl ergibt sich eine Gesamtförderung in Höhe von 39.195 DM bzw. 49.350 DM.

\section{c. Kritische Würdigung}

Die Gewährung von Basissubventionen hat in einem rationalen Fördersystem keinen Platz, da dadurch gegen den Tragbarkeits- und den Fühlbarkeitsgrundsatz verstoßen wird. Das Prinzip der Tragbarkeit wird verletzt, weil die Mietvergünstigungen nicht an der Einkommenssituation der Mieter ausgerichtet werden, sondern auch solchen Haushalten zufließen, deren Einkommen im Förderzeitraum die Bezugsberechtigungsgrenzen überschritten haben und die somit nicht mehr zum Adressatenkreis der EOF zählen. Diese Haushalte kommen wegen der verzögerten Dynamisierung der Basismieten paradoxerweise gerade in späteren Jahren, wenn sie infolge des Einkommensanstiegs die Förderung am wenigsten benötigen, in den Genuß der höchsten Basissubventionen. Zugleich haben Fehlbeleger im Zeitablauf einen immer geringeren Anreiz, aus den geförderten Wohnungen auszuziehen, so daß allokativ unerwünschte Mobilitätshemmnisse auftreten dürften.

Durch die Abweichungen der höchstzulässigen von den marktüblichen Mieten wird außerdem gegen das Prinzip der Fühlbarkeit verstoßen. In einigen Bundes-

1 Dies läßt sich darauf zurückführen, daß der Mietenanstieg (Differenz zwischen der Anfangsmiete und der dynamisierten Miete) bei einem hohen Ausgangsniveau absolut größer ist als bei einer niedrigen Anfangsmiete, die mit dem gleichen Prozentsatz dynamisiert wird. 
ländern werden die Wohnkostenrelationen zwischen den Regionen nicht unerheblich verfälscht - oft mit der Folge, daß Mieter in attraktiven Wohngegenden eine überproportional hohe Vergünstigung erhalten. Im Widerspruch zum Fühlbarkeitsgrundsatz steht auch die Nichtberücksichtigung der auf dem Wohnungsmarkt zu beobachtenden Differenzierung der Quadratmetermieten nach der Wohnungsgröße. Durch die Verfälschungen der Wohnkostenrelationen werden auf indirektem Wege allokativ unerwünschte Verhaltensanpassungen der Wirtschaftssubjekte hervorgerufen. Beispielsweise führt die besondere Mietverbilligung in attraktiven Wohnorten dazu, daß Haushalte, die sonst vielleicht preisgünstigere Wohnungen in Vororten mit einem geringeren Attraktivitätsniveau gesucht hätten, ein verstärktes Interesse haben, in die Innenstädte zu ziehen.

Die genannten Nachteile lassen sich m.E. durch die vermeintlichen Vorteile einer pauschalen Verbilligung der Basismieten nicht aufwiegen. Überdies verlieren die Argumente für eine Absenkung der Basismiete bei genauer Betrachtung an Gewicht. So kann keineswegs davon ausgegangen werden, daß alle Mieter in den geförderten Objekten auf Dauer einer Mietvergünstigung bedürfen. Auch das zweite Argument, wonach die verbilligte Basismiete als Teilkompensation für die überdurchschnittlichen Wohnkosten von Neubauwohnungen sowie für mögliche Beeinträchtigungen des Wohnumfeldes dienen soll, kann nicht überzeugen. Denn wenn man den zum Bezug berechtigten Mietern anstelle einer Basissubvention eine erhöhte Zusatzförderung gewährt, läßt sich der gleiche Effekt erreichen - mit dem Unterschied, daß Haushalte, deren Einkommen im Zeitablauf die Bezugsberechtigungsgrenze übersteigen, dann die volle Marktmiete zu zahlen haben. Sollten die Fehlbeleger dadurch zum Auszug aus den Sozialwohnungen veranlaßt werden, wäre dies sogar erwünscht, denn die Sozialwohnungen stehen dann wieder für förderberechtigte Haushalte zur Verfügung.

Bei der EOF sollte daher auf eine Mietpreisbindung verzichtet und die Grundförderung ausschließlich als Gegenleistung für die Belegungsbindung gewährt werden. $\mathrm{Zu}$ erwägen wäre allenfalls eine Fixierung der anfänglichen Basismiete auf dem Niveau der ortsüblichen Vergleichsmiete, um zu vermeiden, daß der Investor überhöhte Erstvermietungsmieten verlangt. Die vielfach praktizierte Koppelung der Mietendynamisierung an die Degression der Grundförderung, die dem Kostenmietprinzip entstammt und den Zweck hat, eine bestimmte Ertragshöhe pro qm förderfähige Wohnfläche zu garantieren, sollte ebenfalls aufgegeben werden, da sie zu einer unnötigen Komplizierung der Förderung führt und deren Transparenz verringert. 


\section{Subventionswirkungen der Zusatzförderung}

\section{a. Zur Grundproblematik einer Verknüpfung von Objekt- und Subjektförderung}

Kennzeichnend für die EOF ist die Ergänzung der Objektförderung durch eine subjektorientierte Komponente, durch die die Tragbarkeit der Mieten abgesichert werden soll. Die Zusatzförderung ist neben dem Wohngeld und der Fehlbelegungsabgabe das dritte staatliche Instrument zur Erreichung einer einkommensorientierten Wohnkostenbelastung. Wie bereits erwähnt, kommt sie der Fehlbelegungsabgabe sehr nahe, da sie an das geförderte Objekt gebunden und vielfach ähnlich wie jene ausgestaltet ist. Der Hauptunterschied zwischen den beiden Instrumenten ist eher formaler Art: Während die Fehlbelegungsabgabe als Zuschlag auf die Mindestmiete konzipiert ist, handelt es sich bei der Zusatzförderung um einen Abschlag von der höchstzulässigen Basismiete.

Aus der Objektgebundenheit der Zusatzförderung folgt, daß sie nur einer begrenzten Anzahl von Haushalten - nämlich den Mietern der geförderten Wohnungen - zugute kommt und daß sie zeitlich auf die Dauer der Mietpreisbindung beschränkt ist. Die EOF läuft also ebenso wie die klassische Objektförderung auf eine selektive Begünstigung derjenigen hinaus, die das Glück hatten, eine Sozialwohnung zu bekommen, während sich die Mehrheit der Bezieher niedriger Einkommen auf dem freien Wohnungsmarkt versorgen und gegebenenfalls mit Wohngeld zufrieden geben muß. Der Gleichbehandlungsgrundsatz ist verletzt. Dadurch, daß die Zusatzförderung bei einem Wohnungswechsel nicht „mitgenommen“" werden kann, treten außerdem die für den gesamten sozialen Mietwohnungsbau typischen Mobilitätshemmnisse auf. Die Opportunitätskosten eines Ortswechsels steigen, denn die betroffenen Haushalte können wegen der begrenzten Zahl der Sozialwohnungen kaum davon ausgehen, wieder eine geförderte Wohnung zu bekommen. Auch dürfte die Bereitschaft zu Familienvergrößerungen nach dem Bezug der Wohnungen sinken, denn die Haushalte müßten sonst u.U. ihre Sozialwohnung aufgeben und - sofern keine andere Sozialwohnung zur Verfügung steht - sich auf dem freien Wohnungsmarkt versorgen.

Besonders problematisch wirkt sich der Umstand aus, daß die Subjektförderung an den Bezug neuerrichteter oder modernisierter Wohnungen geknüpft ist. Diese weisen im Vergleich mit dem übrigen Wohnungsbestand ein überdurchschnittliches Kosten- und Qualitätsniveau auf und würden sich bei freier Vermietung daher im oberen Preissegment bewegen. Durch die baualtersbedingten Preisnachteile der geförderten Wohnungen werden die Subventionseffekte der Zusatzförderung konterkariert, so daß die geförderten Haushalte gegenüber den Mietern älterer Bestandswohnungen häufig keine oder nur eine geringfügige 
Besserstellung bei den Wohnkosten erfahren. ${ }^{1}$ Die Größenordnung der baualtersbedingten Mietunterschiede ist im Rahmen der 1\%-Gebäude- und Wohnungsstichprobe von 1993 ermittelt worden (vgl. Übersicht 13).

\section{Übersicht 13: Baualtersbedingte Mietunterschiede (Ergebnisse der 1\%-Gebäude- und Wohnungsstichprobe von 1993) ${ }^{2}$}

\begin{tabular}{|l|c|}
\hline $\begin{array}{l}\text { Datum der Errichtung } \\
\text { des Wohngebäudes }\end{array}$ & $\begin{array}{c}\text { Durchschnittliche Bruttokaltmiete pro qm und Monat von } \\
\text { freifinanzierten Wohnungen im alten Bundesgebiet }\end{array}$ \\
\hline bis 1900 & $8,28 \mathrm{DM}$ \\
\hline $1901-1918$ & $8,79 \mathrm{DM}$ \\
\hline $1919-1948$ & $8,61 \mathrm{DM}$ \\
\hline $1949-1968$ & $9,60 \mathrm{DM}$ \\
\hline $1969-1978$ & $10,41 \mathrm{DM}$ \\
\hline $1979-1981$ & $10,87 \mathrm{DM}$ \\
\hline $1982-1987$ & $11,76 \mathrm{DM}$ \\
\hline nach 1987 & $12,88 \mathrm{DM}$ \\
\hline
\end{tabular}

Nach der Erhebung weisen Altbauwohnungen (bis 1948 errichtet) in Westdeutschland gegenüber den nach 1987 errichteten freifinanzierten Neubauwohnungen einen Preisvorteil von über 4 DM auf. Aus den Stichprobenergebnissen läßt sich schließen, daß die Mieten der Altbauwohnungen auch heute im Durchschnitt kaum von den Mindestmieten im vierten Förderweg abweichen. ${ }^{3}$ Belegt wird dies auch durch die Werte des RDM-Immobilien-Preisspiegels von 1996.

1 Wohngeldberechtigte Sozialmieter werden allerdings dadurch bessergestellt, daß die Obergrenzen für die wohngeldfähige Miete bei den neuerrichteten Sozialwohnungen höher angesetzt sind als bei Wohnungen aus dem älteren Bestand und sie daher u.U. höhere Transfers erhalten.

2 Angaben des Statistischen Bundesamtes.

3 So waren für die Altbauwohnungen im Erhebungszeitraum nettokalt durchschnittlich 7,37 DM pro qm zu zahlen, während sich die anfänglichen Mindestmieten der einkommensorientiert geförderten Wohnungen zwischen 7,00 DM und 9,50 DM pro qm bewegen. Allerdings muß bei diesem Vergleich berücksichtigt werden, daß die Wohnungsstichprobe bereits einige Jahre zurückliegt und daß in ihr nicht nur die neuabgeschlossenen, sondern auch die bereits seit längerem bestehenden Mietverhältnisse erfaßt sind. 
Danach liegen die Neuvertragsmieten bei Altbauten mit mittlerem Wohnwert nur in Städten mit einem hohen Attraktivitätsniveau wie z.B. München, Köln, Bonn, Stuttgart, Heidelberg etc. nennenswert über den anfänglichen Mindestmieten einkommensorientiert geförderter Wohnungen. ${ }^{1}$

Aus den vorangegangenen Überlegungen läßt sich ableiten, daß die Begünstigung der Mieter einkommensorientiert geförderter Wohnungen oftmals nicht im Preisvorteil der Mietwohnung, sondern vielmehr in deren moderner Ausstattung liegen dürfte. Die Zusatzförderung hat hier mehr oder weniger die Funktion, Qualitätsvorteile von Neubauwohnungen auch für geringverdienende Mieter finanzierbar zu machen. Wegen der - im Vergleich zum ersten Förderweg - im Durchschnitt kürzeren Bindungszeiträume konzentriert sich die EOF überdies zeitlich noch stärker als jene auf die Phase, in der die geförderten Wohnungen wegen ihres jungen Baualters überdurchschnittlich teuer sind. Daran ist zu kritisieren, daß es gerade in der gegenwärtig angespannten Haushaltslage nicht als Aufgabe des Staates angesehen werden kann, die sozial Schwächsten mit hochwertigem Wohnraum zu versorgen, den sich üblicherweise nur Bezieher überdurchschnittlicher Einkommen leisten können. Für die einkommensschwachen bzw. diskriminierten Personengruppen geht es darum, überhaupt eine hinreichende Wohnung zu bekommen, die sie finanzieren können. Aus diesem Grunde ist auch die Modernisierungsförderung kein geeignetes Instrument zur Versorgung solcher Haushalte, da der Staat zunächst die qualitative Aufwertung der Wohnungen fördert und dann noch einmal fördern muß, um den im Preis gestiegenen Wohnraum für die bezugsberechtigten Haushalte bezahlbar zu machen. ${ }^{2}$ Lediglich in den neuen Bundesländern, wo wegen des schlechten $\mathrm{Zu}$ stands vieler Wohnungen eine umfassende Sanierung oft unumgänglich ist, kann die einkommensorientierte Sanierungsförderung als eine sinnvolle Strategie angesehen werden. Dies gilt um so mehr, wenn - wie in Sachsen - durch die EOF erreicht werden soll, daß die geringverdienenden Mieter auch nach der

1 Bei den Altbauwohnungen wurde ein mittlerer Wohnwert angenommen (z.B. Bad und WC, Verbundglasfenster, Zentralheizung, gute Bausubstanz, gemischtbebaute Wohnlage mit normaler verkehrsmäßiger Erschließung, ausgeglichene Bevölkerungsstruktur). Wie schon erwähnt, berücksichtigt der RDM-Immobilien-Preisspiegel nur die Neuvertragsmieten bei Erst- oder Wiedervermietung. Diese betrugen nach der RDM-Statistik von 1996 pro qm (in Klammern: EOF-Mindestmiete im 1. Jahr) in München 14,90 DM (9,50 DM), in Köln $13 \mathrm{DM}$ (9,35 DM), in Düsseldorf 12,50 DM (9,35 DM), in Stuttgart 13 DM (9 DM) und in Heidelberg 13 DM (8,75 DM). Bei den Angaben handelt es sich um Durchschnittswerte bezogen auf Drei-Zimmer-Wohnungen mit ca. $70 \mathrm{qm}$.

2 Auch wegen ihrer Folgewirkungen auf dem Wohnungsmarkt kann die Modernisierungsförderung kaum als sinnvolle Strategie angesehen werden. Denn durch sie wird der Bestand an einfach ausgestatten, preiswerten Altbauwohnungen verringert und die im allgemeinen auf Wohnungen dieser Kategorie gerichtete Nachfrage geringverdienender Haushalte auf teurere Wohnungen abgedrängt. Vgl. Schneider, H.K., Deichmann, W. (1984), S. $13 \mathrm{f}$. 
Sanierung die gestiegenen Wohnkosten aufbringen können und nicht zum Verlassen ihrer angestammten Wohnung gezwungen sind. Die Förderung trägt hier maßgeblich zur Verhinderung sozialer Spannungen bei.

\section{Übersicht 14: Barwerte der Zusatzförderung in ausgewählten Bundesländern bei einer Wohnungsgröße von 70 qm}

\begin{tabular}{|c|c|c|}
\hline & \multicolumn{2}{|c|}{ Kosten der Zusatzförderung } \\
\hline & $\begin{array}{l}\text { bei Maximalförderung im } \\
\text { Förderzeitraum von (...) Jahren }\end{array}$ & $\begin{array}{l}\text { im Durchschnitt in den ersten } \\
\text { zehn Jahren (in Klammern: } \\
\text { angenommener Prozentsatz der } \\
\text { Haushalte, die beim Bezug die } \\
\text { Grenze des } \S 25 \text { einhalten) }\end{array}$ \\
\hline $\begin{array}{l}\text { Baden-Württemberg } \\
\text { - Stuttgart } \\
\text { - Gemeinde-Kategorie III }\end{array}$ & $\begin{array}{l}29.499 \mathrm{DM}(10) \\
44.495 \mathrm{DM}(20) \\
17.699 \mathrm{DM}(10) \\
26.697 \mathrm{DM}(20)\end{array}$ & $\begin{array}{l}17.725 \mathrm{DM}(67 \%) \\
\text { s.o. } \\
\text { 9.649 DM }(67 \%) \\
\text { s.o. }\end{array}$ \\
\hline $\begin{array}{l}\text { Bayern } \\
\text { - Kategorie I bei anfänglicher } \\
\text { Basismiete von } 19 \mathrm{DM} \text { pro qm } \\
\text { - Kategorie II bei anfänglicher } \\
\text { Basismiete von } 13 \text { DM pro qm }\end{array}$ & $\begin{array}{l}68.856 \mathrm{DM}(15) \\
26.777 \mathrm{DM}(15)\end{array}$ & $\begin{array}{l}44.553 \mathrm{DM}(67 \%) \\
15.888 \mathrm{DM}(67 \%)\end{array}$ \\
\hline Berlin & $64.292 \mathrm{DM}(25)$ & $22.301 \mathrm{DM}(40 \%)$ \\
\hline Brandenburg & $33.371 \mathrm{DM}(20)$ & $11.831 \mathrm{DM}(25 \%)$ \\
\hline $\begin{array}{l}\text { Nordrhein-Westfalen } \\
\text { - Mietenstufe } 1 \\
\text { - Mietenstufe } 5\end{array}$ & $\begin{array}{l}30.701 \mathrm{DM}(20) \\
68.077 \mathrm{DM}(20)\end{array}$ & $\begin{array}{l}13.565 \mathrm{DM}(67 \%) \\
35.708 \mathrm{DM}(67 \%)\end{array}$ \\
\hline Sachsen & $37.674 \mathrm{DM}(10)$ & $9.867 \mathrm{DM}(50 \%)$ \\
\hline Thüringen & $52.988 \mathrm{DM}(24)$ & $20.923 \mathrm{DM}(50 \%)$ \\
\hline
\end{tabular}

Die als Zusatzförderung erbrachten Mittel ließen sich ganz oder zum großen Teil einsparen, wenn der Staat dazu überginge, die unterstützungsbedürftigen Haushalte mit preisgünstigen Wohnungen aus dem älteren Bestand zu versorgen. Voraussetzung dafür ist allerdings, daß das Wohngeld ausreicht, um die 
Tragbarkeit der Wohnkosten sicherzustellen. Ist dies der Fall, gibt es keinen Grund, den Mietern der belegungsgebundenen Wohnungen eine zweite Subjektförderung zu gewähren. Übersicht 14 gibt die Größenordnung der beim Verzicht auf eine Zusatzförderung möglichen Einsparungen für einzelne Bundesländer ${ }^{1}$ wieder. In der mittleren Spalte sind die Förderbarwerte $(q=7 \%)$ aufgeführt, die für eine 70-qm-Wohnung maximal aufgewendet werden müssen, um die Miete im gesamten Förderzeitraum auf das als tragbar definierte Niveau abzusenken. Die Werte in der Spalte ganz rechts stellen den geschätzten Aufwand dar, den die Träger der Zusatzförderung in den ersten zehn Förderjahren für eine Wohnung dieser Größe im Durchschnitt erbringen müssen. ${ }^{2}$ Es zeigt sich, daß der für die Abfederung der Mieten erbrachte Mitteleinsatz keineswegs vernachlässigbar ist. Er übersteigt nicht selten die Grundförderung, in Einzelfällen ist er sogar mehrfach so hoch (vgl. Übersicht 5 in Kapitel 2.F.II).

Die Grundregel einer Reform der Objektförderung sollte daher sein, den Erwerb von Belegungsrechten von der Neubauförderung abzukoppeln. Ein Schritt in die richtige Richtung wäre auch getan, wenn die durch die Neubauförderung gewonnenen Belegungsrechte nicht mehr für die Neubauwohnungen selbst, sondern für ältere Wohnungen aus dem Bestand des Investors verwendet würden. Der Erwerb mittelbarer Belegungsbindungen spielt im Rahmen der EOF aber bislang nur eine untergeordnete Rolle. Eine der wenigen Maßnahmen dieser Art stellt das Bremer Kombimodell dar, das sich dadurch auszeichnet, daß die Endmieten der Bestandswohnungen bei gleichem Mitteleinsatz auf ein niedrigeres Niveau abgesenkt werden als die der neugebauten Wohnungen im Grundmodell. Seit neuestem bietet auch das Land Baden-Württemberg den Investoren an, die durch Inanspruchnahme des OS-10-Darlehens eingegangene Belegungsbindung durch Unterbringung in einer nicht gebundenen Wohnung aus ihrem Bestand zu erfüllen. Für das Land und die Kommune hat dieses Verfahren den Vorteil, daß sie überhaupt keine Zusatzförderung erbringen müssen.

1 Es wurden nur solche Bundesländer ausgewählt, bei denen hinlängliche Aussagen über die Höhe der im gesamten Förderzeitraum gewährten Zusatzförderung gemacht werden können.

2 Die anfänglichen Belegungsstrukturen wurden so gewählt, daß diesbezügliche Vorgaben der Länder - soweit sie existieren - eingehalten werden. Die Einkommensgruppen, nach denen bei der Belegung unterschieden wird, werden durch eine kleine Zahl von Haushalten repräsentiert, die innerhalb der jeweiligen Gruppe gleichmäßig verteilt sind. In den Berechnungen berücksichtigt ist der Umstand, daß die Einkommen der Mieter im Zeitablauf zumindest nominal - steigen werden, während die Einkommensgrenze bis zur nächsten Neufestsetzung unverändert bleibt. Ausgegangen wurde von einem allgemeinen Einkommenszuwachs in Höhe von 3\% pro Jahr. Wegen der Unwägbarkeiten im Zusammenhang mit einer mittelfristig zu erwartenden Anpassung der Einkommensgrenzen und der damit verbundenen möglichen Neueinordnung der Haushalte in die einzelnen Einkommensgruppen schien es bei der Ermittlung der Durchschnittswerte wenig sinnvoll, einen über zehn Jahre hinausreichenden Betrachtungszeitraum zu wählen. 


\section{b. Abgrenzung des zu berücksichtigenden Einkommens}

Die Höhe der Zusatzförderung richtet sich in allen Bundesländern, die einkommensorientiert fördern, nach dem Gesamteinkommen im Sinne des § 25 Abs. 1, 3 II. WoBauG. Eine Ausnahme stellt nur das Möglinger Modell dar, bei dem vom Brutto-Gesamteinkommen der geförderten Haushalte ausgegangen wird. ${ }^{1}$ Die Wahl des Gesamteinkommens nach $\S 25$ als Grundlage für die Bemessung der Zusatzförderung hat den Vorteil, daß die zuständigen Stellen bei der Ermittlung der Transfers kein anderes Verfahren anwenden müssen, als für die Entscheidung über die Bezugsberechtigung der Haushalte ohnehin erforderlich ist. Andererseits stellen sich nunmehr besondere Anforderungen an die Exaktheit der Einkommensermittlung, da anhand ihres Ergebnisses nicht mehr nur über das Vorliegen der Förderberechtigung, sondern auch über den Grad der Förderungswürdigkeit entschieden wird.

Bis zum Inkrafttreten des Wohnungsbauförderungsgesetzes 1994 war die Einkommensermittlung nach § 25 noch durch einige Unzulänglichkeiten gekennzeichnet, die mitunter zu erheblichen Abweichungen vom aktuell verfügbaren Einkommen geführt haben. Durch das Wohnungsbauförderungsgesetz sind diese Schwächen großenteils beseitigt und zugleich eine Annäherung des Verfahrens an die Einkommensermittlung im Wohngeldrecht vorgenommen worden. So wurde der Katalog der zu berücksichtigenden Einkünfte um zahlreiche steuerfreie Einnahmen erweitert, die Freistellung gesetzlicher und tariflicher Kinderzulagen zu Löhnen, Gehältern und Renten sowie vergleichbarer Bezüge abgeschafft und die 10prozentigen Pauschalabzüge für Kranken- und Rentenversicherungsbeiträge eingeführt. Die Bestimmungen über den Ermittlungszeitraum des Jahreseinkommens wurden dahingehend verändert, daß nunmehr verstärkt auf die in den zwölf Monaten nach der Antragstellung zu erwartenden Einkünfte abgestellt wird, damit die Einkommensermittlung zu einem wirklichkeitsund zeitnahen Ergebnis führt. Eine wesentliche Verbesserung gegenüber den bis dahin geltenden Regelungen stellt auch die neue Systematik der Frei- und Abzugsbeträge nach $\S 25 \mathrm{~d}$ dar. Zur stärkeren Förderung alleinstehender Mütter und Väter ist in Anlehnung an $\S 15$ Abs. 2 WoGG ein besonderer Freibetrag für Kinder unter 12 Jahren eingeführt worden, durch den die zusätzlichen Belastungen berücksichtigt werden sollen, die entstehen, wenn Alleinerziehende wegen Erwerbstätigkeit oder Ausbildung nicht nur kurzfristig vom Haushalt

1 Das Brutto-Gesamteinkommen entspricht der Summe der Jahreseinkommen aller zum Haushalt rechnenden Familienmitglieder. Das Jahreseinkommen ist wie im Wohngeldrecht zu ermitteln. Gerechtfertigt wird die Wahl der Bezugsgröße damit, daß das Bruttoeinkommen einfacher zu ermitteln sei als das verfügbare Einkommen. Da sich die Zusatzförderung nach der Formel „Wohnkosten abzüglich Wohngeld $=20 \%$ des Bruttoeinkommens“ bemißt, wird durch sie die Differenzierung des Wohngeldes nach dem verfügbaren Einkommen aufgehoben. Erhält also beispielsweise eine Person wegen Behinderung ein erhöhtes Wohngeld, so reduziert sich der Anspruch auf Zusatzförderung um den gleichen Betrag. 
abwesend sind und daher ihre Kinder durch Dritte betreuen lassen müssen. Neu ist auch der Freibetrag für eigene Einnahmen von Kindern, der sich an die Bestimmungen des Wohngeldgesetzes ( $\S 15$ Abs. 3) anlehnt. Reformiert wurde auch die Sonderförderung für Behinderte und junge Ehepaare, die nun nicht mehr durch Aufschläge auf die Einkommensgrenze, sondern über Freibeträge vom Gesamteinkommen erfolgt. Bei der alten Vorgehensweise führten prozentuale Anhebungen oder Absenkungen der Einkommensgrenze zu entsprechenden Veränderungen der Aufschläge, was wenig sinnvoll erscheint, wenn man davon ausgeht, daß die tatsächlichen Mehrbelastungen dieser Personengruppen einkommensunabhängig anfallen.

Trotz der Verbesserungen durch das Wohnungsbauförderungsgesetz 1994 ist die Einkommensermittlung nach $\S 25$ noch immer durch Unzulänglichkeiten gekennzeichnet. Wie im Wohngeldrecht bleiben das steuerfreie Kindergeld und das ebenfalls steuerfreie Erziehungsgeld unberücksichtigt, obwohl auch diese Zuflüsse das verfügbare Haushaltseinkommen erhöhen. ${ }^{1}$ Bei korrekter Einbeziehung der Kindergeldbeträge in die Einkommensermittlung würde das Gesamteinkommen eines Ehepaares mit Kind gemessen an der Einkommensgrenze des $\S 25$ um 6,4\%, bei zwei Kindern um 10,7\% und bei drei Kindern um 15,5\% höher ausfallen. ${ }^{2}$ Nimmt man das Erziehungsgeld hinzu, sind die Vorteile aus der Nichtanrechnung noch größer.

Bei den Pauschalabzügen für Steuern und Beiträge zur Kranken- und/oder Rentenversicherung ist die Harmonisierung mit dem Wohngeldrecht noch unvollendet: Während der Abzug nach $\S 25$ b II. WoBauG bei Vorliegen nur einer einzigen der genannten Abgaben 10\% beträgt, ist gemäß $\S 17$ Abs. 2 WoGG in diesem Fall ein Abzug von 12,5\% vorzunehmen. Das System pauschaler Abzüge hat den Vorzug der einfachen Handhabung, ist aber zugleich mit dem Nachteil verbunden, daß erhebliche Abweichungen von den richtigen Ansätzen auftreten können. Eine weitgehende Übereinstimmung der pauschalen mit den tatsächlich zu leistenden Abgaben ist nur bei den Pflichtbeiträgen zu den Sozialversicherungen gegeben: Die Pauschalabzüge von insgesamt $20 \%$ entsprechen in etwa der tatsächlichen Belastung der Erwerbstätigen aus der Beitragspflicht zu den gesetzlichen Sozialversicherungen (einschließlich der bei der Einkommensermittlung nicht eigens berücksichtigten Beiträge zur Arbeitslosen- und Pflegeversicherung). Gravierende Abweichungen von den Pauschalen können

1 Da das Kindergeld eine allgemeine Leistung des Staates darstellt, auf die ein Rechtsanspruch besteht, ist die Nichtberücksichtigung dieser Zahlungen nicht allzu problematisch, da Familien mit gleicher Kinderzahl in derselben Weise von der Freistellung profitieren.

2 Bei einer Berücksichtigung im Rahmen des § 25 a II. WoBauG wären diese Prozentsätze allerdings geringer, da die Kindergeldbeträge noch um die Pauschalabzüge nach $\S 25 \mathrm{~b}$ gekürzt werden müßten. 
dagegen auftreten, wenn anstelle von Pflichtbeiträgen $\mathrm{zu}$ den gesetzlichen Kranken- und Rentenversicherungen „mehr als nur geringfügige laufende Beiträge zu öffentlichen oder privaten Versicherungen oder ähnlichen Einrichtungen" nach $\S 25$ b Abs. 2 entrichtet werden, die in ihrer Zweckbestimmung den Pflichtbeiträgen entsprechen (z.B. Beiträge zur Lebensversicherung, Beiträge zu Betriebsgemeinschaften für zusätzliches Ruhegeld etc.). Auch für solche Beiträge können Pauschalabzüge von jeweils $10 \%$ angesetzt werden können, selbst wenn sie einen deutlich niedrigeren Anteil am Einkommen ausmachen. ${ }^{1}$ Die aufgezeigte Problematik betrifft u.a. die Beamten, da sie keine Beiträge zur Altersversorgung entrichten müssen und daher noch einen Pauschalabzug frei haben, den sie beispielsweise durch Abschluß einer Lebensversicherung ausschöpfen können.

Beim Pauschalabzug für Steuern vom Einkommen sind mehr als nur geringfügige Abweichungen von der tatsächlichen Belastung sogar der Regelfall. Während die Bezieher niedriger Erwerbseinkommen oft eine wesentlich geringere als die pauschal ermittelte Steuerlast haben, liegt diese bei Haushalten oberhalb der Grenze des $\S 25$ mitunter deutlich über $10 \%$. Bei Personen mit sehr geringen Einkünften wird der Pauschalabzug sogar vorgenommen, wenn die entrichteten Steuern - etwa im Rahmen einer Einkommensteuerveranlagung - in voller Höhe erstattet werden. ${ }^{2}$ Dagegen haben z.B. Nichtverheiratete, deren Einkommen die Grenze des $\S 25$ um $60 \%$ überschreitet, eine Steuerlast, die mehr als doppelt so hoch ist wie der Pauschalabzug. ${ }^{3}$ Aus verteilungspolitischer Sicht sind diese Diskrepanzen tolerierbar, da die geringverdienenden Haushalte begünstigt und die besserverdienenden benachteiligt werden. Weniger akzeptabel ist, daß die prozentualen Abweichungen der tatsächlichen Steuerlast von der $10 \%$-Pauschale auch bei einkommensmäßig gleichgestellten Haushalten sehr unterschiedlich ausfallen können. So hat eine erwerbstätige Person mit Kind im Jahr 1997 bei einem Bruttojahresverdienst von 50.000 DM (einschließlich Wer-

1 Die Versicherungsbeiträge müssen eine Geringfügigkeitsgrenze überschreiten, die in Anlehnung an das Wohngeldrecht mit $80 \mathrm{DM}$ monatlich je Versicherung anzusetzen ist; vgl. Wirth, L., Kommentar zu $\S 25$ b II. WoBauG, S. 8f. Gerade bei mitgliederstarken Haushalten mit höheren Einkommen können die tatsächlich gezahlten Beträge erheblich unter den Pauschalabzügen liegen. So dürfte z.B. ein Beamter mit einer nicht-erwerbstätigen Ehefrau und zwei Kindern, der über ein Einkommen verfügt, das die Grenze des $\S 25$ um 40\% überschreitet, und der Lebensversicherungsbeiträge in Höhe der Geringfügigkeitsgrenze leistet, bei richtiger Einkommensermittlung nur einen Abzug von 1,1\% vornehmen.

2 Vgl. Wirth, L., Kommentar zur $\S 25$ b II. WoBauG, S. 5.

3 Bei Ein-Personen-Haushalten mit entsprechendem Einkommen liegt die tatsächliche Steuerquote gegenwärtig bei $21,7 \%$. Der Gesamtverband der Wohnungswirtschaft hat angesichts dieser Diskrepanzen eine Anhebung des Pauschalabzugs auf 15\% vorgeschlagen; Gesamtverband der Wohnungswirtschaft e.V. (1994a), S. 117. Vgl. auch Bundesverband Freier Wohnungsunternehmen e.V. (1994), S. 188 (16). 
bungskostenpauschale in Höhe von 2.000 DM) gemessen am Jahreseinkommen nach $\S 25$ a eine Steuerquote von 15,5\%, ein kinderloses Ehepaar mit dem gleichen Bruttoverdienst dagegen von nur 8,4\%. Die Unterschiede in der Steuerquote resultieren daraus, daß die Vorteile des Ehegattensplittings beim Pauschalabzug nicht berücksichtigt werden - mit der Folge einer systematischen Besserstellung der Eheleute gegenüber den Nichtverheirateten.

Zur Ungenauigkeit der Einkommensermittlung trägt bei, daß die Pauschalabzüge für Steuern, Kranken- und Rentenversicherungsbeiträge vom gesamten Jahreseinkommen nach $\S 25$ a vorgenommen werden und zwar auch dann, wenn darin steuerfreie Einkommensteile enthalten sind oder Einkünfte, für die keine Kranken- oder Rentenversicherungsbeiträge zu entrichten sind (z.B. Einkünfte aus Vermietung und Verpachtung oder aus Kapitalvermögen). ${ }^{1}$ Wegen der zu weit gefaßten Bezugsgröße fallen die prozentualen Abzugsbeträge in der Tendenz zu hoch aus. Bei Haushalten mit einem großen Anteil solcher Einkunftsarten am Jahreseinkommen kann dies zu erheblichen Begünstigungen führen.

$\mathrm{Zu}$ bemängeln ist auch, daß bei den Frei- und Abzugsbeträgen noch keine vollständige Harmonisierung mit dem Wohngeldrecht stattgefunden hat. Unterschiede bestehen in der Höhe der Beträge sowie in der Art ihrer Berücksichtigung bei der Einkommensermittlung: Während sie nach den $\S \S 12$ a, 15 und 16 des Wohngeldgesetzes vom Jahreseinkommen der einzelnen Familienmitglieder abgesetzt und erst danach die Pauschalabzüge für Steuern und Sozialversicherungsbeiträge vorgenommen werden, sieht das Wohnungsbaugesetz ihren Abzug von dem bereits um die Pauschalabzüge gekürzten Gesamteinkommen des Haushalts vor. Dies hat zur Folge, daß sich die Frei- und Abzugsbeträge bei der Einkommensermittlung nach $\S 25$ in ungeminderter Höhe auswirken, beim Wohngeld dagegen zu einer Verringerung der Pauschalabzüge für Steuern und Sozialversicherungsbeiträge führen. Des weiteren unterscheiden sich die Verfahren der Einkommensermittlung durch die Freibetragsregelung nach $\S 25 \mathrm{~d}$ Abs. 1 Satz 4 II. WoBauG, für die es im Wohngeldrecht keine Entsprechung gibt. Nach der Gesetzesvorschrift dürfen junge Ehepaare pauschal 8.000 DM vom Gesamteinkommen absetzen, sofern keiner der Ehegatten das 40. Lebensjahr vollendet hat (§26 Abs. 2 Satz 2) und das fünfte Kalenderjahr nach dem Jahr der Eheschließung noch nicht abgelaufen ist. Begründet wird dies damit, $\mathrm{da} ß$ in den ersten Jahren nach der Eheschließung erhöhte Aufwendungen für die Haushaltsausstattung getroffen werden. ${ }^{2}$ An der Argumentation ist zu kritisieren, daß diese Mehraufwendungen in der heutigen Zeit nicht mehr so sehr auf den Zeitraum nach der Eheschließung konzentriert sind. Bei der einkommensorientierten Förderung kann der Freibetrag mithin zu paradoxen Begünstigungen

1 Vgl. Wirth, L., Kommentar zu § 25 b II. WoBauG, S. 4.

2 Deutscher Bundestag (1994a), S. 24. 
führen. Hat beispielsweise ein Paar über einen längeren Zeitraum eine nichteheliche Lebensgemeinschaft geführt und erst kurz vor Bezug der Sozialwohnung geheiratet, so erhält es in den ersten Jahren des Förderzeitraumes eine erhöhte Zusatzförderung, während andere Paare, die zu einem früheren Zeitpunkt geheiratet haben, die erhöhte Zusatzförderung nur über einen kürzeren Zeitraum oder gar nicht in Anspruch nehmen können.

\section{c. Periodizität der Einkommensprüfung und Berücksichtigung zwischenzeitlicher Einkommensänderungen}

Kennzeichnend für die EOF ist die periodische Anpassung der Zusatzförderung an die Einkommenssituation der geförderten Haushalte. Dadurch sollen Fehlsubventionen im Zeitablauf vermieden und zugleich das Entstehen besonderer Härten, etwa in Folge von Einkommensrückgängen, vermieden werden. Um die Einkommenssituation der Haushalte möglichst zeitnah erfassen zu können, müssen die zuständigen Stellen Einkommensprüfungen in kurzen Abständen vornehmen. Dagegen spricht der hohe Verwaltungsaufwand, den eine so engmaschige Kontrolle zwangsläufig mit sich bringt. Auch dürfte der Grenznutzen mit der Häufigkeit der Einkommensprüfungen abnehmen. In welchem Abstand die Einkommensprüfungen im Optimalfall vorzunehmen sind, hängt in erster Linie von der Art der Einkünfte ab. Handelt es sich um Einnahmen, die regelmäßig in annähernd gleicher Höhe anfallen (insbesondere Beamten- oder Angestelltengehälter, Renten etc.), dürfte eine Einkommensprüfung in mehrjährigen Abständen zumeist ausreichend sein. Bei unregelmäßigen oder zeitlich befristeten Einkünften (z.B. Entlohnung für Gelegenheitsarbeiten, Lohnersatzleistungen etc.) sowie Einkünften, die zwar regelmäßig anfallen, aber in ihrer Höhe schwanken (Einkünfte aus Land- und Forstwirtschaft, Gewerbebetrieb und selbständiger Arbeit) kann eine verläßliche Prognose dagegen nicht einmal für einen Ein-Jahres-Zeitraum gestellt werden. Veränderungen sind außerdem bei der Zahl der zum Haushalt rechnenden Personen möglich. Auch hier kann die Prognosesicherheit nur im Einzelfall beurteilt werden.

Wie bereits in Kapitel 2.F.IX dargestellt, haben die Bundesländer Regelbewilligungszeiträume für die Zusatzförderung mit einer Länge von einem bis zu vier Jahren festgelegt. Ergänzend sehen die Förderbestimmungen einiger Bundesländer auch die Möglichkeit einer Neufestsetzung der Zusatzförderung im laufenden Bewilligungszeitraum vor. $\mathrm{Zu}$ unterscheiden sind dabei zwei Fälle: Handelt es sich um Einkommensrückgänge oder sonstige Veränderungen, die einen erhöhten Förderanspruch begründen, haben die Haushalte eine Antragsmöglichkeit auf Neufestsetzung der Zusatzförderung. Einkommenssteigerungen oder sonstige Veränderungen, die den Förderanspruch mindern, können dage- 
gen durch eine Auskunfts- oder Mitwirkungspflicht des Mieters berücksichtigt werden. ${ }^{1}$ Übersicht 15 gibt die bestehenden Regelungen der Länder zur Neufestsetzung der Zusatzförderung im laufenden Bewilligungszeitraum wieder. ${ }^{2}$ Wie sich zeigt, ist eine außerplanmäßige Anpassung der Zusatzförderung in der Mehrzahl der aufgeführten Länder nur dann vorgesehen, wenn sie zugunsten des Mieters ausfällt. Dies mag u.a. darauf zurückzuführen sein, daß es den Ländern mehr darauf ankommt, Härtefälle infolge einer zu niedrigen Förderung zu vermeiden, als darauf, das Auftreten von Fehlsubventionierungen zu verhindern. Auch besteht vielerorts Skepsis im Hinblick auf die Kooperationsbereitschaft der Haushalte bei Veränderungen des Förderanspruchs zu ihren Ungunsten. So wurde von Mitarbeitern baden-württembergischer Kommunen die Meinung vertreten, daß die Mitwirkungspflicht die Haushalte überfordere und mit einem hohen Verwaltungs- und Kontrollaufwand einhergehe. Indes erscheint der Nachweis des Verstoßes nicht allzu schwer, da die zuständige Stelle spätestens im Zuge der turnusgemäßen Einkommensprüfungen Kenntnis über die veränderte Einkommenssituation erhält. ${ }^{3}$

1 Die Antragsmöglichkeit ist dem Wohngeld- und Fehlbelegungsrecht entlehnt. Nach § 29 Abs. 1 WoGG wird das Wohngeld auf Antrag neu bewilligt, wenn sich im laufenden Bewilligungszeitraum 1. die Zahl der zum Haushalt rechnenden Familienmitglieder oder 2. die zu berücksichtigende Miete oder Belastung um mehr als 15\% erhöht oder 3. das Familieneinkommen um mehr als $15 \%$ verringert hat, sofern diese Veränderungen zu einer Erhöhung des Wohngeldanspruchs führen. Ähnliche Bestimmungen finden sich im AFWoG sowie den Landesregelungen zur Fehlbelegungsabgabe. Die bundesgesetzliche Regelung nach $\S 7$ Abs. 2 AFWoG sieht vor, daß die Leistungspflicht auf Antrag mit Wirkung vom ersten Tag des auf den Antrag folgenden Kalendermonats an auf den Betrag herabzusetzen ist, der den Verhältnissen im Zeitpunkt des Antrags entspricht, wenn dieser Betrag niedriger ist, weil 1. das Einkommen die Einkommensgrenze nicht mehr überschreitet oder 2. das Einkommen sich um mehr als $15 \%$ verringert hat oder 3. die Zahl der Personen, die nicht nur vorübergehend zum Haushalt gehören, sich erhöht hat, oder 4. das für die Wohnung zulässige Entgelt ohne Betriebskosten, Zuschläge und Vergütungen sich um mehr als $20 \%$ erhöht hat. Eine Mitwirkungspflicht gibt es dagegen weder im Wohngeld- noch im Fehlbelegungsrecht.

2 Aufgeführt sind diejenigen Länder, die entsprechende Bestimmungen in ihre Landesvorschriften oder Eckwerte aufgenommen haben. Eine Antragsmöglichkeit bzw. Mitwirkungspflicht kann aber auch in anderen Ländern bestehen, wenn die einzelvertraglichen Vereinbarungen dies vorsehen. Beispielsweise haben einzelne Kommunen in BadenWürttemberg eigene Bestimmungen über eine außerplanmäßige Neubewilligung der Zusatzförderung getroffen.

3 Eine Ausnahme liegt vor, wenn der Mieter vor Ende des Regelbewilligungszeitraumes aus der Wohnung auszieht. Fehlsubventionierungen müssen auch in Kauf genommen werden, wenn es sich um vorübergehende Einkommenssteigerungen handelt, die aber i.d.R. ohnehin nicht angegeben werden müssen. 
Übersicht 15: Bestimmungen einzelner Bundesländer zur außerplanmäßigen Neufestsetzung der Zusatzförderung

\begin{tabular}{|l|l|}
\hline \multicolumn{2}{|c|}{ Antragsmöglichkeit / Mitwirkungspflicht } \\
\hline Berlin & $\begin{array}{l}\text { Antragsmöglichkeit bei Verringerung des Einkommens um 10\% oder mehr } \\
\text { sowie bei Tatsachen, die die Einkommensgrenze erhöhen }\end{array}$ \\
\hline Bremen & $\begin{array}{l}\text { Antragsmöglichkeit, wenn sich das tatsächliche Einkommen der } \\
\text { Wohnungsinhaber für mindestens sechs Monate um mindestens 15\% } \\
\text { verringert und dadurch eine Fallgruppenänderung eintritt }\end{array}$ \\
\hline $\begin{array}{l}\text { Nordrhein- } \\
\text { Westfalen }\end{array}$ & $\begin{array}{l}\text { Antragsmöglichkeit, wenn sich die für die Bemessung der } \\
\text { einkommensabhängigen Leistungen maßgebenden Verhältnisse für die } \\
\text { Dauer von mindestens sechs Monaten zugunsten des Mieters verändern }\end{array}$ \\
\hline $\begin{array}{l}\text { Rheinland- } \\
\text { Pfalz }\end{array}$ & $\begin{array}{l}\text { (a) Antragsmöglichkeit, wenn sich das Gesamteinkommen im Sinne der §§ 25 bis } \\
\text { 25 dII. WoBauG um mehr als 15\% verringert hat oder die Miete um mehr als 15\% } \\
\text { angehoben wurde oder sich die Zahl der Familienmitglieder erhöht hat } \\
\text { (b) Auskunftspflicht, wenn sich die monatlichen Einnahmen im Sinne des } \\
\text { § 25 a II. WoBauG nicht nur vorübergehend um mehr als 15\% erhöht haben oder } \\
\text { sich die Miete nicht nur vorübergehend um mehr als 15\% ermäBigt }\end{array}$ \\
\hline Sachsen & $\begin{array}{l}\text { Generelle Antragsmöglichkeit und Mitwirkungspflicht bei Änderungen in der } \\
\text { HaushaltsgröBe, Miete, Wohnfläche, im Familieneinkommen etc. }\end{array}$ \\
\hline $\begin{array}{l}\text { Schleswig- } \\
\text { Holstein }\end{array}$ & $\begin{array}{l}\text { Antragsmöglichkeit auf Neubewilligung zum 1. April oder 1. Oktober eines } \\
\text { Jahres, wenn sich gegenüber der letzten Überprüfung eine Änderung der } \\
\text { persönlichen Verhältnisse ergeben hat, die eine Neueinstufung rechtfertigt }\end{array}$ \\
\hline Antragsmöglichkeit bei Verringerung des Mietereinkommens um mehr als 15\%
\end{tabular}

Größere Schwierigkeiten bereitet die Durchsetzung eines Rückzahlungsanspruchs: Die zuständige Stelle hat zunächst den Eintrittszeitpunkt der Einkommensveränderung festzustellen. Sind die betroffenen Haushalte nicht bereit oder in der Lage, die benötigten Nachweise vorzulegen, muß strenggenommen eine Rückzahlung für den gesamten Regelbewilligungszeitraum eingefordert werden, was aber gerade bei mehrjährigen Zeiträumen zu hohen Forderungen und auf Mieterseite zu Härtefällen führen kann. Statt eine Rückzahlung zu fordern, könnte die zuständige Stelle auch eine Verrechnung mit zukünftigen Ansprüchen vornehmen. Dies setzt aber voraus, daß die Mieter aufgrund ihres Einkommens noch einen Anspruch auf Zusatzförderung haben und im Verrechnungszeitraum keinen Wohnungswechsel vornehmen. Die Durchsetzung der Mitwirkungspflicht dürfte in jedem Fall mit Ärger und Streitigkeiten verbunden 
sein, die das Vertrauensverhältnis zwischen Mieter und Förderstelle beeinträchtigen.

Trotz dieser Probleme ist die Mitwirkungspflicht gerade bei längeren Bewilligungszeiträumen kaum verzichtbar, sollen Fehlsubventionierungen größeren Ausmaßes vermieden werden. Um so unverständlicher mutet es an, daß nur Sachsen und Rheinland-Pfalz eine solche Pflicht in ihre Landesbestimmungen zur EOF aufgenommen haben. Kurioserweise handelt es sich dabei um Länder, in denen die turnusgemäßen Einkommensprüfungen ohnehin nur geringe zeitliche Abstände (zwölf Monate) aufweisen, die Gefahr allzu hoher Fehlsubventionierungen also gar nicht besteht. Das Gegenteil ist dagegen in Ländern mit mehrjährigen Regelbewilligungszeiträumen und hohen Förderbeträgen der Fall. In Berlin etwa betragen die kumulierten Barwerte $(q=7 \%)$ der im dreijährigen Regelbewilligungszeitraum maximal gewährten Mietzuschüsse bei einer Wohnung mit durchschnittlicher Größe (70 qm) 15.431 DM, in Nordrhein-Westfalen sogar bis zu 16.864 DM, wenn es sich um eine Gemeinde der Mietenstufe 5 handelt. Aus fiskalischer Sicht ist es wohl kaum zu vertreten, Subventionen dieser Größenordnung unabhängig von der weiteren Einkommensentwicklung des Mieters zu vergeben. Den betroffenen Ländern - in erster Linie sind dies Berlin, Bremen, Nordrhein-Westfalen und Thüringen - ist daher zu empfehlen, entweder kürzere als die gegenwärtigen Bewilligungszeiträume festzulegen oder eine Mitwirkungspflicht in die Förderkonditionen aufzunehmen.

\section{d. Zusammenhang von Einkommen und Transferhöhe}

Wie sich schon bei der Fehlbelegungsabgabe gezeigt hat, haben die Länder unterschiedliche Vorstellungen von der Tragbarkeit der Wohnkostenbelastungen. Es ist daher nicht verwunderlich, daß die einkommensorientierten Endmieten in den einzelnen Bundesländern - auch bei Gleichheit von Einkommen, Haushaltsgröße und Wohnwert der Wohnung - mitunter sehr verschieden ausfallen können. Diagramm 4 verdeutlicht dies am Beispiel der Förderbestimmungen für Sachsen, Rheinland-Pfalz und Nordrhein-Westfalen. Dargestellt ist jeweils die herabsubventionierte Nettokaltmiete für einen Drei-Personen-Haushalt im Jahr des Erstbezugs einer 70-qm-Wohnung mit einer anfänglichen Basismiete in Höhe von 13 DM pro qm. ${ }^{1}$

1 Eine anfängliche Basismiete von $13 \mathrm{DM}$ pro qm ist in Sachsen unter der Voraussetzung möglich, daß die Baukosten über $1.900 \mathrm{DM} / \mathrm{qm}$ betragen haben. In Baden-Württemberg muß es sich um eine Gemeinde der Kategorie I mit weniger als 100.000 Einwohnern handeln und in Nordrhein-Westfalen um eine Gemeinde der Mietenstufe 3. 
Diagramm 4: Einkommensorientierte Anfangsmieten in ausgewählten Bundesländern bei einer 70-qm-Wohnung

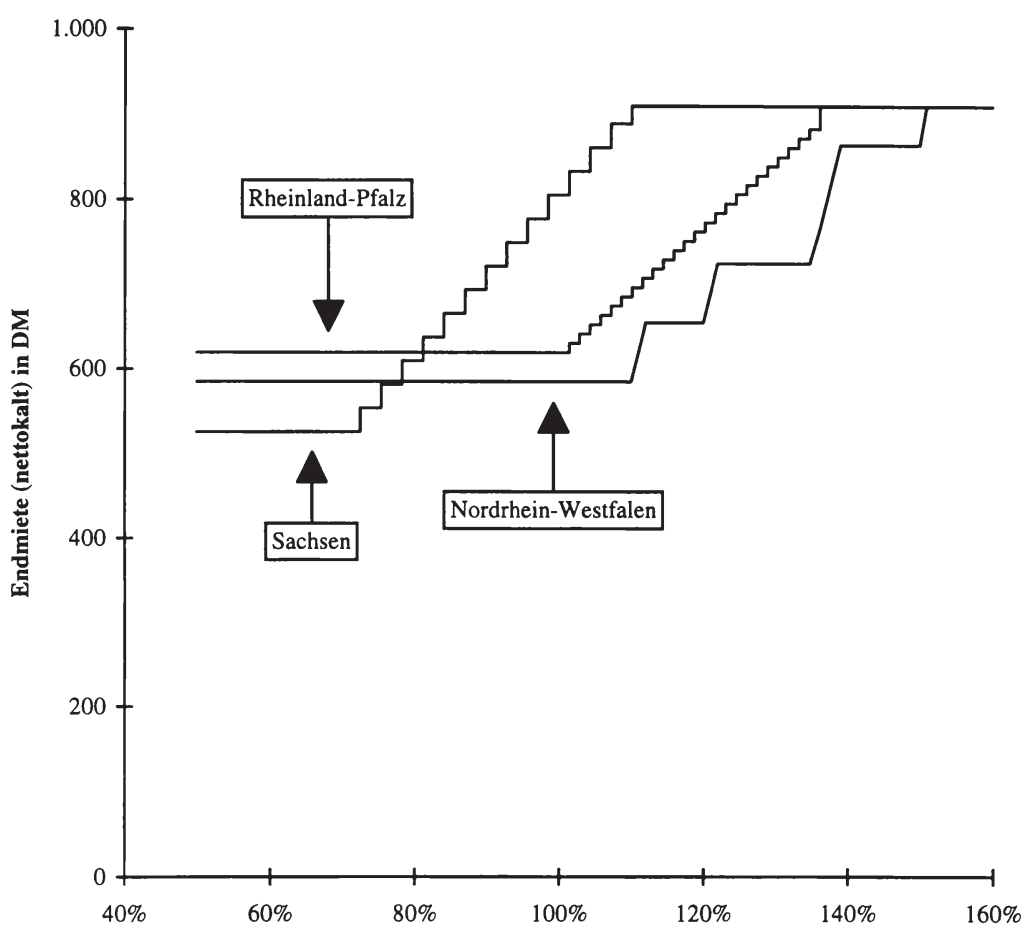

Einkommen in \% der Grenze des $§ 25$ II. WoBauG

Die Unterschiedlichkeit der Zusatzförderung äußert sich insbesondere darin, daß der Abbau der Transfers in Sachsen schon weit unterhalb der Einkommensgrenze, in Nordrhein-Westfalen dagegen erst bei einer mehr als zehnprozentigen Überschreitung der Einkommensgrenze einsetzt. Daraus folgt, daß der Haushalt aus Sachsen bei einem Einkommen knapp oberhalb der Grenze des $\S 25$ eine um ca. $300 \mathrm{DM}$ (das sind etwa $8 \%$ vom Gesamteinkommen) höhere Mietbelastung hinnehmen muß als der gleiche Haushalt in NordrheinWestfalen. Bei den Mindestmieten, die sich zwischen 525 DM und 619 DM bewegen, fallen die Abweichungen geringer aus. Aufs Ganze gesehen sind die 
Unterschiede zwischen den EOF-Modellen der Länder aber deutlich geringer als bei der Fehlbelegungsabgabe.

In den meisten Bundesländern wird die Zusatzförderung erst dann gekürzt, wenn die Einkommensgrenze des $\S 25$ überschritten ist. Von der Höherbelastung werden demnach ausschließlich die Einkommensgruppen getroffen, die im ersten Förderweg als Fehlbeleger klassifiziert werden. Nur in Bremen und Sachsen sowie beim Wolfsburger und dem Möglinger Modell setzt die Förderdegression bereits unterhalb der Einkommensgrenze ein. Bei einem Abbau der Zusatzförderung erst oberhalb der Einkommensgrenze tritt das Problem auf, daß die Transferfunktion aus Wohngeld und Zusatzförderung zwischen der Wohngeldgrenze - das ist das Einkommen, bei dem der Wohngeldanspruch ausläuft und der deutlich höheren Einkommensgrenze einen breiten einkommensunelastischen Mittelbereich aufweist.

Diagramm 5 zeigt am Beispiel eines Drei-Per-sonen-Haushaltes mit einer 70qm-Wohnung in Baden-Württemberg (Gemein-de der Kategorie I mit über 100.000 Einwohnern), wie sich die mangelnde Verzahnung mit dem Wohngeld auf die Höhe der Wohnkostenbelastung - gemessen als Verhältnis der Bruttowarmmiete zum Gesamteinkommen nach $\S 25$ - auswirkt. Der Funktionsverlauf der Wohnkostenbelastung (durchgezogene Linie) ist durch vier Bereiche gekennzeichnet: Im Bereich I werden Leistungen nach dem Wohngeldgesetz gewährt, zugleich erhält der Haushalt die maximale Zusatzförderung in Höhe von 315 DM pro Monat. Durch die Wohngeldzahlungen wird erreicht, daß die Belastungsquote mit fallendem Einkommen nur geringfügig ansteigt. Im Bereich III erfolgt der treppenförmige Abbau der Zusatzförderung, das Verhältnis von Einkommen und Wohnkosten bleibt so lange annähernd konstant, bis die $\mathrm{Zu}-$ satzförderung auf Null heruntergefahren ist und der Mieterhaushalt die volle Basismiete zu zahlen hat (Bereich IV). Da mit der Basismiete die Obergrenze der Wohnkosten erreicht ist, führt jeder weitere Einkommensanstieg nun zu einem Absinken der Belastungsquote.

Die mangelhafte Verzahnung von EOF und Wohngeld tritt im Funktionsbereich II zutage, der dadurch gekennzeichnet ist, daß zwar kein Wohngeld mehr, aber nach wie vor die maximale Zusatzförderung gewährt wird. Die Wohnkosten werden - wie im Bereich IV - durch Einkommensveränderungen nicht beeinflußt. Daraus ergibt sich, daß Mieter mit großen Einkommensunterschieden die gleiche Subvention erhalten. Der Tragbarkeitsgrundsatz ist verletzt. Im Diagramm äußert sich dies darin, daß das Prozentverhältnis von Wohnkosten und Einkommen mit steigendem Einkommen sinkt, während die zumutbaren Mietquoten mit steigendem Einkommen eigentlich höher angesetzt (vgl. z.B. die Miet- und Lastenbeihilfen von 1960, die Wohnbeihilfen von 1963 etc.), zumindest aber konstant gehalten werden müßten. 
Diagramm 5: Belastungsquote eines Drei-Personen-Haushaltes bei Erstbezug einer einkommensorientiert geförderten 70-qm-Wohnung in einer baden-württembergischen Großstadt

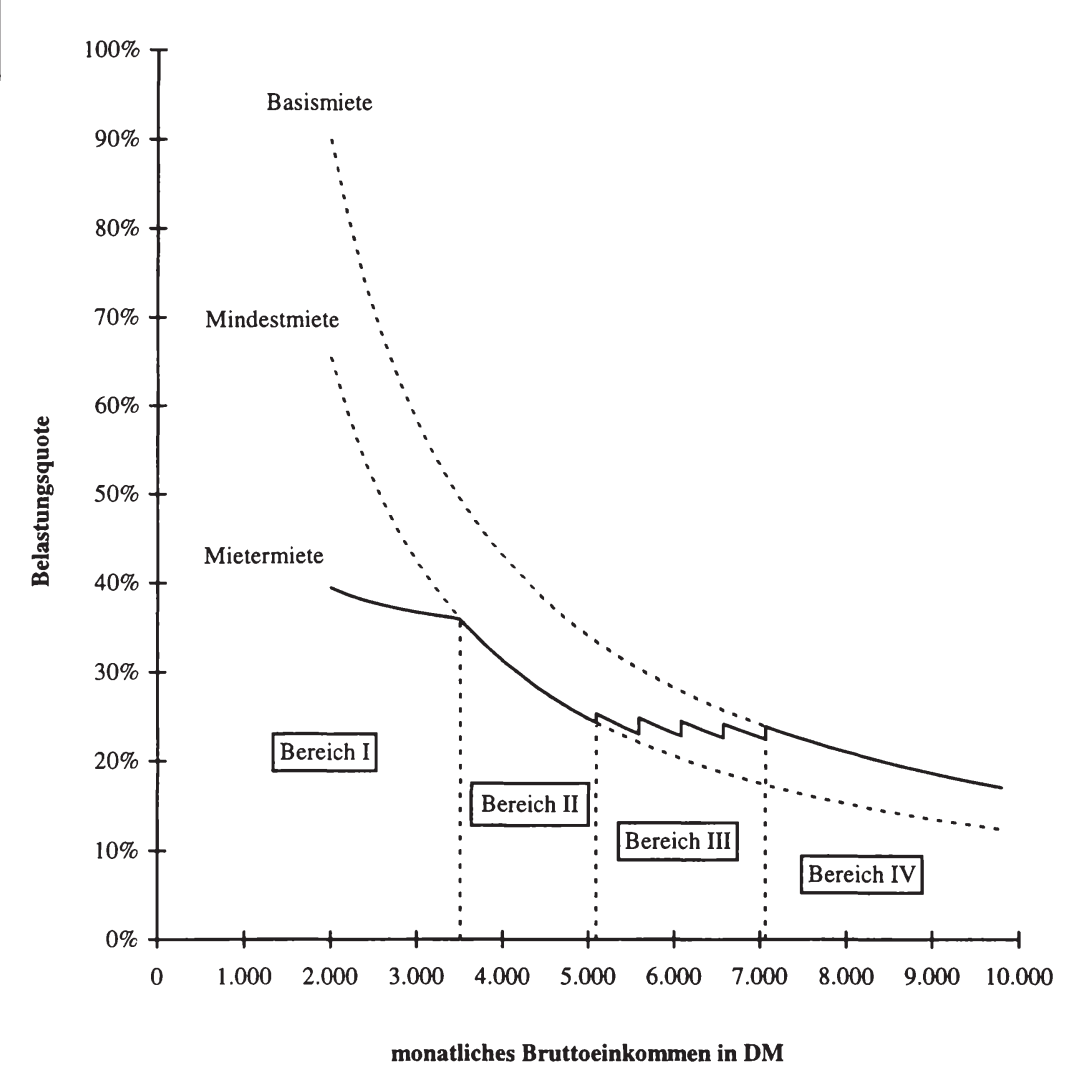

In der Graphik wird auch deutlich, daß Bereich II keineswegs von vernachlässigbarer Größe ist. Gegenwärtig (Stand: September 1997) endet der Wohngeldanspruch je nach Haushaltsgröße, Gemeindekategorie und Höhe der Mindestmiete im Einkommensbereich zwischen $25 \%$ und $40 \%$ unterhalb der Grenze des $\S 25$. Bei einem Drei-Personen-Haushalt kann der Abstand zwischen Wohngeld- und Einkommensgrenze bis zu 2.000 DM brutto monatlich betragen. Zwar 
wird sich die Wohngeldgrenze wegen der Dynamisierung der Mieten und der regelmäßigen Anhebungen der Wohngeldbeträge in Zukunft nach rechts verlagern, so daß das beschriebene Problem in der Tendenz entschärft wird. Auf der anderen Seite könnte eine Anhebung der Einkommensgrenze nach $\S 25$ diesen Effekt zumindest teilweise wieder rückgängig machen. Ferner läßt sich selbst bei einer zu erwartenden Annäherung der Wohngeld- an die Einkommensgrenze die aktuell unbefriedigende Situation kaum rechtfertigen. Aus fiskalischer und verteilungspolitischer Sicht erscheint es daher unerläßlich, die Staffelung der Zusatzförderung von vornherein stärker an den Bestimmungen des Wohngeldrechts auszurichten.

Ein weiterer Kritikpunkt an der Ausgestaltung der Zusatzförderung ist der überwiegend treppenförmige Verlauf der Transferfunktionen. Denn es kann der Fall eintreten, daß Haushalte, deren Einkommen nur knapp unter der Grenze zur nächsten Förderstufe liegen, wegen minimaler Verdienstzuwächse große Einbußen bei der Zusatzförderung hinnehmen müssen, durch die sie netto schlechtergestellt werden. Damit wird gegen das Postulat verstoßen, daß Zuwächse im Bruttoeinkommen auch zu einer Erhöhung, keinesfalls aber zu einer Verrringerung des verfügbaren Einkommens führen sollen. Von der Problematik betroffen sind die Bundesländer, in denen die Förderung in wenigen abrupten Schritten von durchschnittlich 1 DM pro qm und Monat abgebaut wird (BadenWürttemberg, Bayern, Berlin, Bremen, Pilotmodell Niedersachsen, SchleswigHolstein und Thüringen). Mit Erreichen der jeweils nächsten Einkommenskategorie geht das verfügbare Einkommen zunächst in Höhe der Zuschußkürzung zurück. Erst bei einem weiteren Anstieg der Bruttoeinkünfte in Höhe von

$$
\Delta Y_{B R}=-\Delta Z\left(1-t^{\prime}\right)
$$

mit

$\mathrm{t}^{\prime}=$ Grenzabgabensatz bezogen auf Steuern vom Einkommen und Sozialabgaben,

erreicht es wieder das unmittelbar vor Rückführung der Transfers realisierte Niveau. Bei 70 qm Wohnfläche und einer Rückführung der Förderung um jeweils $1 \mathrm{DM}$ führt der Übergang von einer Einkommenskategorie zur nächsthöheren zu einer Zuschußkürzung von jährlich 840 DM. Der zur Kompensation der Transfereinbußen benötigte Bruttozusatzverdienst beträgt bei einem Grenzabgabensatz von 55\% 1.867 DM. So haben Haushalte in Baden-Württemberg, 
Bayern, Berlin etc., die um 21\% über der Einkommensgrenze liegen, nach Abzug der Wohnkosten ein geringeres verfügbares Einkommen als bei einer Überschreitung der Grenze um 19\%. In einzelnen Bundesländern wie z.B. Thüringen oder Bayern ${ }^{1}$, sind sogar Mietsprünge von mehr als $1 \mathrm{DM}$ pro qm und Monat möglich, so daß der beschriebene Effekt noch stärker zur Geltung kommen kann.

Um Mietsprünge zu vermeiden, hat die nordrhein-westfälische Landesregierung bestimmt, daß die Anhebung der Wohnkosten bei Erreichen der jeweils nächsten Einkommenskategorie den Betrag nicht übersteigen darf, um den das Gesamteinkommen die Schwelle zur betreffenden Einkommenskategorie überschritten hat. Ist das monatliche Gesamteinkommen also beispielsweise um 30 DM über die um $20 \%$ erhöhte Einkommensgrenze hinaus angewachsen, so darf die monatliche Mietzahlung nicht um $1 \mathrm{DM}$ pro qm, sondern nur um insgesamt $30 \mathrm{DM}$ angehoben werden. Die Grenzbelastung kann so $100 \%$ nicht übersteigen. Indes wird die Ermittlung der Zusatzförderung durch die Kappungsgrenze erheblich verkompliziert, und die treppenartige Transferfunktion bleibt im Prinzip erhalten (vgl. Diagramm 4). In Rheinland-Pfalz und Sachsen hat man das Problem der Mietsprünge dadurch entschärft, daß die Zusatzförderung in vielen kleinen Schritten zurückgeführt wird. Zu fragen ist, warum überhaupt an der treppenförmigen Förderdegression festgehalten wird. Sinnvoller wäre es, wenn die Transferfunktion im abfallenden Bereich einen linearen Verlauf hätte. Wie eine entsprechende Ausgestaltung der Zusatzförderung aussehen könnte, wird an späterer Stelle (Kapitel 4.D.III.b) dargelegt.

\section{e. Einfluß der Haushaltsgröße auf die Förderung}

Die Anzahl der zum Haushalt rechnenden Familienmitglieder ist in zweifacher Hinsicht von Bedeutung. Zum einen wird durch sie der Wohnraumbedarf bestimmt, der mitentscheidend ist für die Höhe der aufzubringenden Wohnkosten. Zum anderen verändert sich mit der Anzahl der Familienmitglieder das pro Kopf verfügbare Einkommen. Beide Tatbestände seien an einem Beispiel verdeutlicht: Ein Ehepaar, das in einer Zwei-Zimmer-Wohnung lebt, erwarte ein Kind. Aus dem bislang für zwei Personen verwendeten Einkommen muß künftig ein drittes Familienmitglied ernährt werden, so daß für den einzelnen weniger zur Verfügung steht (Einkommenseffekt). Hinzu kommt, daß wegen der Familienvergrößerung im allgemeinen mehr Wohnfläche benötigt wird. Das Ehepaar wird sich u.U. nach einer größeren und damit i.d.R. auch teureren

1 In Bayern können in Gemeinden mit sehr hohen Basismieten (z.B. München) Mietsprünge von mehr als $1 \mathrm{DM}$ auftreten, wenn die um $60 \%$ erhöhten Einkommensgrenze knapp überschritten wird, da die Zahlungen dann abrupt auf null zurückgeführt werden. 
Wohnung umsehen, so daß das nach Abzug der Wohnkosten pro Kopf verfügbare Einkommen noch weiter sinkt (Bedarfseffekt).

Im Rahmen der EOF sollten sowohl der Einkommenseffekt als auch der Bedarfseffekt Berücksichtigung finden. Bei den Fördermodellen von Rheinland-Pfalz und Möglingen ist diese Anforderung nicht erfüllt, da die Wohnkosten auf ein von der Haushaltsgröße unabhängiges Prozentverhältnis zum Einkommen herabsubventioniert werden, so daß der wohnkostenunabhängige Einkommenseffekt unberücksichtigt bleibt. Dies sei anhand eines Beispiels verdeutlicht: Bei einem Gesamteinkommen gemäß § 25 II. WoBauG in Höhe von 4.500 DM und einer Monatsmiete (Mietbegriff nach Wohngeldrecht) von 1.100 DM bekommt ein Drei-Personen-Haushalt in Rheinland-Pfalz 110 DM, ein Vier-PersonenHaushalt erhält bei gleichem Gesamteinkommen und gleicher Miete ebenfalls 110 DM. Die Zusatzförderung für den Vier-Personen-Haushalt fällt nur dann höher aus, wenn der Unterschied in der Familiengröße mit erhöhten Wohnkosten einhergeht (Bedarfseffekt). Diese Mehrkosten werden sogar zu 100\% ausgeglichen, was sich durch eine Abwandlung des oben angeführten Beispiels verdeutlichen läßt. Beträgt die monatliche Miete des Vier-Personen-Haushaltes nicht 1.100 DM, sondern - etwa infolge des Bezugs einer größeren Sozialwohnung - $200 \mathrm{DM}$ mehr, dann fällt die Zusatzförderung mit $310 \mathrm{DM}$ ebenfalls um 200 DM höher aus. Von der Nichtberücksichtigung des Einkommenseffektes sind vor allem diejenigen Haushalte betroffen, die aus finanziellen oder sonstigen Gründen auch nach der Familienvergrößerung in ihrer Sozialwohnung verbleiben.

Bei den übrigen Varianten der EOF wirkt sich auch der Einkommenseffekt auf die Höhe der Zusatzförderung aus, da die Quadratmetermieten nach dem Einkommen und der Haushaltsgröße gestaffelt sind. Dies sei anhand von Diagramm 6 verdeutlicht, das die Transferfunktion eines Berliner Drei-PersonenHaushaltes mit einer 70-qm-Wohnung darstellt. Der durch das Hinzukommen eines Familienmitglieds ausgelöste Einkommenseffekt führt zu einer Verlagerung der Transferfunktion nach rechts. Da nun auch die maßgebliche Einkommensgrenze weiter rechts liegt, setzt der Abbau der Zusatzförderung erst bei einem höheren Einkommen ein. ${ }^{1}$ Im Bereich niedriger Einkommen hat sich zudem der Wohngeldanspruch erhöht. ${ }^{2}$

1 Beispielsweise liegt ein Haushalt mit einem monatlichen Bruttoeinkommen in Höhe von 6.000 DM um ca. 18\% über der maßgeblichen Einkommensgrenze (41.400 DM) und erhält daher nur einen Zuschuß von $5 \mathrm{DM}$ pro qm und Monat. Als Vier-Personen-Haushalt unterliegt er der um 8.000 DM erhöhten Einkommensgrenze (49.400 DM), so daß ihm bei unverändertem Einkommen nunmehr die maximale Zusatzförderung in Höhe von $7 \mathrm{DM}$ zusteht.

2 Interessanterweise steigt der zusätzliche Wohngeldbetrag zunächst mit steigendem Einkommen an. 
Diagramm 6: Auswirkungen einer Haushaltsvergrößerung auf die Höhe der Wohntransfers (kein Wohnungswechsel) am Beispiel eines

\section{Drei-Personen-Haushaltes in Berlin}

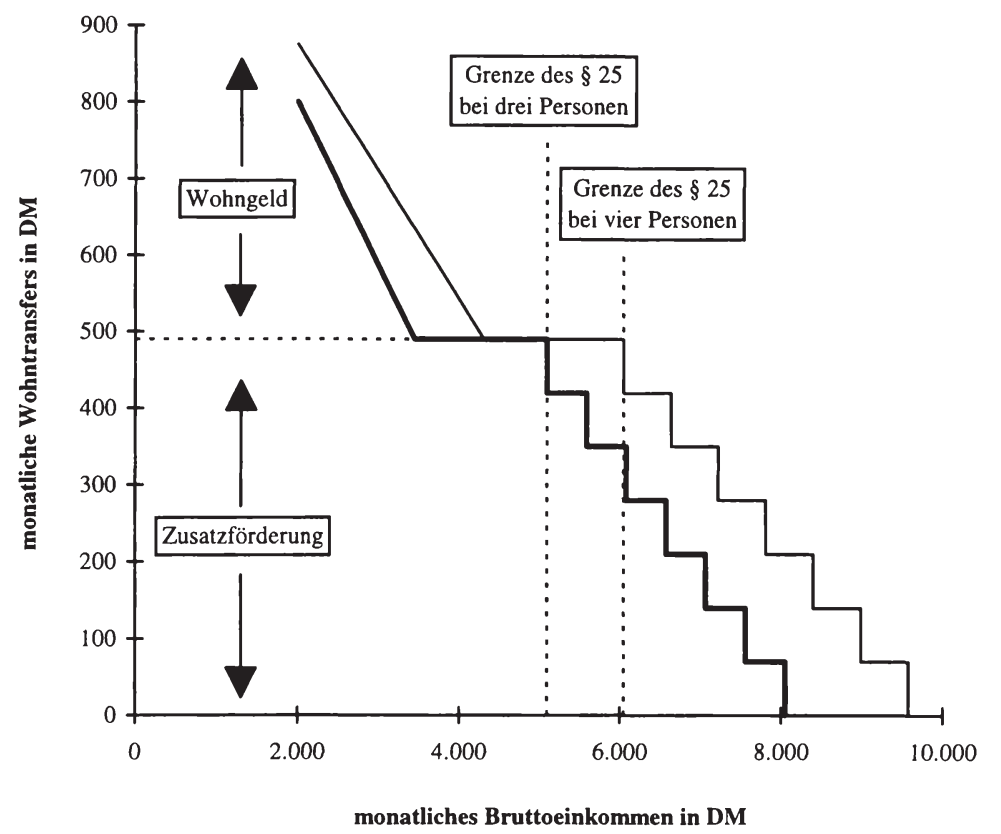

Noch größer fallen die Unterschiede aus, wenn man die Förderung eines DreiPersonen-Haushaltes mit einer 70-qm-Wohnung der Förderung eines VierPersonen-Haushaltes mit einer 85-qm-Wohnung gegenüberstellt. Dies ist darauf zurückzuführen, daß die Transferfunktion des größeren Haushaltes nun nicht nur nach rechts (Einkommenseffekt), sondern wegen des Bedarfseffektes auch nach oben verlagert wird. Diese Verschiebung erklärt sich daraus, daß die $\mathrm{Zu}-$ satzförderung als Zuschuß pro qm förderfähige Wohnfläche gewährt wird, der in der größeren Wohnung lebende Haushalt daher eine entsprechend höhere Fördersumme erhält. Wegen der gestiegenen Wohnkosten hat sich der Wohngeldanspruch geringverdienender Haushalte nochmals erhöht. 
Diagramm 7: Vergleich der Förderung eines Drei- und eines Vier-PersonenHaushaltes in verschieden großen Wohnungen am Beispiel Berlins

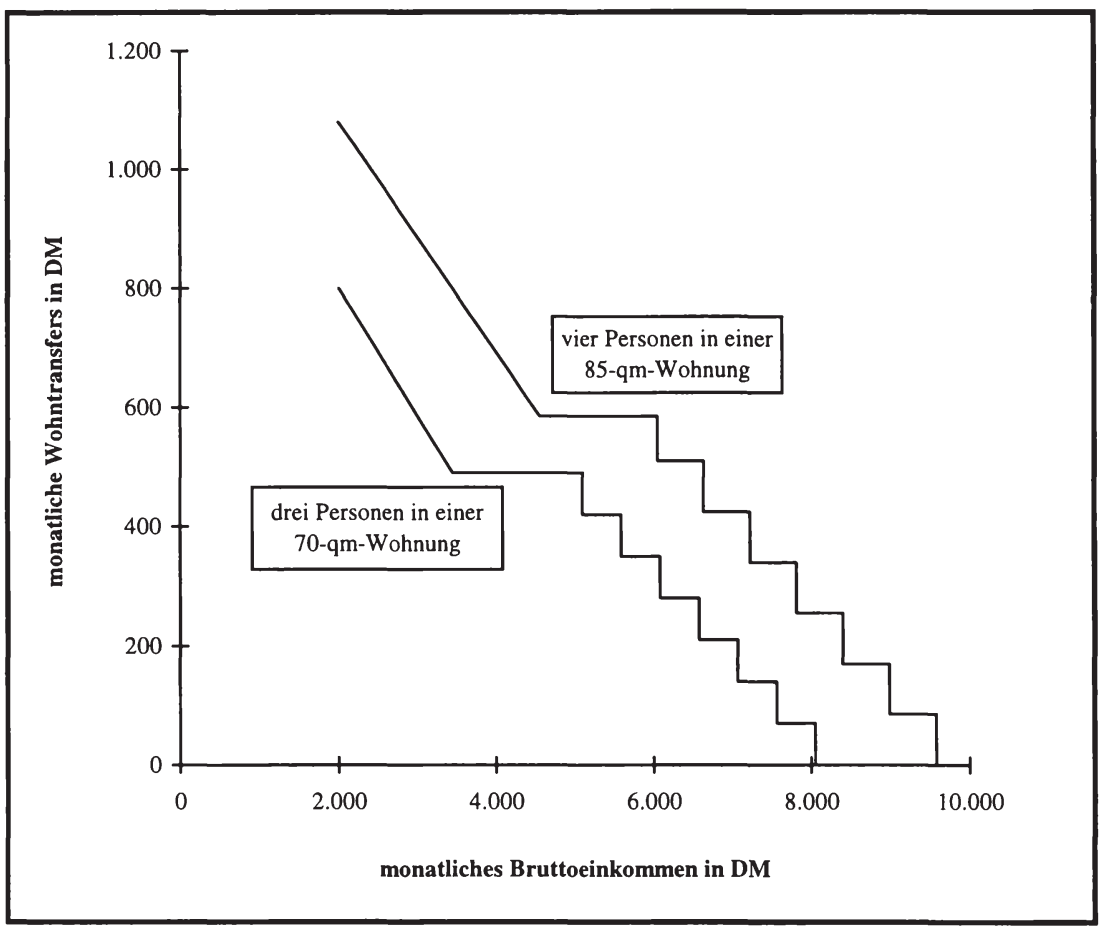

Wie in den beiden Graphiken deutlich wird, ist die Besserstellung des großen gegenüber dem kleineren Haushalt davon abhängig, in welchem Einkommensbereich der Vergleich erfolgt. Die Transfererhöhung beträgt in Diagramm 6 zwischen null und $210 \mathrm{DM}$ und in Diagramm 7 zwischen null und 255 DM pro Monat. Sieht man von den Mietern ab, die überhaupt keine Zusatzförderung bekommen, dann erhalten die geringsten zusätzlichen Transfers solche Haushalte, deren Einkommen vor der Familienvergrößerung knapp unter der Grenze des $\S 25$ lagen, da ihnen auch danach die gleiche Zusatzförderung pro qm gezahlt wird und ein Wohngeldanspruch weiterhin nicht besteht. Erfolgt kein Umzug in eine größere Wohnung (Diagramm 6), ändert sich die Höhe der Zahlungen nicht. Dagegen steigt die Förderung bei einem Einkommen von beispielsweise 8.200 DM auch ohne Wohnungswechsel gleich um 210 DM an. Die ungleich- 
mäßigen Vergünstigungen resultieren aus dem teils waagerechten teils treppenförmigen Verlauf der Transferfunktion, auf den bereits im vorangegangenen Kapitel eingegangen worden ist. Die Betrachtungen zeigen, daß die Ausgestaltung der EOF noch erheblich verbessert werden kann.

\section{f. Berücksichtigung von Wohnwertunterschieden}

Eine wichtige Anforderung an die Zusatzförderung besteht darin, daß Wohnwertunterschiede über den Preis ,fühlbar" bleiben müssen. „Wenn lediglich das Einkommen die monatliche Mietzahlung bestimmt, zahlt ein Mieter in einer 'guten' Wohnung genau so viel Miete wie ein anderer Haushalt in einer 'schlechten' Wohnung. ... Gleiche Haushalte in ungleichen Wohnungen werden ohne Begründung gleich behandelt."' Die Forderung nach horizontaler Gerechtigkeit ist verletzt.

Wie ein Blick auf die aktuellen Förderkonditionen der EOF zeigt, wird dem Fühlbarkeitsgrundsatz oftmals gar nicht oder nur unzureichend entsprochen. Dies resultiert zum einen daraus, daß die Basismieten in einigen Ländern nur unzulänglich an den im Einzelfall erzielbaren Marktmieten ausgerichtet sind (vgl. Kapitel 3.C.II.b). Die folgenden Überlegungen konzentrieren sich auf die Zusatzförderung als Ursache solcher Mietpreisverzerrungen. Diese ist in einigen Ländern so ausgestaltet, daß die in den Basismieten noch vorhandene Differenzierung nach dem Wohnwert mehr oder weniger aufgehoben wird. Eine rein einkommensorientierte Zusatzförderung, die Wohnwertunterschiede überhaupt nicht berücksichtigt, wird in Rheinland-Pfalz gewährt. Dort sind die Zuschüsse so gestaffelt, daß das Verhältnis der Wohnkosten gemäß $\S 5$ WoGG zum Gesamteinkommen nach $\S 25$ stets in der Nähe von $23 \%$ liegt. Unterschiede in den Wohnkosten nach $\S 5$ WoGG werden durch die Transfers in voller Höhe ausgeglichen. So erhält ein Haushalt A, der in einer um 200 DM teureren Wohnung lebt als ein anderer, ansonsten gleicher Haushalt B, eine um 200 DM höhere Zusatzförderung. Der Bezug der preiswerten Wohnung zahlt sich für Haushalt B erst aus, wenn er aufgrund seines Einkommens und der niedrigeren Basismiete keine Zusatzförderung mehr erhält. Jede weitere Einkommenssteigerung führt dann nämlich zu einem Absinken der Belastungsquote, während diese für Haushalt A zunächst weiterhin bei 23\% liegt und erst nach Erreichen der höheren Basismiete ebenfalls absinkt.

Auch in Sachsen und Schleswig-Holstein sind die herabsubventionierten Endmieten von der Höhe der Basis- bzw. Vergleichsmieten unabhängig. Anders als in Rheinland-Pfalz bleiben aber die Mietunterschiede, die aus Abweichungen

Pfeiffer, U. u.a. (1996), Teil A, S. 15. 
bei der Wohnungsgröße resultieren, weiterhin fühlbar. So hat ein Drei-Personen-Haushalt in Schleswig-Holstein mit einem Einkommen unterhalb der Grenze des $\S 25$ für eine 65-qm-Wohnung im Erstbezugsjahr eine Nettokaltmiete von $598 \mathrm{DM}$ (= $65 \mathrm{qm} * 9,20 \mathrm{DM} / \mathrm{qm}$ ) zu entrichten, für eine $10 \mathrm{qm}$ größere Wohnung dagegen eine Miete von $690 \mathrm{DM}$ (= $75 \mathrm{qm} * 9,20 \mathrm{DM} / \mathrm{qm})$. Sonstige Qualitätsmerkmale (z.B. im Hinblick auf die Lage und den Zuschnitt der Wohnung, die Art der Fenster, der Fußböden etc.) bleiben unberücksichtigt. Die Wohnwertunterschiede schlagen sich erst dann in den Wohnkosten nieder, wenn der geförderte Haushalt aufgrund seines Einkommens zur Zahlung der Vergleichsmiete verpflichtet wird. In Sachsen hat die Festsetzung rein subjektorientierter Mietermieten außerdem zur Folge, daß Unterschiede in den auf die Basismiete umlegbaren Modernisierungskosten für die Empfänger der Zusatzförderung nicht mehr fühlbar sind. Die Abweichungen kommen erneut erst dann zum Tragen, wenn kein Anspruch mehr auf Zusatzförderung besteht.

Auch in Baden-Württemberg, Bayern und Nordrhein-Westfalen werden die bei den Basismieten noch vorhandenen Preisdifferenzen durch die Zusatzförderung abgebaut. Indes findet keine völlige Nivellierung der Preisstrukturen statt. So weisen die Mindestmieten in Bayern, die den Bewilligungsmieten im ersten Förderweg entsprechen, lediglich Abstände von maximal $3 \mathrm{DM}$ pro qm auf. Sie betragen in Gemeinden der Kategorie I gegenwärtig 9,50 bis 10,50 DM, in Gemeinden der Kategorie II 8,50 bis 9,50 DM und in solchen der Kategorie III 7,50 bis 8,50 DM. Da der Abbau der Zusatzförderung in absolut gleichen Schritten von je einer Mark pro qm erfolgt, setzt sich die Mietpreisverzerrung in den Einkommensbereich oberhalb der Grenze des $\S 25$ fort.

In Nordrhein-Westfalen bewegen sich die anfänglichen Basismieten zwischen 11 DM (Mietenstufe 1) und 17 DM (Mietenstufe 5) und in Baden-Württemberg zwischen 11 DM (Kategorie III) und 14 DM (Stuttgart), während die Mindestmieten in Nordrhein-Westfalen zwischen 7,55 DM und 9,35 DM und in BadenWürttemberg zwischen $8 \mathrm{DM}$ und $9 \mathrm{DM}$ liegen. Die nivellierende Wirkung der Zusatzförderung läßt sich daran verdeutlichen, daß die anfängliche Basismiete in der teuersten Gemeindekategorie um 54,5\% (Nordrhein-Westfalen) bzw. 27,3\% (Baden-Württemberg) über der Basismiete in der preisgünstigsten Gemeindekategorie liegt, während dieser Abstand bei den Mindestmieten nur noch $23,8 \%$ bzw. 12,5\% beträgt. Offensichtlich dominiert auch in diesen Bundesländern die Auffassung, daß den Empfängern der Zusatzförderung die relativen Mietpreisnachteile von Wohnungen in ,guter“ Lage nicht zugemutet werden können. 


\section{g. Übergang der Wohnungen in den Markt}

Kennzeichnend für die Objektförderung ist, daß die Wohnungen nur für eine begrenzte Zeit - zumeist ist dies der Förderzeitraum - einer Mietpreisbindung unterliegen. Danach können die Investoren ihre Mietforderung unter Beachtung der Vorschriften des MHG bis auf das Niveau der Vergleichsmiete heranführen. Bei Wohnungen, die im ersten Förderweg gefördert worden sind, verhindert die Kappungsgrenze nach $\S 2$ Abs. 1 MHG, daß es bei Auslaufen der Bindung zu gravierenden Mietsprüngen kommt. Hat beispielsweise ein Haushalt in den letzten drei Jahren der Wohnungsbindung eine Nettokaltmiete von 8 DM pro qm entrichtet, so darf der Eigentümer die Miete bei Wegfall der Preisbindung um nicht mehr als 1,60 DM (bei Fertigstellung vor 1981) bzw. 2,40 DM (bei späterer Fertigstellung) erhöhen. Eine Sonderregelung gilt für Haushalte, die vor dem Auslaufen der Bindung eine Fehlbelegungsabgabe entrichtet haben, deren Betrag oberhalb der zulässigen Mieterhöhung liegt. Da solche Mieter beim Übergang der Wohnungen in den Markt paradoxerweise eine Entlastung bei den Wohnkosten hätten, darf in diesen Fällen nach § 2 Abs. 1 a MHG die Miete über die Kappungsgrenze hinaus bis zu dem Betrag angehoben werden, den die Mieter bis dahin einschließlich der Fehlbelegungsabgabe gezahlt haben. ${ }^{1}$ Die Bestimmung läuft darauf hinaus, daß die betroffenen Haushalte in den ersten drei Jahren nach Auslaufen der Bindungen überhaupt keine Mehrbelastungen hinnehmen müssen. ${ }^{2}$

Ganz anders verhält es sich bei der EOF, da Ausgangsbasis für die Mieterhöhung die vertragliche Basismiete ist. Die vor Wegfall der Belegungsbindung als Mietzuschuß oder Forderungsverzicht geleistete Zusatzförderung kann unverzüglich eingestellt werden, ohne daß dadurch gegen mietrechtliche Bestimmungen verstoßen wird. Beim Übergang der Wohnungen in den Markt kann es daher zu einem sprunghaften Anstieg der Wohnkosten auf ein vom Mieter kaum tragbares Niveau kommen. Gerade bei den geringverdienenden Mietern, die bis zum Ende des Bindungszeitraumes noch eine hohe Zusatzförderung erhalten haben, muß mit Härtefällen gerechnet werden. Die Länder oder Kommunen könnten sich genötigt sehen, eine Nachsubventionierung vorzunehmen. ${ }^{3}$

Welche Größenordnung der Anstieg der Endmieten annehmen kann, sei am Beispiel eines Drei-Personen-Haushaltes aus Stuttgart verdeutlicht. Bei einem

Vgl. Gramlich, B. (1994), S. 149f.

2 Konsequenter wäre es, wenn sich die Kappungsgrenze beim Mieterhöhungsverlangen auf die Sozialmiete zuzüglich Fehlbelegungsabgabe beziehen würde.

3 Vgl. Deutscher Mieterbund e.V. (1994), S. 284f. (4f.); Institut Wohnen und Umwelt (1994), S. 324f. (6f.). 
Einkommen unterhalb der Grenze des $\S 25$ muß der Haushalt im letzten Monat vor Auslaufen der 10jährigen Belegungsbindung eine Mindestmiete in Höhe von 11,40 DM pro qm zahlen. Durch den Wegfall der Zusatzförderung erhöhen sich die Wohnkosten auf 16,40 DM pro qm. Da die Basismiete in den drei Jahren vor Auslaufen der Bindung nur um maximal 0,60 DM angehoben werden durfte, kann der Vermieter bis zum Erreichen der Kappungsgrenze von 30\% noch 4,14 DM aufschlagen, so daß die Mietbelastung von einem Monat auf den nächsten um ca. 80\% auf 20,54 DM ansteigen kann. Neben der Kappungsgrenze wird die Mietenentwicklung nach Auslaufen der Bindung vor allem durch das Niveau der ortsüblichen Vergleichsmieten bestimmt. Bei sehr kurzen Förderzeiträumen ist davon auszugehen, daß die Vergleichsmieten nach Auslaufen der Bindungen überdurchschnittlich hoch sind, da die Wohnungen noch zum jüngeren Bestand zählen. Aus den ehemaligen Sozialwohnungen sind Wohnungen der gehobenen Preiskategorie geworden. Weniger problematisch ist die Situation, wenn die Förderung über einen längeren Zeitraum erfolgt, da die Objekte dann nach Auslaufen der Bindung wegen des älteren Baudatums einem günstigeren Vergleichsmietenniveau unterliegen. Die Sozialmieter werden es sich dann eher leisten können, in ihren Wohnungen zu bleiben.

Die Sozialverträglichkeit der Mieten nach Ablauf der Belegungsbindung wird auch davon abhängen, in welchem Maße die erhöhten Wohnkosten durch das Wohngeld abgefedert werden. Um dies abschätzen zu können, haben Mitarbeiter des Wohnungsbauministeriums die durchschnittlichen Neubaumieten des Jahres 1973 für verschiedene Städte mit der allgemeinen Preisentwicklung fortgeschrieben und den Wohngeld-Höchstbeträgen des Jahres 1992 gegenübergestellt. ${ }^{1}$ Es ergab sich, daß die Höchstbeträge 1973 noch unter den Anfangsmieten, am Ende des Untersuchungszeitraumes dagegen über den fortgeschriebenen Mieten lagen, da sie stärker gestiegen waren als die Preise. Die Aussagefähigkeit dieser Studie ist jedoch gering, denn die künftige Entwicklung der Wohngeld-Höchstbeträge und ihr Verhältnis zu den Wohnkosten lassen sich nicht auf der Basis von Vergangenheitswerten prognostizieren.

In den Plänen der Länder und Kommunen ist das Auftreten von Härtefällen am Ende der Bindungszeiträume offensichtlich nicht hinreichend berücksichtigt worden. Allzu einseitig wurde und wird noch davon ausgegangen, daß die Mieter im Belegungszeitraum reale Einkommenszuwächse erzielen, die sie am Ende der Preisbindung in die Lage versetzen, die ortsüblichen Vergleichsmieten für die geförderten Wohnungen aufzubringen. Für Beamte und Angestellte, die am Anfang ihrer beruflichen Laufbahn stehen, kann diese Einkommensentwicklung durchaus als Regelfall angesehen werden, nicht dagegen bei Gelegenheitsarbeitern, ungelernten Kräften oder Beschäftigten in krisenanfälligen Sektoren. Kaum prognostizierbar ist die Einkommensentwicklung von Mietern, die zum

1 Bundesministerium für Raumordnung, Bauwesen und Städtebau (1994), S. 1f., mit Anlage. 
Bezugszeitpunkt arbeitslos sind und/oder Sozialhilfe empfangen. Nimmt man die Belegungsstrukturen in Baden-Württemberg zum Maßstab, werden die Haushalte, die im Förderzeitraum in die oberen Einkommensstufen hineinwachsen, nicht sehr zahlreich sein. Neben der Entwicklung der Einkünfte könnte auch die Fluktuation unter den Mietern dazu beitragen, daß sich die Einkommensstruktur in den geförderten Objekten nicht in dem gewünschten Ausmaß verbessert. Denn es ist zu vermuten, daß eher solche Haushalte aus den geförderten Wohnungen ausziehen, die sich aufgrund gestiegener Einkommen eine frei finanzierte Mietwohnung oder ein Eigenheim leisten können, während die Neubelegung der freigewordenen Wohnungen mehrheitlich mit einkommensmäßig schlechter gestellten Haushalten erfolgt. Durch die Mietvorteile, die auch besserverdienenden Mietern von Sozialwohnungen zufließen, dürfte die Fluktuation allerdings gebremst werden.

Da eine Nachsubventionierung i.d.R. nicht zu erwarten ist, könnten sich gerade geringverdienende Haushalte gezwungen sehen, die Wohnungen am Ende des Bindungszeitraumes zu verlassen; ein Teil davon wird erneut von den Wohnungsämtern versorgt werden müssen, was besonders deshalb ärgerlich ist, weil zu diesem Zweck u.U. wieder teuere Belegungsrechte erworben werden müssen. Aber selbst wenn es den Mietern gelingt, eine preisgünstige Ersatzwohnung zu finden, bleibt zu kritisieren, daß die Mieter aus finanziellen Gründen zum Verlassen ihres Wohnumfeldes gezwungen sind. Hinzu kommt, daß die betroffenen Haushalte meist nicht erst am Ende des Förderzeitraumes, sondern u. U. bereits eine gewisse Zeit vorher ausziehen werden. Für die Vermieter ergibt sich daraus die Schwierigkeit, daß sie für die nur noch kurzzeitig mietverbilligten Wohnungen einen neuen Mieter aus dem Kreis der bezugsberechtigten Haushalte finden müssen. Gelingt ihnen dies nicht, kommt es zu Leerstand und Mietausfällen.

Aus diesen Gründen ist zu überlegen, ob die Zusatzförderung nicht in absinkenden Beträgen noch einige Jahre über die Dauer der Mietpreis- und Belegungsbindung hinaus gewährt werden sollte. Dies hätte den Vorteil, daß die Anhebung der Vertragsmieten und der Wegfall der Zusatzförderung nicht zeitlich zusammenfallen und die geringverdienenden Mieter sich ohne akuten finanziellen Druck noch nach Auslaufen der Bindung um eine Ersatzwohnung bemühen könnten. Eine entsprechende Ausgestaltung der Zusatzförderung, bei der Übergangshärten vermieden werden, ist bislang nur in Berlin vorgenommen worden (Diagramm 8). Dort bekommen Haushalte, die am Ende des 15jährigen Regelbindungszeitraumes die Grenze des $§ 25$ einhalten, noch für weitere zehn Jahre eine Zusatzförderung. Liegen die Mietereinkommen nach Ablauf der Regelbindung um bis zu $20 \%$ über der Grenze, werden noch für maximal fünf Jahre Zuschüsse gewährt. In den fünf bzw. zehn zusätzlichen Förderjahren wird die Zusatzförderung jährlich um 0,40 DM pro qm abgebaut, während die Basismie- 
ten auf ihrem Stand am Ende des 15jährigen Förderzeitraumes in Höhe von 19,40 DM/qm verbleiben.

Diagramm 8: Dynamisierung der Mietermieten bei der EOF in Berlin

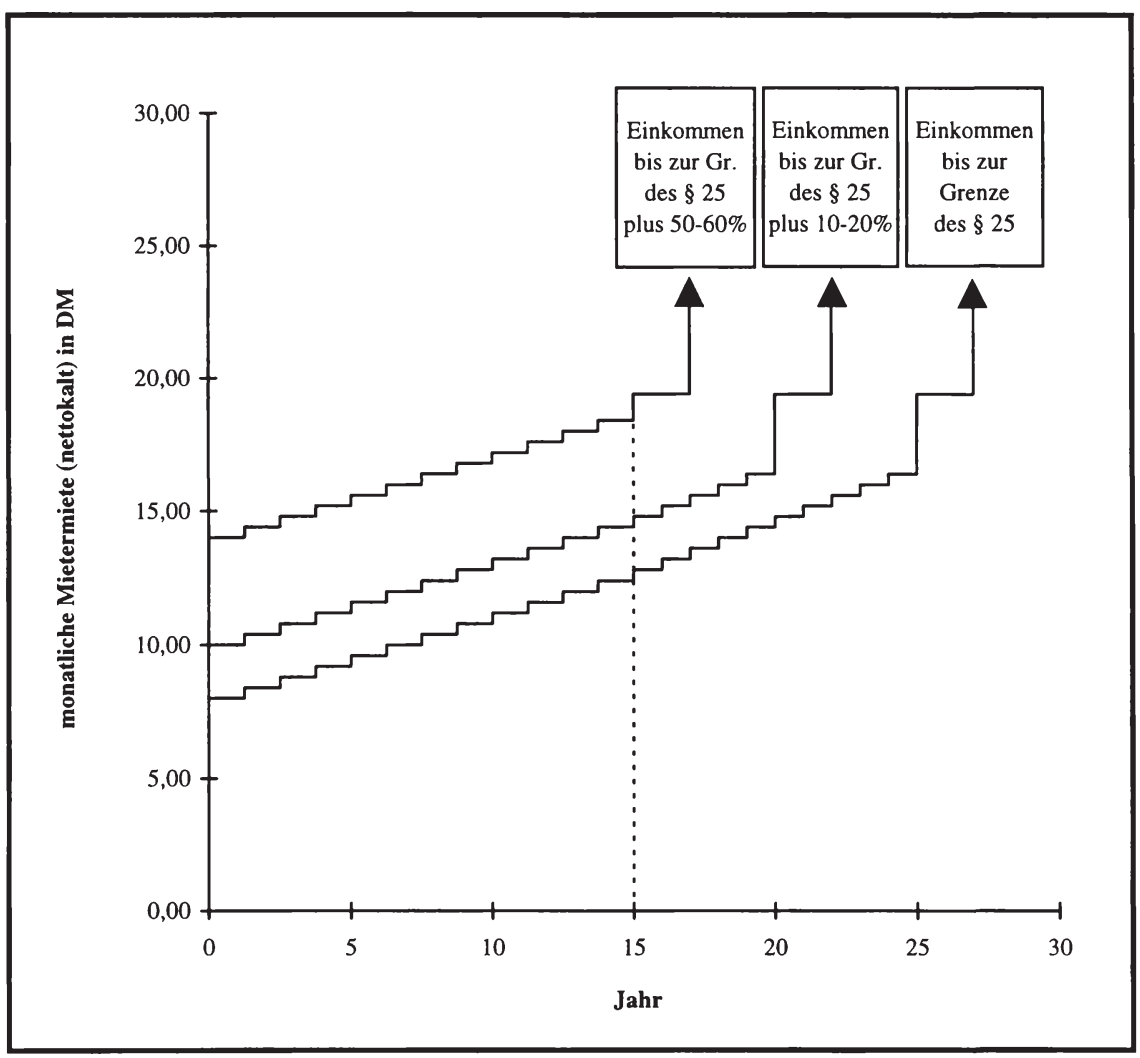

Mietsprünge werden außerdem dadurch verhindert, daß Anhebungen der Vertragsmieten gemäß MHG erst zwei Jahre nach dem Wegfall der Zusatzförderung am Ende des Regelbindungszeitraumes bzw. des Verlängerungszeitraumes möglich sind. Nur bei Haushalten, die bereits vor Ablauf der Bindung keine $\mathrm{Zu}$ satzförderung (mehr) erhalten haben, dürfen die Vertragsmieten sofort angeho- 
ben werden. Ohne diese Übergangsregelungen hätte nach 15 Jahren der Extremfall eines Mietenanstiegs um mehr als 100 Prozent von 12,40 auf 24,98 DM eintreten können. ${ }^{1}$

Dem Berliner Modell ist zugute zu halten, daß es als einziges die Probleme des Übergangs der Sozialwohnungen in den Markt berücksichtigt. Zu bemängeln ist die punktuelle Ausrichtung auf die Einkommensverhältnisse am Ende des 15. Förderjahres. So erhalten Haushalte, die zu diesem Zeitpunkt die Einkommensobergrenze bzw. die um 20\% erhöhte Grenze überschreiten, in den Folgejahren auch dann eine zeitlich verkürzte oder überhaupt keine Zusatzförderung, wenn sie drastische Einkommenseinbußen hinnehmen müssen, während andere Haushalte, die die maßgeblichen Grenzen am Ende des 15. Förderjahres noch einhalten und danach starke Verdienstzuwächse erzielen, u.U. auch weiterhin gefördert werden. Problematisch ist auch die verzögerte Anhebung der Basismiete bei geringverdienenden Haushalten. Sie dürfte die Kapitalanleger in ihrem Bemühen bestärken, Haushalte mit einer guten finanziellen Perspektive bei der Wohnungszuteilung zu bevorzugen.

Die beschriebenen Nachteile ließen sich vermeiden, wenn die Mietbindung für alle Haushalte gleichzeitig aufgehoben, die Zusatzförderung aber noch eine Zeitlang in periodisch absinkenden Beträgen weitergezahlt würde. Denkbar wäre eine Rückführung der Zuschüsse um 1 DM pro Jahr. Die Vorgehensweise hätte im Berliner Modell zur Folge, daß die Zusatzförderung für Haushalte, deren Einkommen unterhalb der Grenze des $\S 25$ liegt, im 16. Jahr auf 6 DM pro qm, im 17. Jahr auf 5 DM u.s.w. abgesenkt würde. Mieter, deren Einkommen die Grenze des $\S 25$ um 30 bis $40 \%$ überschreiten und die im Berliner Modell nach Ablauf der Regelbindungsdauer keine Zusatzförderung mehr erhalten, würden bei der vorgeschlagenen Variante immerhin noch 2 DM im 16. Jahr und $1 \mathrm{DM}$ im 17. Jahr bekommen. Die Vorgehensweise läßt sich aber auch auf jedes andere Modell übertragen, bei dem die Zusatzförderung als Zuschuß zur Basismiete gewährt wird. Mietsprünge sind dann nur noch infolge der Anhebung der Basismieten gemäß $\S 2$ MHG möglich. Die aus der Fixierung auf die Einkommensverhältnisse am Ende des Regelbindungszeitraumes resultierenden Ungerechtigkeiten würden vermieden, und auf seiten der Investoren bestünden auch keine Unsicherheiten über die Dauer der Bindung an die höchstzulässige Basismiete.

Durch den Wegfall der Zusatzförderung erfährt der Haushalt eine Mehrbelastung von 7 DM. Hinzu kommt eine mögliche Anhebung der Vertragsmiete um bis zu 5,58 DM (30\% von $18,60 \mathrm{DM})$. 


\section{Zum Verwaltungsaufwand bei der EOF}

Eine in der Planungsphase des Wohnungsbauförderungsgesetzes 1994 häufig geäußerte Kritik an der EOF bestand darin, daß sie wegen der integrierten Subjektförderung mit einem hohen Verwaltungsaufwand verbunden sei. ${ }^{1}$ Tatsächlich ist die EOF wegen der Notwendigkeit regelmäßiger Einkommensprüfungen zwangsläufig komplizierter als die herkömmlichen Formen der vereinbarten Förderung, was aber im Hinblick auf die verteilungspolitischen Vorteile grundsätzlich akzeptiert werden kann. Die Zusatzförderung ist in dieser Hinsicht nicht anders zu beurteilen als die Fehlbelegungsabgabe im ersten Förderweg. Bedenklich ist allerdings, daß mit ihr das ohnehin komplexe Transfersystem der Bundesrepublik um ein weiteres Instrument ergänzt und damit in seiner $\mathrm{Ge}$ samtheit noch undurchsichtiger und verwaltungsaufwendiger geworden ist. So hat bereits die Ausarbeitung der Förderkonditionen in starkem Umfang Verwaltungsressourcen gebunden. Auch müssen Sachbearbeiter mit den für die Ermittlung und Auszahlung der Transfers erforderlichen Verfahrensabläufen vertraut gemacht werden. Die routinebedingten Effizienzsteigerungen dürften - anders als bei der Fehlbelegungsabgabe - nur gering ausfallen, da die Zahl der einkommensorientiert geförderten Objekte zumindest derzeit noch vergleichsweise niedrig ist. Das vom Bundesbauministerium vorgebrachte Argument, mit dem neuen System werde personelle Kapazität durch den Wegfall der Fehlbelegung frei, trifft nur für die wenigen nach dem neuen Modell geförderten Wohnungen zu. Die Einsparungen dürften gemessen an den Mehraufwendungen aus dem Nebeneinander von Fehlbelegungsabgabe und Zusatzförderung eher gering ausfallen. Hinzu kommt, daß die Zusatzförderung zumindest anfänglich an fast alle Mieter der geförderten Objekte zu leisten ist, da sie an der höchstzulässigen Basismiete anknüpft, während die Fehlbelegungsabgabe nur von den im Zeitablauf als Fehlbeleger klassifizierten Haushalten erhoben werden muß.

Wie hoch der bürokratische Zusatzaufwand ausfällt, hängt aber auch nicht unwesentlich von der Ausgestaltung der EOF durch die Länder ab. So wurden für die Zusatzförderung häufig kürzere Bewilligungszeiträume festgesetzt als bei der Fehlbelegungsabgabe, so daß Einkommensprüfungen in kürzerem zeitlichem Rhythmus vorgenommen werden müssen. Von besonderer Bedeutung ist auch das Verfahren der Bewilligung und Auszahlung der Transfers. Die Fördervarianten der einzelnen Bundesländer sind in dieser Hinsicht sehr unterschiedlich zu beurteilen. Als Beispiel für eine unkomplizierte Handhabung läßt sich die EOF in Sachsen anführen. Dort wird die Zusatzförderung nach folgendem Verfahren abgewickelt: Der Mieter erhält vom Vermieter das Formular für den

Vgl. z.B. Bundesministerium für Raumordnung, Bauwesen und Städtebau (1993), S. 6; Hintzsche, B. (1993), S. 587; Gierke, H.-G. (1994), S. 6f.; Bundesvereinigung der kommunalen Spitzenverbände (1994), S. 248f. (11f.); Deutsches Volksheimstättenwerk e.V. (1994), S.311 (12). 
Erstantrag auf Zusatzförderung und den Vordruck „Einkommenserklärung für den sozialen Wohnungsbau“. Den Antrag auf Zusatzförderung, die Einkommenserklärung und den unterschriebenen Mietvertrag legt er der Wohngeldstelle vor, die das zu berücksichtigende Einkommen des Haushalts nach § 25 II. WoBauG und die Höhe der Zusatzförderung feststellt. Dem Mieter erteilt sie einen Bescheid über die Zusatzförderung, informiert den Vermieter über die Bewilligung der Förderung und zahlt die Förderung als Zuschuß zur Miete monatlich an den Mieter aus. Ein wesentlicher Vorteil dieses Verfahrens, das ähnlich auch in Rheinland-Pfalz praktiziert wird, liegt darin, daß durch die Übertragung der Zuständigkeit auf die Wohngeldstelle Synergieeffekte genutzt werden können. ${ }^{1}$ Diese dürften am größten ausfallen, wenn die zuständige Stelle die Einkommensprüfung und Auszahlung für beide Transfers gemeinsam vornimmt, was wegen der übereinstimmenden Bewilligungsdauer von Wohngeld und Zusatzförderung problemlos möglich ist. ${ }^{2}$ Der mit der hohen Periodizität der Einkommensprüfungen verbundene Zusatzaufwand bei den nicht wohngeldberechtigten Mietern wird dadurch teilweise kompensiert. Das oben beschriebene Verfahren zeichnet sich zudem dadurch aus, daß der Vermieter nicht mehr als nötig in die Abwicklung der Transfers einbezogen wird, da die Zahlungen beim Mieter eingehen und keinen Einfluß auf die Mietforderung des Investors haben.

Etwas aufwendiger gestaltet sich der Verfahrensablauf, wenn die Zusatzförderung an den Vermieter ausgezahlt wird, da das Dreiecksverhältnis von Förderstelle, Mieter und Vermieter dann kompliziertere Regelungen erfordert. Der Vermieter muß dann vor Beginn des Mietverhältnisses darüber informiert werden, welche Zuschüsse er erhält, damit er seine Mietforderung danach ausrichten kann. Bei jeder Neufestsetzung der Zusatzförderung hat er eine Mietanpassung vorzunehmen, über die er wiederum vorab in Kenntnis gesetzt werden muß. Auch ist das Verfahren mit einem höheren Kontrollaufwand verbunden, wenn die zuständigen Stellen sicherstellen wollen, daß der Investor die Förderung in der tatsächlichen Höhe an die Mieter weitergibt. Im übrigen hängt es wiederum von der Detailgestaltung ab, wie hoch der mit dieser Auszahlungsvariante verbundene Zusatzaufwand ausfällt. Als Zuschuß mit schuldbefreiender Wirkung für den Mieter ist die Zusatzförderung fördertechnisch wohl am einfachsten zu handhaben, während die schleswig-holsteinische Variante, bei der die einkommensorientierte Mietbelastung über die Verzinsung der Förderdarlehen gesteuert wird, erheblich komplizierter sein dürfte.

1 Vgl. Tesch, J. (1994), S. 353f. (9f.).

2 In Rheinland-Pfalz wurde bereits ein Computerprogramm entwickelt, daß die Höhe der Zusatzförderung und des Wohngeldes simultan feststellt. 
Als Beispiel für eine besonders aufwendige Verfahrensgestaltung läßt sich die EOF in Nordrhein-Westfalen anführen. Dort wird die Zusatzförderung in Form eines Verzichts auf „einkommensabhängige Leistungen“ gewährt (vgl. Kapitel 2.F.VI), die der Vermieter der Wohnungsbauförderungsanstalt normalerweise entrichten müßte. Das Verfahren ist so geregelt, daß die Mieter ihr Einkommen von der zuständigen Stelle prüfen lassen und dem Vermieter anschließend eine Bescheinigung über den Mietbetrag vorlegen, von dessen Erhebung abzusehen ist. Der Vermieter muß auf der Grundlage dieser Bescheinigungen ein detailliertes Mieterverzeichnis erstellen, in dem er u.a. die Wohnungsgrößen, die Einkommenskategorie der Mieterhaushalte und die Höhe des Verzichts auf einkommensabhängige Leistungen angibt. Das Mieterverzeichnis reicht er bei der für die Einkommensprüfung zuständigen Stelle ein, die die Wohnungsbelegung kontrolliert und die Informationen in einem „Wohnungsverzeichnis“ an die Wohnungsbauförderungsanstalt weiterleitet. Diese übersendet dem Vermieter eine Ausfertigung des Wohnungsverzeichnisses, in dem für die einzelnen Wohnungen die Beträge der einkommensabhängigen Leistungen und der Miete aufgeführt sind, von deren Erhebung abgesehen wird. Der Vermieter hat seine Mietforderung und die einkommensabhängigen Leistungen in entsprechendem Umfang nach unten anzupassen.

Das Problematische an dem beschriebenen Verfahrensablauf liegt insbesondere im Auseinanderfallen der für die Ermittlung und der für die Auszahlung der $\mathrm{Zu}$ satzförderung zuständigen Stellen. Durch das Hinzutreten der Wohnungsbauförderungsanstalt wird das ohnehin komplexe Dreiecksverhältnis von zuständiger Stelle, Mieter und Vermieter zum Vierecksverhältnis erweitert - mit der Folge, daß die Verfahrenswege verlängert und zusätzliche Verwaltungsressourcen gebunden werden. Da ein Großteil des Verwaltungsaufwandes vom Vermieter übernommen werden muß, dürfte das Modell eine deutlich verringerte Attraktivität für potentielle Investoren aufweisen.

Auch die Bestimmungen zur Finanzierung der Zusatzförderung können den mit der EOF verbundenen Verwaltungsaufwand erheblich beeinflussen. So muß bei einer (Mit-)Finanzierung der Transfers durch die Kommunen zunächst abgesichert werden, daß die jeweilige Gemeinde überhaupt zur Förderung bereit ist. Wird die Zusatzförderung anteilig vom Land und der Gemeinde erbracht, haben die Gebietskörperschaften zudem Ausgleichszahlungen vorzunehmen. Ein typisches Beispiel für die aus der Mischfinanzierung resultierenden Komplikationen liefert das Land Baden-Württemberg. Dort muß dem Antrag des Bauherrn auf Grundförderung, der über die Stadt bei der Landeskreditbank BadenWürttemberg (LAKRA) eingereicht wird, eine Erklärung der Gemeinde beigefügt werden, in der sie sich zur Übernahme der Zusatzförderung verpflichtet. Ferner stellt die Gemeinde bei der LAKRA einen grundsätzlichen Antrag auf teilweise Erstattung der von ihr ausgezahlten Zusatzförderung, was die LAKRA 
durch Erteilung eines Grundbescheids gegenüber der Gemeinde bestätigt. Auf Antrag des Bauherrn hat sich die Gemeinde per Grundbescheid auch diesem gegenüber zur Übernahme der Zusatzförderung zu verpflichten. Erst jetzt setzt das Verfahren der Ermittlung, Bewilligung und Auszahlung der Zusatzförderung im einzelnen ein. Am Ende des Verfahrensablaufs hat die Kommune noch bei der LAKRA die teilweise Erstattung der Zusatzförderung im einzelnen zu beantragen, worauf diese einen Zuwendungsbescheid (Einzelbescheid) über die teilweise Erstattung gegenüber der Kommune erläßt. 


\section{Teil: Wohnungspolitische Reformansätze}

\section{A. Notwendigkeit einer grundlegenden Neugestaltung der Wohnungspolitik}

Wie die vorangegangenen Ausführungen gezeigt haben, ist die Neubauförderung auch bei marktnaher Ausgestaltung der Förderkonditionen und einkommensorientierter Mietstaffelung kein geeignetes Instrument zur Versorgung sozial schwacher Haushalte mit preisgünstigem Wohnraum. Die zentrale Problematik des sozialen Mietwohnungsbaues liegt in der Verknüpfung mehrerer wohnungspolitischer Zielsetzungen in einem Instrument: Die Fördervorhaben sollen nicht nur zur quantitativen Ausweitung des Mietwohnungsbestandes, sondern auch zur besseren Versorgung von sozial schwachen Haushalten mit preiswertem Wohnraum beitragen. Diese Vorgehensweise hat im ersten Förderweg wegen des Kostenmietprinzips und der starken Zunahme der Bau- und Grundstückskosten zu einem gewaltigen Anstieg der pro Wohnung benötigten Subventionsvolumina geführt. Bei der EOF wird zwar vom Kostenmietprinzip abgewichen, doch ist ein hoher Fördermitteleinsatz zu erbringen, um die überdurchschnittlichen Marktmieten der Neubauwohnungen auf das vom Sozialmieter tragbare Niveau abzusenken. Wegen der hohen Fördersummen pro Wohnung kann überdies nur ein kleiner Teil der geringverdienenden Haushalte in die Förderung einbezogen werden, während der Großteil der Förderberechtigten leer ausgeht. Auch für den Erwerb der Belegungsbindungen ist die Neubauoder Modernisierungsförderung nicht der geeignete Weg, da in den geförderten Objekten - wegen der Durchmischungszielsetzung - auch Belegungsrechte zugunsten solcher Mieter erworben werden, die sich ohne staatliche Hilfe mit Wohnraum versorgen könnten.

Die mit dem sozialen Mietwohnungsbau angestrebten Ziele - Erhöhung des Wohnungsbestandes, soziale Absicherung des Wohnens und Versorgung von Problemgruppen des Wohnungsmarktes - sollten daher entkoppelt und durch eigens darauf ausgerichtete Instrumente verfolgt werden. Diese stehen bereits zur Verfügung, weisen jedoch noch Mängel auf (so das Wohngeld - vgl. Kapitel 4.C - und die steuerliche Wohnungsbauförderung - vgl. Kapitel 4.B.I) oder werden bislang nicht im gewünschten Maße eingesetzt (Erwerb von Belegungsrechten im Wohnungsbestand - vgl. Kapitel 4.D). Eine Abkehr von der Objektförderung läßt sich wohl nur durchsetzen, wenn sie durch eine Verbesserung der genannten Instrumente flankiert wird. Außerdem sollte die Funktionsfähigkeit des Mietwohnungsmarktes durch Korrekturen beim Mietrecht (vgl. Kapitel 4.B.III) und in der Bodenpolitik (vgl. Kapitel 4.B.II) verbessert werden. 


\section{B. Alternative Maßnahmen zur Ausweitung des Mietwohnungsangebotes}

\section{Vergünstigungen im Rahmen der Einkommensteuer}

Vor allem in der politischen Diskussion wird immer wieder darauf verwiesen, wie wichtig gerade bei Auftreten von Wohnungsmarktengpässen die gezielte Ausweitung des Wohnungsbestandes zugunsten sozial schwacher Haushalte sei. Dabei wird offenbar unterschätzt, in welchem Maße diese Personengruppen auch von der Ausweitung des nicht gebundenen Wohnungsbestandes profitieren. Verantwortlich dafür sind sogenannte „Filtering“-Prozesse, ausgelöst durch Umzugsketten, bei denen gutsituierte Haushalte in neugebaute Wohnungen umziehen und ältere, preiswerte Wohnungen frei machen, die den Beziehern niedriger Einkommen zur Verfügung stehen. Zwar wird das Filtering dadurch begrenzt, daß die neugebauten Wohnungen zum Teil auch von neugebildeten Haushalten bezogen oder durch Modernisierung in Wohnraum der oberen oder mittleren Preisklasse umgewandelt werden. Gleichwohl trägt die allgemeine Wohnungsbauförderung entscheidend dazu bei, daß die Wohnungsnot geringverdienender Haushalte, die auf preisgünstigen Wohnraum angewiesen sind, entschärft wird. ${ }^{1}$

Eine der wichtigsten Maßnahmen zur Ausweitung des nicht gebundenen Mietwohnungsbestandes ist die degressive Gebäudeabschreibung nach $\S 7$ Abs. 5 EStG, die - wie bereits gezeigt - auf einen zinslosen Steuerkredit hinausläuft und für nicht bilanzierungspflichtige Investoren bei rechtzeitiger WeiterveräuBerung der Immobilie sogar zu einer endgültigen Steuerersparnis führen kann. Durch die beschleunigte Abschreibung wird die Rentabilität der Investitionen erhöht und die - in den Anfangsjahren meist besonders angespannte - Liquiditätslage des Erwerbers deutlich verbessert. Bei einer Abkehr von der Objektförderung könnte ein Teil der ersparten Mittel im Rahmen der steuerlichen Förderung eingesetzt werden. Denkbar wäre eine leichte Anhebung der in den Anfangsjahren zulässigen Abschreibungssätze.

Noch besser erscheint es, die Aufstockung der steuerlichen Förderung mit einer grundlegenden Reform dieses Instruments in Richtung auf eine höhere Subventionsgerechtigkeit zu verbinden. Mit den gegenwärtigen Abschreibungsvergünstigungen wird gegen diesen Grundsatz massiv verstoßen, da die steuerliche Entlastung vom individuellen Grenzsteuersatz des Investors bestimmt wird und die einzelnen Erwerber von Wohneigentum deshalb bei gleichen Bauinvestitionen sehr unterschiedliche Vergünstigungen erhalten. Eine solche Ungleichbehandlung läßt sich nicht rechtfertigen, denn die erhöhten Abschreibungen stellen ja nur fiktive Verluste dar und haben daher ,nichts mit einer Verminderung

1 Vgl. Deutscher Verband für Wohnungswesen, Städtebau und Raumordnung - Kommission (1996), S. 38. 
der steuerlichen Leistungsfähigkeit zu tun, an der die Progression der Einkommensteuer anknüpfen soll. Es handelt sich somit um eklatante Verstöße gegen die Subventions- und Steuergerechtigkeit."1 Die Abschreibungsvergünstigungen sollten deshalb durch eine einkommensunabhängige Förderung ersetzt werden. Orientierungsgröße für die Entlastungshöhe und die Dauer der Vergünstigungen könnte die 1996 an die Stelle des Sonderausgabenabzugs nach $\S 10 \mathrm{e}$ EStG getretene Eigenheimzulage ${ }^{2}$ sein, die über einen Zeitraum von acht Jahren in jährlich konstanten Beträgen von bis zu 5.000 DM (Neuschaffung von Wohnraum) bzw. bis zu 2.500 DM (Erwerb von bestehendem Wohnraum, Ausbau und Erweiterung) gewährt wird. Zu denken wäre auch an eine degressive Gestaltung der Zulage. Befürchtungen, nach denen die staatliche Förderung durch eine entsprechende Reform an Attraktivität einbüßen würde, haben sich bereits bei der Eigenheimzulage als unbegründet erwiesen. Es hat sich vielmehr gezeigt, ,daß eine Gleichbehandlung bei den Subventionen eher anregend auf den Wohnungsbau wirkt - insbesondere bei denen, die über wenig Eigenkapital verfügen und geringen Grenzsteuersätzen unterliegen, was vor allem für die ostdeutsche Bevölkerung gilt." ${ }^{\text {3 }}$

Eine Abwicklung der Zulage im Rahmen der Einkommensteuer würde voraussetzen, daß sie als Abzugsbetrag von der Steuerschuld gewährt wird - bei Auszahlung negativer Beträge. Die Zulage käme dann auch Wohnungsgesellschaften, die nicht einkommen- oder körperschaftsteuerpflichtig sind, sowie Investoren mit wenig Eigenkapital und niedrigen Grenzsteuersätzen in voller Höhe zugute. ${ }^{4}$ Eine solche Reform der Wohnungsbauförderung könnte je nach Höhe der Zulage auch aufkommensneutral gegenüber der bisherigen Förderung nach $§ 7$ Abs. 5 ausfallen, so daß keine zusätzlichen Mittel aus dem sozialen Wohnungsbau zu ihrer Finanzierung benötigt würden. In der gegenwärtigen Lage auf dem Mietwohnungsmarkt, die durch einen weitgehenden Ausgleich von Angebot und Nachfrage gekennzeichnet ist, könnten die eingesparten Mittel wohl in anderer Weise sinnvoller eingesetzt werden.

1 Oberhauser, A. (1997), S. 585.

2 Nach dem Eigenheimzulagengesetz (EigZulG) i.d.F. der Bekanntmachung vom 30. Januar 1996 (BGBl. I S. 113), geändert durch Gesetz vom 20. Dezember 1996 (BGBl. I S. 2049).

3 Oberhauser, A. (1997), S. 585f.

4 Vgl. Oberhauser, A. (1997), S. 586. 


\section{Verstärkte Ausweisung von Bauland}

Eine Abkehr von der Objektförderung könnte noch leichter hingenommen werden, wenn es gelänge, die vom Staat selbst verursachten Kosten im Wohnungsbau abzusenken. Neben der Durchforstung verzichtbarer und zum Teil überzogener Bauvorschriften ${ }^{1}$ ist vor allem eine verstärkte Ausweisung von Bauland nötig. Durch ihre vielerorts restriktive Baulanderschließungspolitik haben die Gemeinden zum überdurchschnittlichen Anstieg der Grundstückspreise und damit der Gesamtkosten des Wohnungsbaues stark beigetragen. Ihre Zurückhaltung bei der Ausweisung von Bauland wurzelt vielfach in der Sorge um den Verlust von Freiflächen und die wachsende Versiegelung des Bodens. Diese Angst vor einer allzu starken Inanspruchnahme von Flächen für Siedlungszwecke erweist sich jedoch - bezogen auf die gesamte Bundesrepublik - als unbegründet. So genügt unter realistischen Annahmen bereits ein Anteil von 0,06\% der Gesamtfläche des Bundesgebietes für den Bau von einer Million zusätzlicher Wohnungen. ${ }^{2}$ Probleme aus der Versiegelung des Bodens bestehen allenfalls in den Ballungskernen.

Aufgrund der dichten Besiedelung haben viele Großstädte heute nur noch eingeschränkte Entwicklungsmöglichkeiten innerhalb ihrer Grenzen. Sie sind auf eine verstärkte Baulandausweisung der Umlandgemeinden angewiesen, zu der diese jedoch - aus den oben genannten Gründen - oft nicht in genügendem Umfang bereit sind. Auch werden die Vorhaltekosten für die Erschließung und die Infrastruktureinrichtungen häufig als zu hoch angesehen. Diese Kosten werden zwar großenteils von den Investoren selbst in Form von Erschließungsbeiträgen oder durch laufende Gebühren (Straßenreinigung, Abwasserbeseitigung, Müllbeseitigung) abgedeckt. Fiskalische Probleme können aber entstehen, wenn Kommunen große Baugebiete neu ausweisen und sich daraus ein erheblicher Zuwachs der Einwohnerzahl ergibt. „Eine solche Konzentration der Bautätigkeit ist aus Gründen der allgemeinen Siedlungsentwicklung erwünscht. Die einzelnen betroffenen Gemeinden stehen jedoch vor Schwierigkeiten, weil sie die zusätzlichen Einnahmen als nicht ausreichend ansehen, um die Mehrkosten und eine erhöhte Verschuldung zu finanzieren. ${ }^{33}$ Neben diese Umwelt- und Kostenargumente treten nicht selten Befürchtungen hinsichtlich einer Überfremdung, einer Überlastung der Infrastruktureinrichtungen etc.

I Vgl. Schnurr, J. (1994), S. 779.

2 Vgl. Expertenkommission Wohnungspolitik (1995), S. 80.

3 Expertenkommission Wohnungspolitik (1995), S. 91. Vgl. auch Kirchner, J. (1992), S. 484. 
Eine stärkere Expansion der betroffenen Gemeinden setzt voraus, daß die Einwohner und ihre politischen Vertreter die ökologisch motivierten Ängste vor einer zu starken Inanspruchnahme der Flächen abbauen. Auch wäre an eine Erhöhung der finanziellen Anreize für eine Ausweisung von Baurechten zu denken. In diese Richtung geht ein Vorschlag der Expertenkommission Wohnungspolitik, wonach die Mehrkosten eines Einwohnerzuwachses im kommunalen Finanzausgleichssystem durch höhere Zuweisungen berücksichtigt werden sollten. Als Übergangslösung bis zu einer entsprechenden Reform schwebt der Kommission die Gewährung spezieller Förderprogramme für Wohnungsbauschwerpunkte vor. ${ }^{1} \mathrm{Zu}$ erwägen ist ferner eine gesetzliche Einschränkung der kommunalen Planungshoheit zugunsten überörtlicher Planungsinteressen. Entsprechende Regelungen stehen zwar im Spannungsverhältnis mit der kommunalen Selbstverwaltungsgarantie, doch können sie sich gerade in den Umlandgemeinden der Ballungskerne als notwendig erweisen, wenn diese trotz verbesserter finanzieller Anreize nicht dazu bereit sind, der Ballung und Zersiedelung an den Stadträndern durch Schaffung neuer Entwicklungszentren entgegenzuwirken.

\section{Deregulierung des Mietrechts}

Ein weiterer Ansatzpunkt zur Verbesserung der Angebotsbedingungen auf dem Wohnungsmarkt liegt im Abbau gesetzlicher Beschränkungen der Kündigungsrechte des Vermieters (Bestandsschutz) und der Mietpreissetzung (Mietpreisrecht). Sowohl der Bestandsschutz als auch das Mietpreisrecht sind derzeit in starken Maße gesetzlich normiert. Die rechtliche Beschränkung der freien Mietvertragsgestaltung resultiert in erster Linie aus dem Bestreben nach allgemeiner Sicherheit der Wohnungsversorgung. Vom existentiellen Charakter der Wohnversorgung wird auf die grundsätzliche Marktunterlegenheit der Nachfrager gegenüber den Anbietern auf dem Wohnungsmarkt geschlossen. Gerade in Zeiten großer Angebotsdefizite soll den Mietern ein gewisser Schutz gegenüber den wirtschaftlichen Interessen der Vermieter gewährt werden. ${ }^{2}$ Durch die mietrechtlichen Beschränkungen werden aber zugleich die Ertragserzielungschancen nicht nur der etablierten, sondern auch aller potentiellen Wohnungsanbieter verschlechtert, so daß die Investitionsneigung im Mietwohnungsbau sinkt. ${ }^{3}$ Die verringerte Investitionsbereitschaft hat zur Folge, daß das Woh-

I Vgl. Expertenkommission Wohnungspolitik (1995), S. $91 \mathrm{f}$.

2 Vgl. Wölling, A. (1991), S. 139f.

$3 \mathrm{Zu}$ den ökonomischen Auswirkungen des Bestandsschutzes und seiner Flankierung durch das Mietrecht vgl. Eekhoff, J. (1981) und die daran anknüpfende Analyse von Eckart, W. 
nungsangebot noch knapper wird und der Staat in zunehmendem Maße Fördermittel aufwenden muß, um die Folgen seiner Eingriffe in die Mietvertragsgestaltung zu korrigieren.

Will der Staat seine Fördertätigkeit reduzieren, so erscheint eine Reform des Mietrechts angebracht. Dabei geht es nicht darum, den Kündigungsschutz und das Mietpreisrecht ganz abzuschaffen, denn dies wäre weder durchsetzbar noch erwünscht. Die generelle Zielrichtung einer Reform sollte vielmehr darin bestehen, die negativen Angebotswirkungen des Mieterschutzes zu begrenzen und damit insbesondere denjenigen Haushalten zu helfen, die als Wohnungssuchende die Hauptleidtragenden einer anbieterfeindlichen Regulierung sind. Ein erster Schritt besteht in der Vereinfachung des durch ständige Gesetzesänderungen überreglementierten Mietrechts. Auf lange Sicht muß das Mietrecht „von Beständigkeit in der Gesetzgebung und Rechtsprechung geprägt sein, damit die bestehende Rechtsunsicherheit bei allen Betroffenen behoben wird und verläßliche Rahmenbedingungen für ein günstiges Investitionsklima auf dem Wohnungsmarkt geschaffen werden".'

Der Staat sollte davon abkommen, auf jede Veränderung der Wohnungsmarktlage durch vermeintlich notwendige Anpassungen des gesetzlichen Rahmens zu reagieren. „Diese Sprunghaftigkeit macht das Wohnraummietrecht nicht nur für die Parteien in bestehenden Mietverhältnissen unberechenbar, weil der Inhalt ihres Vertrages in der Regel mit jeder Gesetzesänderung ebenfalls geändert wird. Unberechenbar ist das Mietrecht auch für langfristig kalkulierende Investoren, weil sie sich nicht darauf verlassen können, daß die heute bestehenden rechtlichen Rahmenbedingungen auch morgen noch gelten werden." ${ }^{2}$ Vermieden werden sollte auch jede räumliche Differenzierung des Mietrechts in Form von Sonderregelungen für Gebiete mit gefährdeter Wohnungsversorgung. ${ }^{3}$ Die

(1984); vgl. auch Börsch-Supan, A. (1986) und die Kommentierung von Schwager, R. (1994); ferner Homburg, S. (1993) sowie die ökonomische Interpretation der Entwicklung des Regulierungsgeflechts auf dem Mietwohnungsmarkt bei Bison, J. (1996), S. $223 \mathrm{ff}$.

1 Expertenkommission Wohnungspolitik (1995), S. 425.

2 Expertenkommission Wohnungspolitik (1995), S. 112.

3 Eine solche Differenzierung erfolgt im 1993 erlassenen Gesetz über eine Sozialklausel in Gebieten mit gefährdeter Wohnungsversorgung (BGBl. I S. 487; ergangen als Artikel 14 des Gesetzes zur Erleichterung von Investitionen und der Ausweitung und Bereitstellung von Wohnbauland vom 22. April 1993, BGB1. I S. 466). Darin werden die Landesregierungen ermächtigt, durch Rechtsverordnung Gebiete zu bestimmen, in denen die Versorgung der Bevölkerung mit Mietwohnungen als gefährdet eingestuft wird. Nach dem Gesetz ist in diesen Gebieten die Kündigung des Erwerbers einer vermieteten Wohnung aufgrund von Eigenbedarf oder der Hinderung an einer angemessenen wirtschaftlichen Verwertung erst nach zehn (statt üblicherweise drei) Jahren möglich. Die Regelung schmälert nicht nur die 
gegenwärtigen mietrechtlichen Bestimmungen sind in Richtung auf eine größere Vertragsfreiheit zu modifizieren. Ein Beispiel hierfür ist die Heraufsetzung der Zeiträume, innerhalb derer befristete Mietverträge ohne Bestandsschutz abgeschlossen werden können. Denkbar wäre auch eine Einschränkung oder Abschaffung der Sozialklausel in $\S 556$ a BGB, wonach der Mieter einer Kündigung des Mietverhältnisses auch bei Vorliegen eines berechtigten Interesses des Vermieters widersprechen kann, wenn die vertragsgemäße Beendigung für ihn oder seine Familie eine Härte bedeuten würde. Eine solche Härte liegt z.B. vor, wenn es dem Mieter nicht gelingt, angemessenen Ersatzwohnraum zu beschaffen. Die Sozialklausel sollte zumindest abgeschwächt werden, etwa indem vom Mieter selbst zu verantwortende Tatbestände sowie Probleme bei der Beschaffung von Ersatzwohnraum nicht mehr berücksichtigt werden. Im Mietpreisrecht wäre die Aufhebung der Kappungsgrenze des § 2 MHG zu empfehlen, zumal die Mieterhöhungsmöglichkeiten bereits durch die Vergleichsmietenregelung begrenzt sind. Abgeschafft werden sollte ferner die Obergrenze für Neuvertragsmieten nach $\S 5 \mathrm{WiStG}{ }^{1}$

\section{Senkung der individuellen Wohnkostenbelastung durch Gewährung von Wohngeld}

Die soziale Absicherung des Wohnens für Bezieher niedriger Einkommen sollte ausschließlich über das Wohngeld angestrebt werden. Nach allgemeiner Meinung ist das Wohngeld das dazu am besten geeignete Instrument. ${ }^{2}$ Seine Vorzü-

Erträge aus dem Verkauf von Mietwohnungen, sie führt auch zu einer großen Rechtsunsicherheit, denn der räumliche Anwendungsbereich des Gesetzes steht im Ermessen der Landesregierungen und kann von diesen jederzeit verändert werden.

1 Die Empfehlungen zum Mietpreisrecht decken sich mit den Vorschlägen der Expertenkommission; vgl. Expertenkommission Wohnungspolitik (1995), S. 122ff. Vgl. auch Eekhoff, J. (1993), S. 24ff.

2 Eine häufig geäußerte Kritik am Wohngeld bezieht sich auf die Zweckgebundenheit der Transfers. Diese Kritik ist berechtigt, wenn man von der Prämisse ausgeht, daß der einzelne Haushalt selbst am besten weiß, wie er seine knappen materiellen Ressourcen nutzenmaximal für die einzelnen Verwendungszwecke einsetzt. Zweckgebundene Transfers wie das Wohngeld führen nämlich zu einer Verzerrung der Preisverhältnisse, die unter der oben gemachten Prämisse allokativ unerwünscht ist; vgl. Aaron, H. J., v. Furstenberg, G. M. (1971); Nachtkamp, H. H., Hudelmaier, P. R. (1993), S. 1ff und 34f. „Zu einer anderen Beurteilung gelangt man allerdings dann, wenn man von der Vorstellung eines meritorischen Bedarfs ausgeht, also annimmt, daß der einzelne im Hinblick auf die Wohnungsnachfrage bei freier Entscheidung eine für ihn selbst ungünstige Nachfrage ausübt. Wählt man einen solchen meritorischen Ansatz, so muß die gewählte Lösung daran gemessen 
ge liegen darin, daß es an den Bestimmungsfaktoren der individuellen Bedürftigkeit, dem Einkommen, der Familiengröße und der Miethöhe ausgerichtet ist und zudem in nur einjährigen Zeitabständen an die Veränderungen dieser GröBen angepaßt wird. „Besonders hervorzuheben ist, daß ein Rechtsanspruch auf Wohngeld besteht. Das ist eines der wichtigsten Merkmale echter Sozialsysteme, weil dadurch die Gleichbehandlung der Bürger gesichert wird."' Auch aus allokativer Sicht ist die Allgemeinheit des Wohngeldes positiv zu bewerten, denn die Mieter sind bei der Entscheidung über ihren Wohnraumkonsum nicht auf eine bestimmte, geförderte Wohnung festgelegt, sondern können unter Beibehaltung des Subventionsanspruchs aus dem gesamten Bestand an Wohnungen diejenige auswählen, die ihren Präferenzen am ehesten entspricht. Schließlich trägt das Wohngeld durch seine nachfragestimulierende Wirkung zur Ausweitung des Wohnraumangebotes und damit zur Verbesserung der Wohnungsversorgung bei. ${ }^{2}$

Um die soziale Absicherung des Wohnens zu gewährleisten, sollte allerdings noch mehr als in der Vergangenheit darauf geachtet werden, daß die Tabellenwerte und die Höchstbeträge der berücksichtigungsfähigen Wohnkosten regelmäßig aktualisiert werden. Bislang wurden diese nur etwa alle fünf bis sechs Jahre angepaßt, was zu einer Beeinträchtigung der sozialen Sicherungsfunktion des Wohngeldes geführt hat. Denn in den Zeiträumen zwischen den Anpassungen kommt es wegen des allgemeinen Anstiegs des Einkommens und der Miete zu einem realen - vielfach auch nominalen - Rückgang der Wohngeldtransfers und dadurch bedingt zu einer Erhöhung der Wohnkostenbelastung. Als besonders problematisch erweisen sich die stagnierenden Miethöchstbeträge, denn die von der Bevölkerung durchschnittlich aufzubringenden Wohnkosten werden im Zeitablauf immer unzulänglicher erfaßt. Der Anteil der Haushalte mit Mieten oberhalb der Höchstbeträge nimmt zu; Einkommenserhöhungen führen bei diesen Haushalten zu einer von der Mietenentwicklung unabhängigen Kürzung des Wohngeldanspruchs.

werden, inwieweit die Wohnungsnachfrage den Vorstellungen des Subventionsgebers entspricht.“Külp, B. u.a. (1984), S. 111.

1 Eekhoff, J. (1993), S. 97.

2 Vgl. Kirchner, J. (1994), S. 195ff. zu den Ergebnissen einer empirischen Studie von Mayo / Barnbrock und einer Simulationsstudie von Ohls. Vgl. auch Külp, B. u.a. (1984), S. $107 f f$. 
Die Problematik sei am Beispiel eines Drei-Personen-Haushaltes mit einer Mietwohnung neueren Baudatums (angenommene Bezugsfertigkeit ab 1. Januar 1978 ) in einer Gemeinde der Mietenstufe 5 verdeutlicht. Bei einem monatlichen Familieneinkommen in Höhe von 1.750 DM und einer wohngeldfähigen Miete von $665 \mathrm{DM}$ stehen diesem Haushalt $161 \mathrm{DM}$ Wohngeld zu. Wird unterstellt, daß das Einkommen und die Miete pro Jahr um 3\% steigen, dann verringert sich der Wohngeldanspruch - trotz gleicher prozentualer Belastung des Einkommens (vor Abzug des Wohngeldes) - von Jahr zu Jahr auf 152 DM, 148 DM, 138 DM etc. Das Beispiel wurde so gewählt, daß der Rückgang der Wohngeldbeträge allein auf die Tabellenwerte zurückzuführen ist. Die Wohngeldbeträge sinken noch stärker, wenn der Mietenanstieg wegen der Höchstbeträge nicht mehr berücksichtigt wird. Dies ist im vorliegenden Beispiel der Fall, wenn von einer Gemeinde der Mietenstufe 3 (Höchstbetrag: 665 DM) ausgegangen wird. Der Wohngeldanspruch des Haushaltes sinkt dann - unter sonst gleichen Annahmen - von anfangs $161 \mathrm{DM}$ auf $143 \mathrm{DM}, 131 \mathrm{DM}, 113 \mathrm{DM}$ etc. Bereits im vierten Jahr beträgt er nur noch $64 \%$ dessen, was bei Fortschreibung des Wohngeldes mit $3 \%$ auszuzahlen gewesen wäre. Wie das Beispiel zeigt, ist die soziale Sicherungsfunktion des Wohngeldes nur zu gewährleisten, wenn die Mietobergrenzen und Wohngeldbeträge in kürzeren als den bislang üblichen Zeitabständen an die Entwicklung der Einkommen und der Mieten angepaßt werden. Der Anpassungsrhythmus sollte drei Jahre im allgemeinen nicht überschreiten.

Überdacht werden sollte auch die Differenzierung des Wohngeldes nach Baualters- und Ausstattungsklassen, die auf der Zielsetzung beruht, den Wohngeldbeziehern trotz ihrer niedrigen Einkünfte „den Zugang zum gesamten Wohnungsmarkt, also auch dem Markt für gut ausgestattete Neubauwohnungen, zu erleichtern und ihnen eine 'angemessene' Wohnungsversorgung insbesondere in qualitativer Hinsicht zu ermöglichen" ${ }^{\text {"l }}$. Der im Wohngeld ohnehin vorhandene Anreiz zu einem erhöhten Wohnkonsum wird damit in Richtung auf eine aus allokativer und fiskalischer Sicht unerwünschte - Versorgung mit teueren, gut ausgestatteten Neubauwohnungen verstärkt. ${ }^{2}$ Dies sei wiederum am Beispiel eines Drei-Personen-Haushaltes aus einer Gemeinde der Mietenstufe IV verdeutlicht. Der Höchstbetrag für die berücksichtigungsfähige Miete beläuft sich für diesen Haushalt bei einer Wohnung der niedrigsten Alters- und Ausstattungskategorie (Bezugsfertigstellung vor 1966, ohne Sammelheizung und ohne Bad oder Duschraum) auf 415 DM und bei einer Wohnung der höchsten Kategorie (Bezugsfertigstellung nach 1991) auf 850 DM. Bei einem monatlichen Familieneinkommen von $1.600 \mathrm{DM}$ beträgt der maximale Wohngeldanspruch bei der Altbauwohnung 76 DM und bei der Neubauwohnung 301 DM. Im ersten Fall macht die Subvention 18,3\%, im zweiten Fall 35,4\% der maximal be-

Keil, K. (1996), S. 210.

2

Vgl. Nachtkamp, H. H., Hudelmaier, P. R. (1993), S. 27. 
rücksichtigungsfähigen Miete aus. An den Höchstbeträgen gemessen hat die Neubauwohnung einen Preisnachteil von 435 DM, dem jedoch ein um 225 DM erhöhtes Wohngeld gegenübersteht. Über die Hälfte der Mehrkosten für die Neubauwohnung wird damit vom Staat finanziert.

Die besondere Subventionierung von Wohnungen jüngeren Baudatums wird auch deshalb kritisch gesehen, weil „,vom Baualter immer weniger auf die Qualität der Wohnung geschlossen werden kann. Viele alte Gebäude sind grundlegend modernisiert worden und stehen den Neubauten in der Ausstattung und Qualität in nichts nach." ${ }^{\text {"l }} \mathrm{Da}$ für eine auf Neubaustandard modernisierte Wohnung weniger Wohngeld gewährt wird als für eine gleich teure nicht modernisierte Wohnung jüngeren Baudatums, kommt es $\mathrm{zu}$ Verzerrungen und Verstößen gegen die horizontale Gerechtigkeit. Würde die Differenzierung der Höchstbeträge nach Ausstattung und Baualtersstufe aufgehoben, ließen sich die beschriebenen Nachteile vermeiden.

Weniger problematisch ist die Differenzierung der Wohngeldhöchstbeträge nach dem Mietenniveau der Gemeinden. Zwar wird dadurch das Wohnen in teuren Ballungsgebieten zusätzlich subventioniert ${ }^{2}$, doch dürften wohngeldinduzierte Wanderungen - mit der Folge räumlicher Allokationsineffizienzen - wegen der hohen Kosten überregionaler Mobilität eher gering ausfallen. Dem steht der verteilungspolitische Vorteil gegenüber, daß die erhöhte Wohnkostenbelastung von Geringverdienern in teuren Wohngegenden besser abgefedert wird. „Bei einheitlichen Obergrenzen müßten die Wohngeldleistungen insgesamt übertrieben großzügig ausfallen, um in den Hochpreisregionen die gleiche Entlastungswirkung zu erzielen. Da die Gefahr gering ist, effiziente Abwanderung zu verhindern und ineffiziente Zuwanderung auszulösen, kann der fiskalische Aufwand durch die regionale Differenzierung des Wohngeldes verringert werden."3

Indes wäre zu überlegen, ob die Differenzierung der Wohngeldleistungen nicht durch einen von den Kommunen mit überdurchschnittlichem Mietniveau zu finanzierenden Prozentaufschlag auf das allgemeine Wohngeld erfolgen sollte. Für eine solche Lösung spricht, daß die Gemeinden durch das Knapphalten von Bauland nicht selten maßgeblich zum Mietenanstieg beitragen. Außerdem könnten gezielt diejenigen Gemeindemitglieder an den erhöhten Aufwendungen beteiligt werden, die von der Baulandknappheit und der Mietenentwicklung profitieren. Dies sind vor allem die Eigentümer der in ihrem Wert gestiegenen

1 Eekhoff, J. (1993), S. 99.

2 Vgl. Nachtkamp, H. H., Hudelmaier, P. R. (1993), S. $27 f$.

3 Hubert, F. (1995), S. 21. 
Grundstücke. Bei einer Finanzierung des kommunalen Zusatzwohngeldes über eine Grundsteuererhöhung ließe sich ein teilweiser Ausgleich unter den von der Bodenknappheit begünstigten und den davon benachteiligten Bürgern einer Gemeinde vornehmen. ${ }^{1}$

\section{Versorgung von Haushalten mit besonderen Marktzutrittsproblemen durch den Erwerb von Belegungsrechten im Wohnungsbestand}

\section{Gängige Formen des Erwerbs von Belegungsrechten}

Auch bei einer Ausweitung des ungebundenen Wohnungsbestandes und einer Aufstockung des Wohngeldes besteht das Problem der Wohnungsversorgung von Personen fort, die aufgrund besonderer sozialer Merkmale bei den Wohnungsanbietern auf Mißtrauen oder Ablehnung stoßen und daher nicht in der Lage sind, angemessenen Wohnraum zu finden. Um diesen Menschen zu helfen, muß der Staat auch künftig Belegungsrechte erwerben. Dies um so mehr, als empirische Untersuchungen darauf hindeuten, daß die Zahl der versorgungsbedürftigen Problemfälle in den letzten Jahren gestiegen ist. ${ }^{2}$ Hinzu kommt, daß sich die Zahl der im sozialen Mietwohnungsbestand verfügbaren Belegungsrechte in den kommenden Jahren deutlich verringern wird. ${ }^{3}$ Da eine Deckung des Bedarfs an neuen Belegungsrechten im Rahmen des sozialen Mietwohnungsbaues im erforderlichen Umfang gar nicht finanzierbar wäre, wird die öffentliche Hand zunehmend auf kostengünstige Maßnahmen zum Erwerb solcher Rechte im Wohnungsbestand zurückgreifen müssen. Dafür kommen vor allem die nicht preisgebundenen älteren Wohnungen im privaten Wohnungsbestand, die öffentlich geförderten Wohnungen mit gerade auslaufenden Bindungen sowie die nicht geförderten Wohnungen kommunaler Wohnungsunternehmen in Frage.

Vgl. Eekhoff, J. (1993), S. 100; Keil, K. (1996), S. 211 f.

2 Vgl. Expertenkommission Wohnungspolitik (1995), S. 42.

3 So wird Schätzungen zufolge ein Drittel der 1993 noch vorhandenen knapp 2,7 Millionen Sozialwohnungen des ersten Förderwegs bis zum Jahr 2000 aus der Bindung gefallen sein; vgl. Pfeiffer, U. u.a. (1996), S. 140f. Hinzu kommt, daß die Belegungsbindungen bei der zuletzt verstärkt betriebenen vereinbarten Förderung vergleichsweise kurz ausfallen, so daß auch von dieser Seite her schon frühzeitig ein Ersatzbedarf auftreten wird. 
In der Vergangenheit haben sich die Gemeinden nur in bescheidenem Umfang außerhalb des sozialen Mietwohnungsbaues um den Erwerb von Belegungsrechten bemüht. Nach einer von J. Kirchner u.a. ${ }^{1}$ in den Jahren 1989 und 1990 am Beispiel von zwölf Großstädten vorgenommenen Untersuchung haben die am Wohnungsbestand ansetzenden Förderangebote bei den Eigentümern vielfach nur mäßige Resonanz gefunden, was allerdings maßgeblich auf die konkrete Ausgestaltung der Maßnahmen in den untersuchten Städten zurückgeführt werden kann. Kommunale Belegungsrechte im Wohnungsbestand - teilweise handelt es sich nur um Belegungsbindungen zugunsten bestimmter sozialer Gruppen - wurden bislang vor allem durch den Einsatz der folgenden Instrumente erworben:

- Prämienprogramme. Die Kommune zahlt dem Wohnungseigentümer einen einmaligen Zuschuß als Gegenleistung dafür, daß ,er einem von der zuständigen Stelle als berechtigt qualifizierten oder direkt vorgeschlagenen Haushalt eine Wohnung in seinem Bestand überläßt'“2 . Prämien werden in der Praxis sowohl für das einmalige Belegungsrecht als auch zeitraumbezogen mit der Möglichkeit mehrerer Belegungen vergeben. Handelt es sich um einmalige Belegungsrechte, wird die Gewährung der (vollen) Prämie meist an die Bedingung geknüpft, daß das Mietverhältnis eine gewisse Zeit lang Bestand hat. Bei einer Auflösung des Mietverhältnisses vor Ablauf der Frist stellen einige Kommunen dem Vermieter frei, ob er eine weitere Belegung durch die Gemeinde akzeptieren oder die Prämie anteilig zurückzahlen will. Üblicherweise werden in Verbindung mit dem Belegungsrecht auch Mietobergrenzen in Höhe der ortsüblichen Vergleichsmiete oder einem darunterliegenden Mietzins vereinbart. Die Prämien haben dann die Funktion, neben den Risiken der Belegungsbindung auch die aus der Preisbindung resultierenden Mindereinnahmen der Wohnungseigentümer auszugleichen. Obwohl die Prämienprogramme mithin als die „klassische“ Form des Erwerbs von Belegungsbindungen bzw. Belegungsrechten im Wohnungsbestand angesehen werden, sind die bisherigen Erfahrungen mit diesem Instrument nicht gerade ermutigend. So hat die Auswertung der Prämienprogramme von sechs Großstädten ergeben, daß die Förderangebote bei den Wohnungseigentümern zumeist nur auf geringe Resonanz gestoßen sind. Die Mitarbeiter der zuständigen Stellen führten dies allerdings auf Mängel in der Ausgestaltung der Programme, vor allem ihre zu geringe Dotierung, sowie auf eine unzureichende Öffentlichkeitsarbeit zurück. ${ }^{3}$

1 Kirchner, J., Roth, W., Sautter, H. (1991). In die Studie wurden die Städte Hamburg, Bremen, Hannover, Düsseldorf, Köln, Dortmund, Kassel, Frankfurt am Main, Stuttgart, Freiburg, Nürnberg und München einbezogen.

Keil, K. (1996), S. 221.

3 Vgl. Kirchner, J., Roth, W., Sautter, H. (1991), S. $22 \mathrm{ff}$. 
- Neubauförderung mit mittelbarer Belegung im Bestand. Belegungsrechte im Wohnungsbestand werden auch auf dem Wege der Neubauförderung erworben, indem die an der Förderung beteiligte Kommune den Investor dazu verpflichtet, ihr neben der geförderten Neubauwohnung auch eine Wohnung aus seinem (älteren) Bestand für die Belegung mit Wohnungsnotfällen zur Verfügung zu stellen. Die Gegenleistung für das Belegungsrecht an der Bestandswohnung besteht hier im Nettovorteil der Neubauförderung. Nach der Kirchner-Studie haben sich die Modelle mit mittelbarer Belegungsbindung in einigen Städten als verhältnismäßig erfolgreich erwiesen. ${ }^{1}$ Wie bereits dargestellt, wird der Erwerb mittelbarer Belegungsbindungen vereinzelt auch im Rahmen der EOF angestrebt.

- Kooperation mit Wohnungsunternehmen. Eine sehr wichtige und erfolgreiche Maßnahme ist die Kooperation der Kommunen mit den ortsansässigen Wohnungsunternehmen. Diese verpflichten sich vertraglich oder formlos gegenüber der Gemeinde, einen Teil ihres Wohnungsbestandes für eine Belegung mit Haushalten aus den kommunalen Notfallkarteien zur Verfügung zu stellen. Die Kooperationsvereinbarungen sehen meist keine direkten Gegenleistungen der Gemeinden vor. Dafür erhalten die Investoren meist indirekte Vergünstigungen, etwa in Form einer bevorzugten oder ausschließlichen Berücksichtigung bei der Vergabe öffentlicher Fördermittel im sozialen Wohnungsbau. Auch ist das Zustandekommen der Kooperation oftmals darauf zurückzuführen, daß die Kommunen an den betroffenen Unternehmen beteiligt sind. Beim Bremer Kooperationsmodell besteht die „Gegenleistung“ des Landes im Verzicht auf Erlaß einer Verordnung gemäß $\S 5$ a WoBindG, wonach die Landesregierungen zur Ausweisung von Gebieten mit erhöhtem Wohnraumbedarf ermächtigt sind, in denen sie per Rechtsverordnung Belegungsrechte für die frei oder bezugsfertig werdenden öffentlich geförderten Sozialwohnungen ausüben dürfen (vgl. Fußnote zum $\S 5$ a WoBindG in Kapitel 1.D.I). Außerdem gewährt die Stadt im Einzelfall zeitlich befristete Garantien für die Mietzahlungen und die Kosten der Instandhaltung bzw. Renovierung. Über die Kooperation mit Wohnungsunternehmen konnten die Kommunen in verhältnismäßig großem Umfang Belegungsrechte erwerben. ${ }^{2}$

- Übernahme von Ausfallbürgschaften. Einige Kommunen decken als Gegenleistung für das Belegungsrecht die wirtschaftlichen Vermietungsrisiken ganz oder teilweise durch Übernahme von Ausfallbürgschaften ab. Solche Bürgschaften können das Mietausfallwagnis (einschließlich Nebenkosten), Instandhaltungskosten, Reparaturen von Schäden an der Mietsache, Verfahrens- und Räumungskosten einer berechtigten Räumungsklage sowie Mietminderungsan-

1 Vgl. Kirchner, J., Roth, W., Sautter, H. (1991), S. 31f.

2 Vgl. Kirchner, J., Roth, W., Sautter, H. (1991), S. 16ff.; Keil, K. (1996), S. $219 f f$. 
sprüche anderer Mieter bei Störungen und Belästigungen durch den von der Kommune vermittelten Haushalt umfassen. Ein besonderes Gewicht nimmt die Übernahme solcher Bürgschaften in Köln ein. Durch Abschluß von Gewährleistungsverträgen wurden dort Belegungsrechte für ca. 11.000 Wohnungen erworben. Überwiegend handelt es sich dabei um objektbezogene, also an die Wohnung gebundene Gewährleistungen. Für einen kleinen Teil der Wohnungen wurden zusätzlich oder ausschließlich subjektbezogene Gewährleistungsverträge geschlossen, bei denen die Bürgschaft für eine ganz konkrete Person übernommen wird. ${ }^{1}$

- Anmietung von Wohnraum. Bei dieser Form des Belegungsrechtserwerbs tritt die Gemeinde selbst als Wohnungsnachfrager auf und stellt die gemietete Wohnung einem Haushalt ihrer Wahl zur Verfügung. In der Regel wird dem Eigentümer die marktübliche oder eine etwas darüber liegende Miete unter Einschluß der Nebenkosten garantiert; außerdem verpflichtet sich die Gemeinde zur Übernahme der Kosten für der Instandsetzung und zur Beseitigung von Schäden an der Mietsache. Bei der Anmietung von Wohnraum wird danach unterschieden, ob sie der kurzfristigen Unterbringung von Obdachlosen oder der dauerhaften Versorgung in Wohnungsnot befindlicher Haushalte dienen soll. Im ersten Fall erfolgt die Unterbringung durch Polizeiverfügung. Zwischen der einweisenden Kommune und dem Obdachlosen entsteht ein auf kurze Zeit zu begrenzendes öffentlich-rechtliches Gebrauchsüberlassungsverhältnis, auf das die Vorschriften des Mietrechts keine Anwendung finden. Anders liegt der Fall bei der Wohnraumanmietung zum Zweck der dauerhaften Versorgung wohnungssuchender Haushalte. Die Gemeinde geht mit den begünstigten Haushalten dann meist längerfristige privatrechtliche Mietverhältnisse ein, die in vollem Umfang den Bestimmungen des Mietpreisrechts und des Bestandsschutzes unterliegen. In der Praxis kommt der Zwischenmietung von Wohnraum bislang noch keine besondere Bedeutung zu.

- Beschlagnahmung von Wohnraum. Dabei handelt es sich um eine an enge rechtliche Voraussetzungen geknüpfte Polizeiverfügung zur Vermeidung von Obdachlosigkeit, die nur dann zulässig ist, wenn die Obdachlosigkeit nicht auf andere Weise verhindert oder beseitigt werden kann. Die Polizeibehörde übernimmt meist alle wirtschaftlichen Einbußen, die dem Wohnungseigentümer aus der kommunalen Einweisung des begünstigten Haushalts in seine Wohnung entstehen. Das Nutzungsverhältnis ist öffentlich-rechtlich und auf maximal sechs Monate begrenzt. In einigen Gemeinden, z.B. Dortmund oder Bremen, erfolgt die Beschlagnahme im Einvernehmen mit den Wohnungseigentümern. Dies ist insbesondere dann sinnvoll, wenn die Voraussetzungen für die rechtliche Zulässigkeit der Beschlagnahmung nicht erfüllt sind und eine gerichtliche Überprüfung die Nichtigkeit der Einweisung ergeben würde. Die einvernehmli-

1 Vgl. Kirchner, J., Roth, W., Sautter, H. (1991), S. 35. 
che Beschlagnahme von Wohnraum bietet zudem die Möglichkeit, ein längerfristiges Unterbringungsverhältnis zu begründen, das zu einem späteren Zeitpunkt in den Abschluß eines ordentlichen Mietvertrages einmünden kann. Durch den Einsatz dieses Instrumentes konnten in Bremen jährlich 200 bis 220 Wohnungen, in Dortmund - zwischen 1983 und 1989 - sogar mehr als doppelt so viele Wohnungen im Jahresdurchschnitt für die Unterbringung von Wohnungsnotstandsfällen gewonnen werden. ${ }^{1}$

- Ankauf von Wohnraum. Bei dieser Maßnahme müssen die Kommunen nicht nur große finanzielle Belastungen, sondern auch die aus dem Vermögensbesitz resultierenden Risiken auf sich nehmen. Dazu sind sie aber i.d.R. nicht bereit, so daß dem gemeindlichen Ankauf von Wohnungen in der Praxis so gut wie keine Bedeutung zukommt. Hinzu kommt, daß den Gemeinden überwiegend sehr teuere oder ungeeignete Objekte mit erheblichem Instandhaltungsrückstand zum Kauf angeboten werden. ${ }^{2}$

\section{Wege zur Erhöhung der Effektivität kommunaler Belegungspolitik}

Das bislang nur geringe Bemühen der Gemeinden um Belegungsrechte außerhalb des Sozialwohnungsbestands und der mäßige Erfolg eines Großteils ihrer Förderangebote deuten darauf hin, daß die Voraussetzungen für eine wirksame und effiziente kommunale Belegungspolitik noch nicht hinreichend erfüllt sind. $\mathrm{Zu}$ diesen Voraussetzungen gehört unter anderem eine adäquate finanzielle Ausstattung der Gemeinden, die effiziente Ausgestaltung der Förderinstrumente und eine stärkere Öffentlichkeitsarbeit.

Soll der kommunale Erwerb von Belegungsrechten im Wohnungsbestand künftig ein stärkeres Gewicht bekommen, muß zunächst einmal gewährleistet sein, daß den Kommunen die dafür benötigten Mittel in hinreichendem Umfang zur Verfügung stehen. Gegenwärtig beteiligen sich Bund und Länder überwiegend an Maßnahmen zur Neuschaffung von Wohnraum, während die Kommunen für den Erwerb von Belegungsrechten im Bestand zumeist allein aufkommen müssen. Künftig wird es in erster Linie Aufgabe der Länder sein, die Kommunen beim Erwerb von Belegungsrechten durch den Einsatz von Mitteln aus ihrem Haushalt zu unterstützen. Zusätzliche Belastungen der Länderhaushalte lassen

I Vgl. Keil, K. (1996), S. 227f. Die Autorin nimmt Bezug auf Hubert, F., Tomann, H. (1991), Der Erwerb von Belegungsrechten im Wohnungsbestand. Eine ökonomische Wirkungsanalyse, Gutachten im Auftrag des Bundesministeriums für Raumordnung, Bauwesen und Städtebau, Berlin.

2 Vgl. Kirchner, J., Roth, W., Sautter, H. (1991), S. 34f. 
sich vermeiden, wenn nur Mittel verwendet werden, die sonst in die Neubauförderung geflossen wären. Wegen der fehlenden Investitionsbezogenheit der Maßnahmen scheidet eine direkte Beteiligung des Bundes auf der Grundlage des Art. 104 a Abs. 4 GG verfassungsrechtlich aus. Ein Ausgleich könnte allerdings auf indirektem Wege im Rahmen des vertikalen Finanzausgleichs durch eine leichte Anhebung des Länderanteils an der Mehrwertsteuer vorgenommen werden. „Der Bund hat bisher Belegungsrechte durch Beteiligung an den Programmen des sozialen Wohnungsbaus mitfinanziert. Mit der Rückführung des sozialen Wohnungsbaus wird eine Verteilungsmasse verfügbar, die im Rahmen des vertikalen Finanzausgleichs zugunsten der Länder eingebracht werden kann. "

Um möglichst vielen Haushalten zu einer Unterkunft verhelfen zu können, sollten die Kommunen die dafür zur Verfügung stehenden Mittel möglichst sparsam einsetzen. Sie haben sich daher in erster Linie um solche Wohnungen zu bemühen, bei denen die für die Belegung zu erbringenden Kompensationsleistungen möglichst niedrig ausfallen. Dies sind vor allem einfach ausgestattete Wohnungen mit durchschnittlichem oder unterdurchschnittlichem Wohnwert und geringen Vergleichsmieten. Als besonders geeignet dürften sich die aus den Bindungen fallenden Sozialwohnungen der 50er und 60er Jahre erweisen: „Zum einen, weil sie trotz der umfangreichen Wohnwertverbesserungen mit ihrem bescheidenen Zuschnitt eher im unteren Bereich der Wohnwertskala liegen und damit auch nach der Mietfreigabe vergleichsweise niedrige Mieten erzielen werden. Zum anderen, weil ihre Eigentümer bereits Erfahrungen mit den Wohnungsämtern machen konnten und daher - so diese gut waren - eher bereit sein werden, der Kommune einen Einfluß auf die Belegung einzuräumen.“2 Weniger geeignet erscheinen dagegen Wohnungen neueren Baudatums oder modernisierte Altbauwohnungen mit hohem Ausstattungsniveau, da solche Wohnungen i.d.R. ein höheres Preisniveau aufweisen. Da es sich bei den begünstigten Personengruppen überwiegend um Haushalte mit niedrigen Einkommen handelt, kämen die Kommunen kaum umhin, zusätzliche Fördermittel für die Gewährung von Mietbeihilfen einzusetzen. Außerdem sind Verschleiß und Beschädigungen bei aufwendig ausgestatteten Wohnungen im Regelfall mit erhöhten Kosten verbunden, für die letztlich die Kommunen aufkommen müßten.

Bei der Ausgestaltung der gemeindlichen Kompensationsleistungen sind zwei Vorgehensweisen zu unterscheiden: Einerseits kann die Kommune den Wohnungseigentümer - wie bei den Prämienprogrammen oder der Neubauförderung mit mittelbarer Belegungsbindung - durch fixe Förderbeträge vorab dafür entschädigen, daß er die in ihrer Höhe noch ungewissen Kosten der Belegungsbin-

1 Expertenkommission Wohnungspolitik (1995), S. 357.

2 Expertenkommission Wohnungspolitik (1995), S. 223 
dung trägt. Andererseits kann sie diese Kosten aber auch ganz oder teilweise selbst übernehmen, etwa indem sie Ausfallbürgschaften gewährt oder als Zwischenmieter der Wohnungen auftritt. Wie bereits in Kapitel 3.B.IV.b dargelegt wurde, kann die öffentliche Hand Mittel einsparen, wenn sie nachträglich für die tatsächlichen Kosten der Belegungsbindung aufkommt, da die Mittelvergabe dann einzelfallbezogen erfolgt und keine Risikoprämien geleistet werden müssen. Als besonders geeignet erweist sich die Zwischenmietung mit Übernahme sämtlicher Instandhaltungs- und Reparaturkosten. Das beim Investor verbleibende Risiko dürfte dann im Einzelfall sogar geringer sein als bei freier Vermietung. Wird ihm zudem eine Miete in Höhe des marktüblichen Niveaus gezahlt, so kann sich die Vermietung an die Kommune - auch ohne zusätzliche Entgelte - als lohnende Alternative erweisen. Gleiches gilt für die einvernehmliche Beschlagnahme von Wohnraum, wenn die Kommune dem Eigentümer neben der Marktmiete sämtliche Kosten garantiert. Die (einvernehmliche) Beschlagnahme hat als polizeiliche Maßnahme den Vorteil, daß die durch sie begründeten öffentlich-rechtlichen Unterbringungsverhältnisse nicht dem privatrechtlichen Bestandsschutz unterliegen. Die Maßnahme bietet die Möglichkeit, den Kündigungsschutz zu umgehen und eine Wohnungszuteilung ,auf Probe“ vorzunehmen. Der Vermieter kann dann selbst entscheiden, ob er mit dem eingewiesenen Haushalt ein längerfristiges privatrechtliches Mietverhältnis eingehen will.

Der Ankauf von Wohnraum dürfte für den großangelegten Erwerb von Belegungsrechten dagegen aus finanziellen Gründen kaum in Betracht kommen. Auch die Übernahme von Bürgschaften ist nur bedingt zu empfehlen, da sie einen hohen Verwaltungsaufwand zur Kontrolle der von den Vermietern ausgewiesenen Kosten erfordert. Die Eigentümer haben überdies keinen Anreiz, dazu beizutragen, daß sich die Kosten der Belegungsbindung in Grenzen halten. So muß sich die zuständige Stelle etwa bei Reparaturarbeiten nicht nur die Höhe der tatsächlichen Aufwendungen nachweisen lassen, sondern auch die Wirtschaftlichkeit der vorgenommenen Maßnahmen prüfen. Die damit verbundenen Aufwendungen und Schwierigkeiten lassen sich vermeiden, wenn die Kommune - wie im Fall der Zwischenmietung - die Ermittlung und Beseitigung von Schäden selbst übernimmt. 


\section{Zur Ausgestaltung von Mietsubventionen}

\section{a. Sollten die Belegungsrechte an eine Mietvergünstigung gekoppelt werden?}

In der gegenwärtigen Förderpraxis werden auch die nicht im Sozialwohnungsbestand erworbenen Belegungsrechte überwiegend mit einer Mietpreisbindung versehen (z.B. der Verpflichtung des Mieters, auch bei Wiedervermietung die Vergleichsmiete einzuhalten). Einige Gemeinden gewähren sogar ein kommunales Wohngeld, um die Tragbarkeit der Wohnkostenbelastung zu garantieren. Es stellt sich die Frage, ob solche außerhalb des Wohngeldsystems gewährten Mietvergünstigungen überhaupt gerechtfertigt sind. Für eine solche Verknüpfung von Belegungsrechten und Mietsubventionen spricht die Unzulänglichkeit des gegenwärtigen Wohngeldsystems. Wegen der verzögerten Anpassung der Tabellenwerte und der Höchstbeträge an die Mietenentwicklung sind Zweifel angebracht, daß das Wohngeld die Tragbarkeit der Wohnkosten garantieren kann. Da es sich bei den Nutzern der kommunal vergebenen Wohnungen überwiegend um Bezieher niedriger Einkommen handeln dürfte, liegt es nahe, wenigstens für diese Haushalte durch Gewährung von Mietverbilligungen die Tragbarkeit der Wohnkosten sicherzustellen. Nach Auffassung der Kommission des Deutschen Verbandes für Wohnungswesen, Raumordnung und Städtebau e.V. sollten deshalb die Kommunen in Regionen mit hohem Mietniveau einkommensabhängige Mietzuschüsse gewähren. ${ }^{1}$

Den Gegnern einer zweiten Subjektförderung, darunter die Expertenkommission Wohnungspolitik, erscheint es ,im Hinblick auf die Gerechtigkeit und die Effizienz der Wohnungssozialpolitik ... empfehlenswert, beim Erwerb von Belegungsrechten auf jede Form der Mietbindung zu verzichten.“2 Nach Meinung des Verfassers ist als Hauptargument gegen jede Form selektiver Mietvergünstigungen anzuführen, daß der Grundsatz der Gleichbehandlung verletzt wird. So ist nicht einzusehen, daß ein Haushalt, der wegen nachteiliger sozialer Merkmale in eine kommunale Wohnung ziehen darf, eine geringere Miete zahlen soll als ein einkommensmäßig gleichgestellter Haushalt, der sich eine identische Wohnung selbst beschaffen konnte. Der Erwerb von Belegungsbindungen, der als Maßnahme zur Überwindung von Zugangsbeschränkungen zum Wohnungsmarkt gedacht ist, sollte nicht dazu führen, daß die vormals benachteiligten Haushalte nun eine Bevorzugung erfahren. Da die Belegungsrechte im preisgünstigen Wohnungsbestand erworben werden, lassen sich Mietverbilligungen auch nicht mit dem Preisnachteil von Neubauwohnungen begründen.

1 Vgl. Deutscher Verband für Wohnungswesen, Städtebau und Raumordnung e.V. - Kommission (1996), S. 71.

2 Expertenkommission Wohnungspolitik (1995), S. 222. 
Sie sind allenfalls in Gegenden mit einem sehr hohen Mietniveau zu rechtfertigen, sowie in Fällen, in denen die Kommunen - mangels Alternativen - auf neuere Wohnungen zur Unterbringung der versorgungsbedürftigen Haushalte zurückgreifen müssen.

Unabhängig vom hier vertretenen Standpunkt kann die wachsende Bedeutung kommunaler Mietsubventionen nicht bestritten werden. Die nachfolgenden Überlegungen befassen sich daher mit der Frage, wie die Vergünstigungen sinnvoll ausgestaltet werden könnten. Die Überlegungen lassen sich - soweit sie die Ausgestaltung einer Zusatzförderung betreffen - auf die einkommensorientierte Förderung von Neubaumaßnahmen übertragen.

\section{b. Vorschläge zur Ausgestaltung von Mietsubventionen}

Die im Zusammenhang mit den Belegungsbindungen gewährten Mietsubventionen können in sehr unterschiedlicher Weise ausgestaltet werden. Eine erste Möglichkeit besteht darin, den Mietzins im Zeitpunkt der Wohnungsvergabe auf das Niveau der ortsüblichen Vergleichsmiete zu beschränken. Der Mietvorteil entspricht dann dem Betrag, um den die marktübliche Neuvertragsmiete die Vergleichsmiete überschreitet. Für diese Form der Mietbegrenzung spricht, daß sie mit einem relativ geringen Verwaltungsaufwand verbunden ist, da lediglich die Vergleichsmieten, nicht aber die Mietereinkommen ermittelt werden müssen. Ein weiterer Vorteil kann darin gesehen werden, daß die Mieter in den staatlich vergebenen Wohnungen nur geringfügig gegenüber anderen Haushalten bevorzugt werden. Fehlsubventionierungen als Folge von Einkommenssteigerungen dürften überdies kaum auftreten, da die Mietvorteile nur in der Anfangsphase des Mietverhältnisses bestehen. Gegen eine bloße Bindung an die ortsübliche Vergleichsmiete läßt sich einwenden, daß das Wohngeld auch bei Vermeidung der bei Neuvermietung erlaubten Aufschläge auf das Vergleichsmietenniveau nicht immer ausreicht, um die Tragbarkeit der Wohnkosten sicherzustellen. Für Geringverdiener könnte sich die ortsübliche Vergleichsmiete gerade in den teuren Großstädten als zu hoch erweisen.

Aus diesem Grunde käme die Absenkung der Mieten auf das Niveau der Höchstbeträge nach $\S 8 W o G G$ in Betracht. Die Wohngeldhöchstbeträge liegen meist deutlich unter den ortsüblichen Vergleichsmieten, so daß Härtefälle kaum noch auftreten dürften. Für die Mieter der kommunal vergebenen Wohnungen würde es sich dann auch nicht mehr nachteilig auswirken, daß die Wohngeldhöchstbeträge der Mietenentwicklung hinterherlaufen. Eine pauschale Festsetzung der Mieten auf das Niveau der Wohngeldhöchstbeträge ist dennoch kaum zu empfehlen, da sie mit der Gefahr hoher Fehlsubventionierungen verbunden 
ist und die wenig differenzierten Höchstbeträge den Wohnwert nur unzulänglich widerspiegeln. Die Grundsätze der Tragbarkeit und der Fühlbarkeit wären verletzt. Problematisch ist auch, daß die im Wohngeld unerwünschte Höchstbetragsstaffelung nach Baualter und Ausstattung bestehen bleiben müßte.

Diagramm 9: Konzept einer „stufenlosen“ Zusatzförderung

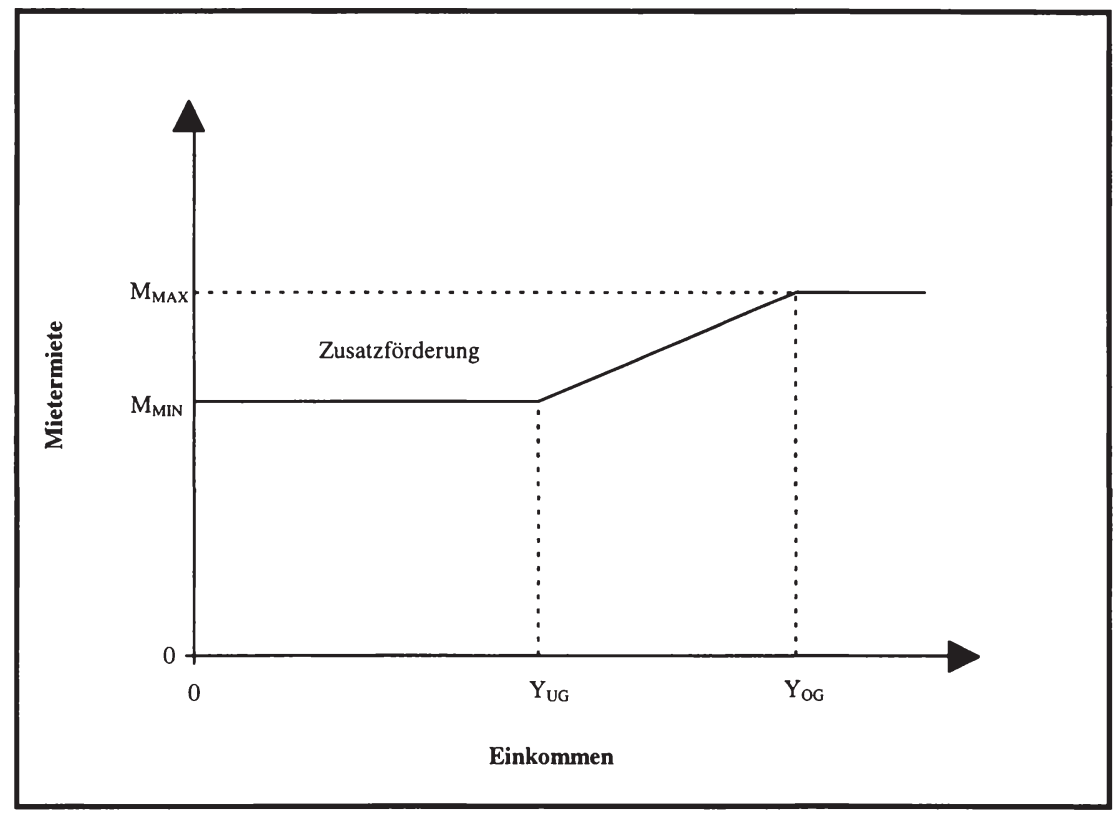

Sollen die Nachteile der beiden dargestellten Varianten vermieden werden, ist eine Staffelung der Transfers nach dem Mietereinkommen unumgänglich. Die Kommunen hätten den Mietern der Wohnungen, für die sie das Belegungsrecht ausüben, eine periodisch an die Einkommensentwicklung anzupassende Zusatzförderung zu gewähren. Diese sollte so ausgestaltet sein, daß die Unzulänglichkeiten der EOF vermieden werden. Unter anderem müßte eine stetige Differenzierung der Transfers nach dem Grad der Unter- bzw. Überschreitung der Einkommensgrenze vorgenommen werden, damit keine Belastungssprünge auftreten. Außerdem sollte gewährleistet sein, daß die Rückführung der Transfers 
nicht allzu weit oberhalb des Einkommens beginnt, bei dem der Wohngeldanspruch endet. Diagramm 9 zeigt schematisch auf, wie die Zusatzförderung in Abhängigkeit vom Einkommen ausgestaltet werden könnte.

Liegt das Einkommen $(\mathrm{Y})$ unterhalb der Untergrenze $\mathrm{Y}_{\mathrm{UG}}$, wird die maximale Zusatzförderung gewährt, die Wohnkosten entsprechen (vor Abzug eventueller Wohngeldleistungen) der Mindestmiete $\mathbf{M}_{\mathrm{MIN}}$. Oberhalb von $\mathrm{Y}_{\mathrm{UG}}$ setzt der lineare Abbau der Zusatzförderung ein, bis die Einkommensobergrenze $\mathrm{Y}_{\mathrm{OG}}$ erreicht wird. Haushalte mit einem Einkommen von $\mathrm{Y}_{\mathrm{OG}}$ oder mehr haben die volle Vertragsmiete $\mathbf{M}_{\operatorname{MAX}}$ zu entrichten. Von der Konkretisierung der Oberund Untergrenzen für Einkommen und Wohnkosten hängt es ab, wie stark die Belastbarkeit der Haushalte ausgeschöpft wird, welche Grenzbelastungen auftreten und inwieweit Wohnwertunterschiede berücksichtigt werden. Als Mietobergrenze $\mathbf{M}_{\text {MAX }}$ kommen nur die marktübliche Neuvermietungsmiete oder die Vergleichsmiete in Betracht, da sie die Wohnwertunterschiede widerspiegeln und Fehlsubventionierungen (weitgehend) vermieden werden könnten. Für die Mindestmieten wäre ein politisch zu bestimmender Prozentsatz der Mietobergrenzen festzulegen. Auch könnten die Wohngeldhöchstbeträge als Mietuntergrenze angesetzt werden, was allerdings mit dem bereits erwähnten Nachteil verbunden wäre, daß Wohnwertunterschiede nur unzulänglich berücksichtigt würden.

Wie bei der EOF könnten die Eckwerte $\mathrm{Y}_{\mathrm{UG}}$ und $\mathrm{Y}_{\mathrm{OG}}$ in Prozentsätzen der Einkommensgrenze nach $\S 25$ II. WoBauG festgelegt werden. Um die Belastbarkeit der Mieter voll auszuschöpfen, müßten die zuständigen Behörden $Y_{U G}$ unterhalb der Grenze des $\S 25$ ansetzen. Andererseits sollte $Y_{U G}$ nicht geringer ausfallen als das Einkommen, bei dem der Wohngeldanspruch ausläuft, da sonst unerwünschte Überschneidungen der beiden Instrumente - verbunden mit hohen Grenzbelastungen - auftreten könnten. Für die Einkommensobergrenze empfehlen sich Werte, die nicht allzu weit oberhalb der Grenze des $\S 25$ liegen, da die Förderung dann auf die unteren Einkommensschichten konzentriert wird, was angesichts der Knappheit der Fördermittel und der großen Zahl förderbedürftiger Haushalte sinnvoll erscheint. Die Höhe der Zusatzförderung $(Z)$ wird durch folgende Gleichung bestimmt:

$$
\begin{aligned}
\mathrm{Z} & =\mathrm{M}_{\mathrm{MAX}}-\mathrm{M}_{\mathrm{MIN}} \\
& =\left(\mathrm{M}_{\mathrm{MAX}}-\mathrm{M}_{\mathrm{MIN}}\right)\left[\left(\mathrm{Y}_{\mathrm{OG}}-\mathrm{Y}\right) /\left(\mathrm{Y}_{\mathrm{OG}}-\mathrm{Y}_{\mathrm{UG}}\right)\right] \\
& =0
\end{aligned}
$$

für $\mathrm{Y}<\mathrm{Y}_{\mathrm{UG}}$

für $\mathrm{Y}_{\mathrm{UG}} \leq \mathrm{Y} \leq \mathrm{Y}_{\mathrm{OG}}$

für $\mathrm{Y}>\mathrm{Y}_{\mathrm{OG}}$

Denkbar wäre eine Ausgestaltung der folgenden Art: Als Mietobergrenze wird die ortsübliche Vergleichsmiete und als Mindestmiete die um 30\% reduzierte 
Vergleichsmiete angesetzt. Der Abbau der Zusatzförderung beginnt bei Einkommen, die um 20\% unter der Grenze des $\S 25$ liegen, und endet bei einer Überschreitung der Grenze um 10\%. Der Betrag der Zusatzförderung ist dann einfach zu ermitteln: Jeder Prozentpunkt, um den das Einkommen die Untergrenze übersteigt, führt zu einer Transferkürzung um $1 \%$ der ortsüblichen Vergleichsmiete. Liegt das Einkommen beispielsweise um sechs Prozentpunkte oberhalb von $\mathrm{Y}_{\mathrm{UG}}$ (d.h. die Einkommensgrenze wird um $14 \%$ unterschritten), beträgt die Mietermiete $76 \%$ der Vergleichsmiete (statt $70 \%$ bei Maximalförderung).

Bei der dargestellten Variante der Zusatzförderung wird $Y_{O G}$ nicht nach der Höhe der ortsüblichen Vergleichsmiete differenziert. Dieser Tatbestand könnte sich als problematisch erweisen, wenn die Einkommensobergrenze niedrig angesetzt wird, denn Haushalte, die nur mit teueren Wohnungen aus dem jüngeren Bestand versorgt werden konnten, müssen dann schon bei niedrigen Einkommen hohe Wohnkosten aufbringen. Das Problem wird entschärft, wenn statt einer Obergrenze ein Abschöpfungssatz $\lambda$ für das über $Y_{U G}$ hinausgehende Einkommen festgelegt wird. Bei dieser Vorgehensweise wird die Transfergrenze $Y_{O G}$ mit zunehmender Vergleichsmiete (und entsprechend höherer Zusatzförderung) nach oben verlagert. Die Höhe der Zusatzförderung ergibt sich als:

$$
\begin{aligned}
\mathrm{Z} & =\mathrm{M}_{\mathrm{MAX}}-\mathrm{M}_{\mathrm{MIN}} \\
& =\mathrm{M}_{\mathrm{MAX}}-\mathrm{M}_{\mathrm{MIN}}-\lambda\left(\mathrm{Y}-\mathrm{Y}_{\mathrm{UG}}\right) \\
& =0
\end{aligned}
$$

für $Y<Y_{U G}$

für $\mathrm{Y}_{\mathrm{UG}} \leq \mathrm{Y} \leq \mathrm{Y}_{\mathrm{UG}}+\left(\mathrm{M}_{\mathrm{MAX}}-\mathrm{M}_{\mathrm{MIN}}\right) / \lambda$

für $\mathrm{Y}>\mathrm{Y}_{\mathrm{UG}}+\left(\mathrm{M}_{\mathrm{MAX}}-\mathrm{M}_{\mathrm{MIN}}\right) / \lambda$

Das Vorgehen bei der Ermittlung der Transfers sei am Beispiel eines DreiPersonen-Haushaltes in einer 70-qm-Wohnung mit einer Vergleichsmiete von 900 DM (nettokalt) verdeutlicht. Die Einkommensuntergrenze liege wiederum um 20\% unterhalb der in $\S 25$ genannten Werte und die Mindestmiete bei $70 \%$ der Vergleichsmiete, was im Beispiel 630 DM entspricht. Der marginale Abschöpfungssatz $\lambda$ betrage 0,2 , d.h. jede Erhöhung des Gesamteinkommens um 1 DM führt zu einer Transferkürzung um 0,20 DM. Bei einem Gesamteinkommen bis $\mathrm{Y}_{\mathrm{UG}}(=2.760 \mathrm{DM}$ monatlich) steht dem geförderten Haushalt die maximale Zusatzförderung in Höhe von $270 \mathrm{DM}$ zu. Liegt das Gesamteinkommen oberhalb von $\mathrm{Y}_{\mathrm{UG}}$, beispielsweise bei $3.500 \mathrm{DM}$, so hat die zuständige Stelle einen monatlichen Zuschuß in Höhe von

$$
270-0,2(3.500-2.760)=122 \mathrm{DM}
$$


zu zahlen. Die Transfergrenze $\mathrm{Y}_{\mathrm{OG}}$, von der ab keine Zusatzförderung mehr gewährt wird, liegt bei

$$
2.760+270 / 0,2=4.110 \mathrm{DM}
$$

was einer Überschreitung der Grenze des $\S 25$ um 19\% entspricht. Beträgt die monatliche Vergleichsmiete 1.200 DM statt wie bisher $900 \mathrm{DM}$, erhöht sich die maximale Zusatzförderung (=30\% der Vergleichsmiete) von 270 auf $360 \mathrm{DM}$, und die Förderung läuft - wegen des konstanten Abschöpfungssatzes - bei einem höheren Einkommen aus.

Die Transfergrenze ist auf

$$
2.760+(360 / 0,2)=4.560 \mathrm{DM}
$$

angestiegen. Die Haushalte erhalten nun bis zu einer 32prozentigen Überschreitung der Einkommensgrenze Mietzuschüsse. Im Vergleich zur ersten Variante der Zusatzförderung mit invariabler Transfergrenze sind die Wohnkosten stärker an der Belastbarkeit ausgerichtet. Auf der anderen Seite wird das Verhältnis der Vergleichsmieten durch die Transfers verzerrt, dem Fühlbarkeitsgrundsatz also in geringerem Maße entsprochen. Beide Varianten zeichnen sich dadurch aus, daß die Transfers linear an das Einkommen angepaßt und daher Grenzbelastungen von über $100 \%$ vermieden werden.

Um den mit der Einkommensermittlung und Transfergewährung verbundenen Verwaltungsaufwand möglichst gering zu halten, sollte die Zuständigkeit bei der Wohngeldstelle liegen. Am einfachsten wäre folgende Vorgehensweise: Die Mieter der kommunal vergebenen Wohnungen schulden dem Eigentümer oder der zwischenmietenden Gemeinde die volle Vergleichsmiete. Bei der Wohngeldstelle können sie den Mietvertrag vorlegen, in dem die Berechtigung auf Erhalt einer Zusatzförderung vermerkt ist. Die Wohngeldstelle stellt zunächst das Gesamteinkommen nach § 25 Abs. 1, 3 II. WoBauG und anhand dessen die Höhe der Zusatzförderung fest. Auf der Grundlage der um die Zusatzförderung gekürzten Vergleichsmiete wird dann der gegebenenfalls bestehende Wohngeldanspruch ermittelt. Dies bereitet nur noch einen geringen zusätzlichen Aufwand, der durch eine vollständige Angleichung der Einkommensbegriffe des Wohngeldgesetzes und des Zweiten Wohnungsbaugesetzes noch verringert werden könnte. 
Besteht ein Anspruch auf Zusatzförderung und Wohngeld, bietet sich die gemeinsame Auszahlung beider Transfers an. Die Entscheidung darüber, ob die Mittel über den Mieter oder direkt an den Vermieter überwiesen werden, hängt davon ab, welches Gewicht dem Datenschutz eingeräumt wird. Die Auszahlung an den Vermieter dürfte aber regelmäßig dann zu empfehlen sein, wenn die Kommune selbst Empfänger der Mietzahlungen ist oder die Gefahr einer zweckfremden Mittelverwendung durch den Mieter besteht. Die Zuständigkeit der Wohngeldstelle für die Zusatzförderung legt die gemeinsame Neufestsetzung beider Transfers in dem vom Wohngeldgesetz vorgeschriebenen Turnus von zwölf Monaten nahe. Jährliche Einkommensprüfungen haben den Vorteil, daß Fehlsubventionierungen im Zeitablauf weitgehend vermieden werden können. 


\section{Zusammenfassung und Ausblick}

Die vorangegangenen Ausführungen haben gezeigt, daß die einkommensorientierte Förderung des sozialen Mietwohnungsbaues nach $\S 88$ e II. WoBauG dem herkömmlichen ersten Förderweg konzeptionell überlegen ist. Durch den verstärkten Einsatz dieser Förderform - man kann sie als ,vereinbarte Förderung“ mit eingebauter Fehlbelegungsabgabe charakterisieren - können die Länder ihre Wohnungspolitik in Richtung auf eine höhere Effizienz und Verteilungsgerechtigkeit umgestalten. Die Abkehr vom Kostenmietprinzip eröffnet ihnen die Möglichkeit einer sparsameren, von der Kostenentwicklung im Wohnungssektor unabhängigen Mittelvergabe, die nach dem Prinzip von Leistung und Gegenleistung erfolgt: Der Investor erhält eine Grundförderung, die ihn dafür entschädigt, daß er für seine Wohnung eine Belegungsbindung zugunsten des förderberechtigten Personenkreises eingeht und daß er sich mit einer zumeist etwas unterhalb der Marktmiete liegenden höchstzulässigen Basismiete zufrieden gibt. Durch die einkommensabhängige Zusatzförderung, die periodisch an die Einkommenssituation der Mieter angepaßt wird, können die Wohnkosten an der individuellen Belastbarkeit ausgerichtet und Fehlsubventionierungen vermieden werden. Auch die im ersten Förderweg typischen Mietpreisverzerrungen im Wohnungsbestand treten bei der EOF nicht auf, wenn gewährleistet ist, daß sich die Basismieten am Vergleichsmietenniveau orientieren.

Die oben gemachten Aussagen stehen unter dem Vorbehalt, daß erst auf der Basis der Umsetzung des $\S 88$ e in den Ländern beurteilt werden kann, inwieweit die bei der EOF vorhandenen Spielräume für eine gerechtere und effizientere Förderung genutzt werden. Inzwischen sind zwei Drittel der Länder in die einkommensorientierte Förderung eingestiegen. Mit der Ausgestaltung der EOF in diesen Bundesländern hat sich die vorliegenden Arbeit befaßt. Sie kommt zu dem Ergebnis, daß die Umsetzung der EOF mitunter weit hinter den Möglichkeiten zurückgeblieben ist, die diese Förderform bietet.

Die Grundförderung wird überwiegend in der Form von Festbeträgen gewährt, die in keinem oder nur losem Zusammenhang zu den wirtschaftlichen Einbußen stehen, für die sie den Investor entschädigen sollen. Dies wird bereits an den gravierenden Unterschieden bei dem von den Ländern erbrachten Mitteleinsatz deutlich. Auch die innerhalb einzelner Länder vorgenommene Differenzierung der Förderbeträge läßt erkennen, wie wenig die Grundförderung nach den ökonomisch relevanten Gesichtspunkten ausgestaltet worden ist. So nimmt Berlin eine Staffelung der Darlehenszinssätze nach der Aufwendigkeit der Bauausführung vor; in Brandenburg richtet sich die Darlehenshöhe nach dem Eigenkapitalanteil des Investors. Beide Länder geben ein Beispiel dafür, wie schwer es 
den staatlichen Förderstellen fällt, sich bei der EOF vollständig vom Kostenmietprinzip zu lösen.

Ein Großteil des als Grundförderung erbrachten Mitteleinsatzes dient zum Erwerb von Belegungsbindungen am neugeschaffenen Wohnraum. Da über die Höhe der Grundförderung bereits vor Beginn des Bindungszeitraumes entschieden wird, wenn beide Vertragsseiten noch keine Kenntnis darüber haben, welche Zusatzkosten durch die Ausübung des Belegungsrechts tatsächlich entstehen, wird die vom Staat zu erbringende Kompensation höher sein müssen als die erwarteten Mehraufwendungen durch unliebsame Mieter, da das Risiko beim Investor bleibt. Dieser wird für die Risikoübernahme eine Prämie verlangen, deren Höhe vom Grad der Ungewißheit über die tatsächlichen Kosten abhängt. Die Prämien sind bei der einkommensorientierten Förderung besonders hoch zu veranschlagen, da die Wohnungen wegen des Bemühens um sozial und einkommensmäßig gemischte Belegungsstrukturen an Haushalte vergeben werden sollen, die sich im Hinblick auf die Bonität und das Sozialverhalten stark unterscheiden. Dies hat zur Folge, daß die Länder für das Belegungsrecht an den Wohnungen auch dann hohe Beträge einsetzen müssen, wenn diese an „gute“ Mieter mit überdurchschnittlichen Einkommen vergeben werden.

Die Länder haben sich bislang nicht darum bemüht, solche Ineffizienzen zu vermeiden, Dabei könnten sie erhebliche Einsparungen realisieren, wenn sie von der Pauschalförderung abrückten und dazu übergingen, die mit der Belegungsbindung verbundenen Mehraufwendungen nachträglich zu erstatten oder wie bei der Zwischenmietung der geförderten Wohnungen - gleich selbst zu übernehmen. Für die Grundförderung müßten dann - nicht zuletzt wegen des Wegfalls der Risikoprämien - erheblich weniger Mittel aufgewendet werden. Gegebenenfalls käme der Grundförderung nur noch die Funktion zu, die Wohnungseigentümer für die Einbußen aus der Mietpreisbindung zu entschädigen. Die Risikoübernahme durch den Staat ist besonders zu empfehlen, wenn es sich um Investoren handelt, die nur über eine oder wenige Wohnungen verfügen, da sie von den im Einzelfall auftretenden Zusatzkosten besonders betroffen sind. Die Attraktivität der EOF wäre dann von der Risikoneigung der Vermieter unabhängig, und die Länder hätten geringere Schwierigkeiten, eine ausreichende Zahl von Investoren für die geplanten Fördervorhaben zu gewinnen.

Neben dem Erwerb von Belegungsbindungen besteht die zweite Funktion der EOF in der Anpassung der Wohnkosten an die individuelle Belastbarkeit der Mieter. $\mathrm{Zu}$ unterscheiden sind die Mietverbilligungen, die im Rahmen der Grundförderung durch Absenkung der höchstzulässigen Basismiete unter das marktübliche Niveau erbracht werden (Basissubvention) und die am Mietereinkommen ausgerichtete Zusatzförderung. Bei der Basissubvention besteht eine Einkommensabhängigkeit nur insoweit, als jeder Haushalt, der aufgrund seines 
Einkommens eine nach dem neuen Modell geförderte Wohnung beziehen konnte, davon profitiert. Die Verbilligung der Basismieten hat den Vorteil, daß die Wohnungen für besserverdienende Haushalte, die keine oder nur eine geringe Zusatzförderung erhalten, attraktiver werden. Gerade bei entspannter Wohnungsmarktlage haben diese Haushalte keine Schwierigkeiten, sich auf dem freien Wohnungsmarkt zu versorgen. Erste Erfahrungen bei der Zuteilung der geförderten Wohnungen deuten darauf hin, daß die Zielsetzung einer durchmischten Belegungsstruktur ohne eine Mietverbilligung auch für besserverdienende Haushalte kaum realisierbar ist. Die Regelungen der Länder laufen in der Tendenz darauf hinaus, daß in attraktiven Großstädten mit einem überdurchschnittlichen Mietniveau besonders hohe Basissubventionen gewährt werden und daß die Vergünstigungen wegen restriktiver Kappungsgrenzen für die Dynamisierung der Basismieten im Zeitablauf steigen. Berechnungen für Stuttgart haben ergeben, daß die kumulierten Vorteile aus der Absenkung der Basismieten unter das ortsübliche Mietniveau bei einer 70-qm-Wohnung unter realistischen Annahmen in 20 Jahren eine Größenordnung von 50.000 DM erreichen können.

Die Basissubventionen stellen einen Schwachpunkt im Konzept der EOF dar, da sie auch solchen Haushalten zufließen, deren Einkommen die Bezugsberechtigungsgrenzen überschritten haben und die somit nicht mehr zum Adressatenkreis der EOF gehören. Diese Haushalte erhalten wegen der verzögerten Dynamisierung der Basismieten paradoxerweise gerade in den späten Förderjahren, wenn sie wegen des Einkommensanstiegs keine staatlichen Hilfen mehr brauchen, die höchsten Mietverbilligungen. Die baualters- und lagebedingten Mietpreisverzerrungen sind auch aus allokativer Sicht problematisch, da sie den Zuzug in teure, dicht besiedelte Gebiete fördern und die Bereitschaft der Sozialmieter zu einem Wohnungswechsel zusätzlich verringern. Der Staat sollte daher Mietvergünstigungen ausschließlich im Rahmen der Zusatzförderung gewähren. Tritt der Staat zudem als Zwischenmieter der belegungsgebundenen Wohnungen auf oder übernimmt Ausfallbürgschaften, dann könnte auf eine Grundförderung unter Umständen ganz verzichtet werden.

Trotz der Basissubventionen werden Mieter mit niedrigen Einkommen oft erst durch die Zusatzförderung in die Lage versetzt, die Wohnkosten der geförderten Wohnungen aufzubringen. Dies ist in erster Linie darauf zurückzuführen, daß die EOF an Neubau- oder Modernisierungsmaßnahmen anknüpft. Die Wohnungen weisen deshalb ein überdurchschnittliches Baukosten- und Qualitätsniveau auf und würden sich bei freier Vermietung im oberen Preissegment bewegen. Statistische Erhebungen über die baualtersbedingten Mietdifferenzen im Wohnungsbestand führen zu dem Schluß, daß selbst Geringverdiener, denen die maximale Zusatzförderung gezahlt wird, mitunter keine oder nur geringe Entlastungen gegenüber Mietern in Altbauwohnungen haben. Die für die Zusatz- 
förderung erbrachten Mittel ließen sich großenteils einsparen, wenn die EOF auf den direkten oder mittelbaren Erwerb von Belegungsbindungen im preisgünstigen Wohnungsbestand umgestellt würde.

Die Zusatzförderung wird in den meisten Bundesländern als Zuschuß zur Basismiete gewährt, während die Fehlbelegungsabgabe als einkommensabhängiger Aufschlag auf die Sozialmiete ausgestaltet ist. Trotz dieser konzeptionellen Gegensätzlichkeit haben viele Länder die Zusatzförderung in ähnlicher Weise wie die Fehlbelegungsabgabe ausgestaltet. Die Wohnkosten richten sich dort nach dem Gesamteinkommen im Sinne des § 25 II. WoBauG und werden mit zunehmendem Einkommen schrittweise bis zur Höchstmiete angehoben.

Eine Parallele zur Fehlbelegungsabgabe liegt auch darin, daß mit dem Abbau der Förderung zumeist erst oberhalb der Einkommensgrenze nach $\S 25$ begonnen wird. Dies hat zur Folge, daß die EOF nur unzulänglich mit dem Wohngeld verzahnt wird, denn die Wohngeldleistungen laufen bereits bei Einkommen weit unterhalb der Grenze des $\S 25$ aus. Die Transferfunktion aus Wohngeld und Zusatzförderung weist daher unterhalb der Einkommensgrenze einen relativ breiten Bereich auf, in dem sich Veränderungen des Einkommens nicht auf die Wohnkosten auswirken. Durch die treppenförmige Staffelung der Zusatzförderung tritt zudem das Problem auf, daß Haushalte, die mit ihrem Gesamteinkommen knapp unter der Grenze zur nächsten Förderstufe liegen, unter Einbeziehung der Transfers ein höheres verfügbares Einkommen haben als Haushalte, die die Grenze knapp überschreiten.

Aus der Gestaltung der Zusatzförderung resultiert ferner, daß die Anpassungen der Transfers an Veränderungen der Familiengröße völlig unsystematisch und ungleichmäßig ausfallen. Die Aufstockung der Förderung infolge der Geburt eines Kindes kann die Größenordnung des Kindergeldes erreichen, wenn es sich um einen besserverdienenden Haushalt handelt, der vor der Familienvergrößerung keine oder nur eine geringe Zusatzförderung erhalten hat; oder sie kann null betragen, wenn ein Haushalt, der nicht wohngeldberechtigt ist, aufgrund seines niedrigeren Einkommens bereits vor der Geburt die maximale Zusatzförderung erhalten hat.

Eine wichtige Anforderung an die Zusatzförderung ist, daß Wohnwertunterschiede, die in der Basismiete zum Ausdruck kommen, weiterhin "fühlbar“ bleiben. Einige Bundesländer mißachten diesen Grundsatz, indem sie vom Basismietniveau unabhängige Endmieten festlegen, die sich allein an der Einkommenssituation der Mieter orientieren. In Rheinland-Pfalz sowie beim Pilotmodell der baden-württembergischen Kommune Möglingen werden die Wohnkosten durch die Zusatzförderung auf eine pauschale, weder nach der Haushaltsgröße noch dem Wohnwert differenzierte Quote vom Einkommen herab- 
subventioniert. Daneben haben zahlreiche Länder die Zusatzförderung so ausgestaltet, daß die Unterschiede in den Basismieten nicht nur absolut, sondern auch im Verhältnis geringer werden. Die schon in den Basismieten vorgenommene Nivellierung der Mietunterschiede wird durch die Zusatzförderung noch verstärkt.

Außerdem kann es trotz der Zusatzförderung zu gravierenden Fehlsubventionierungen kommen. Dies trifft vor allem auf die Bundesländer zu, in denen die Transfers nur in mehrjährigem Rhythmus an die Einkommensentwicklung der Haushalte angepaßt werden. Paradoxerweise müssen die Mieter gerade in diesen Ländern keine Mitteilung machen, wenn sie im laufenden Bewilligungszeitraum Einkommenssteigerungen erzielen konnten, die eine außerplanmäßige Neufestsetzung der Zusatzförderung begründen. Problematisch ist ferner der Umstand, daß die Transfers am Ende des Förderzeitraumes - unabhängig von der Einkommenssituation der Mieter - auf null zurückgefahren werden und der Investor im gleichen Zeitpunkt die im Rahmen des MHG zulässige Anhebung der Basismieten vornehmen kann. Der Anstieg der Wohnkosten kann für geringverdienende Haushalte, die am Ende des Förderzeitraumes noch die maximale Zusatzförderung erhalten haben, in den meisten Bundesländern eine GröBenordnung von 50 bis $100 \%$ erreichen. Die sprungartige Zunahme der Wohnkosten wird durch das Wohngeld i.d.R. nicht aufzufangen sein und u.U. eine Nachsubventionierung erforderlich machen. Sinnvoller wäre es, die EOF von vornherein so auszugestalten, daß die Zusatzförderung in jährlich abnehmenden Beträgen - z.B. mit einer Degression von 1 DM pro Jahr - über den Bindungszeitraum hinaus gewährt wird.

Die Ausführungen haben gezeigt, daß die für den sozialen Mietwohnungsbau typischen Mängel bei der EOF lediglich gemildert, aber nicht beseitigt werden. Diese Mängel lassen sich großenteils auf die verfehlte Grundkonzeption der Objektförderung zurückführen, die in der Versorgung sozial schwacher Haushalte mit teuren Neubauwohnungen besteht. Sinnvoller wäre es, die im sozialen Mietwohnungsbau angestrebten wohnungspolitischen Ziele - dies sind vor allem die Erhöhung des Wohnungsbestandes, die soziale Absicherung des Wohnens für Geringverdiener und die gezielte Versorgung von Problemgruppen des Wohnungsmarktes - zu entkoppeln und durch den verstärkten Einsatz anderer, eigens dafür konzipierter Instrumente zu verfolgen. Die soziale Absicherung des Wohnens läßt sich am besten dadurch erreichen, daß das Wohngeld aufgestockt und in der Folgezeit häufiger an die Entwicklung der Einkommen und der Mieten angepaßt wird. Um die Versorgung der Problemgruppen des Wohnungsmarktes zu gewährleisten, sollten die Kommunen eine ausreichende Zahl von Belegungsrechten im preisgünstigen Wohnungsbestand erwerben. Die Länder müßten sie dabei durch Mittel aus ihrem Haushalt unterstützen. Dringend geboten ist der Abbau der vom Staat selbst geschaffenen Angebotshemmnisse, 
die vor allem in der restriktiven Bodenpolitik der Kommunen und dem durch hohe Komplexität und zeitliche Unbeständigkeit gekennzeichneten Bau- und Mietrecht liegen.

Für die aufgeführten Reformschritte hat sich insbesondere die Expertenkommission Wohnungspolitik in ihrem Gutachten von 1995 ausgesprochen. Nach Meinung der Experten sollte der soziale Wohnungsbau - zumindest in der Form einer Kombination von Mietverbilligung und Belegungsbindung - nicht mehr weitergeführt werden. Dagegen hat die Bundesregierung in einer Stellungnahme zum Kommissionsbericht die Auffassung vertreten, daß auf den sozialen Wohnungsneubau - allerdings in der reformierten Form der vereinbarten bzw. einkommensorientierten Förderung - ,in absehbarer Zeit nicht verzichtet werden kann" " . Am 2. Mai 1997 legte sie einen Referentenentwurf für eine grundlegende Reform des Wohnungsbaurechts vor, nach dem der erste Förderweg abgeschafft und künftig ausschließlich flexible und einkommensorientierte Förderformen praktiziert werden sollen. ${ }^{2}$ Nicht zuletzt wegen dieser politischen Signale kann davon ausgegangen werden, daß die EOF - wenn auch auf einer neuen rechtlichen Basis - in Zukunft die dominierende Form der sozialen Mietwohnungsbauförderung sein wird.

Eine solche Reform stellt gegenüber der aktuellen Situation eine Verbesserung dar und greift gleichwohl zu kurz. Die Vorschläge der Bundesregierung und ihre Resonanz bei den Oppositionsparteien zeigen aber, daß eine vollständige Abschaffung des sozialen Mietwohnungsbaues politisch nicht durchsetzbar ist. Vor allem politökonomische Gründe sprechen dagegen: Die Mängel des sozialen Wohnungsbaues sind in der Bevölkerung wenig bekannt. Hinzu kommt, daß selektive Vergünstigungen auch bei den Wählern, die leer ausgehen, keineswegs auf Ablehnung stoßen, solange sie das Etikett „,sozial“ tragen. Ein Politiker, der sich für die Abschaffung der Objektförderung einsetzt, wird daher bei den Wählern kaum auf Sympathie stoßen.

1 Deutscher Bundestag (1995), S. 10

2 Vgl. Schwender, H. W., Söfker, W., Zur Reform des Wohnungsbaurechts und des Wohnungsrechts, S. $13 \mathrm{ff}$. 


\section{Anhang}

\section{Übersicht 16: Förderkonditionen in Baden-Württemberg}

\begin{tabular}{|c|c|c|c|c|c|c|c|}
\hline $\begin{array}{l}\text { Gegenstand } \\
\text { der Förderung }\end{array}$ & \multicolumn{7}{|c|}{$\begin{array}{l}\text { Neuschaffung von allgemeinen Mietwohnungen durch Neubau, Ausbau, } \\
\text { Umbau und Erweiterungsmaßnahmen }\end{array}$} \\
\hline \multirow[t]{11}{*}{ Grundförderung } & \multicolumn{7}{|c|}{ Förderdarlehen OS 10 (10 Jahre) } \\
\hline & \multicolumn{2}{|l|}{ Gemeinde-Kategorie: } & \multicolumn{2}{|l|}{ I } & II & \multicolumn{2}{|r|}{ III } \\
\hline & \multicolumn{2}{|c|}{ Beträge in DM/qm: } & \multicolumn{2}{|c|}{\begin{tabular}{|l|l}
2.100 & \\
\end{tabular}} & \multicolumn{2}{|c|}{\begin{tabular}{l|l}
1.800 & \\
\end{tabular}} & 1.600 \\
\hline & \multicolumn{7}{|c|}{$\begin{array}{l}\text { Zuschlag von } 150 \mathrm{DM} / \mathrm{qm} \text { bei Nichtinanspruchnahme der degressiven AfA } \\
\text { Zins: Kapitalmarktzins minus 4,10\% in den ersten zwei Jahren nach } \\
\text { angenommener Bezugsfertigkeit; danach alle zwei Jahre Anhebung um } \\
\text { 0,25 Prozentpunkte; ab 11. Jahr Kapitalmarktzins } \\
\text { Tilgung: } 1 \text { bis 3\% zuzüglich der durch die Tilgung ersparten Zinsen } \\
\text { Darlehenskosten: einmalige Bearbeitungsgebühr von } 1 \% \text { und einmalige } \\
\text { Geldbeschaffungskosten von 0,5\% } \\
\text { oder: Förderdarlehen OS } 20 \text { (20 Jahre) }\end{array}$} \\
\hline & \multirow{2}{*}{\begin{tabular}{|l|} 
Gemeinde- \\
Kategorie \\
\end{tabular}} & \multicolumn{4}{|c|}{ I } & \multirow[t]{2}{*}{ II } & \multirow[t]{2}{*}{ III } \\
\hline & & Stuttgart & $>100.00$ & Einw. & sonst & & \\
\hline & Beträge in DM/qm: & 1.000 & 90 & & 750 & 675 & \begin{tabular}{|l|}
600 \\
\end{tabular} \\
\hline & \multicolumn{7}{|c|}{$\begin{array}{l}\text { Zuschlag von } 50 \mathrm{DM} / \mathrm{qm} \text { bei Nichtinanspruchnahme der degressiven AfA } \\
\text { Zins: } 0 \% \text { in den ersten zwei Jahren nach angenommener Bezugsfertigkeit, } \\
\text { danach alle zwei Jahre Anhebung um 0,25 Prozentpunkte } \\
\text { Tilgung: mindestens } 1 \% \text { pro Jahr aus dem Ursprungskapital zuzüglich ersparter } \\
\text { Zinsen; danach Rückzahlung oder Umschuldung zu Kapitalmarktbedingungen } \\
\text { Darlehenskosten: einmalige Bearbeitungsgebühr von } 0,5 \text { bis } 1 \% \text { ( je nach } \\
\text { Darlehenshöhe) sowie laufende Verwaltungskosten von } 0,5 \% \\
\text { oder: Förderung mit Aufwendungszuschüssen }\end{array}$} \\
\hline & \multicolumn{3}{|c|}{ Gemeinde-Kategorie: } & I & & II & III \\
\hline & \multicolumn{4}{|c|}{\begin{tabular}{|l|r|} 
Zuschuß pro Monat in DM/qm - 1. Jahr: & 7,90 \\
Absenkung der Zuschüsse um 0,60 DM pro Jahr
\end{tabular}} & & 7,00 & 6,60 \\
\hline & \multicolumn{7}{|c|}{$\begin{array}{l}\text { Der Zuschlag für die Nichtinanspruchnahme der degressiven AfA wird als } \\
\text { Baukostenzuschuß in Höhe von } 50 \mathrm{DM} / \mathrm{qm} \text { gewährt. } \\
\text { Bei } 20 \text { jähriger Bindung kann neben den Aufwendungszuschüssen ein Bau- } \\
\text { kostenzuschuß von bis zu } 200 \mathrm{DM} / \mathrm{qm} \text { (für maximal } 70 \text { qm) gewährt werden. }\end{array}$} \\
\hline
\end{tabular}




\section{Übersicht 16 (Fortsetzung)}

\begin{tabular}{|c|c|c|c|c|c|c|c|}
\hline $\begin{array}{l}\text { Belegungs- } \\
\text { bindung }\end{array}$ & \multicolumn{7}{|c|}{$\begin{array}{l}\text { Belegungsrecht / Belegungsmix: } \\
\text { Das Belegungsrecht liegt bei der die Zusatzförderung erbringenden Gemeinde. } \\
\text { Bei der Erstbelegung soll mindestens die Hälfte der Wohnungen mit Haus- } \\
\text { halten belegt werden, die die Grenze des § } 25 \mathrm{II} \text {. WoBauG einhalten. } \\
\text { Wird keine Zusatzförderung geleistet, kann die 10jährige Belegungsbindung } \\
\text { (OS-10-Darlehen) unter bestimmten Voraussetzungen auch durch } \\
\text { Unterbringung im nicht gebundenen Wohnungsbestand des Investors } \\
\text { erfüllt werden. Die mittelbar gebundene Wohnung muß nach Größe und } \\
\text { Raumzahl mit der neugebauten Wohnung vergleichbar sein und darf nur } \\
\text { Mietern mit einem Einkommen bis zur Grenze des § } 25 \text { zu der für diesen } \\
\text { Berechtigtenkreis vorgesehenen Endmiete überlassen werden. Die Miete der } \\
\text { neugebauten Wohnung darf die Basismiete i.d.R. nicht überschreiten. } \\
\text { Bindungsdauer: } \\
10 \text { Jahre (OS-10-Darlehen) oder } 20 \text { Jahre (OS-20-Darlehen) }\end{array}$} \\
\hline \multirow[t]{5}{*}{ Basismiete } & \multicolumn{7}{|c|}{ Bei Erstvermietung: } \\
\hline & \multicolumn{5}{|c|}{\begin{tabular}{|l|l|} 
Gemeinde- & I \\
\cline { 2 - 2 }
\end{tabular}} & \multirow[t]{2}{*}{ II } & \multirow[t]{2}{*}{ III } \\
\hline & Kategorie: & \begin{tabular}{|l|} 
Stuttgart \\
\end{tabular} & \multicolumn{2}{|c|}{$>100.000$ Einw. } & sonst & & \\
\hline & DM/qm, nettokalt: & 14,00 & \multicolumn{2}{|c|}{13,50} & \begin{tabular}{|l|l|}
13,00 \\
\end{tabular} & 12,00 & 11,00 \\
\hline & \multicolumn{7}{|c|}{$\begin{array}{l}\text { Dynamisierung: } \\
\text { Anhebung um bis zu } 0,60 \mathrm{DM} / \mathrm{qm} \text { alle zwei Jahre }\end{array}$} \\
\hline \multirow[t]{9}{*}{ Subjektförderung } & \multicolumn{7}{|c|}{$\begin{array}{l}\text { Förderart: Zuschuß über den Miete } \\
\text { mietung durch die Gemeinde mögli } \\
\text { Förderbeträge in DM/qm: }\end{array}$} \\
\hline & \multirow{2}{*}{$\begin{array}{l}\text { Gemeinde- } \\
\text { Kategorie: }\end{array}$} & \multicolumn{6}{|c|}{ Einkommen bis zur Grenze des $\S 25$ plus $\ldots$} \\
\hline & & \begin{tabular}{|l|}
$0 \%$ \\
\end{tabular} & $10 \%$ & $20 \%$ & & $30 \%$ & $40 \%$ \\
\hline & \begin{tabular}{|l|l|} 
I & Stuttgart \\
\end{tabular} & 5,00 & 4,00 & 3,00 & & 2,00 & 1,00 \\
\hline & $>100.000$ Einw. & 4,75 & 4,00 & 3,00 & & 2,00 & 1,00 \\
\hline & sonst & 4,50 & 3,75 & 3,00 & & 2,00 & 1,00 \\
\hline & II & 3,75 & 3,00 & 2,35 & & 1,50 & 0,75 \\
\hline & III & 3,00 & 2,25 & 1,50 & & 0,75 & 0,00 \\
\hline & \multicolumn{7}{|c|}{$\begin{array}{l}\text { Kommunale Mitfinanzierung: 50\%; in den ersten zwölf Monaten ab Erstbezug } \\
\text { übernimmt das Land den Gemeindeanteil bis zu einem Betrag von } 2.000 \text { DM. } \\
\text { Die Zusatzförderung kann auch (zu 100\%) durch Dritte, z.B. den } \\
\text { Arbeitgeber, erbracht werden. } \\
\text { Einkommensprüfung } \\
\text { i.d.R. alle zwei Jahre }\end{array}$} \\
\hline Quelle & \multicolumn{7}{|c|}{$\begin{array}{l}\text { Verwaltungsvorschrift des Wirtschaftsministeriums zum Landeswohnungs- } \\
\text { bauprogramm } 1997 \text { (VwV-LWBPr 1997) vom 20. Dezember 1996, in: Gemein- } \\
\text { sames Amtsblatt des Landes Baden-Württemberg 1997, S. } 51\end{array}$} \\
\hline
\end{tabular}




\section{Übersicht 17: Förderkonditionen in Bayern}

\begin{tabular}{|c|c|c|c|c|c|c|}
\hline $\begin{array}{l}\text { Gegenstand } \\
\text { der Förderung }\end{array}$ & \multicolumn{6}{|c|}{$\begin{array}{l}\text { Neubau von Miet- und Genossenschaftswohnungen an Standorten mit einem } \\
\text { besonders dringlichen Wohnungsbedarf }\end{array}$} \\
\hline \multirow[t]{6}{*}{ Grundförderung } & \multicolumn{6}{|c|}{$\begin{array}{l}\text { Baudarlehen der Bayerischen Landesbodenkreditanstalt } \\
\text { Festbeträge in DM: }\end{array}$} \\
\hline & & 1 Zimmer & 2 Zimmer & 3 Zimmer & 4 Zimmer & 5 Zimmer \\
\hline & Gebietskategorie I & 30.300 & 44.800 & 59.400 & 73.900 & 85.800 \\
\hline & Gebietskategorie II & 23.100 & 34.300 & 45.400 & 56.500 & 65.600 \\
\hline & Gebietskategorie III & \begin{tabular}{|l|}
19.000 \\
\end{tabular} & 28.000 & 37.200 & 46.200 & 53.700 \\
\hline & \multicolumn{6}{|c|}{$\begin{array}{l}\text { Erhöhung um maximal } 10 \% \text { bei Nichtinanspruchnahme der degressiven AfA } \\
\text { Zins: 0\% im 15jährigen Bindungszeitraum, danach } 7 \% \\
\text { Tilgung: mindestens } 1 \% \text { jährlich unter Zuwachs der ersparten Zinsen. } \\
\text { Darlehenskosten: Einmaliger Verwaltungskostenbeitrag von } 2 \% \text {, ferner } \\
\text { ein laufender Verwaltungskostenbeitrag von 0,5\% jährlich vom Nennbetrag } \\
\text { des Darlehens; sinkt das Darlehen durch planmäßige Tilgung unter die Hälfte } \\
\text { des Nennbetrages, dann wird der laufende Verwaltungskostenbeitrag aus } \\
\text { der Hälfte des Nennbetrages errechnet. }\end{array}$} \\
\hline $\begin{array}{l}\text { Belegungs- } \\
\text { bindung }\end{array}$ & \multicolumn{6}{|c|}{$\begin{array}{l}\text { Einkommensgrenze beim Bezug: } \\
\S 25 \text { II. WoBauG plus } 30 \% \\
\text { Belegungsrecht / Belegungsmix: } \\
\text { Die zuständige Stelle hat mindestens drei Wohnungssuchende zur Auswahl } \\
\text { zu stellen. Bei der Erst- und Wiederbelegung soll mindestens die Hälfte } \\
\text { der Wohnungen mit Haushalten belegt werden, deren Einkommen die Grenze } \\
\text { des } § 25 \text { II. WoBauG nicht überschreiten. } \\
\text { Bindungsdauer: } \\
15 \text { Jahre }\end{array}$} \\
\hline Basismiete & \multicolumn{6}{|c|}{$\begin{array}{l}\text { Bei Erstvermietung: } \\
\text { Die höchstzulässige Anfangsmiete orientiert sich am unteren Rand der } \\
\text { ortsüblichen Erstvermietungsmiete für vergleichbaren neugeschaffenen } \\
\text { Wohnraum. Sie wird im Einzelfall bei der Bewilligung im Benehmen mit der } \\
\text { Gemeinde festgelegt und im Darlehensvertrag mit dem Bauherrn vereinbart. } \\
\text { Dynamisierung: } \\
\text { Für Mieterhöhungen während der Bindungsdauer gilt § } 2 \text { MHG mit der } \\
\text { Maßgabe, daß der untere Rand der Vergleichsmiete eingehalten werden muß. } \\
\text { Eine Erhöhung nach } \S 5 \text { MHG ist ausgeschlossen. }\end{array}$} \\
\hline
\end{tabular}




\section{Übersicht 18 (Fortsetzung)}

\begin{tabular}{|c|c|c|c|c|c|c|c|c|}
\hline $\begin{array}{l}\text { Belegungs- } \\
\text { bindung }\end{array}$ & \multicolumn{8}{|c|}{$\begin{array}{l}\text { Belegungsmix: } \\
\text { Mindestens } 30 \% \text {, höchstens 50\% der Wohnungen eines Objektes sind an } \\
\text { Haushalte zu vermieten, deren Einkommen die Grenze des } \S 25 \mathrm{II} \text {. WoBauG } \\
\text { nicht überschreitet. } \\
\text { Bindungsdauer: } \\
\text { Die vertraglich vereinbarten Mietpreisbegrenzungen enden für Mieter, deren } \\
\text { Einkommen bei Ablauf des } 15 \text {. Kalenderjahres nach Bezugsfertigkeit die Grenze } \\
\text { des } \S 25 \text { II. WoBauG } \\
\text { - nicht übersteigt: nach } 27 \text { Jahren (gerechnet ab Bezugsfertigkeit) } \\
\text { - um nicht mehr als } 20 \% \text { übersteigt: nach } 22 \text { Jahren } \\
\text { - um nicht mehr als } 60 \% \text { übersteigt: nach } 17 \text { Jahren } \\
\text { - um mehr als } 60 \% \text { übersteigt: nach } 15 \text { Jahren. }\end{array}$} \\
\hline Basismiete & \multicolumn{8}{|c|}{$\begin{array}{l}\text { Bei Erstvermietung: } \\
15 \mathrm{DM} / \mathrm{qm} \text {, nettokalt } \\
\text { Dynamisierung: } \\
\text { Anhebung um } 0,40 \mathrm{DM} / \mathrm{qm} \text { alle } 15 \text { Monate während des } 15 \text { jährigen Grund- } \\
\text { förderungszeitraumes (Degression der Grundförderung); die Vertragsmiete am } \\
\text { Ende des (ggf. verlängerten) Bindungszeitraumes beträgt 19,40 DM/qm. }\end{array}$} \\
\hline Subjektförderung & \multicolumn{8}{|c|}{$\begin{array}{l}\text { Zusatzförderung: } \\
\text { Förderart: Zuschuß über den Mieter }\end{array}$} \\
\hline & \begin{tabular}{|l|}
$\begin{array}{l}\text { Einkommen bis zur Grenze } \\
\text { des } \S 25 \text { plus ... }\end{array}$ \\
Beträge in DM/am:
\end{tabular} & $\frac{0 \%}{7,00}$ & $\frac{10 \%}{6,00}$ & $\frac{20 \%}{5,00}$ & $\frac{30 \%}{4.00}$ & $\frac{40 \%}{3,00}$ & $\frac{50 \%}{2.00}$ & $\frac{60 \%}{1.00}$ \\
\hline & \multicolumn{8}{|c|}{$\begin{array}{l}\text { Leistungszeitraum: } 15 \text { Jahre. Für Mieter, deren Einkommen die Grenze des } \S 25 \\
\text { nach } 15 \text { Jahren um } 0 \text { (20)\% überschreitet, wird der Leistungszeitraum um } \\
10 \text { (5) Jahre verlängert. Die Zusatzförderung wird im Verlängerungszeitraum } \\
\text { pro Jahr um 0,40 DM abgebaut. } \\
\text { Einkommensprüfung: } \\
\text { alle drei Jahre }\end{array}$} \\
\hline Quelle & \multicolumn{8}{|c|}{ Informationspapier der Berliner Investitionsbank (Stand: Mai 1996) } \\
\hline
\end{tabular}




\section{Übersicht 19: Förderkonditionen in Brandenburg}

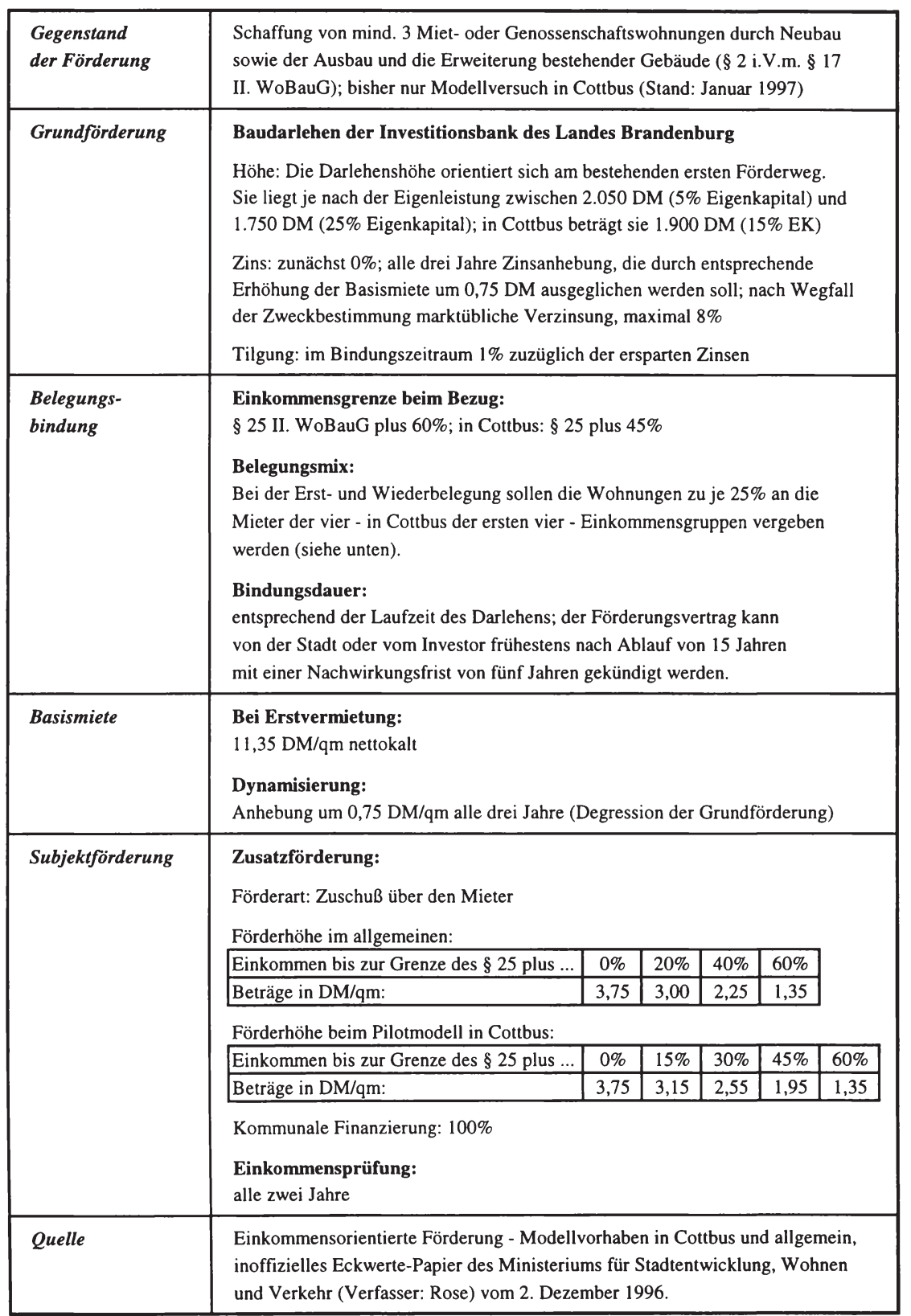




\section{Übersicht 20a (Fortsetzung)}

\begin{tabular}{|c|c|c|c|c|c|c|}
\hline \multirow{4}{*}{ Basismiete } & \multicolumn{6}{|c|}{ Bei Erstvermietung im Jahr 1997: } \\
\hline & \multicolumn{2}{|c|}{ Wohnungsgröße: } & unter $60 \mathrm{qm}$ & \multicolumn{2}{|c|}{ 60-79,99 qm } & ab $80 \mathrm{qm}$ \\
\hline & \multicolumn{2}{|c|}{ nettokalt, in DM/qm: } & 12,00 & & 11,50 & 11,20 \\
\hline & \multicolumn{6}{|c|}{$\begin{array}{l}\text { Die Beträge erhöhen sich ab den Bezugsfertigkeiten } 1998 \text { um 0,30 DM/qm } \\
\text { pro Kalenderjahr. }\end{array}$} \\
\hline \multirow[t]{9}{*}{ Subjektförderung } & \multirow{2}{*}{\multicolumn{6}{|c|}{$\begin{array}{l}\text { Zusatzförderung: } \\
\text { Förderart: Aufwendungszuschuß an den Investor mit schuldbefreiender } \\
\text { Wirkung für den Mieter }\end{array}$}} \\
\hline & & & & & & \\
\hline & $\begin{array}{l}\text { Fall- } \\
\text { gruppe: }\end{array}$ & \multicolumn{3}{|c|}{$\begin{array}{l}\text { Einkommen bis zur Grenze des } \\
\S 25 \text { i.V.m. § } 3 \text { Abs. } 1 \text { BremAFWoG . }\end{array}$} & \multicolumn{2}{|l|}{\begin{tabular}{|l} 
Beträge \\
in DM/qm:
\end{tabular}} \\
\hline & $\mathrm{A}$ & \multicolumn{3}{|c|}{ minus $35 \%$} & \multicolumn{2}{|l|}{2,50} \\
\hline & 1 & \multicolumn{3}{|c|}{ minus $25 \%$} & \multicolumn{2}{|l|}{2,40} \\
\hline & 2 & \multicolumn{3}{|c|}{ minus $10 \%$} & \multicolumn{2}{|l|}{1,60} \\
\hline & 3 & \multicolumn{3}{|c|}{ plus/minus $0 \%$} & \multicolumn{2}{|l|}{0,80} \\
\hline & 4 & \multicolumn{3}{|c|}{ plus $10 \%$} & \multicolumn{2}{|l|}{-} \\
\hline & \multicolumn{6}{|c|}{$\begin{array}{l}\text { Einkommensprüfung: } \\
\text { zunächst nach Ablauf des vierten und des achten Förderungsjahres }\end{array}$} \\
\hline Quelle & \multicolumn{6}{|c|}{$\begin{array}{l}\text { Richtlinien zur Durchführung der einkommensorientierten Förderung (EoF) von } \\
\text { Mietwohnungen im Lande Bremen - 4. Förderungsweg - vom 20. September } \\
\text { 1996, in: Amtsblatt der Freien Hansestadt Bremen vom 14. November 1996, } \\
\text { S. } 761\end{array}$} \\
\hline
\end{tabular}




\section{Übersicht 20b: Förderkonditionen in Bremen - Kombimodell}

\begin{tabular}{|c|c|c|c|c|c|}
\hline $\begin{array}{l}\text { Gegenstand } \\
\text { der Förderung }\end{array}$ & \multicolumn{5}{|c|}{$\begin{array}{l}\text { Förderung neugeschaffener Mietwohnungen aufgrund einer mittelbaren } \\
\text { Belegungs- und Mietpreisbindung einer mindestens gleichen Anzahl nicht } \\
\text { geförderter Wohnungen aus dem Bestand des Investors }\end{array}$} \\
\hline Grundförderung & \multicolumn{5}{|c|}{$\begin{array}{l}\text { siehe Grundmodell: Förderung über Bundesdarlehen, ggf. das kommunale } \\
\text { Zusatzdarlehen und die Aufwendungszuschüsse I und II. Wegen der ggf. } \\
\text { höheren Basismieten beim neugeschaffenen Wohnraum (siehe unten) kann } \\
\text { durch die Aufwendungszuschüsse und die Basismiete eine über } 17 \mathrm{DM} / \mathrm{qm} \\
\text { hinausgehende Aufwandsdeckung erreicht werden. Sie beträgt 17,80 DM/qm } \\
\text { bei der Fallgruppe } 5 \text { und } 18,60 \mathrm{DM} / \mathrm{qm} \text { bei der Fallgruppe } 6 \text { (siehe unten). }\end{array}$} \\
\hline $\begin{array}{l}\text { Belegungs- } \\
\text { bindung }\end{array}$ & \multicolumn{5}{|c|}{$\begin{array}{l}\text { Einkommensgrenze beim Bezug: } \\
\text { Neugeschaffene Mietwohnung: } \S 25 \text { II. WoBauG i.V.m. } \S 3 \text { Abs. } 1 \\
\text { BremAFWoG plus } 40 \% \text {; } \\
\text { Bestandswohnung: } \S 25 \text { II. WoBauG i.V.m. § } 3 \text { Abs. } 1 \text { BremAFWoG minus 10\% } \\
\text { Belegungsrecht: } \\
\text { siehe Grundmodell } \\
\text { Bindungsdauer: } \\
\text { Neugeschaffene Mietwohnung: fünf Jahre; Bestandswohnung: } 25 \text { Jahre }\end{array}$} \\
\hline Basismiete & \multicolumn{5}{|c|}{$\begin{array}{l}\text { Bei Erstvermietung 1997: } \\
\text { einkommensorientierte Mietsätze (siehe unten) } \\
\text { Dynamisierung: } \\
\text { Neugeschaffene Whg.: Erhöhung im fünfjährigen Bindungszeitraum gemäß } \\
\text { MHG, allerdings unter Ausschluß der } \S \S 3,5 \text { und } 10 \text { a MHG } \\
\text { Bestandswohnung: Anhebung um höchstens } 0,30 \mathrm{DM} / \mathrm{qm} \text { alle zwölf Monate }\end{array}$} \\
\hline \multirow[t]{12}{*}{ Subjektförderung } & \multicolumn{5}{|c|}{ Einkommensorientierte Mietsätze (ohne Differenzierung der Grundförd.) } \\
\hline & \multirow{2}{*}{\multicolumn{2}{|c|}{\begin{tabular}{|l|l|}
$\begin{array}{l}\text { Fall- } \\
\text { gruppe: }\end{array}$ & $\begin{array}{l}\text { Einkommen bis zur Grenze } \\
\text { des § 25 i.V.m. § 3 Abs. } 1 \\
\text { BremAFWoG ... }\end{array}$ \\
\end{tabular}}} & \multicolumn{3}{|c|}{ Wohnungsgröße: } \\
\hline & & & unter $60 \mathrm{qm}$ & $60-79,99 \mathrm{qm}$ & $\mathrm{ab} 80 \mathrm{qm}$ \\
\hline & \multicolumn{5}{|c|}{ Neugeschaffene Whg.: Erstvermietung 1997, 1. Jahr, in DM/qm, nettokalt: } \\
\hline & 5 & plus $25 \%$ & 12,80 & \begin{tabular}{|l|l|}
12,30 \\
\end{tabular} & 12,00 \\
\hline & 6 & plus $40 \%$ & 13,60 & 13,10 & 12,80 \\
\hline & \multicolumn{5}{|c|}{\begin{tabular}{|l|l} 
Mietsätze der Fallgruppen A bis 3: siehe Grundmodell \\
\end{tabular}} \\
\hline & \multicolumn{5}{|c|}{ Bestandswohnung: Erstvermietung 1997, 1. Jahr, in DM/qm, nettokalt: } \\
\hline & $\mathrm{A}$ & minus $35 \%$ & 8,01 & 7,56 & 7,29 \\
\hline & 1 & minus $25 \%$ & 8,10 & 7,65 & 7,38 \\
\hline & 2 & minus $10 \%$ & 8,82 & \begin{tabular}{|l|l}
8,37 \\
\end{tabular} & 8,10 \\
\hline & \multicolumn{5}{|c|}{$\begin{array}{l}\text { Die Beträge erhöhen sich mit jedem Kalenderjahr - beginnend für die } \\
\text { förderungsgemäße Vermietung ab 1. Januar 1998, um 0,30 DM/qm. } \\
\text { Einkommensprüfung: } \\
\text { Neugeschaffene Mietwohnung: nach Bezug keine weitere Einkommensprüfung } \\
\text { Bestandswohnung: wie im Grundmodell }\end{array}$} \\
\hline Quelle & \multicolumn{5}{|c|}{ siehe Grundmodell } \\
\hline
\end{tabular}




\section{Übersicht 20c: Förderkonditionen in Bremen - „Modell 1+3“}

\begin{tabular}{|c|c|c|c|c|}
\hline $\begin{array}{l}\text { Gegenstand } \\
\text { der Förderung }\end{array}$ & \multicolumn{4}{|c|}{$\begin{array}{l}\text { Förderung der Schaffung neuen Wohnraumes durch Ausbau, Erweiterung } \\
\text { oder Modernisierung ( } \S 17 \text { II. WoBauG) unter der Voraussetzung, daß der } \\
\text { Bauherr aus seinem Wohnungsbestand i.d.R. drei weitere mietpreis- und } \\
\text { belegungsfreie Wohnungen ohne Förderung umfassend modernisiert und } \\
\text { für diese Mietwohnungen Belegungsbindungen eingeht. }\end{array}$} \\
\hline \multirow[t]{8}{*}{ Grundförderung } & \multicolumn{4}{|c|}{$\begin{array}{l}\text { siehe Grundmodell: Förderung über Bundesdarlehen, ggf. das kommunale } \\
\text { Zusatzdarlehen und die Aufwendungszuschüsse. Diese haben bei } \\
\text { Bezugsfertigkeit } 1997 \text { - abweichend vom Grundmodell - folgende Höhe: }\end{array}$} \\
\hline & Wohnungsgröße: & unter $60 \mathrm{qm}$ & $60-79,99 \mathrm{qm}$ & ab $80 \mathrm{qm}$ \\
\hline & \multicolumn{4}{|c|}{ Ausbau bestehender Gebäude ( $\S 17$ Abs. 1 II. WoBauG) } \\
\hline & Zuschuß I (DM/qm): & - & - & - \\
\hline & Zuschuß II (DM/qm): & - & 0,50 & 0,80 \\
\hline & \multicolumn{4}{|c|}{\begin{tabular}{|l|} 
Erweiterung bestehender Gebäude ( $(17$ Abs. 2 II. WoBauG) \\
\end{tabular}} \\
\hline & Zuschuß I (DM/qm): & 0,50 & 0,50 & 0,50 \\
\hline & Zuschuß II (DM/qm): & 2,00 & 2,50 & 2,80 \\
\hline $\begin{array}{l}\text { Belegungs- } \\
\text { bindung }\end{array}$ & \multicolumn{4}{|c|}{$\begin{array}{l}\text { Einkommensgrenze beim Bezug: } \\
\S 25 \text { II. WoBauG i.V.m. § } 3 \text { Abs. 1BremAFWoG plus } 10 \% \\
\text { Belegungsrecht: } \\
\text { Sowohl die neugeschaffene Wohnung als auch die zusätzlichen modernisierten } \\
\text { Bestandswohnungen unterliegen dem Wohnungsnotstandsvertrag. } \\
\text { Bindungsdauer: } \\
25 \text { Jahre }\end{array}$} \\
\hline Basismiete & \multicolumn{4}{|c|}{$\begin{array}{l}\text { Bei Erstvermietung: } \\
\text { neugeschaffene Wohnung: wie im Grundmodell } \\
\text { zusätzlich modernisierte Bestandswohnungen: einkommensabhängige } \\
\text { Vertragsmieten (siehe unten) } \\
\text { Dynamisierung: } \\
\text { Anhebung um } 0,30 \mathrm{DM} / \mathrm{qm} \text { alle zwölf Monate }\end{array}$} \\
\hline Subjektförderung & \multicolumn{4}{|c|}{$\begin{array}{l}\text { Zusatzförderung: } \\
\text { neugeschaffene Wohnung: wie im Grundmodell; } \\
\text { zusätzlich modernisierte Bestandswohnungen: einkommensabhängige } \\
\text { Vertragsmieten; sie entsprechen den Endmieten im Grundmodell } \\
\text { (Basismiete minus Zusatzförderung) } \\
\text { Einkommensprüfung: } \\
\text { neugeschaffene Wohnung: wie im Grundmodell } \\
\text { zusätzlich modernisierte Bestandswohnungen: keine Einkommensprüfung }\end{array}$} \\
\hline Quelle & \multicolumn{4}{|l|}{ siehe Grundmodell } \\
\hline
\end{tabular}




\section{Übersicht 21: Förderkonditionen in Hessen}

\begin{tabular}{|c|c|c|c|c|}
\hline $\begin{array}{l}\text { Gegenstand } \\
\text { der Förderung }\end{array}$ & \multicolumn{4}{|c|}{$\begin{array}{l}\text { Schaffung von abgeschlossenen Mietwohnungen durch Neubau und } \\
\text { Maßnahmen nach } \S 17 \text { II. WoBauG (Ausbau, Erweiterung, Modernisierung) }\end{array}$} \\
\hline \multirow[t]{9}{*}{ Grundförderung } & \multicolumn{4}{|l|}{ Baudarlehen des Landes } \\
\hline & Mietenstufe nach Anlage 1 zur WoGV: & 1 und 2 & 3 und 4 & 5 und 6 \\
\hline & Beträge in DM: & 1.150 & 1.350 & 1.600 \\
\hline & \multirow{6}{*}{\multicolumn{4}{|c|}{$\begin{array}{l}\text { Zins und Tilgung nach (a) oder (b): } \\
\text { a) Zins: zunächst } 0 \% \text {; dann Anhebung gemäß Dynamisierung der Basismiete } \\
\text { Tilgung: nicht festgelegt } \\
\text { b) Zins: } 0 \% \text { in den ersten } 30 \text { Jahren, dann } 6 \% \\
\text { Tilgung: } 1 \% \text { im 1. bis } 15 \text {. Jahr, } 2 \% \text { im } 16 \text {. bis } 30 \text {. Jahr; danach } 3 \% \text {; } \\
\text { die Annuität beträgt ab dem } 31 \text {. Jahr } 6,3 \% \text { des ursprünglichen } \\
\text { Darlehensbetrages } \\
\text { Darlehenskosten: einmaliges Bearbeitungsentgelt von } 1 \% \text { des Baudarlehens } \\
\text { und laufender jährlicher Verwaltungskostenbeitrag in Höhe von } 0,3 \% \\
\text { des Baudarlehens }\end{array}$}} \\
\hline & & & & \\
\hline & & & & \\
\hline & & & & \\
\hline & & & & \\
\hline & & & & \\
\hline \multirow[t]{12}{*}{$\begin{array}{l}\text { Belegungs- } \\
\text { bindung: }\end{array}$} & \multirow{12}{*}{\multicolumn{4}{|c|}{$\begin{array}{l}\text { Einkommensgrenze beim Bezug: } \\
\text { wie im hessischen Mietwohnungsbauprogramm } \\
\text { Belegungsmix: } \\
\text { Bei Erst- und Wiederbelegung sollen mindestens } 50 \% \text { der insgesamt } \\
\text { geförderten Wohnfläche Wohnungssuchenden überlassen werden, deren } \\
\text { Einkommen die Grenze des } \S 25 \text { II. WoBauG nicht übersteigt (Nutzergruppe 1), } \\
\text { sofern kein anderes Nutzungsverhältnis vereinbart ist. Die restlichen } \\
\text { Wohnungen sind an Wohnberechtigte zu vermieten, die die } \\
\text { Einkommensgrenzen des hessischen Mietwohnungsbauprogramms } \\
\text { einhalten (Nutzergruppe } 2 \text { ). } \\
\text { Belegungsrecht: } \\
\text { Die für die Nutzergruppe } 1 \text { bestimmten Wohnungen sind nach dem } \\
\text { Verfahren gemäß §§ } 4 \text { - } 5 \text { a WoBindG zu belegen, die übrigen Wohnungen } \\
\text { durch den Vermieter nach Vorlage einer Berechtigungsbescheinigung } \\
\text { für Wohnungen der vereinbarten Förderung. } \\
\text { Bindungsdauer: } \\
\text { mindestens } 30 \text { Jahre }\end{array}$}} \\
\hline & & & & \\
\hline & & & & \\
\hline & & & & \\
\hline & & & & \\
\hline & & & & \\
\hline & & & & \\
\hline & & & & \\
\hline & & & & \\
\hline & & & & \\
\hline & & & & \\
\hline & & & & \\
\hline Basismiete & \multirow{3}{*}{\multicolumn{4}{|c|}{$\begin{array}{l}\text { Bei Erstvermietung: } \\
\text { Die Basismiete wird von der Kommune in Anlehnung an die Höchstmieten } \\
\text { im hessischen Mietwohnungsbauprogramm festgelegt. Sie ist mit dem Land } \\
\text { abzustimmen. } \\
\text { Dynamisierung: } \\
\text { je nach Einzelfall }\end{array}$}} \\
\hline & & & & \\
\hline & & & & \\
\hline
\end{tabular}




\section{Übersicht 21 (Fortsetzung)}

\begin{tabular}{|l|l|}
\hline Subjektförderung & Zusatzförderung: \\
& Förderart: Die Kommune gewährt ein Darlehen mit einem einkommensabhängig \\
gestalteten Zins oder gewährt einen Zuschuß über den Mieter oder an den \\
Vermieter. \\
Höhe der Zusatzförderung: Die Kommune legt in Anlehnung an die Einstiegs- \\
miete im ersten Förderweg eine Mindestmiete fest, die mit dem Land abzustim- \\
men ist. Die Basismiete und Mindestmiete bilden zusammen mit der jeweils maß- \\
geblichen Einkommensgrenze die Eckwerte für eine Tabelle zur individuellen \\
einkommensorientierten Mietabstufung, die ebenfalls mit dem Land abgestimmt \\
werden muß. Die Tabelle kann eine gesonderte Mietbelastung für Haushalte \\
vorsehen, deren Einkommen im Bindungszeitraum über die bei Erstbelegung \\
zulässigen Einkommensgrenzen hinaus gestiegen ist. Sie ist Bestandteil der \\
Förderungsvereinbarung. \\
Einkommensprüfung: \\
mindestens alle zwei Jahre
\end{tabular}

\section{Übersicht 22: Förderkonditionen in Niedersachsen}

\begin{tabular}{|l|l|}
\hline $\begin{array}{l}\text { Gegenstand } \\
\text { der Förderung }\end{array}$ & $\begin{array}{l}\text { bisher nur Modellversuch in Wolfsburg auf der Grundlage des } \\
\S 88 \mathrm{~d} \text { II. WoBauG (Programmjahr 1994) }\end{array}$ \\
\hline Grundförderung & Niedersachsen allgemein: je nach Fördervereinbarung. \\
& $\begin{array}{l}\text { Vereinbarung beim Pilotmodell in Wolfsburg (Gesamtkosten: 2,5 Mio. DM): } \\
\text { Baudarlehen des Landes } \\
\text { Höhe: } 600.000 \mathrm{DM} \\
\text { Zusatzdarlehen des Landes } \\
\text { Höhe: } 447.000 \mathrm{DM}\end{array}$ \\
& $\begin{array}{l}\text { Baudarlehen der Stadt Wolfsburg } \\
\text { Höhe: } 274.000 \text { DM }\end{array}$ \\
& $\begin{array}{l}\text { Durch die Zinsvergünstigung wird die Kostenmiete auf 11,50 DM/qm } \\
\text { herabsubventioniert. }\end{array}$ \\
\hline
\end{tabular}




\section{Übersicht 22 (Fortsetzung)}

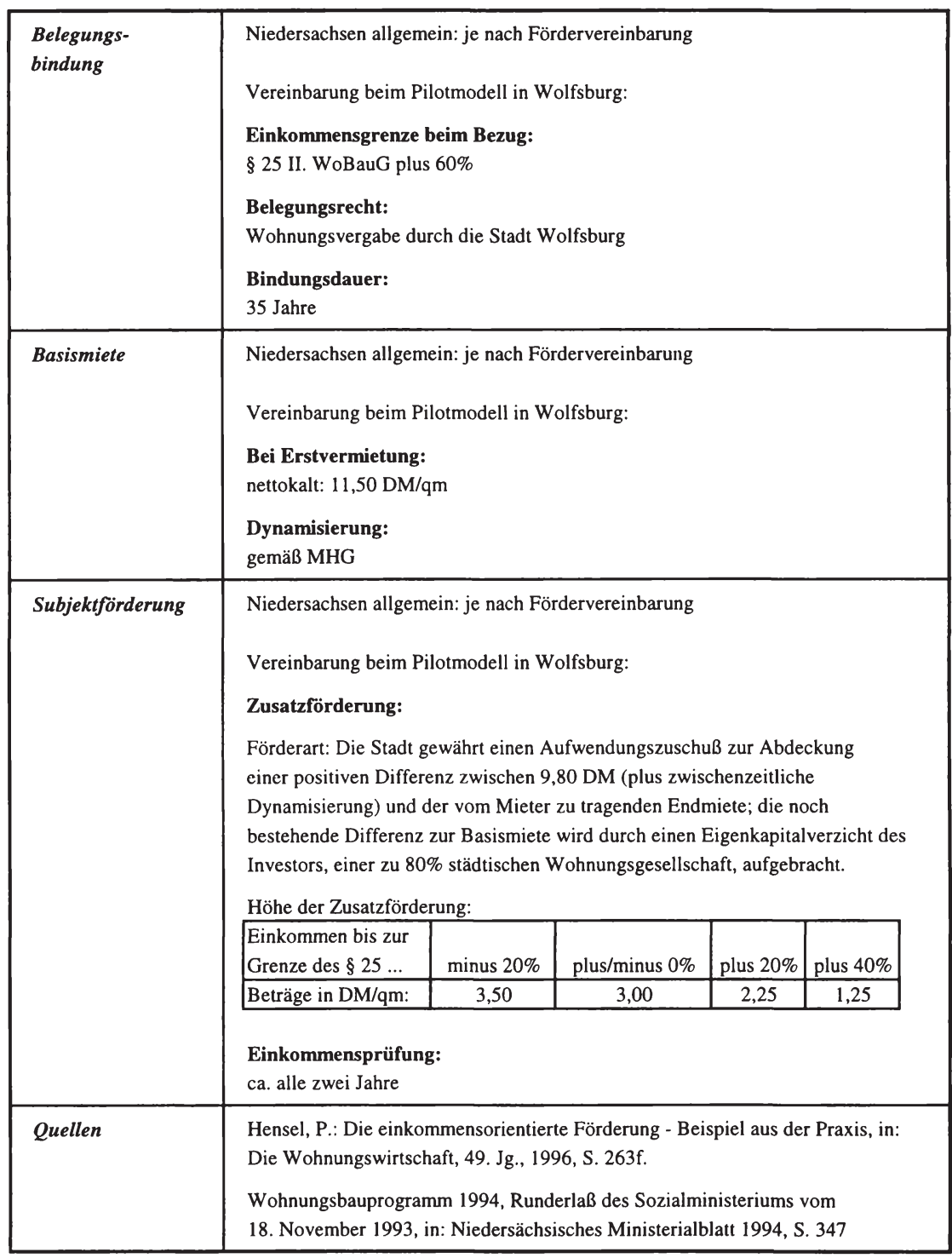




\section{Übersicht 23: Förderkonditionen in Nordrhein-Westfalen}

\begin{tabular}{|c|c|c|c|}
\hline $\begin{array}{l}\text { Gegenstand } \\
\text { der Förderung }\end{array}$ & \multicolumn{3}{|c|}{$\begin{array}{l}\text { Neubau von Miet- und Genossenschaftswohnungen auf der Grundlage des } \\
\S 88 \mathrm{~d} \text { II. WoBauG - vereinbarte Förderung }\end{array}$} \\
\hline Grundförderung & 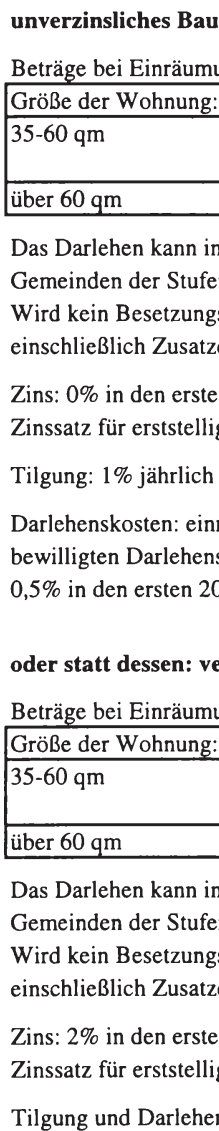 & $\begin{array}{l}48.300 \mathrm{DM} \\
\text { einden der Mie } \\
\text { d } 5 \text { um } 200 \mathrm{DM} \\
\text { eingeräumt, so } \\
\text { en) auf höchste } \\
\text { ahren, dann Ve } \\
\text { potheken } \\
\text { Zuwachs der du } \\
\text { r Verwaltungsl } \\
\text { laufender Verw } \\
\text { n } \\
\text { liches Baudarl } \\
\text { nes Besetzungs } \\
\text { Grundbetrag: } \\
81.000 \text { DM }\end{array}$ & 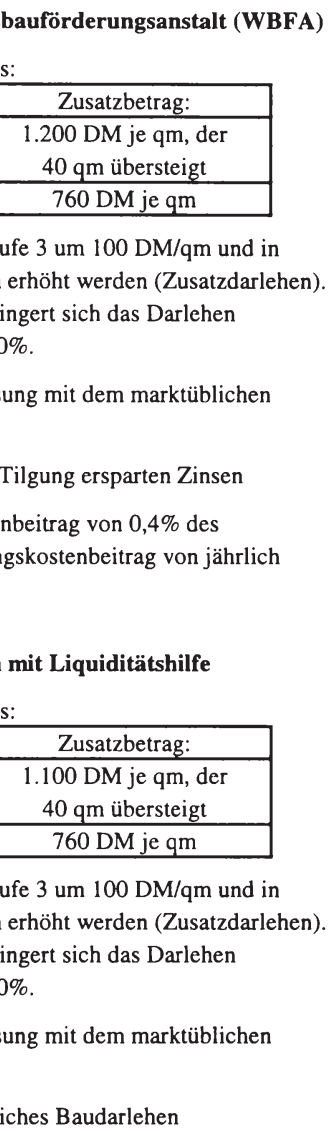 \\
\hline $\begin{array}{l}\text { Belegungs- } \\
\text { bindung }\end{array}$ & $\begin{array}{l}\text { Einkommensgrenze } \\
\S 25 \text { II. WoBauG plu } \\
\text { Belegungsrecht: } \\
\text { Nimmt der Investor d } \\
\text { zuständigen Stelle da } \\
\text { Wohnung nur Wohn } \\
\text { benannt hat. Bei Inan } \\
\text { oben) kann der Inves } \\
\text { selbst auswählen. }\end{array}$ & $\begin{array}{l}\text { Bezug: } \\
\text { verminderte Da } \\
\text { etzungsrecht eir } \\
\text { chenden überla } \\
\text { hnahme des gel } \\
\text { Mieter aus de }\end{array}$ & $\begin{array}{l}\text { en in Anspruch, so hat er der } \\
\text { iumen oder er darf die } \\
\text { die die zuständige Stelle } \\
\text { en Darlehensbetrages (siehe } \\
\text { eis der Berechtigten }\end{array}$ \\
\hline
\end{tabular}




\section{Übersicht 23 (Fortsetzung)}

\begin{tabular}{|c|c|c|c|c|c|c|c|}
\hline $\begin{array}{l}\text { noch: Belegungs- } \\
\text { bindung }\end{array}$ & \multicolumn{7}{|c|}{$\begin{array}{l}\text { Belegungsmix: } \\
\text { Unabhängig davon sind mindestens zwei Drittel der geförderten Wohnungen } \\
\text { an Wohnungssuchende zu vergeben, deren Einkommen die Grenze des } \\
\S 25 \mathrm{II} \text {. WoBauG um nicht mehr als } 5 \% \text { überschreitet (Wohnungsgruppe I), } \\
\text { während die übrigen Wohnungen für Wohnungssuchende mit Einkommen bis } \\
\text { zu der um } 60 \% \text { erhöhten Grenze des } \S 25 \text { bestimmt sind (Wohnungsgruppe II). } \\
\text { Die Wohnungen der Wohnungsgruppe I können nach Ablauf von } 15 \text { Jahren } \\
\text { auch Wohnungssuchenden überlassen werden, deren Einkommen die Grenze } \\
\text { des } \S 25 \text { um bis zu } 60 \% \text { überschreitet. } \\
\text { Bindungsdauer: } \\
20 \text { Jahre }\end{array}$} \\
\hline \multirow[t]{4}{*}{ Basismiete } & \multicolumn{7}{|l|}{ Bei Erstvermietung: } \\
\hline & \multicolumn{2}{|c|}{$\begin{array}{l}\text { Mietenstufe nach Anlage } 1 \\
\text { zu } \S 1 \text { Abs. } 3 \text { WoGV: }\end{array}$} & 1 & 2 & 3 & 4 & 5 (und Köln) \\
\hline & \multicolumn{2}{|c|}{ nettokalt, in DM/qm: } & 11,00 & 12,00 & 13,00 & \begin{tabular}{l|l}
15,00 & \\
\end{tabular} & 17,00 \\
\hline & \multicolumn{7}{|c|}{$\begin{array}{l}\text { Dynamisierung: } \\
\text { Mietanhebung im Rahmen des MHG nur bis zu dem Betrag, der sich bei } \\
\text { Anhebung der Erstvermietungsmiete um } 2 \% \text { pro Jahr ergibt. }\end{array}$} \\
\hline \multirow[t]{9}{*}{ Subjektförderung } & \multicolumn{7}{|c|}{$\begin{array}{l}\text { Zusatzförderung: } \\
\text { Förderart: Der Investor verpflichtet sich, während der Dauer der Belegungs- } \\
\text { bindung einkommensabhängige Leistungen (EAL) an die WBFA zu } \\
\text { entrichten. Die WBFA verzichtet nach Maßgabe des jeweiligen Mieterein- } \\
\text { kommens ganz oder teilweise auf Erhebung der EAL. Dieser Verzicht wird als } \\
\text { Mietnachlaß an die Mieter weitergegeben. } \\
\text { Verzicht auf EAL, in DM/qm: }\end{array}$} \\
\hline & \multirow{2}{*}{\begin{tabular}{|l|} 
Einkommen bis zur \\
Grenze des $\S 25 \ldots$
\end{tabular}} & \multicolumn{6}{|c|}{ Mietenstufe (Anlage 1 zu $\S 1$ Abs. 3 WoGV): } \\
\hline & & 1 & 2 & & 3 & 4 & \begin{tabular}{l|l} 
& 5 und Köln \\
\end{tabular} \\
\hline & plus $10 \%$ & 3,45 & 4,15 & & 4,65 & 6,15 & 7,65 \\
\hline & plus 20\% & 2,45 & 3,15 & & 3,65 & 5,15 & 6,65 \\
\hline & plus $35 \%$ & 1,45 & 2,15 & & 2,65 & 4,15 & 5,65 \\
\hline & plus 50\% & - & 0,15 & & 0,65 & 2,15 & 3,65 \\
\hline & plus $60 \%$ & - & - & & - & 0,65 & 2,65 \\
\hline & \multicolumn{7}{|c|}{$\begin{array}{l}\text { Einkommensprüfung: } \\
\text { Für Wohnungen der Förderungsjahre } 1996 \text { / } 1997 \text { / } 1998 \text { erstmals am 1. Juli } \\
2001 \text { / } 2002 \text { / 2003. Bei den Wohnungen der weiteren Förderungsjahre findet } \\
\text { die erste Anpassung zum 1. Juli des fünften Kalenderjahres nach dem } \\
\text { Kalenderjahr statt, in dem der Bewilligungsbescheid erteilt worden ist. Danach } \\
\text { werden Einkommensprüfungen im Abstand von drei Jahren vorgenommen. }\end{array}$} \\
\hline Quelle & \multicolumn{7}{|c|}{$\begin{array}{l}\text { Bestimmungen zur Einkommensabhängigen Förderung von Mietwohnungen } \\
\text { (WFB-EAF), Runderlaß des Ministeriums für Bauen und Wohnen vom } \\
\text { 19. August 1996, in: Ministerialblatt für das Land Nordrhein-Westfalen 1996, } \\
\text { S. } 1644\end{array}$} \\
\hline
\end{tabular}




\section{Übersicht 24: Förderkonditionen in Rheinland-Pfalz}

\begin{tabular}{|c|c|}
\hline $\begin{array}{l}\text { Gegenstand } \\
\text { der Förderung }\end{array}$ & $\begin{array}{l}\text { Neuschaffung von abgeschlossenen Miet- und Genossenschaftswohnungen } \\
\text { nach Maßgabe der jährlichen Wohnungsbauprogramme durch } \\
\text { - Neubau } \\
\text { - Ausbau von Dachgeschossen, } \\
\text { - die unter wesentlichem Bauaufwand durchgeführte Umwandlung von } \\
\text { Räumen, die bisher anderen als Wohnzwecken dienten } \\
\text { - den unter wesentlichem Bauaufwand vorgenommenen Umbau von } \\
\text { Wohnraum, der infolge Änderung der Wohngewohnheiten nicht mehr für } \\
\text { Wohnzwecke geeignet ist, zur Anpassung an die veränderten } \\
\text { Wohngewohnheiten } \\
\text { - die Erweiterung eines bestehenden Gebäudes durch Aufstockung des } \\
\text { Gebäudes oder durch Anbau an das Gebäude }\end{array}$ \\
\hline Grundförderung & $\begin{array}{l}\text { Baudarlehen der Landesbank Rheinland-Pfalz } \\
\text { Betrag: maximal } 600 \text { DM/qm (siehe Mietwohnungsbauprogramm 1995) } \\
\text { Zins: 6\%; im Bindungszeitraum Absenkung auf bis zu 0,5\%; auch danach } \\
\text { Absenkung auf i.d.R. 3\% oder - in begründeten Ausnahmefällen - auf } \\
\text { den alten Zinssatz möglich } \\
\text { Tilgung: mindestens } 1 \% \text { jährlich unter Zuwachs der ersparten Zinsen } \\
\text { oder statt dessen: Bauzuschüsse } \\
\text { Betrag: maximal } 300 \text { DM/qm (siehe Mietwohnungsbauprogramm 1995) }\end{array}$ \\
\hline $\begin{array}{l}\text { Belegungs- } \\
\text { bindung }\end{array}$ & $\begin{array}{l}\text { Einkommensgrenze beim Bezug: } \\
\S 25 \text { II. WoBauG plus } 60 \% \\
\text { Belegungsrecht: } \\
\text { Belegung durch den Investor nach Vorlage der Berechtigungsbescheinigung } \\
\text { durch den Mieter } \\
\text { Bindungsdauer: } \\
15 \text { Jahre }\end{array}$ \\
\hline Basismiete & $\begin{array}{l}\text { Bei Erstbelegung: } \\
\text { je nach Förderungsvereinbarung; höchstens ortsübliche Vergleichsmiete } \\
\text { Dynamisierung: } \\
\text { Anhebung begrenzt durch Vergleichsmiete und den Betrag, der sich bei } \\
\text { Fortschreibung der Erstvermietungsmiete um 3\% pro Jahr ergibt }\end{array}$ \\
\hline Subjektförderung & $\begin{array}{l}\text { Zusatzförderung: } \\
\text { Förderart: Zuschuß über den Mieter } \\
\text { Höhe: Absenkung der höchstzulässigen Miete (Mietenbegriff nach } \S 5 \text { WoGG) } \\
\text { auf } 22 \text { bis } 25 \% \text { des Gesamteinkommens nach } \S 25 \text { II. WoBauG } \\
\text { Einkommensprüfung: } \\
\text { alle zwölf Monate }\end{array}$ \\
\hline
\end{tabular}




\section{Übersicht 24 (Fortsetzung)}

Quellen
Einkommensorientierte Förderung von Mietwohnungen nach $\S 88$ e Zweites Wohnungsbaugesetz (Modellvorhaben), Verwaltungsvorschrift des Ministeriums der Finanzen vom 17. Januar 1996, in: Ministerialblatt der Landesregierung von Rheinland-Pfalz 1996, S. 148

Vollzug des Zweiten Wohnungsbaugesetzes (II. WoBauG); hier: Mietwohnungsbauprogramm 1995, - 1. und 3. Förderweg, - Sonderprogramm "Kostengünstiges elementiertes Bauen", - Modellversuch "Einkommensorientierte Förderung", - Modellversuch "Erwerb von Belegungsrechten", Verwaltungsvorschrift des Ministeriums der Finanzen vom 31. Januar 1995, in: Ministerialblatt der Landesregierung von Rheinland-Pfalz 1995, S. 158

\section{Übersicht 25: Förderkonditionen in Sachsen}

\begin{tabular}{|c|c|c|c|}
\hline $\begin{array}{l}\text { Gegenstand } \\
\text { der Förderung }\end{array}$ & \multicolumn{3}{|c|}{$\begin{array}{l}\text { ausschließlich Modernisierung im Rahmen der Sanierung von } \\
\text { Mietwohnungen }\end{array}$} \\
\hline \multirow[t]{12}{*}{ Grundförderung } & \multicolumn{3}{|c|}{$\begin{array}{l}\text { Fördervoraussetzung: Der Vermieter nimmt ein zinsverbilligtes Darl } \\
\text { nach dem Wohnraum-Modernisierungsprogramm der Kreditanstalt f } \\
\text { Wiederaufbau in Höhe von } 500 \text { DM/qm in Anspruch. } \\
\text { baukostenabhängiges Darlehen MB } 10 \text { der Sächsischen Aufbauk }\end{array}$} \\
\hline & & \multicolumn{2}{|c|}{ Darlehensbeträge in $\mathrm{DM} / \mathrm{qm}$... } \\
\hline & Baukosten in DM/qm: & $\begin{array}{l}\text {... mit Steuerver- } \\
\text { günstigungen: }\end{array}$ & $\begin{array}{l}\text {... ohne Steuerver- } \\
\text { günstigungen: }\end{array}$ \\
\hline & ab 1.100 & 150 & 250 \\
\hline & ab 1.200 & 200 & 325 \\
\hline & ab 1.300 & 250 & 400 \\
\hline & ab 1.400 & 300 & 475 \\
\hline & ab 1.500 & 350 & 550 \\
\hline & ab 1.600 & 400 & 625 \\
\hline & ab 1.700 & 450 & 700 \\
\hline & ab 1.800 & 500 & 750 \\
\hline & ab 1.900 & 550 & 800 \\
\hline
\end{tabular}

Zins: 4,5\% während der Laufzeit von zehn Jahren; ab dann nach Vereinbarung

Tilgung: $1 \%$ zuzüglich der ersparten Zinsen während der Laufzeit von zehn Jahren; ab dann nach Vereinbarung

Darlehenskosten: einmalige Bearbeitungsgebühr von $1 \%$ des Darlehensbetrages bei der ersten Auszahlung. Die laufenden Verwaltungskosten von jährlich 0,5\% des Restdarlehensbetrages sind im Zinssatz enthalten. 


\section{Übersicht 25 (Fortsetzung)}

\begin{tabular}{|c|c|c|c|c|c|c|c|c|c|c|c|}
\hline $\begin{array}{l}\text { Belegungs- } \\
\text { bindung }\end{array}$ & \multicolumn{11}{|c|}{$\begin{array}{l}\text { Einkommensgrenze: } \\
\text { keine } \\
\text { Bindungsdauer: } \\
10 \text { Jahre }\end{array}$} \\
\hline \multirow[t]{4}{*}{ Basismiete } & \multicolumn{11}{|c|}{$\begin{array}{l}\text { Im ersten Jahr: } \\
\text { Miete vor Sanierung zuzüglich bis zu } 11 \% \text { der für Modernisierungs- } \\
\text { maßnahmen angefallenen Kosten, verteilt auf zwölf Monate; daneben ist } \\
\text { eine baukostenabhängige Kappungsgrenze einzuhalten: }\end{array}$} \\
\hline & \multicolumn{2}{|c|}{$\begin{array}{l}\text { Baukosten } \\
\text { ab ... DM/qm: }\end{array}$} & 1.100 & 1.200 & 1.300 & 1.400 & 1.500 & 1.600 & 1.700 & 1.800 & 1.900 \\
\hline & \multicolumn{2}{|c|}{\begin{tabular}{|l|}
$\mathrm{DM} / \mathrm{qm}:$ \\
\end{tabular}} & 9,00 & 9,50 & 10,00 & 10,50 & 11,00 & 11,50 & 12,00 & 12,50 & 13,00 \\
\hline & \multicolumn{11}{|c|}{$\begin{array}{l}\text { Dynamisierung: } \\
\text { Erhöhung der Basismiete um höchstens } 0,50 \mathrm{DM} / \mathrm{qm}\end{array}$} \\
\hline \multirow[t]{8}{*}{ Subjektförderung } & \multicolumn{11}{|c|}{$\begin{array}{l}\text { Zusatzförderung: } \\
\text { Förderart: Zuschuß über den Mieter } \\
\text { Einkommensabhängige Endmieten: }\end{array}$} \\
\hline & $\begin{array}{l}\text { Pers.- } \\
\text { zahl: }\end{array}$ & \multicolumn{4}{|c|}{$\begin{array}{l}\text { Bis zu einem Gesamtein- } \\
\text { kommen nach } \S 25 \text { von } \\
\text { monatlich ... }\end{array}$} & \multicolumn{2}{|c|}{$\begin{array}{l}\text { zu zahlen: } \\
\text { Mindest- } \\
\text { miete je qm: }\end{array}$} & \multicolumn{4}{|c|}{$\begin{array}{l}\text { Danach : je zusätzliche } \\
100 \text { DM Gesamteinkommen } \\
\text { nach § } 25 \text { im Monat: }\end{array}$} \\
\hline & 1 & & \multicolumn{3}{|c|}{$1.500 \mathrm{DM}$} & \multicolumn{2}{|c|}{$7,00 \mathrm{DM}$} & \multicolumn{4}{|c|}{$\begin{array}{c}\text { bis } 1.600 \mathrm{DM} \text { : plus } 0,10 \mathrm{DM} \\
\text { danach: plus } 0,60 \mathrm{DM}\end{array}$} \\
\hline & 2 & & \multicolumn{3}{|c|}{$2.000 \mathrm{DM}$} & \multicolumn{2}{|c|}{$7,50 \mathrm{DM}$} & \multicolumn{4}{|c|}{ plus $0,50 \mathrm{DM}$} \\
\hline & 3 & & \multicolumn{3}{|c|}{$2.500 \mathrm{DM}$} & \multicolumn{2}{|c|}{$7,50 \mathrm{DM}$} & \multicolumn{4}{|c|}{ plus $0,40 \mathrm{DM}$} \\
\hline & 4 & & \multicolumn{3}{|c|}{$3.300 \mathrm{DM}$} & \multicolumn{2}{|c|}{$7,50 \mathrm{DM}$} & \multicolumn{4}{|c|}{ plus $0,30 \mathrm{DM}$} \\
\hline & 5 & & \multicolumn{3}{|c|}{$3.700 \mathrm{DM}$} & \multicolumn{2}{|c|}{$7,50 \mathrm{DM}$} & \multicolumn{4}{|c|}{ plus $0,30 \mathrm{DM}$} \\
\hline & \multicolumn{11}{|c|}{$\begin{array}{l}\text { Einkommensprüfung: } \\
\text { i.d.R. alle zwölf Monate }\end{array}$} \\
\hline Quellen & \multicolumn{11}{|c|}{$\begin{array}{l}\text { Landesprogramm } 1996 \text { zur Wiedergewinnung, Erhaltung und Erneuerung } \\
\text { von Mietwohnungen im Freistaat Sachsen (VwV-LMW/Pr. } 1996 \text { - Miet- } \\
\text { wohnungsbauprogramm), Verwaltungsvorschrift des Sächsischen Staats- } \\
\text { ministeriums des Innern, 28. November } 1995 \\
\text { Fragen und Antworten zur einkommensabhängigen Förderung für die } \\
\text { Sanierung von Mietwohnungen, Informationsbroschüre des } \\
\text { Staatsministeriums des Innern }\end{array}$} \\
\hline
\end{tabular}




\section{Übersicht 26: Förderkonditionen in Schleswig-Holstein}

\begin{tabular}{|c|c|c|c|}
\hline $\begin{array}{l}\text { Gegenstand } \\
\text { der Förderung }\end{array}$ & \multicolumn{3}{|c|}{$\begin{array}{l}\text { Schaffung von Miet- und Genossenschaftswohnungen durch Neubau, } \\
\text { Aus- und Umbau sowie Erweiterung bestehender Gebäude im Sinne des } \\
\S 17 \text { II. WoBauG }\end{array}$} \\
\hline \multirow[t]{3}{*}{ Grundförderung } & \multicolumn{3}{|c|}{$\begin{array}{l}\text { zinsverbilligtes Baudarlehen der Investitionsbank Schleswig-Holstein } \\
\text { (Grunddarlehen) } \\
\text { Höhe: } 60 \% \text { der Sätze des ersten Förderwegs (als Förderpauschale) }\end{array}$} \\
\hline & \begin{tabular}{|l|} 
Wohnungsgröße: \\
unter $50 \mathrm{qm}$ \\
50 bis $59,99 \mathrm{qm}$ \\
60 bis $69,99 \mathrm{qm}$ \\
70 bis $79,99 \mathrm{qm}$ \\
80 bis $89,99 \mathrm{qm}$ \\
\end{tabular} & $\begin{array}{c}\text { Personenzahl: } \\
1 \\
2 \\
3 \\
4 \\
5\end{array}$ & \begin{tabular}{|c|} 
Höhe des Baudarlehens: \\
$51.000 \mathrm{DM}$ \\
$56.100 \mathrm{DM}$ \\
$60.000 \mathrm{DM}$ \\
$65.100 \mathrm{DM}$ \\
$68.700 \mathrm{DM}$ \\
\end{tabular} \\
\hline & \multicolumn{3}{|c|}{$\begin{array}{l}\text { Für größere Wohnungen wird das Baudarlehen um } 540 \text { DM je qm zusätzliche } \\
\text { Wohnfläche erhöht. } \\
\text { plus: Darlehen II } \\
\text { Höhe: } 600 \text { DM/qm } \\
\text { ggf. weiteres Darlehen } \\
\text { - für die Anpassung des Wohnraums für Schwerbehinderte } \\
\text { - bei Niedrigenergiehäusern } \\
\text { - für Wohnungen kinderreicher Familien } \\
\text { - für Altenwohnungen mit Betreuungsangebot } \\
\text { plus: zunächst unverzinsliches kommunales Baudarlehen } \\
\text { Höhe: mindestens } 10 \% \text { der Gesamtkosten }\end{array}$} \\
\hline $\begin{array}{l}\text { Belegungs- } \\
\text { bindung }\end{array}$ & \multicolumn{3}{|c|}{$\begin{array}{l}\text { Einkommensgrenze beim Bezug: } \\
\S 25 \text { II. WoBauG plus } 40 \% \\
\text { Belegungsrecht / Belegungsmix: } \\
\text { Die Belegung wird vom Investor nach Vorlage einer Berechtigungs- } \\
\text { bescheinigung durch den Mieter vorgenommen. Mindestens } 50 \% \text { der } \\
\text { Gesamtwohnfläche aller Wohnungen soll mit Haushalten belegt werden } \\
\text { (Erst- und Wiedervermietung), die die Einkommensgrenze des } \\
\text { § } 25 \text { II. WoBauG einhalten oder nur unwesentlich überschreiten. Die } \\
\text { verbleibende Wohnfläche soll möglichst gleichmäßig mit Haushalten der } \\
\text { anderen Einkommensstufen (siehe unten) belegt werden. Abweichende } \\
\text { Belegungen können zwischen dem Vermieter und der Kommune vereinbart } \\
\text { werden. } \\
\text { Bindungsdauer: } \\
\text { Bis zum Ende des Kalenderjahres, in dem das Grunddarlehen und das } \\
\text { Darlehen II nach Maßgabe der Tilgungsbedingungen zurückgezahlt sind; im } \\
\text { Falle einer vorzeitigen Rückzahlung (frühestens zehn Jahre nach Auszahlung } \\
\text { der letzten Rate möglich) mit dem Ablauf des zehnten Kalenderjahres nach dem } \\
\text { Jahr der Rückzahlung, längstens jedoch wie bei planmäßiger Tilgung }\end{array}$} \\
\hline
\end{tabular}




\section{Übersicht 26 (Fortsetzung)}

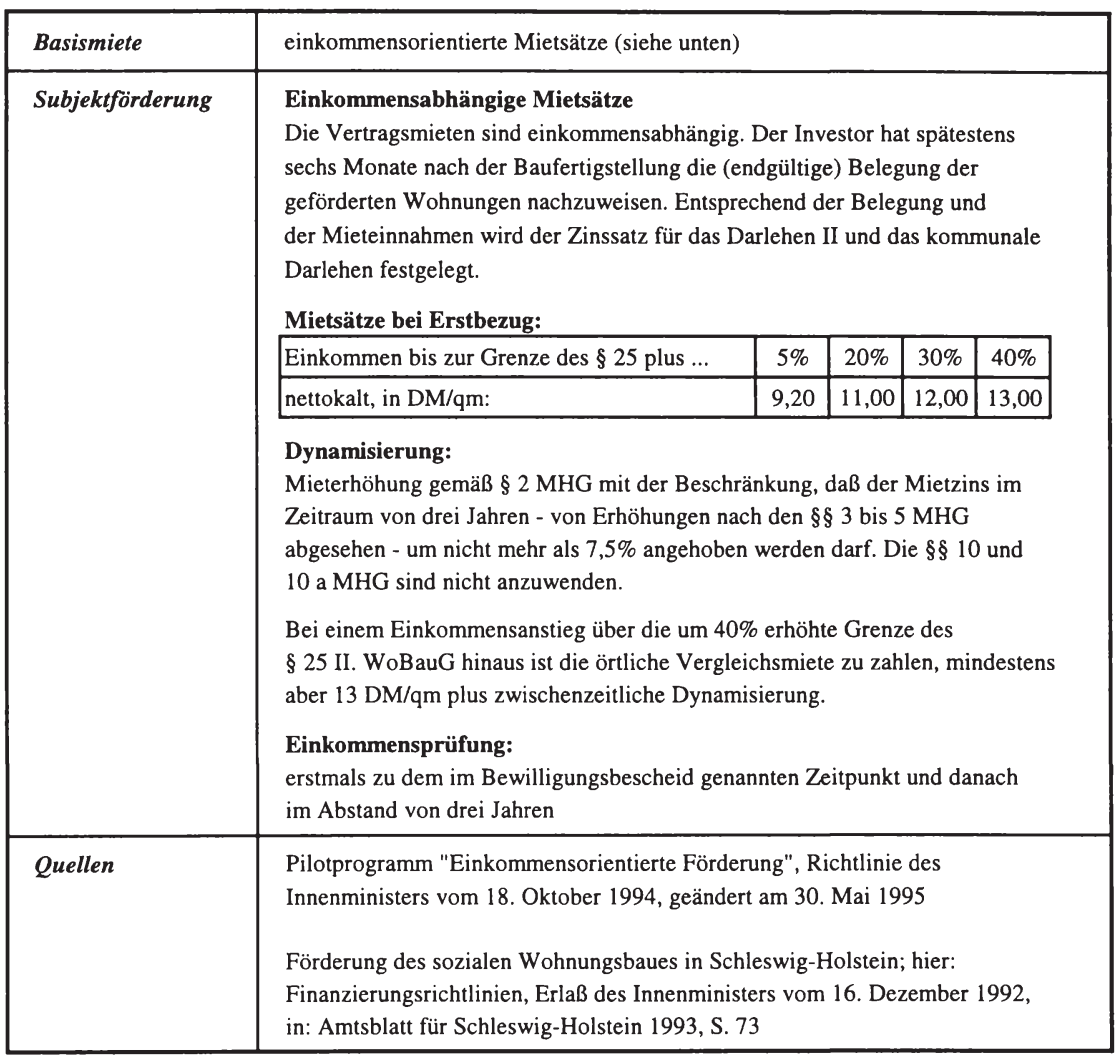




\section{Übersicht 27: Förderkonditionen in Thüringen}

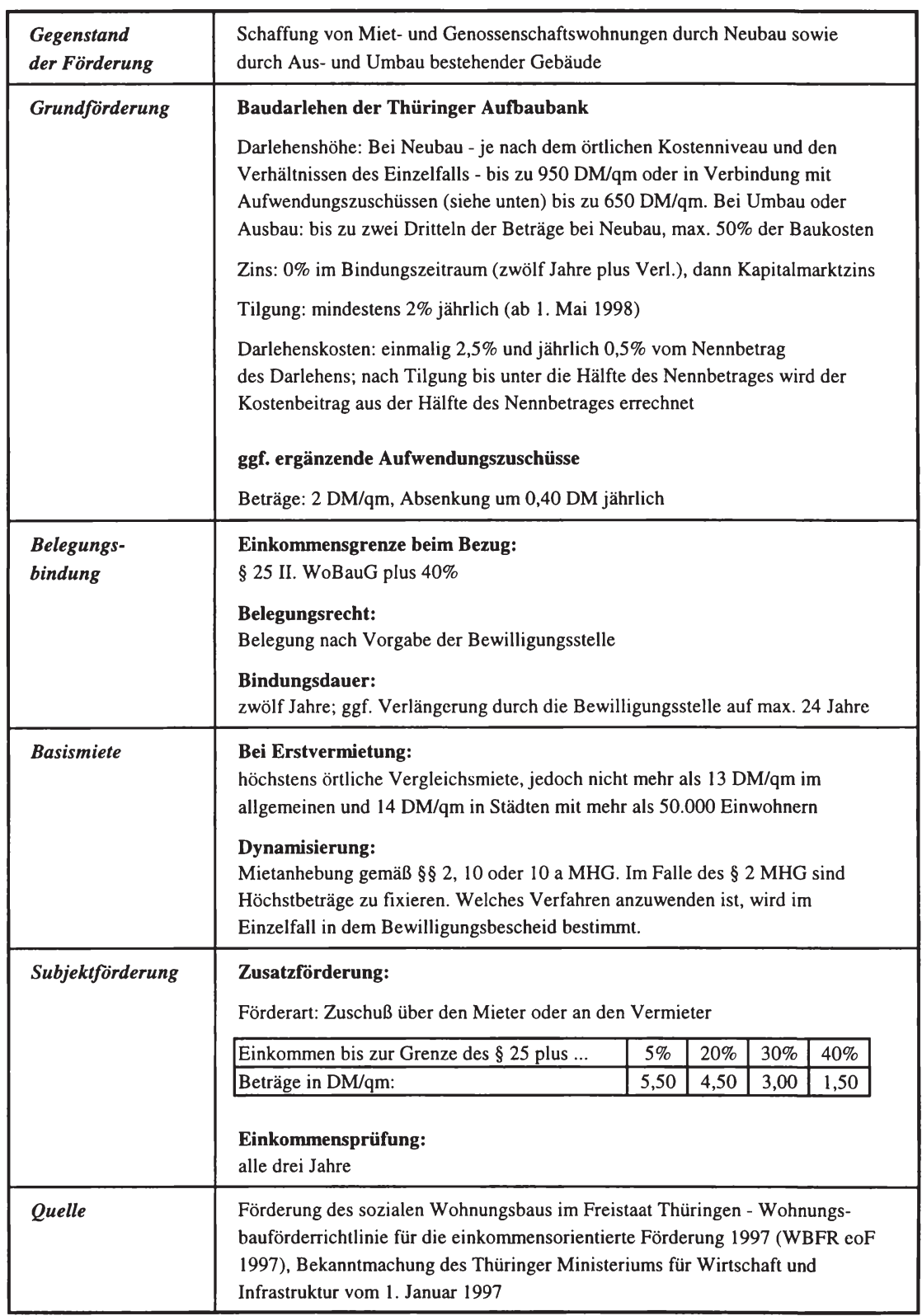


Burkhard Pahnke - 978-3-631-75215-9

Downloaded from PubFactory at 01/11/2019 07:00:27AM

via free access 


\section{Literaturverzeichnis}

Aaron, H. J., v. Furstenberg, G. M. (1971), The inefficiency of transfers in kind: The case of housing assistance, in: Western economic journal, Vol. 9, S. 184-191.

Arbeitsgemeinschaft des Evangelischen Siedlungswerks e.V. und des Katholischen Siedlungsdienstes e.V. (1994), Stellungnahme zum Entwurf eines Gesetzes zur Förderung des Wohnungsbaues (Wohnungsbauförderungsgesetz 1994) - Drucksache 12/6616 - und zum Entwurf eines Gesetzes zur Neuregelung der Bundesfinanzhilfen für den sozialen Wohnungsbau (Wohnungsbaufinanzierungsgesetz 1993) - Drucksache 12/6880, Anlage 6 des Kurzprotokolls der 76. Sitzung des (19.) Ausschusses für Raumordnung, Bauwesen und Städtebau vom 2. März 1994, Bonn, S. 223-237.

Becker, J. (1993), Einkommensabhängige Wohnungsbauförderung. Erste Erfahrungsberichte der Wohnungsunternehmen, in: Die Wohnungswirtschaft, 46. Jg., S. 121-123.

Behnken, R. (1982), Soziale Gerechtigkeit und Wohnungspolitik. Eine empirische Verteilungsanalyse für die Bundesrepublik Deutschland, Schriften des Internationalen Instituts für Empirische Sozialökonomie, Band 4, Berlin.

Behring, K. (1994), Erhöhung der Einkommensgrenzen im sozialen Wohnungsbau?, in: Ifo-Schnelldienst, 47. Jg., Nr. 10-11, S. 23-28.

Bellinger, C.-H., Kommentar zu § 5 WoBindG, in: Schwender, H. W. (Hrsg.), Wohnungsbaurecht, Band 3.1, Loseblattsammlung, Stand: November 1997, Essen.

Bellinger, C.-H., Kommentar zu § 5a WoBindG, in: Schwender, H. W. (Hrsg.), Wohnungsbaurecht, Band 3.1, Loseblattsammlung, Stand: November 1997, Essen.

Berkefeld, D., Kommentar zum $\S 88$ e II. WoBauG, in: Schwender, H. W. (Hrsg.), Wohnungsbaurecht, Band 2, Loseblattsammlung, Stand: November 1997, Essen.

Bison, J. (1996), Die Regulierung des Mietwohnungsmarktes in der Bundesrepublik Deutschland. Eine positive ökonomische Analyse, Frankfurt am Main. 
Börsch-Supan, A. (1986), On The West German Tenants' Protection Legislation, in: Journal of Institutional and Theoretical Economics, (Zeitschrift für die gesamte Staatswissenschaft), Vol. 142, S. 380-404.

Break, G. F. (1980), Financing Government in a Federal System, Washington, D.C.

Brintzinger, O. L. (1993), Anforderungen an eine Neugestaltung der Wohnungsbauförderung - aus Sicht der Länder, in: Wohnungswirtschaftliche Informationen, Beilage zu Heft 48, S. 3-6.

Bundesministerium für Raumordnung, Bauwesen und Städtebau (1993), Bericht zur einkommensorientierten Wohnungsbauförderung; Ergebnisse und Umsetzung des Planspiels in Würzburg am 16./17. September 1993, Bonn.

Bundesministerium für Raumordnung, Bauwesen und Städtebau (1994), Vermerk betr.: Problem des Übergangs in den Markt bei Auslaufen der einkommensorientierten Wohnungsbauförderung; Mietenfortschreibung, Preisindex und Wohngeldentwicklung, Bonn.

Bundesministerium für Raumordnung, Bauwesen und Städtebau (1996), Umsetzung der einkommensorientierten Förderung in den Ländern, Bericht vom 11. Oktober 1996, Bonn.

Bundesverband Freier Wohnungsunternehmen e.V. (1994), Stellungnahme zum Entwurf eines Gesetzes zur Förderung des Wohnungsbaues (Wohnungsbauförderungsgesetz 1994) - Drucksache 12/6616 - und zum Entwurf eines Gesetzes zur Neuregelung der Bundesfinanzhilfen für den sozialen Wohnungsbau (Wohnungsbaufinanzierungsgesetz 1993) - Drucksache 12/6880, Anlage 4 des Kurzprotokolls der 76. Sitzung des (19.) Ausschusses für Raumordnung, Bauwesen und Städtebau vom 2. März 1994, Bonn, S. 169-217.

Bundesvereinigung der kommunalen Spitzenverbände (1994), Stellungnahme zum Entwurf eines Gesetzes zur Förderung des Wohnungsbaues (Wohnungsbauförderungsgesetz 1994) - Drucksache 12/6616 - und zum Entwurf eines Gesetzes zur Neuregelung der Bundesfinanzhilfen für den sozialen Wohnungsbau (Wohnungsbaufinanzierungsgesetz 1993) - Drucksache 12/6880, Anlage 7 des Kurzprotokolls der 76. Sitzung des (19.) Ausschusses für Raumordnung, Bauwesen und Städtebau vom 2. März 1994, Bonn, S. 238-250. 
Deutscher Bundesrat (1993), Entwurf eines Gesetzes zur Neuregelung der Bundesfinanzhilfen für den sozialen Wohnungsbau (Wohnungsbaufinanzierungsgesetz 1993 - WoBauFinG 1993 -), Drucksache 655/93 vom 26. November 1993, Bonn.

Deutscher Bundestag (1992a), Wohngeld- und Mietenbericht 1991, Drucksache 12/2356 vom 27. März 1992, Bonn.

Deutscher Bundestag (1992b), Zukunft des sozialen Wohnungsbaus, Antwort der Bundesregierung auf eine Kleine Anfrage der Fraktion der SPD, Drucksache 12/2883 vom 23. Juni 1992, Bonn.

Deutscher Bundestag (1994a), Entwurf eines Gesetzes zur Förderung des Wohnungsbaues (Wohnungsbauförderungsgesetz 1994 - WoBauFördG 1994), Drucksache 12/6616 vom 19. Januar 1994, Bonn.

Deutscher Bundestag (1994b), Wohngeld- und Mietenbericht 1993, Drucksache 12/7153 vom 25. März 1994, Bonn.

Deutscher Bundestag (1994c), Öffentliche Anhörung zum Entwurf eines Gesetzes zur Förderung des Wohnungsbaues (Wohnungsbauförderungsgesetz 1994) - Drucksache 12/6616 - und zum Entwurf eines Gesetzes zur Neuregelung der Bundesfinanzhilfen für den sozialen Wohnungsbau (Wohnungsbaufinanzierungsgesetz 1993) - Drucksache 12/6880, Kurzprotokoll der 76. Sitzung des (19.) Ausschusses für Raumordnung, Bauwesen und Städtebau vom 2. März 1994, Bonn.

Deutscher Bundestag (1994d), Beschlußempfehlung und Bericht des Ausschusses für Raumordnung, Bauwesen und Städtebau (19. Ausschuß), Drucksache 12/7399 vom 26. April 1994, Bonn.

Deutscher Bundestag (1995), Stellungnahme der Bundesregierung zum Bericht der Expertenkommission Wohnungspolitik - Drucksache 13/159 -, Drucksache 13/1268 vom 5. Mai 1995, Bonn.

Deutscher Bundestag (1996), Wohngeld- und Mietenbericht, Drucksache 13/4254 vom 29. März 1996, Bonn. 
Deutscher Mieterbund e.V. (1994), Stellungnahme zum Entwurf eines Gesetzes zur Förderung des Wohnungsbaues (Wohnungsbauförderungsgesetz 1994) - Drucksache 12/6616 - und zum Entwurf eines Gesetzes zur Neuregelung der Bundesfinanzhilfen für den sozialen Wohnungsbau (Wohnungsbaufinanzierungsgesetz 1993) - Drucksache 12/6880, Anlage 13 des Kurzprotokolls der 76. Sitzung des (19.) Ausschusses für Raumordnung, Bauwesen und Städtebau vom 2. März 1994, Bonn, S. 281-294.

Deutscher Verband für Wohnungswesen, Städtebau und Raumordnung e.V. Kommission (1996), Verbesserung der Markt- und Einkommensorientierung der öffentlichen Förderung im Wohnungsbau, Bonn.

Deutsches Volksheimstättenwerk e.V. (1994), Stellungnahme zum Entwurf eines Gesetzes zur Förderung des Wohnungsbaues (Wohnungsbauförderungsgesetz 1994) - Drucksache 12/6616 - und zum Entwurf eines Gesetzes zur Neuregelung der Bundesfinanzhilfen für den sozialen Wohnungsbau (Wohnungsbaufinanzierungsgesetz 1993) - Drucksache 12/6880, Anlage 15 des Kurzprotokolls der 76. Sitzung des (19.) Ausschusses für Raumordnung, Bauwesen und Städtebau vom 2. März 1994, Bonn, S. 300-317.

Deutsches Volksheimstättenwerk e.V. (1996), Erprobung der einkommensorientierten Förderung in Nordrhein-Westfalen, Gutachten im Auftrag des Ministeriums für Bauen und Wohnen des Landes Nordrhein-Westfalen, Bonn.

Dick, E., Eckart, W. (1989), Renditeaussichten im Wohnungsbau mit und ohne vereinbarte Förderung, in: Der langfristige Kredit, 40. Jg., S. 610-617.

Die Grünen - Arbeitskreis IV (Wohnungspolitik/Städtebau) der Grünen Bundestagsfraktion (1991), Menschenfreundliche Wohnungen und Städte (Stellungnahme vom November 1990), in: Der langfristige Kredit, 42. Jg., S. 19-24.

Dyong, H., Einführung zum Gesetz über den Abbau der Fehlsubventionierung im Wohnungswesen (AFWoG), in: Schwender, H. W. (Hrsg.), Wohnungsbaurecht, Band 3.2, Loseblattsammlung, Stand: November 1997, Essen.

Dyong, H., Kommentar zum $\S 88$ d II. WoBauG, in: Schwender, H. W. (Hrsg.), Wohnungsbaurecht, Band 2, Loseblattsammlung, Stand: November 1997, Essen. 
Eckart, W. (1984), A Welfare Analysis of the German Tenants' Protection Legislation, in: Journal of Economics (Zeitschrift für Nationalökonomie), Vol. 44, S. 39-56.

Eckart, W. (1990), Rentabilität des Wohnungsbaus im 3. Förderweg, in: Bundesbaublatt, 39. Jg., 1990, S. 72-74.

Eekhoff, J. (1981), Zur Kontroverse um die ökonomischen Auswirkungen des Zweiten Wohnraumkündigungsschutzgesetzes, in: Journal of Institutional and Theoretical Economics, (Zeitschrift für die gesamte Staatswissenschaft), Vol. 137, S. 62-77.

Eekhoff, J. (1989), Entschuldungsgewinne im sozialen Wohnungsbau?, in: Der langfristige Kredit, 40. Jg., S. 626-630.

Eekhoff, J. (1993), Wohnungspolitik, Tübingen.

Expertenkommission Wohnungspolitik (1995), Wohnungspolitik auf dem Prüfstand, Gutachten im Auftrag der Bundesregierung, Tübingen.

Falthauser, K. (1991), Wohnungspolitische Standpunkte der CSU, in: Der langfristige Kredit, 42. Jg., S. 6-9.

Fujita, M. (1989), Urban Economic Theory. Land Use and City Size, Cambridge.

Gandenberger, O. (1989): Einkommensabhängige staatliche Transfers: Bestandsaufnahme, Wirkungen - Handlungsmöglichkeiten und Handlungsgrenzen, Baden-Baden.

Gesamtverband der Wohnungswirtschaft e.V. (1994a), Stellungnahme zum Entwurf eines Gesetzes zur Förderung des Wohnungsbaues (Wohnungsbauförderungsgesetz 1994) - Drucksache 12/6616 - und zum Entwurf eines Gesetzes zur Neuregelung der Bundesfinanzhilfen für den sozialen Wohnungsbau (Wohnungsbaufinanzierungsgesetz 1993) - Drucksache 12/6880, Anlage 2 des Kurzprotokolls der 76. Sitzung des (19.) Ausschusses für Raumordnung, Bauwesen und Städtebau vom 2. März 1994, Bonn, S. 104-134. 
Gesamtverband der Wohnungswirtschaft e.V. (1994b), Stuttgarter Erklärung zur Wohnungspolitik in Deutschland: Für eine Innovations- und Investitionsoffensive, Anlage 3 zum Kurzprotokoll der 76. Sitzung des (19.) Ausschusses für Raumordnung, Bauwesen und Städtebau vom 2. März 1994, Bonn, S. 135-168.

Gesellschaft für Wohnungs- und Siedlungswesen e.V. (1966), Wohnungsbau in weißen Kreisen. Gedanken über eine Reform der öffentlichen Förderung im Wohnungsbau, Beratungsergebnisse der Finanzierungskommission, Hamburg.

Gesellschaft für Wohnungs- und Siedlungswesen e.V. (1983), Möglichkeiten und Grenzen bestandsorientierter Wohnungspolitik, Kommissionsbericht, Hamburg.

Gierke, H.-G. (1994), Einkommensabhängige Wohnungsbauförderung, Arbeitspapier zum „Zwischenahner Gespräch“ am 10./11. Mai 1994.

Glatzer, W. (1980), Wohnungsversorgung im Wohlfahrtsstaat: objektive und subjektive Indikatoren zur Wohlfahrtsentwicklung in der Bundesrepublik Deutschland, Frankfurt am Main / New York.

Goodman, A. C. (1989), Topics in Empirical Urban Housing Research, in: Arnott, R. (Hrsg.), The Economics of Housing Markets, London, S. 49-143.

Gramlich, B. (1994), Mietrecht, Kommentar, München.

Gude, S. (1990), Diskriminierung auf dem Wohnungsmarkt, in: Norton, A., Novy, K. (Hrsg.), Soziale Wohnungspolitik der 90er Jahre: Probleme und Handlungsansätze aus britisch-deutscher Sicht, Basel u.a.O., S. 237-256.

Hamm, H. (1990), Ein Jahr vereinbarte Förderung im sozialen Wohnungsbau, in: Bundesbaublatt, 39. Jg., S. 67-72.

Harke, D. (1984), Wohnraummiete: rechtliche, wirtschaftliche und soziale Aspekte der Vermietung von Wohnungen, Berichte aus der Fachhochschule Darmstadt, Band 10, Darmstadt.

Hecht, M. (1978), Subventionsformen in der Wohnungswirtschaft, München.

Helzer, U., Mündemann, T. (1993), Kunststück mißlungen, in: „Die Zeit“, Nr. 49 vom 3. Dezember 1993, S. 23. 
Heuer, J. (1991), Die Wohnungsmärkte im gesamtwirtschaftlichen Gefüge, in: Jenkis, H. W. (Hrsg.), Kompendium der Wohnungswirtschaft, München, S. 22-40.

Heuer, J. H. B. u.a. (1979), Lehrbuch der Wohnungswirtschaft, Franfurt am Main.

von Heyl, A. (1992), Wohnungsbau - eine Frage des Bodenrechts? Möglichkeiten und Grenzen, der Wohnungsknappheit mit dem Bodenrecht beizukommen, in: Landeszentrale für politische Bildung Baden-Württemberg (Hrsg.), Wohnungspolitik, Reihe „Der Bürger im Staat“, 42. Jg., Stuttgart, S. 264-267.

Hintzsche, B. (1993), Sozialer Wohnungsbau am Scheideweg. Der soziale Wohnungsbau - eine „Errungenschaft der Besserverdienenden“?, in: Der Städtetag, 46. Jg., S. 584-589.

Hitschler, W. (1991), Soziale Wohnungsmarktwirtschaft: Zukünftige Wohnungspolitik der FDP, in: Der langfristige Kredit, 42. Jg., S. $10 \mathrm{f}$.

Homburg, S. (1993), An Analysis of the German Tenant Protection Law, in: Journal of Institutional and Theoretical Economics, (Zeitschrift für die gesamte Staatswissenschaft), Vol. 149, S. 464-474.

Hubert, F. (1995), Zur Reform des Wohngeldes, Veröffentlichung des Instituts für Wirtschaftspolitik und Wirtschaftsgeschichte der Freien Universität Berlin.

Institut Wohnen und Umwelt (1994), Stellungnahme zum Entwurf eines Gesetzes zur Förderung des Wohnungsbaues (Wohnungsbauförderungsgesetz 1994) - Drucksache 12/6616 - und zum Entwurf eines Gesetzes zur Neuregelung der Bundesfinanzhilfen für den sozialen Wohnungsbau (Wohnungsbau-finanzierungsgesetz 1993) - Drucksache 12/6880; ferner Stellungnahme zur Untersuchung des Ministeriums für Bauen und Wohnen des Landes Nordrhein-Westfalen: Vergleich der Wohnungsbauförderung in Baden-Württemberg und Nordrhein-Westfalen, insbesondere zum 4. Förderweg in Baden-Württemberg und zum Vermerk des Bundesministeriums für Raumordnung, Bauwesen und Städtebau vom 27. Januar 1994 zur oben genannten Vergleichsrechnung, Anlage 16 des Kurzprotokolls der 76. Sitzung des (19.) Ausschusses für Raumordnung, Bauwesen und Städtebau vom 2. März 1994, Bonn, S. 318-335. 
Julitz, L. (1993), Kommunen in der Krise (4): Die teuren Sozialwohnungen, in: Frankfurter Allgemeine Zeitung vom 10. November 1993, S. 17.

Kain, J. F., Quigley, J. M. (1975), Housing Markets and Racial Discrimination, New York.

Kansy, D. (1991), Wohnungspolitische Standpunkte der CDU, in: Der langfristige Kredit, 42. Jg., S. 4f.

Keil, K. (1996), Der soziale Mietwohnungsbau: Mängel und Alternativen, Frankfurt am Main.

Kiechle, T. K. (1985), Miete, Einkommen und Wohnungsnachfrage. Eine empirische Analyse zur Nachfrageseite des Wohnungsmarktes von BaselStadt, Basler sozialökonomische Studien, Band 25, Basel.

Kiel, F.-W. (1991), Ein neuer Weg zur Förderung des Wohnungsbaus: Das Fellbacher Modell, Fellbach.

Kirchner, J., Roth, W., Sautter, H. (1991), Sicherung der Wohnungsversorgung durch kommunalen Erwerb von Belegungsrechten im Wohnungsbestand, Forschungsprojekt im Auftrag des Bundesministeriums für Raumordnung, Bauwesen und Städtebau, Darmstadt.

Kirchner, J. (1994), Strategien zur Erhöhung des Wohnungsangebots, in: Zeitschrift für Wirtschafts- und Sozialwissenschaften, 114. Jg., S. 193-214.

Knauer, W. (1968), Tragbare Mieten als wohnungspolitische Zielsetzung. Untersuchung ihrer Begründung, ihrer Wirkungen und Konsequenzen, Veröffentlichungen der Akademie für Wirtschaft und Politik Hamburg, Tübingen.

Köhler, W., Kossmann, R. (1996), Handbuch der Wohnraummiete, München.

Kornemann, R. (1973), Fehlsubventionierungen im öffentlich geförderten sozialen Wohnungsbau, Bonn.

Krabbes, R. (1993), Das Konzept der einkommensorientierten Förderung, in: Die Wohnungswirtschaft, 46. Jg., S. 593-596.

Krabbes, R. (1994), Das Konzept einer einkommensorientierten Förderung, in: Der langfristige Kredit, 45. Jg., S. 105-110. 
Krugman, P. (1996), The Self-Organizing Economy, Cambridge.

Kück, U. (1992), Bestimmungsfaktoren des Wohnungsbaus. Eine statistische Analyse für die Bundesrepublik Deutschland von 1972 bis 1989 unter Berücksichtigung ausgewählter Bauherrengruppen, Bergisch-Gladbach / Köln.

Külp, B. u.a. (1984), Sektorale Wirtschaftspolitik, Heidelberger Lehrtexte Wirtschaftswissenschaften, Berlin u.a.O.

Laux, H. (1993), Betrachtungen zu Kostenmiete und Marktmiete im Wohnungsbau, in: Der langfristige Kredit, 44. Jg., S. 625f.

Leonhardt, K. (1996), Wohnungspolitik in der sozialen Marktwirtschaft, Beiträge zur Wirtschaftspolitik, Band 64, Bern u.a.O.

Mackscheidt, K., Deichmann W. (1982), Zur Leistungsfähigkeit von Subventionen in der Wohnungswirtschaft, Frankfurt am Main.

Meyer, B. (1994), Perspektiven des sozialen Wohnungsbaus, in: Neumann, L. F. (Hrsg.): Wohnungsmarkt in der Krise?: Beiträge aus der Praxis in Ost und West, Köln, S. 34-46.

Meyer, D. (1986), Staatsversagen im Wohnungsmarkt? Eine Analyse der Wirkungen staatlicher Eingriffe, in: Archiv für Kommunalwissenschaften, 25. Jg., S. 200-218.

Müntefering, F. (1991), Wohnungspolitische Standpunkte der SPD, in: Der langfristige Kredit, 42. Jg., S. 12-15.

Musgrave, R. A. u.a. (1987), Die öffentlichen Finanzen in Theorie und Praxis, Band 3, Tübingen.

Nachtkamp, H. H., Hudelmaier, P. R. (1993), Subjektförderung 2000. Eine ökonomische Analyse des geltenden Wohngeldsystems mit Vorschlägen für eine effizientere Gestaltung im Rahmen einer sozial ausgewogenen und ökonomisch tragfähigen Wohnungsbauförderungs- und Mietenpolitik in Deutschland, Hrsg.: Gesamtverband der Wohnungswirtschaft e.V., Schriften des GdW, Nr. 41, Köln.

Neise, H. (o.J.), Möglinger Modell. Neuer Weg des sozialen Wohnungsbaus, Arbeitspapier. 
Neise, H. (1992), Der selbstproduzierte Wohnungsmangel. Die Wohnungsproblematik in der westdeutschen Wohlstandsgesellschaft, in: Landeszentrale für politische Bildung Baden-Württemberg (Hrsg.), Wohnungspolitik, Reihe „Der Bürger im Staat“, 42. Jg., Stuttgart, S. 257-263.

Neise, H. (1994), Reform des sozialen Wohnungsbaus. Modell zugunsten der Einkommensschwachen, in: Der Städtetag, 47. Jg., S. 480-483.

Neumann, L. F., Romahn, H. (1994), Wohnungsversorgung im Spannungsfeld von Markt und Staat, in: Neumann, L. F. (Hrsg.), Wohnungsmarkt in der Krise?: Beiträge aus der Praxis in Ost und West, Köln, S. 9-33.

Oberhauser, A., Rüsch, Ch. (1992), Wohnungspolitik für Familien: Familienorientierte Förderung des Erwerbs selbstgenutzten Wohneigentums unter besonderer Berücksichtigung der Situation in den neuen Bundesländern, hrsg. vom Familienbund der Deutschen Katholiken, Grafschaft.

Oberhauser, A. (1993), Gerechtigkeit und Effizienz im sozialen Wohnungsbau, Referat auf dem Hearing der F.D.P.-Fraktion im Bayerischen Landtag.

Oberhauser, A. (1997), Zielgerichtete Wohnungspolitik bei staatlichen Haushaltsrestriktionen, in: Jahrbücher für Nationalökonomie und Statistik, Band 216, S. 574-594.

Pahnke, B., Spermann, A. (1994), Die einkommensorientierte Förderung - ein Modell für den sozialen Wohnungsbau?, in: Wirtschaftsdienst, 74. Jg., S. 561- 568 .

Partei Demokratischer Sozialismus (PDS) - Kommission „Wirtschafts-, Landwirtschafts- und Sozialpolitik" beim Parteivorstand der PDS (1991), Wohnungspolitische Standpunkte der PDS, in: Der langfristige Kredit, 42. Jg., S. 16-18.

Pergande, H.-G., Einführung zum Zweiten Wohnungsbaugesetz, in: Schwender, H. W. (Hrsg.), Wohnungsbaurecht, Band 1, Loseblattsammlung, Stand: November 1997, Essen.

Pergande, H.-G., Kommentar zu § 1 II. WoBauG, in: Schwender, H. W. (Hrsg.), Wohnungsbaurecht, Band 1, Loseblattsammlung, Stand: November 1997, Essen. 
Pfeiffer, U. u.a. (1996), Möglichkeiten des Abbaus von Mietenverzerrungen im Bestand von Sozialwohnungen, Gutachten der Gesellschaft für Strukturund Stadtforschung ,empirica“ im Auftrag des Bundesministeriums für Raumordnung, Bauwesen und Städtebau, Bonn.

Reschl, R. (1992), Die Gemeinden und die Wohnungspolitik. Spielräume und Handlungsstrategien, in: Landeszentrale für politische Bildung BadenWürttemberg (Hrsg.), Wohnungspolitik, Reihe „Der Bürger im Staat“, 42. Jg., Stuttgart, S. 268-277.

Schneider, H. K., Deichmann, W. (1984), Der Weg zur sozialen Wohnungsmarktwirtschaft, Melle.

Schnurr, J. (1994), Die neue Förderpolitik des Bundes: Erwartungen und Probleme, in: Der Langfristige Kredit, 45. Jg., S. 776-779.

Schwager, R. (1994), On the West German Tenants' Protection Legislation: A Comment, in: Journal of Institutional and Theoretical Economics (Zeitschrift für die gesamte Staatswissenschaft), Vol. 150, S. 411-418.

Schwender, H. W., Kommentar zum § 38 II. WoBauG, in: Schwender, H. W. (Hrsg.), Wohnungsbaurecht, Band 1, Loseblattsammlung, Stand: November 1997, Essen.

Schwender, H. W., Kommentar zum § 42 II. WoBauG, in: Schwender, H. W. (Hrsg.), Wohnungsbaurecht, Band 1, Loseblattsammlung, Stand: November 1997, Essen.

Schwender, H. W., Söfker, W., Zur Reform des Wohnungsbaurechts und des Wohnungsrechts, in: Schwender, H. W. (Hrsg.), Wohnungsbaurecht, Band 1, Loseblattsammlung, Stand: November 1997, Essen.

Schwerz, G. (1994), Wohngeldgesetz und Wohngeldsondergesetz mit der Wohngeldverordnung, Kommentar, Baden-Baden.

Schröder, Ch. (1990), Wohnungspolitik in Deutschland. Erfahrungen und Perspektiven, Beiträge des Instituts der deutschen Wirtschaft zur Wirtschafts- und Sozialpolitik, Nr. 186, Köln.

Sinz, R. (1996), Pilotprojekte einkommensorientierter Förderung: Bundesweite Übersicht und zusammenfassende Analyse der Projekte, Materialien zum Vortrag im 352. Kurs des Instituts für Städtebau Berlin „Bezahlbarer sozialer Wohnungsbau?" vom 21. und 22. Mai 1996 in Berlin. 
Sonnenschein, J. (1995), Wohnraummiete, eine Analyse des geltenden Rechts für die Expertenkommission Wohnungspolitik, Tübingen.

Stadler, O. (1971), Die seit 1971 zulässige Kostenmiete, München.

Sullivan, A. M. (1990), Urban Economics, Homewood / Boston.

Tesch, J. (1994), Stellungnahme zum Entwurf eines Gesetzes zur Förderung des Wohnungsbaues (Wohnungsbauförderungsgesetz 1994) - Drucksache 12/6616 - und zum Entwurf eines Gesetzes zur Neuregelung der Bundesfinanzhilfen für den sozialen Wohnungsbau (Wohnungsbaufinanzierungsgesetz 1993) - Drucksache 12/6880, Anlage 18 des Kurzprotokolls der 76. Sitzung des (19.) Ausschusses für Raumordnung, Bauwesen und Städtebau vom 2. März 1994, Bonn, S. 345-356.

Ulbrich, R. u.a. (1980), Grundsätze für die künftige Wohnungspolitik, Bericht der Projektgruppe „Wohnungspolitik“ des Instituts Wohnen und Umwelt, Darmstadt.

Ulbrich, R. (1992), Verteilungswirkungen wohnungspolitischer Instrumente, Darmstadt.

Völker, A. (1994), Sozialer Wohnungsbau - einkommensorientierte Förderung, in: Bundesbaublatt, 43. Jg., S. 157-165.

Völker, A. (1996), Sozialer Wohnungsbau 1995, in: Bundesbaublatt, 45. Jg., S. $742-749$.

Völker, A. (1997), Sozialer Wohnungsbau 1996, in: Bundesbaublatt, 46. Jg., S. $710-715$.

Winter, G., Winter von Gregory, W. (1983), Die Zuteilung von Sozialwohnungen, Düsseldorf.

Wirth, L., Kommentar zum $\S 25$ II. WoBauG, in: Schwender, H. W. (Hrsg.), Wohnungsbaurecht, Band 1, Loseblattsammlung, Stand: November 1997, Essen.

Wirth, L., Kommentar zum § 25a II. WoBauG, in: Schwender, H. W. (Hrsg.), Wohnungsbaurecht, Band 1, Loseblattsammlung, Stand: November 1997, Essen. 
Wirth, L., Kommentar zum § 25b II. WoBauG, in: Schwender, H. W. (Hrsg.), Wohnungsbaurecht, Band 1, Loseblattsammlung, Stand: November 1997, Essen.

Wirth, L., Kommentar zum § 25c II. WoBauG, in: Schwender, H. W. (Hrsg.), Wohnungsbaurecht, Band 1, Loseblattsammlung, Stand: November 1997, Essen.

Wirth, L., Kommentar zum § 25d II. WoBauG, in: Schwender, H. W. (Hrsg.), Wohnungsbaurecht, Band 1, Loseblattsammlung, Stand: November 1997, Essen.

Wölling, A. (1991), Zieladäquanz wohnungspolitischer Instrumente der öffentlichen Hand, in: Jenkis, H. W. (Hrsg.): Kompendium der Wohnungswirtschaft, München. 


\section{Zu den Förderkonditionen der Pilotmodelle in den Ländern:}

\section{Baden-Württemberg:}

Verwaltungsvorschrift des Wirtschaftsministeriums zum Landeswohnungsbauprogramm 1993 (VwV-LWBPr 1993) vom 23. Oktober 1992, in: Gemeinsames Amtsblatt des Landes Baden-Württemberg 1992, S. 1277.

Verwaltungsvorschrift des Wirtschaftsministeriums zum Landeswohnungsbauprogramm 1994 (VwV-LWBPr 1994) vom 29. Oktober 1993, in: Gemeinsames Amtsblatt des Landes Baden-Württemberg 1993, S. 1149.

Verwaltungsvorschrift des Wirtschaftsministeriums zur einkommensabhängigen Wohnungsbauförderung 1994 (VwV-EAWBF 1994) vom 16. Dezember 1993, in: Gemeinsames Amtsblatt des Landes Baden-Württemberg 1994, S. 17.

Verwaltungsvorschrift des Wirtschaftsministeriums zum Landeswohnungsbauprogramm 1995 (VwV-LWBPr 1995) vom 21. November 1994, in: Gemeinsames Amtsblatt des Landes Baden-Württemberg 1994, S. 901.

Wohnungsbau 1995. Einkommensorientierte Wohnungsbauförderung in BadenWürttemberg. Der 4. Förderweg, Informationsschrift des Wirtschaftsministeriums Baden-Württemberg, März 1995.

Verwaltungsvorschrift des Wirtschaftsministeriums zur ergänzenden Förderung von Mietwohnungen im Rahmen der einkommensorientierten Wohnungsbauförderung (4. Förderweg) vom 24. März 1995, in: Gemeinsames Amtsblatt des Landes Baden-Württemberg 1995, S. 284.

Verwaltungsvorschrift des Wirtschaftsministeriums zum Landeswohnungsbauprogramm 1997 (VwV-LWBPr 1997) vom 20. Dezember 1996, in: Gemeinsames Amtsblatt des Landes Baden-Württemberg 1997, S. 51. 


\section{Bayern:}

Einkommensorientierte Förderung des Wohnungsbaues in Bayern ( $\S 88$ e des Zweiten Wohnungsbaugesetzes - II. WoBauG -), Bekanntmachung des Bayerischen Staatsministeriums des Innern vom 8. 2. 1995.

Einkommensorientierte Förderung des Wohnungsbaues in Bayern $(\S 88$ e des Zweiten Wohnungsbaugesetzes - II. WoBauG -); Änderung der Bekanntmachung vom 8. Februar 1995, Bekanntmachung des Bayerischen Staatsministeriums des Innern vom 4. März 1996.

Einkommensorientierte Förderung des Wohnungsbaues in Bayern $(\S 88$ e des Zweiten Wohnungsbaugesetzes - II. WoBauG -); Änderung der Bekanntmachung vom 8. Februar 1995, Bekanntmachung des Bayerischen Staatsministeriums des Innern vom 20. Januar 1997.

\section{Berlin:}

Einkommensabhängige Wohnungsbauförderung - EOF, Mitteilung der Senatsverwaltung für Bau- und Wohnungswesen vom 2. 10. 1995.

Einkommensorientierte Förderung nach $\S 88$ e II. WoBauG, Förderungsübersicht der Investitionsbank Berlin, Stand: Mai 1996.

\section{Brandenburg:}

Wohnungsbauförderungsbestimmungen 1996 (WFB 96), Runderlaß des Ministers für Stadtentwicklung, Wohnen und Verkehr vom 18. Januar 1996, Amtsblatt für Brandenburg 1996, S. 102.

Richtlinie zur Förderung des sozialen Mietwohnungsbaus (MietwohnungsbauR), Runderlaß des Ministers für Stadtentwicklung, Wohnen und Verkehr vom 22. November 1996, in: Amtsblatt für Brandenburg 1996, S. 1125 .

Einkommensorientierte Förderung, Vermerk aus dem Ministerium für Umwelt, Naturschutz und Raumordnung (Verfasser: Rose) vom 4. Juni 1996.

Einkommensorientierte Förderung, Modellvorhaben allgemein und in Cottbus, Vermerk aus dem Ministerium für Umwelt, Naturschutz und Raumordnung (Verfasser: Rose) vom 2. Dezember 1996. 


\section{Bremen:}

Merkblatt über die einkommensorientierte Förderung von Mietwohnungen im Lande Bremen - 4. Förderungsweg, Stand: September 1995, hrsg. vom Amt für Wohnung und Städtebauförderung der Freien Hansestadt Bremen.

Erläuterungen zur Durchführung der einkommensorientierten Förderung (EoF) von Mietwohnungen im Lande Bremen - 4. Förderungsweg - vom 30. Juli 1996, hrsg. vom Senator für Bau, Verkehr und Stadtentwicklung.

Richtlinien zur Durchführung der einkommensorientierten Förderung (EoF) von Mietwohnungen im Lande Bremen - 4. Förderungsweg - vom 20. September 1996, in: Amtsblatt der Freien Hansestadt Bremen 1996, S. 761.

\section{Hessen:}

Fördergrundsätze Einkommensorientierte Förderung, Eckwerte-Papier des Hessischen Ministeriums für Wirtschaft, Verkehr und Landesentwicklung vom 6. Dezember 1996.

\section{Niedersachsen:}

Wohnungsbauprogramm 1994, Runderlaß des Sozialministeriums vom 18. November 1993, in: Niedersächsisches Ministerialblatt 1994, S. 347.

Hensel, P. (1996): Die einkommensorientierte Förderung, Beispiel aus der Praxis, in: Die Wohnungswirtschaft, 49. Jg., S. $263 f$.

\section{Nordrhein-Westfalen:}

Bestimmungen zur Einkommensabhängigen Förderung von Mietwohnungen (WFB-EAF), Runderlaß des Ministeriums für Bauen und Wohnen vom 19. August 1996, in: Ministerialblatt für das Land Nordrhein Westfalen 1996, S. 1644. 


\section{Rheinland-Pfalz:}

Vollzug des Zweiten Wohnungsbaugesetzes (II. WoBauG); hier: Mietwohnungsbauprogramm 1995, - 1. und 3. Förderweg, - Sonderprogramm „Kostengünstiges elementiertes Bauen“, - Modellversuch „Einkommensorientierte Förderung“, - Modellversuch „Erwerb von Belegungsbindungen“, Verwaltungsvorschrift des Ministeriums der Finanzen vom 31. Januar 1995, in: Ministerialblatt der Landesregierung von Rheinland-Pfalz 1995, S. 158.

Einkommensorientierte Förderung von Mietwohnungen nach $\S 88$ e Zweites Wohnungsbaugesetz (Modellvorhaben), Verwaltungsvorschrift des Ministeriums der Finanzen vom 17. Januar 1996, in: Ministerialblatt der Landesregierung von Rheinland-Pfalz 1996, S. 148.

\section{Sachsen:}

Fragen und Antworten zur einkommensabhängigen Förderung für die Sanierung von Mietwohnungen, Broschüre des Staatsministeriums des Innern vom Juni 1996.

Landesprogramm 1996 zur Wiedergewinnung, Erhaltung und Erneuerung von Mietwohnungen im Freistaat Sachsen, Verwaltungsvorschrift des Staatsministerium des Innern vom 28.11.1995 (VwV - LMW/Pr. 1996 Mietwohnungsprogramm), Broschüre mit Anlagen und Korrekturblatt zur Tabelle 2, Anlage 2, Blatt 3.

\section{Schleswig-Holstein:}

Förderung des sozialen Wohnungsbaues in Schleswig-Holstein; hier: Finanzierungsrichtlinien, Erlaß des Innenministers vom 16. Dezember 1992, in: Amtsblatt für Schleswig-Holstein 1993, S. 73.

Änderung verschiedener wohnungsrechtlicher Erlasse und ergänzender Hinweise infolge des Inkrafttretens des Gesetzes zur Förderung des Wohnungsbaues (Wohnungsbauförderungsgesetz), Erlaß des Innenministers vom 15. September 1994, in: Amtsblatt für Schleswig-Holstein 1994, S. 512.

Pilotprogramm „Einkommensorientierte Förderung“, Erlaß des Innenministers vom 18. Oktober 1994, in: Amtsblatt für Schleswig-Holstein 1994, S. 549. 
Landeswohnungsbauprogramme der Jahre 1995 und 1996; hier: Förderung im Programmjahr 1995, Erlaß des Innenministers vom 9. Januar 1995, in: Amtsblatt für Schleswig-Holstein 1995, S. 30.

Pilotprogramm „Einkommensorientierte Förderung“, Änderung des Innenminister-Erlasses vom 18. Oktober 1994, Bekanntmachung vom 30. Mai 1995.

Pilotprogramm „Einkommensorientierte Förderung“, Richtlinie des Innenministers vom 18. Oktober 1994 in der Fassung der Änderung vom 30. Mai 1995.

Landeswohnungsbauprogramme der Jahre 1995 und 1996; hier: Förderung im Programmjahr 1996, Erlaß des Ministeriums für Frauen, Jugend, Wohnungs- und Städtebau vom 12. Januar 1996, in: Amtsblatt für SchleswigHolstein 1996, S. 92.

Landeswohnungsbauprogramme der Jahre 1997 und 1998; hier: Förderung im Programmjahr 1997, Erlaß des Ministeriums für Frauen, Jugend, Wohnungs- und Städtebau vom 20. Dezember 1996, in: Amtsblatt für Schleswig-Holstein 1997, S. 34.

\section{Thüringen:}

Förderung des sozialen Wohnungsbaus im Freistaat Thüringen - Wohnungsbauförderrichtlinie für die einkommensorientierte Förderung 1996 (WBFR - eoF 1996), Bekanntmachung des Thüringer Ministeriums für Wirtschaft und Infrastruktur vom 1. Januar 1996.

Förderung des sozialen Wohnungsbaus im Freistaat Thüringen - Wohnungsbauförderrichtlinie für die einkommensorientierte Förderung 1997 (WBFR - eoF 1997), Bekanntmachung des Thüringer Ministeriums für Wirtschaft und Infrastruktur vom 1. Januar 1997. 


\section{FINANZWISSENSCHAFTLICHE SCHRIFTEN}

Band 1 Werner Steden: Finanzpolitik und Einkommensverteilung. Ein Wachstums- und Konjunkturmodell der Bundesrepublik Deutschland. 1979.

Band 2 Rainer Hagemann: Kommunale Finanzplanung im föderativen Staat. 1976.

Band 3 Klaus Scherer: Maßstäbe zur Beurteilung von konjunkturellen Wirkungen des öffentlichen Haushalts. 1977.

Band 4 Brita Steinbach: "Formula Flexibility" - Kritische Analyse und Vergleich mit diskretionärer Konjunkturpolitik. 1977.

Band 5 Hans-Georg Petersen: Personelle Einkommensbesteuerung und Inflation. Eine theoretisch-empirische Analyse der Lohn- und veranlagten Einkommensteuer in der Bundesrepublik Deutschland. 1977.

Band 6 Friedemann Tetsch: Raumwirkungen des Finanzsystems der Bundesrepublik Deutschland. Eine Untersuchung der Auswirkungen der Finanzreform von 1969 auf die Einnahmenposition der untergeordneten Gebietskörperschaften und ihrer regionalpolitischen Zieladäquanz. 1978.

Band 7 Wilhelm Pfähler: Normative Theorie der fiskalischen Besteuerung. Ein methodologischer und theoretischer Beitrag zur Integration der normativen Besteuerungstheorie in der Wohlfahrtstheorie. 1978.

Band 8 Wolfgang Wiegard: Optimale Schattenpreise und Produktionsprogramme für öffentliche Unternehmen. Second-Best Modelle im finanzwirtschaftlichen Staatsbereich. 1978.

Band 9 Hans P. Fischer: Die Finanzierung des Umweltschutzes im Rahmen einer rationalen Umweltpolitik. 1978.

Band 10 Rainer Paulenz: Der Einsatz finanzpolitischer Instrumente in der Forschungs- und Entwicklungspolitik. 1978.

Band 11 Hans-Joachim Hauser: Verteilungswirkungen der Staatsverschuldung. Eine kreislauftheoretische Inzidenzbetrachtung. 1979.

Band 12 Gunnar Schwarting: Kommunale Investitionen. Theoretische und empirische Untersuchungen der Bestimmungsgründe kommunaler Investitionstätigkeit in NordrheinWestfalen 1965-1972. 1979.

Band 13 Hans-Joachim Conrad: Stadt-Umland-Wanderung und Finanzwirtschaft der Kernstädte. Amerikanische Erfahrungen, grundsätzliche Zusammenhänge und eine Fallstudie für das Ballungsgebiet Frankfurt am Main. 1980.

Band 14 Cay Folkers: Vermögensverteilung und staatliche Aktivität. Zur Theorie distributiver Prozesse im Interventionsstaat. 1981.

Band 15 Helmut Fischer: US-amerikanische Exportförderung durch die DISC-Gesetzgebung. 1981.

Band 16 Günter Ott: Einkommensumverteilungen in der gesetzlichen Krankenversicherung. Eine quantitative Analyse. 1981.

Band 17 Johann Hermann von Oehsen: Optimale Besteuerung. (Optimal Taxation). 1982.

Band 18 Richard Kössler: Sozialversicherungsprinzip und Staatszuschüsse in der gesetzlichen Rentenversicherung. 1982.

Band 19 Hinrich Steffen: Zum Handlungs- und Entscheidungsspielraum der kommunalen Investitionspolitik in der Bundesrepublik Deutschland. 1983.

Band 20 Manfred Scheuer: Wirkungen einer Auslandsverschuldung des Staates bei flexiblen Wechselkursen. 1983. 
Band 21 Christian Schiller: Staatsausgaben und crowding-out-Effekte. Zur Effizienz einer Finanzpolitik keynesianischer Provenienz. 1983.

Band 22 Hannelore Weck: Schattenwirtschaft: Eine Möglichkeit zur Einschränkung der öffentlichen Verwaltung? Eine ökonomische Analyse. 1983.

Band 23 Wolfgang Schmitt: Steuern als Mittel der Einkommenspolitik. Eine Ergänzung der Stabilitätspolitik? 1984.

Band 24 Wolfgang Laux: Erhöhung staatswirtschaftlicher Effizienz durch budgetäre Selbstbeschränkung? Zur Idee einer verfassungsmäßig verankerten Ausgabengrenze. 1984.

Band 25 Brita Steinbach-van der Veen: Steuerinzidenz. Methodologische Grundlagen und empirisch-statistische Probleme von Länderstudien. 1985.

Band 26 Albert Peters: Ökonomische Kriterien für eine Aufgabenverteilung in der Marktwirtschaft. Eine deskriptive und normative Betrachtung für den Allokationsbereich. 1985.

Band 27 Achim Zeidler: Möglichkeiten zur Fortsetzung der Gemeindefinanzreform. Eine theoretische und empirische Analyse. 1985.

Band 28 Peter Bartsch: Zur Theorie der längerfristigen Wirkungen 'expansiver' Fiskalpolitik. Eine dynamische Analyse unter besonderer Berücksichtigung der staatlichen Budgetbeschränkung und ausgewählter Möglichkeiten der öffentlichen Defizitfinanzierung. 1986.

Band 29 Konrad Beiwinkel: Wehrgerechtigkeit als finanzpolitisches Verteilungsproblem. Möglichkeiten einer Kompensation von Wehrungerechtigkeit durch monetäre Transfers. 1986.

Band 30 Wolfgang Kitterer: Effizienz- und Verteilungswirkungen des Steuersystems. 1986.

Band 31 Heinz Dieter Hessler: Theorie und Politik der Personalsteuern. Eine Kritik ihrer Einkommens- und Vermögensbegriffe mit Blick auf die Leistungstähigkeitstheorie. 1994.

Band 32 Wolfgang Scherf: Die beschäftigungspolitische und fiskalische Problematik der Arbeitgeberbeiträge zur Rentenversicherung. Eine Auseinandersetzung mit der Kritik an der lohnbezogenen Beitragsbemessung. 1987.

Band 33 Andreas Mästle: Die Steuerunion. Probleme der Harmonisierung spezifischer Gütersteuern. 1987.

Band 34 Günter Ott: Internationale Verteilungswirkungen im Finanzausgleich der Europäischen Gemeinschaften. 1987.

Band 35 Heinz Haller: Zur Frage der zweckmäßigen Gestalt gemeindlicher Steuern. Ein Diskussionsbeitrag zur Gemeindesteuerreform. 1987.

Band 36 Thomas Kuhn: Schlüsselzuweisungen und fiskalische Ungleichheit. Eine theoretische Analyse der Verteilung von Schlüsselzuweisungen an Kommunen. 1988.

Band 37 Walter Hahn: Steuerpolitische Willensbildungsprozesse in der Europäischen Gemeinschaft. Das Beispiel der Umsatzssteuer-Harmonisierung. 1988.

Band 38 Ulrike Hardt: Kommunale Finanzkraft. Die Problematik einer objektiven Bestimmung kommunaler Einnahmemöglichkeiten in der gemeindlichen Haushaltsplanung und im kommunalen Finanzausgleich. 1988.

Band 39 Jochen Michaelis: Optimale Finanzpolitik im Modell überlappender Generationen. 1989.

Band 40 Bernd Raffelhüschen: Anreizwirkungen der sozialen Alterssicherung. Eine dynamische Simulationsanalyse. 1989.

Band 41 Berend Diekmann: Die Anleihe- und Darlehenstransaktionen der Europäischen Gemeinschaften. 1990.

Band 42 Helmut Kaiser: Konsumnachfrage, Arbeitsangebot und optimale Haushaltsbesteuerung. Theoretische Ergebnisse und mikroökonometrische Simulation für die Bundesrepublik Deutschland. 1990. 
Band 43 Rüdiger von Kleist: Das Gramm-Rudman-Hollings-Gesetz. Ein gescheiterter Versuch der Haushaltskonsolidierung. 1991.

Band 44 Rolf Hagedorn: Steuerhinterziehung und Finanzpolitik. Ein theoretischer Beitrag unter besonderer Berücksichtigung der Hinterziehung von Zinserträgen. 1991.

Band 45 Cornelia S. Behrens: Intertemporale Verteilungswirkungen in der gesetzlichen Krankenversicherung der Bundesrepublik Deutschland. 1991.

Band 46 Peter Saile: Ein ökonomischer Ansatz der Theorie der intermediären Finanzgewalten Die Kirchen als Parafisci. 1992.

Band 47 Peter Gottried: Die verdeckten Effizienzwirkungen der Umsatzsteuer. Eine empirische allgemeine Gleichgewichtsanalyse. 1992.

Band 48 Andreas Burger: Umweltorientierte Beschättigungsprogramme. Eine Effizienzanalyse am Beispiel des "Sondervermögens Arbeit und Umwelt". 1992.

Band 49 Jeanette Malchow: Die Zuordnung verteilungspolitischer Kompetenzen in der Europäischen Gemeinschaft. Eine Untersuchung aufgrund einer Fortentwicklung der ökonomischen Theorie des Föderalismus. 1992.

Band 50 Barbara Seidel: Die Einbindung der Bundesrepublik Deutschland in die Europäischen Gemeinschaften als Problem des Finanzausgleichs. 1992.

Band 51 Ralph Wiechers: Markt und Macht im Rundfunk. Zur Stellung der öffentlich-rechtlichen Rundfunkanstalten im dualen Rundfunksystem der Bundesrepublik Deutschland. 1992.

Band 52 Klaus Eckhardt: Probleme einer Umweltpolitik mit Abgaben. 1993.

Band 53 Oliver Schwarzkopf: Die Problematik unterschiedlicher Körperschaftsteuersysteme innerhalb der EG. 1993.

Band 54 Thorsten Giersch: Bergson-Wohlfahrtsfunktion und normative Ökonomie. 1993.

Band 55 Li-Fang Chou: Selbstbeteiligung bei Arzneimitteln aus ordnungspolitischer Sicht. Das Beispiel der Bundesrepublik Deutschland. 1993.

Band 56 Harald Schlee: Einkommensteuerliche Behandlung von Transferzahlungen. Zur Neuordnung der Familienbesteuerung sowie der Besteuerung von Versicherungsleistungen und Sozialtransfers. 1994.

Band 57 Alexander Spermann: Kommunales Krisenmanagement. Reaktionen baden-württembergischer Stadtkreise auf steigende Sozialhilfekosten und Einnahmenausfälle (198092). 1993.

Band 58 Otto Roloff / Sibylle Brander / Ingo Barens / Claudia Wesselbaum: Direktinvestitionen und internationale Steuerkonkurrenz. 1994.

Band 59 Claudia Wesselbaum-Neugebauer: Internationale Steuerbelastungsvergleiche. 1994.

Band 60 Stephanie Miera: Kommunales Finanzsystem und Bevölkerungsentwicklung. Eine Analyse des kommunalen Finanzsystems vor dem Hintergrund der sich abzeichnenden Bevölkerungsentwicklung am Beispiel Niedersachsens unter besonderer Berücksichtigung des Landkreises Wolfenbüttel und seiner Gemeinden. 1994.

Band 61 Wolfgang Scherf: Die Bedeutung des kaldorianischen Verteilungsmechanismus für die gesamtwirtschaftlichen Wirkungen der staatlichen Neuverschuldung. 1994.

Band 62 Rainer Volk: Vergleich der Vergünstigungseffekte der verschiedenen investitionsfördernden Maßnahmen. 1994.

Band 63 Hans-Georg Napp: Kommunale Finanzautonomie und ihre Bedeutung für eine effiziente lokale Finanzwirtschaft. 1994. 2., unveränderte Auflage 1994.

Band 64 Bernd Rahmann / Uwe Steinborn / Günter Vornholz: Empirische Analyse der Autonomie lokaler Finanzwirtschaften in der Europäischen Gemeinschaft. 1994. 
Band 65 Carsten Kühl: Strategien zur Finanzierung der Altlastensanierung. 1994.

Band 66 Stephan Boll: Intergenerationale Umverteilungswirkungen der Fiskalpolitik in der Bundesrepublik Deutschland. Ein Ansatz mit Hilfe des Generational Accounting. 1994.

Band 67 Karl Justus Bernhard Neumärker: Finanzverfassung und Staatsgewalt in der Demokratie. Ein Beitrag zur konstitutionellen Finanztheorie. 1995.

Band 68 Christian Haslbeck: Zentrale versus dezentrale Internalisierung externer Effekte bei unvollständiger Information. 1995.

Band 69 Regina Müller: Horizontale oder vertikale Transfers zur Durchsetzung eines horizontalen Finanzausgleichs. 1995.

Band 70 Christian Hockenjos: Öffentliche Sportförderung in der Bundesrepublik Deutschland. Darstellung und finanztheoretische Analyse. 1995.

Band 71 Manfred Rosenstock: Die Kontrolle und Harmonisierung nationaler Beihilfen durch die Kommission der Europäischen Gemeinschaften. 1995.

Band 72 Christian Rüsch: Wohnungsbau- und Wohneigentumspolitik im Rahmen der Einkommensteuer. Eine Analyse unter steuersystematischen, verteilungspolitischen und fiskalischen Aspekten. 1996.

Band 73 Stephan Winters: Die kollektive Vorsorge für den Pflegefall im Alter. Eine Untersuchung am Beispiel der gesetzlichen Pflegeversicherung in den Niederlanden. 1996.

Band 74 Knut Blind: Allokationsineffizienzen auf Sicherheitsmärkten: Ursachen und Lösungsmöglichkeiten. Fallstudie: Informationssicherheit in Kommunikationssystemen. 1996.

Band 75 Barbara Petrick-Rump: Ökonomische Wirkungen von Steueramnestien. Untersuchung konkreter Erfahrungen ausgewählter Länder mit dem Einsatz von Steueramnestien anhand eines effizienten Steueramnestieprogramms. 1996.

Band 76 Georg Hirte: Effizienzwirkungen von Finanzausgleichsregelungen. Eine Empirische Allgemeine Gleichgewichtsanalyse für die Bundesrepublik Deutschland. 1996.

Band 77 Ulrike Kirchhoff: Die rheinland-pfälzischen Gemeinden im System des Finanzausgleichs. 1996.

Band 78 Kerstin Keil: Der soziale Mietwohnungsbau: Mängel und Alternativen. 1996.

Band 79 Bernhard Manzke: Kinderlastenausgleich versus verstärkte Einwanderung. Alternative Ansätze zur langfristigen Sicherung der Gesetzlichen Rentenversicherung. 1997.

Band 80 Hariolf M. Wenzler: Institutionenökonomik und öffentliche Finanzkontrolle. Eine Analyse am Beispiel der Europäischen Union. 1997.

Band 81 Joachim Nagel: Supply-Side Policy in den USA. Eine theoretische und empirische Analyse der angebotsorientierten Wirtschaftspolitik Reagans unter besonderer Berücksichtigung steuerlicher Aspekte. 1997.

Band 82 Heinz Lampert: Krise und Reform des Sozialstaates. 1997.

Band 83 Monika Hanswillemenke / Bernd Rahmann: Zwischen Reformen und Verantwortung für Vollbeschäftigung. Die Finanz- und Haushaltspolitik der sozial-liberalen Koalition von 1969 bis 1982. 1997.

Band 84 Berthold Fürst: Die Maastrichter Budgetkriterien im Konflikt mit der Verschuldungsautonomie der deutschen Gebietskörperschaften. 1997.

Band 85 Burkhard Pahnke: Einkommensorientierte Förderung des sozialen Mietwohnungsbaues. Bestandsaufnahme und Kritik. 1998. 


\section{Krise und Reform des Sozialstaates}

Frankfurt/M., Berlin, Bern, New York, Paris, Wien, 1997. 104 S., 1 Tab. Finanzwissenschaftliche Schriften. Bd. 82

Verantwortlicher Herausgeber: Alois Oberhauser ISBN 3-631-32186-4 · br. DM 39.-*

Die Entstehung und die Entwicklung des Sozialstaates ist eine der bedeutendsten Errungenschaften der Neuzeit. Aufgrund gravierender Veränderungen der wirtschaftlichen und politischen Rahmenbedingungen und der Alterung der Bevölkerungen ist sein wirtschaftliches Fundament gefährdet, aufgrund ideologischer Neuentwicklungen auch seine sozialphilosophische Grundlage. Diese auch den Sozialstaat Bundesrepublik bedrohende Problematik greift der Verfasser auf. Nach einer Darstellung der Entstehung, Entwicklung und Erfolge des Sozialstaates werden seine Grenzen und die aktuelle Diskussion der Krise des Sozialstaates in Deutschland dargestellt. Nach einer Erörterung der Prinzipien des Umbaues des Sozialstaates und einer Skizze der bereits verwirklichten Reformschritte werden der Reformbedarf, die politischen Voraussetzungen für eine Sozialstaatsreform und Reformempfehlungen herausgearbeitet.

Aus dem Inhalt: Entstehung, Entwicklung und Erfolge des Sozialstaats . Grenzen des Sozialstaats - Die Sozialstaatskrise im Licht der aktuellen Diskussion - Prinzipien des Sozialstaatsumbaus - Verwirklichte Reformschritte - Der Reformbedarf - Politische Voraussetzungen der Reform . Reformschritte und Empfehlungen

Frankfurt/M - Berlin · Bern - New York · Paris · Wien

Auslieferung: Verlag Peter Lang AG

Jupiterstr. 15, CH-3000 Bern 15

Telefax (004131) 9402131

*inklusive Mehrwertsteuer

Preisänderungen vorbehalten 
Burkhard Pahnke - 978-3-631-75215-9

Downloaded from PubFactory at 01/11/2019 07:00:27AM

via free access 